\title{
A MEMORY PALACE for the COLLECTIVE MIND
}

\author{
by
}

\author{
Shelby Hagerman
}

A thesis submitted to the Faculty of Graduate and Postdoctoral Affairs in partial fulfillment of the requirements for the degree of

Master of Architecture

Carleton University

Ottawa, Ontario

(C) 2021, Shelby Hagerman 


\section{ABSTRACT}

This thesis explores the notion of the memory palace to investigate how the world we live in can be imagined in the mind. Manhattan, New York City, is a memory palace that reframes and reorients agency, understanding and concern about the complexities of climate change. It becomes a shared mnemonic, exploring how a device that is typically individual can be curated to consider a collective mind.

The creation of portals (micro and macro shadow boxes) that hold juxtaposed artifacts invite new understandings and imaginations of places in the city. They situate the local within the planetary, the individual within the collective, and the human-made within the expansive realms of the nonhuman. This project reflects on what it means to consider the present as something that reaches deep into the past, beyond typical human stories and scales to establish profound understandings of place, memory, and climate change. 


\section{ACKNOWLEDGMENTS}

I wish to express my deepest gratitude to my advisors Zach Colbert and Ozayr Saloojee for their exceptional wisdom, unwavering enthusiasm, and compassionate imagination. Your generous mentorship has been invaluable to me.

To Kristen and Sally, for their continuous encouragement, rewarding collaboration, and abundance of inspiration. I would not have survived this year without you. I would also like to thank all the incredibly talented and encouraging friends I have made throughout my time in architecture school, I have dearly missed our time in studio together this past year.

To my parents, Gale and Jim, and my sister, Avery, for their unconditional love and support. You taught me to collect things, be curious and dream big.

And finally, to Gabe for being by my side this year through moments of joy and moments of distress. You make my every day.

To all these incredible people, thank you for the memories. 


\section{TABLE OF CONTENTS}

$\begin{array}{ll}\text { ABSTRACT } & 2\end{array}$

ACKNOWLEDGMENTS 3

TABLE OF CONTENTS 4

LIST OF FIGURES

GLOSSARY 8

AUTHOR'S NOTE 12

STORY 1: ADMISSION 14

STORY 2: MANNAHATTA 22

STORY 3: HUDSON RIVER $\quad 40$

STORY 4: CENTRAL PARK 56

STORY 5: GRAND CENTRAL $\quad 74$

STORY 6: GIFT SHOP 96

EPILOGUE: FRESH KILLS 110

$\begin{array}{ll}\text { APPENDIX } & 130\end{array}$

$\begin{array}{ll}\text { BIBLIOGRAPHY } & 190\end{array}$ 


\section{LIST OF FIGURES}

FIGURE 1: Manhattan Schist in Central Park 13

FIGURE 2: Mannahatta Portal - Vignette 23

FIGURE 3: Mannahatta Portal - Front View 37

FIGURE 4: Mannahatta Portal - Closed 38

FIGURE 5: Mannahatta Portal - Open 38

FIGURE 6: Mannahatta Portal - Reveal 38

FIGURE 7: Mannahatta Portal - Topography 39

FIGURE 8: Mannahatta Portal - Inside 39

FIGURE 9: Hudson River Portal - Vignette 41

FIGURE 10: Hudson River Portal - Front View 54

FIGURE 11: Hudson River Portal - Surface 55

FIGURE 12: Hudson River Portal - Micro 55

FIGURE 13: Hudson River Portal - Myth 55

FIGURE 14: Central Park Portal - Vignette 57

FIGURE 15: Central Park Images 1

FIGURE 16: Central Park Images 2 71

FIGURE 17: Central Park Portal - Front View 72 
FIGURE 18: Central Park Portal - Romance 73

FIGURE 19: Central Park Portal - Resurface 73

FIGURE 20: Central Park Portal - Leisure 73

FIGURE 21: Grand Central Portal - Vignette 75

FIGURE 22: Mannahatta Portal - Video Documentation 89

FIGURE 23: Hudson River Portal - Video Documentation 90

FIGURE 24: Central Park Portal - Video Documentation 91

FIGURE 25: Grand Central Portal - Video Documentation 92

FIGURE 26: Grand Central Portal - Front View 94

FIGURE 27: Grand Central Portal - Illuminated 95

FIGURE 28: Grand Central Portal - Shelf 95

FIGURE 29: Grand Central Portal - Poem 95

FIGURE 30: The Contested GSSP for the Anthropocene Age 100

FIGURE 31: Collection of Portals 109

FIGURE 32: Fresh Kills Portal - Vignette 111

FIGURE 33: A Mountain of Scraps Collected 121

FIGURE 34: Fresh Kills Portal - Front View 124 


\section{GLOSSARY}

Anthropocene

Artifact

Climate Change

Collective

Collection
The epoch of geological time during which human activity is considered to be the dominant influence on the environment, climate, and ecology of the earth, a formal chrono-stratigraphic unit with a base which has been tentatively defined as the mid-twentieth century. The Anthropocene is commonly taken to extend from the time of the Industrial Revolution to the present, but is sometimes considered to include much or all of the Holocene.

An object made or modified by human workmanship, as opposed to one formed by natural processes.

An alteration in the regional or global climate; esp. the change in global climate patterns increasingly apparent from the mid to late 20th cent. onwards and attributed largely to the increased levels of atmospheric carbon dioxide produced by the use of fossil fuels.

Formed by collection of individual persons or things; constituting a collection; gathered into one; taken as a whole; aggregate, collected.

In relation to a collective body of knowledge, collective understanding, collective worldviews.

The action of collecting or gathering together of scientific specimens, objects of interest, works of art, etc. The action of collecting or bringing under control (one's thoughts, etc.) 
Deep Time

Human

Internet

Local

Meaning

Memory
Time in the far distant past or future; spec. time viewed on a geological or cosmological scale rather than the historical scale.

Of the nature of the human race; that is a human, or consists of human beings; belonging to the species Homo sapiens or other (extinct) species of the genus Homo.

The global network comprising a loose confederation of interconnected networks using standardized communication protocols, which facilitates various information and communication systems such as the World Wide Web and email. Also: the resources accessible via this global network, esp. the World Wide Web.

Of, relating to, inhabiting, or existing in a particular place or region.

The significance, purpose, underlying truth, etc., of something. Something which gives one a sense of purpose, value, etc., especially of a metaphysical or spiritual kind; the (perceived) purpose of existence or of a person's life.

Senses relating to the action or process of commemorating, recollecting, or remembering. The perpetuated knowledge or recollection (of something); that which is remembered of a person, object, or event; (good or bad) posthumous reputation. 
Narrative

Nature

Nonhuman

Present (Now)

Planetary

Portal
An account of a series of events, facts, etc., given in order and with the establishing of connections between them; a narration, a story, an account.

The phenomena of the physical world collectively; esp. plants, animals, and other features and products of the earth itself, as opposed to humans and human creations.

That is not of the human race; not belonging to or characteristic of a human being.

The present time; the period of time now occurring; the current moment, period, or age. Opposed to the past and the future.

Now - typically denotes the present moment - but is used to imply a sense of urgency. Related to 'The Long Now' effort to stretch what humans consider 'now'.

Of or relating to the earth; terrestrial; worldwide, global.

But not 'world' (confused with the 'buman world') and not 'global' (to avoid connotations relating to 'globalization').

A door, gate, doorway, or gateway, of stately or elaborate construction; the entrance to a large or magnificent building.

The crafted scalable repositories of artifacts for the thesis. 
Western

Of, relating to, or characteristic of the western part of the world, in particular Europe and North America.

World

The affairs and conditions of life (as they affect humans); the tide of human events.

The description of nonhuman worlds in the text denotes the state or realm of nonhuman existence on earth.

It should be noted that the definitions presented in this glossary were collected from the Oxford English Dictionary. Some terms are accompanied by additional notes in italics that clarify how they are considered in the thesis. In the process of assembling the glossary, I became repeatedly aware of the European roots that comprise the English language. While I am stating the obvious, I realize it becomes puzzling and difficult to overcome this reality in the mind. As words are bound by thoughts and as thoughts, feelings and speech are bound by words, it becomes evident that the English language manifests significant limitations. How does one think beyond or become critical of Western thought if the words that give shape to those thoughts are themselves Western? I acknowledge that I exist within this cycle and I confront topics within the thesis by reflecting on how my experiences counter these definitions. 


\section{AUTHOR'S NOTE}

This thesis identifies an urgency to productively engage climate change through the creation of alternative epistemologies, ontologies, and politics. The memory palace and the portals hope to contribute to the formation of these alternatives by collecting a planetary imaginary-which ultimately resides in individual minds and memories.

The format of this thesis document was constructed in relation to the process of its making to interrogate the nature of memory itself, and to create an artifact denoting a process that decompartmentalizes modes of making and thinking. The document wishes to evoke curiosities that are deciphered throughout the reading experience, weaving together shadow box collages (portals), stories, and short essays followed by reflections on the process of making, confessions, and personal memories. It is intended that the collection of texts could be shuffled into different configurations allowing readers to curate their own paths through the content in a format that is attuned to their interests. 


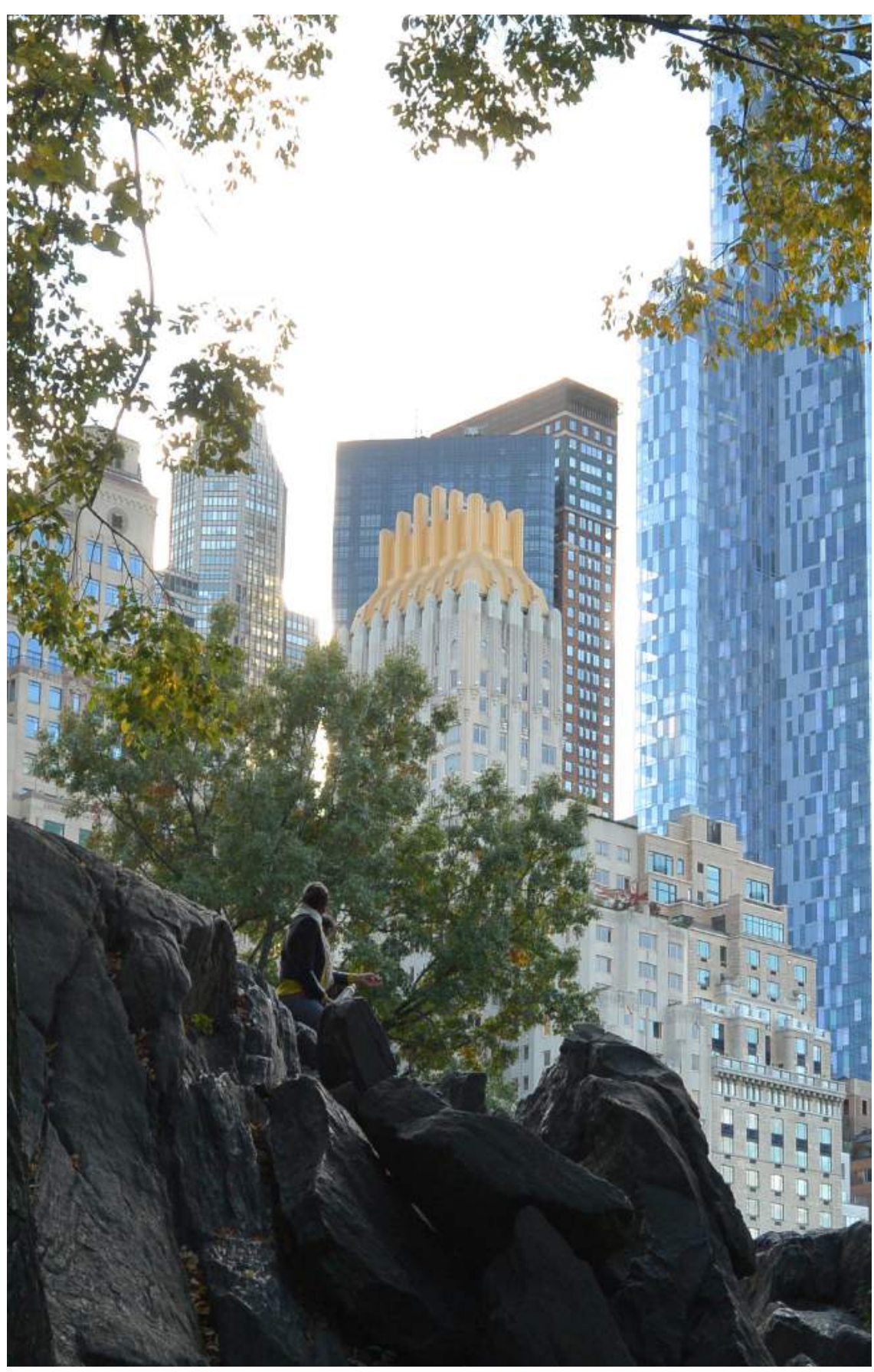

Figure 1. Manhattan Schist in Central Park - I took this photo during my last visit in 2015 


\title{
story 1 \\ ADMISSION
}

featuring

\author{
METHOD OF LOCI \\ CONTEMPORARY USE \\ HOW I AM LOST
}

and

MEMORY AND COLLECTION

PRECEDENTS 
"One ticket please."

"How long do you have to spend with us today?" the woman at the desk asks softly.

"Um... What do you mean? I don't really know yet."

"Well," she says, "we don't accept money for tickets."

"Oh, are you closed? I just wandered in because I noticed the sign on the sidewalk."

"Of course. Yes, we are open. We ask that you pay us with your time. Your time is valuable to us, and it's your careful contemplation of our spaces that make them real for both of us."

I pause, a little confused. I am not sure how this place pays for rent, but I will go along with it.

"Alright, great. You've got me for... an hour?"

"Fantastic," she says. The printer whirrs and she slips a ticket in front of me. "My name is Madeleine, and I will be your guide for today. Welcome to The Palace of Manhattan Memories." 


\section{METHOD OF LOCI}

The method of loci ${ }^{1}$-also known as the memory palace technique—was originally developed in ancient Greek rhetorical treatises. Simonides of Ceos was a Hellenistic lyrical poet and proclaimed that an individual who wished to train their faculty of memory must "select places and form mental images of the things they wish to remember and store those images in the places, so that the order of the places will preserve the order of the things, and the images of the things will denote the things themselves, and we shall employ the places and images respectively as a wax writing-tablet and the letters written on it." ${ }^{2}$ These instructions can be simplified thusly: store what you wish to remember in the form of images that you situate in an imagined place. The places contain the images, which contain memories.

\footnotetext{
${ }^{1}$ The term loci, (singular locus) is derived from Latin, meaning "place, spot, locality,".

"Locus | Origin and Meaning of Locus by Online Etymology Dictionary," accessed March 31, 2021, https://www.etymonline.com/word/locus.

${ }^{2}$ Marcus Tullius Cicero, E. W. Sutton, and H. Rackham. 1942. Cicero. De oratore. In two volumes. Cambridge, Mass: Harvard University Press.
} 


\section{CONTEMPORARY USE}

The memory palace has persisted in contemporary western culture as an enigmatic emblem of genius. It can be argued that the pursuit of genius is at the core of architecture and that it is what motivates each of us to reach beyond what we already know. The memory palace is famously represented in the various adaptations of Sherlock Holmes, presented as the inward space to which he retires and pivotal breakthroughs are assembled to solve the mystery. ${ }^{3}$ It has also become popularized by champions of memory competitions whereby individuals are required to memorize sequences of hundreds of words and numbers. It is claimed that any individual can train their mind to remember information if they practice the memory palace technique. The memorization process is simplified into two components: the path and the information fragments that are placed along it. ${ }^{4}$ The individual imagines a path in their mind (a walk around their home or a walk down the street for example) and they associate fragments of information they wish to remember (such as a grocery list or passage from a book) with segments of the path. To recall the information, they simply retrace their steps allowing them to retrieve the fragments they tethered to each segment of the path.

\footnotetext{
${ }^{3}$ Arthur, Conan Doyle. A Study in Scarlet. London: Ward, Lock \& Co. 1888. Electronic edition by UVa eText Center: Jamie L. Spriggs, 1995. accessed March 31, 2021, http://metaphors.lib.virginia. edu/metaphors/17736

${ }^{4}$ Brian Handwerk, "Neuroscientists Unlock the Secrets of Memory Champions," Smithsonian Magazine, accessed March 31, 2021, https://www.smithsonianmag.com/science-nature/why-youcan-train-your-brain-memory-champion-still-forget-your-car-keys-180962496/.
} 


\section{HOW I AM LOST}

The memory palace fascinates me because it seems completely incompatible with how I process the world and collect memories. There are aspects of my memory that I rely on. I take pride in remembering minute details from experiences that others have forgotten. And yet there are aspects of my memory that I cannot trust. I have difficulty with the proposition to remember information by navigating a place in my mind. I have a poor physical sense of direction and get lost in places I have been to several times. I forget where I am and lose any sense of where landmarks are with respect to other landmarks. I associate the navigation of space with forgetting, not with remembering. These established associations are difficult to undo in my mind as they are attached to strong emotions of embarrassment and worry. If I am unable to adopt the memory palace in its current form to my own understandings of memory, I have a limited capacity to design one for a collective. Therefore, I must be critical about its current condition and take ownership of an alternate memory palace within my work. 


\section{MEMORY AND COLLECTION}

For as long as I can remember, I have collected things. I am a sentimental person. Rocks from hikes, seashells from beaches, photographs taken from trips all over, ticket stubs from tours, museums, movies, and transit, so many free pens from hotels. I have collected books and mugs and notebooks. I have a closet full of cardboard-because architecture school has taught me you can never have too much cardboard. I have kept greeting cards from Christmases and birthdays and anniversaries. I cherish handwritten letters from loved ones who have passed away-I will never let those go.

What do all these things mean to me? I collect to remember. I am afraid of forgetting. People, places, gestures of kindness and love. Melancholic losses. Little victories that felt like monumental ones. Moments of growth and change. These things, these objects, these artifacts-they contain memory and meaning that are greater than me and the moment I am living in. 


\section{PRECEDENTS}

The creation of the portals was inspired by the work of Joseph Cornell, Mona Dworkin, and Geoffrey Farmer. Joseph Cornell's collages invite viewers to lose themselves in the worlds he creates within shadow boxes. His work is sculptural assemblage, ${ }^{5}$ in which he joins unlikely found objects and images in unorthodox unity. I became interested in using the literal framing offered by shadow boxes to create micro and macro worlds-my own readings of places in New York. The use of open-ended boxes portrays and acknowledges my biased curation and framing of place and narrative while implying that they are not close-minded readings of the world. The portals are neither beginning nor end-they belong to the continuous present. They, like memories, are subject to change- they are not static but are records of my perception in this moment. Upon revision and collaboration with others, artifacts would be added, and forgotten from the work. The body of memory represented in this work is meant to be revisited and revised.

Mona Dworkin's mixed media paintings and shadow boxes interpret the fragility of human connections and convey our need for collective understanding and action. ${ }^{6}$ Dworkin incorporates found objects and ephemera in her work to

\footnotetext{
${ }^{5}$ Deborah Solomon, "Joseph Cornell: Pioneer of Assemblage Art | Blog | Royal Academy of Arts," accessed March 25, 2021, https://www.royalacademy.org.uk/article/joseph-cornell-shadow-boxesassemblage-art.

${ }^{6}$ Mona Dworkin. ARTIST'S STATEMENT + CV | Mona Dworkin,” accessed March 25, 2021, https://www.monadworkin.com/pages/about.
} 
personally contextualise women's shared experiences. I have been inspired by the interplay between individual and collective meanings embedded in this work and the role collage plays in this translation.

Geoffrey Farmer's work, namely his installation Leaves of Grass—which I was grateful to visit in person many years ago-also assembles dynamic sculptures which he uses to record the history of American culture told through thousands of clipped images from Life magazine. Farmer's installation stages narrative questions for its viewers and is positioned not as a celebration of American identity, but as a criticism of the pictorial dominance in shaping collective memory and cultural history. ${ }^{7}$ Elaborating on this intention, I have used found images from the internet that pose as the artifacts placed into the portals. These images have supersaturated my research experience for this project. I acknowledge that architectural representation and the challenge of conveying a design thesis virtually tends to give way to visual media. I aimed to engage the other sensory aspects of my work through the tangible crafting of the portals (for me) and then by accompanying them with descriptive narratives that intended to imagine the sensorial and spatial experiences of each portal (for readers of the work).

"Margherita Dessanay. Leaves of Grass by Geoffrey Farmer, FRAME 2012, accessed March 25, 2021, https://www.frameweb.com/article/leaves-of-grass-by-geoffrey-farmer. 


\title{
story 2 \\ MANNAHATTA
}

featuring

MEMORIZATION

REMEMBERING

SENSORY AND REAL

\author{
and \\ WHAT I HAVE MADE \\ WHAT I HAVE WRITTEN
}




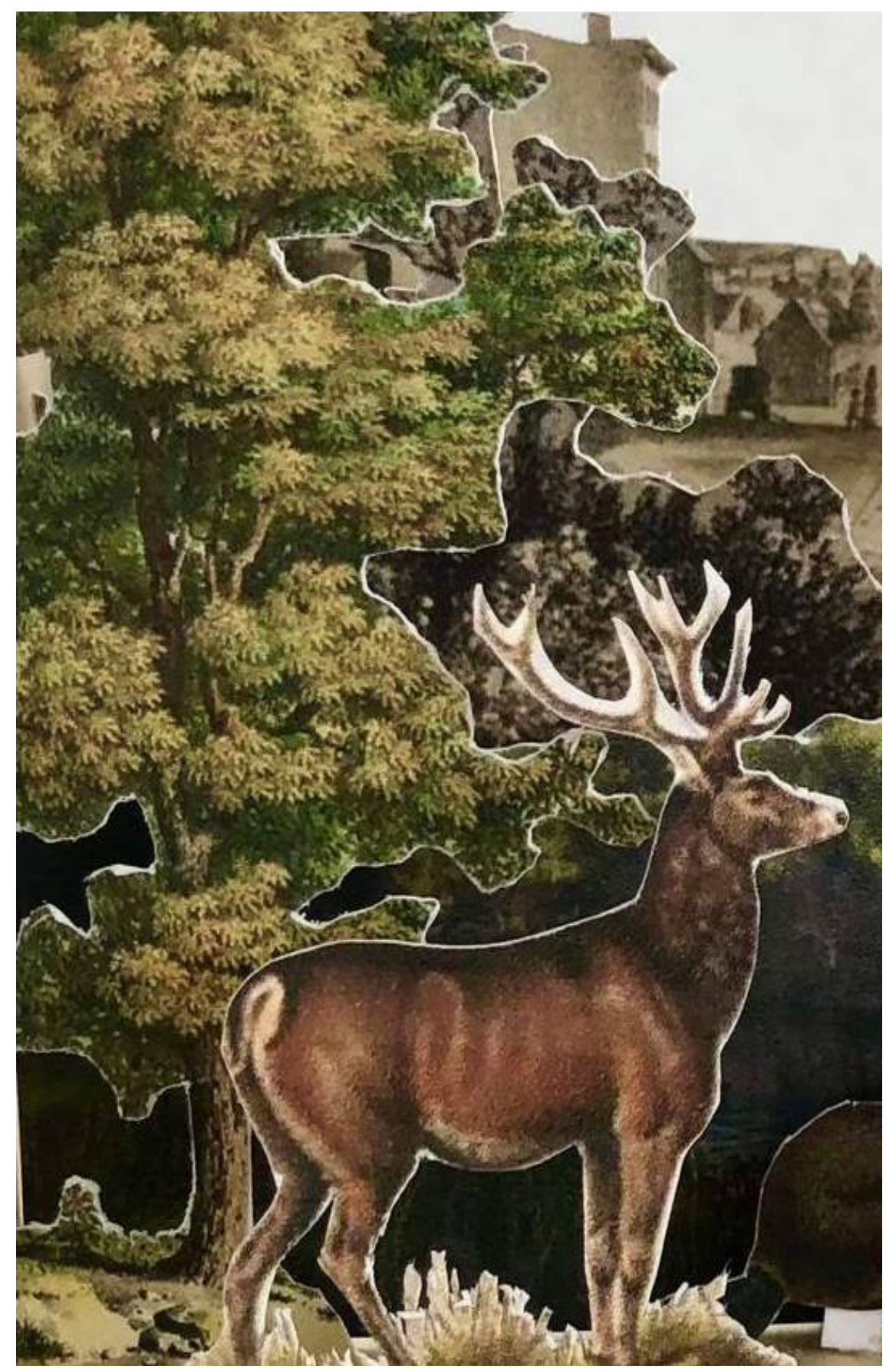

Figure 2. Mannahatta Portal - Vignette 
"This room has a very special door." Madeleine says. "Do you recognize it?"

I study the door. It's really more of a gate. I can see through it. I notice a diagonal line that passes through repeating horizontal and vertical lines. I notice small irregularities in the pattern as I am reaching to form a guess.

"Is it... a map...? Is it... Manhattan...?"

"Precisely!" She is pleased. She pulls the latch and the gate swings open. I am standing in a forest scene. Sounds of birds chirping and trees dancing in the wind fill the room from carefully hidden speakers. An elk, a black bear, a turkey, and a beaver pose in front of a marshy pond framed by tall oak trees. In the distance, I see a dozen or so houses that are sprinkled atop a rugged and undulating landscape.

"Welcome to a glimpse of Manhattan before it was Manhattan." Madeleine announces, pausing for effect. "We are in Mannahatta, the name the Lenape people gave to their native land. We stand here in this forest, on the precipice of conquest. It is 1609, and this is what Henry Hudson finds as he sails ashore."

"Let's take a seat over here for a moment," Madeleine says as she makes her way over to the corner of the room. A tall oak desk is perched atop long and narrow drawers. The stool squeaks as I sit on it. Madeleine is scanning the drawers, and quickly finds the 
one she is looking for. She pulls out a large map, which she lays on the table carefully. She sits quietly as I stand up, leaning over the map to examine it. The paper smells stale as I lean close to it. It's an old map of Manhattan. I find the title on the corner of the page: Topographical map of the City of New York: showing original water courses and made land. The grid plan of the city sits faintly atop rendered curves that denote the topography of the island.

"When we look at New York in maps," Madeleine begins, "we read it as an imagined city. Do you know Rem Koolhaas? The architect?"

I nod yes (I don't know).

"He writes in his book, Delirious New York about the grid as a conceptual speculation." Madeleine closes her eyes, searching for a passage in her mind. "In spite of its apparent neutrality, it implies an intellectual program for the island: in its indifference to topography, to what exists, it claims the superiority of mental construction over reality." She opens her eyes and gazes at me.

"Mental construction over reality... " I repeat. "The grid flattened the topography of this land... and the ecosystem was lost with it."

Madeleine nods. "The grid commodified this land. Rectangles are efficient. Rectangles homogenize. The rugged landscape was made sense of in terms of capital value through the process of its parceling. And these maps," she continues, pushing herself out of her stool to pull open other drawers. I catch quick glimpses of other carefully 
preserved maps. "is the dominantly told story of the city. It's hard to separate Manhattan from the grid that has made it iconic."

She slowly steps away from the desk, walking to the center of the room. We both take a moment to stare again at the staged landscape.

"Alright," she says, walking to the door, "lots more places to visit."

I am lost in thought. I linger here. I think of the topography. I think of the landscape. I think of 1609. The story is so much longer than that. The story is so much deeper than that. This forest is beautiful. But it - like the grid and the city - was not a permanent condition. "Have you thought about the glacier?" I ask.

Madeleine is slightly surprised, turning around to look at me. I search for its name.

“... The Laurentide glacier?... Didn't it melt over the city some eighteen thousand years ago? Isn't that what formed the landscape and the topography long before the forest and the maps?"

It's Madeleine's turn to nod without quite knowing. She is smiling and then winks at me. "Now that is the kind of planetary imagination I love." 


\section{MEMORIZATION}

The act of memorization should be distinguished from the act of remembering. There are things that you memorize but later forget and there are things that you remember that need no memorization. In the case of the former I have developed a personal ritual of memorization over the course of my life as a student. To begin, I write all the information I want to memorize by hand on sheets of paper. This time-consuming process allows me to contemplate the content as I write it. After completing the document-the artifact to be memorized-I read the information repeatedly aloud to myself. If time and company permits, I reinforce my understanding of the document by presenting the text aloud to someone as if I were telling them a story. By reviewing the pages continuously throughout this process-I familiarize myself with it intimately and I am able to visualize the handwritten words on the pages when recalling the information.

I have attempted similar exercises but with typed notes and have found it more difficult to visualize the pages because there are no oddities or imperfections on the artifact. There is no variety in the appearance of the letters, there are no sentences crammed to the edges of the margins or lead smudges on the pages. My hands do not remember how they furiously stroke keys as much as they remember the ache from gripping a pencil for hours. When the information has been relayed to serve its purpose- the test written, the presentation delivered, the meetings complete-much of it is forgotten if I do not return to it. Traces of the information linger in the mind, much of it becomes fuzzy, some of it is misremembered. 
I suppose this is what happens when a memory champion has completed their contest. They forget the sequence of numbers, removing the images from their palace making way for replacements. When considered as a tool to aid in the process of memorization, the contents of the memory palace are constantly shifting and changing, the manifestations of memory in the form of images are impermanent and do not accumulate in the imagined place, instead it is constantly wiped clean. The artifacts placed in the palace are not collected.

What is meaningful to me about my own developed method of memorization is that it is a repetitive, multisensory process involving making something tangible. I feel the pencil in my hand pressing onto the pages I write. I must hear the information as I repeat it aloud to myself, echoing in the room where I study. And then I construct a narrative with the information as I convey it to someone else. I visually recall the intimate details of the imperfect pages. This is something that I have carried into the process of making, thinking, and remembering my thesis project. It is a study that memorizes and remembers through meaningful acts of making. 


\section{REMEMBERING}

What I expect to remember about my thesis work in the many years that will distance me from it is not the uncountable hours I spent in front of my computer screen, typing, reading, and scanning the internet for information. The feelings of intense doubt, fear and confusion will dull in my memory, making way for nostalgia. I will remember the bursts of pure exhilaration I have felt during breakthrough conversations with my insightful advisors. I will long for the comfort of late-night calls with my fellow thesis students. I will remember the time I have spent—and will continue to spend_crafting collections of artifacts. The process of remembering is fundamentally tied to embodied experience.

What interests me most about the memory palace is not that it is a technique of memorization but that it can become an introspective place for remembering. Unlike a space that is cleared and wiped clean, it becomes a repository for places and artifacts that are embedded with memories and it ponders how places contain memory. When positioned in this way, the purpose of the memory palace shifts from being a tool that memorizes and forgets and becomes a place for collecting, accumulating, and remembering. Memory and its complexities are welcomed into the palace in its greater mystical and poetic sense.

Memory shapes who we are, it is how we process and accumulate experience. Memory is emotional. Memory is meaningful. Memory is imagining the past. It eludes rationality and order. It is messy and inconsistent. The mind 
recounts moments and encounters in ways that are not always truthful, and they are never objective. We inherently trust what we remember though we misremember and forget. Our individual worldviews are deeply rooted and are revealed in the memories we recall and the ways we describe them. Every individual remembers and forgets differently. When we recall spaces, they adopt strange qualities. They become fuzzy with uncertainty. Yet memory is so much more than visualization. Memory is sensory.

French novelist Marcel Proust stumbles upon this epiphany as he tastes a madeleine with his tea and suddenly remembers moments from his long ago past revealed in striking detail. He states, "And so it is with our own past. It is a labour in vain to attempt to recapture it: all the efforts of our intellect must prove futile. The past is hidden somewhere outside the realm, beyond the reach of intellect, in some material object (in the sensation which that material object will give us) which we do not suspect. And as for that object, it depends on chance whether we come upon it or not before we ourselves must die." ${ }^{8}$ Proust's reflections ponder the power of objects-or artifacts, as I identify them in this project-and their capacity to unlock sensation and memory. What I wonder about these artifacts is whether they can be designed or produced intentionally. In other words, what is the agency of artifacts in resisting assigned meaning and value? Furthermore, how does the objectification of memory affect our behaviours and worldviews?

${ }^{8}$ Marcel Proust. Swann's Way: In Search of Lost Time Volume 1, trans. C.K. Scott Moncrief and Terrence Kilmartin. (New York :Chatto and Windus and Random House, 1992). 60. 


\section{SENSORY AND REAL}

The portals provoke interest in Object-Oriented Ontology (OOO), a metaphysical perspective which explores the reality and agency of nonhumans and rejects the privileging of human existence. Scholar Ruslanas Baranovas distills OOO by stating firstly that only objects exist. He lists "a chair, sunglasses, mountain, atoms, planets, the universe, Bruno Latour, or a plane crash" as objects and emphasizes that "what qualifies something as an object is not its size or ontological proximity to our everyday experience." ${ }^{\prime 10}$ Secondly, he notes that, "no object can know or encounter another object-in-itself, but only its appearance. The real object always withdraws." ${ }^{11}$ This notion is rooted in philosopher Graham Harman's understanding of OOO where every object consists of a sensory expression (found in experience) and a real expression (found through intellectual probing). ${ }^{12}$ Harman offers understandings about how the qualities of artifacts adopt meaning through vicarious causation, suggesting that two entities meet in the interior of a third entity, existing sideby-side until something occurs to prompt interaction. ${ }^{13}$ Artifacts (objects) placed in the portals interact with you (an object). Your thoughts (real) allow

\footnotetext{
${ }^{9}$ Ruslanas Baranovas, "Virtuality and the Problem of Agency in Object-Oriented Ontology," Open Philosophy 3, no. 1 (May 27, 2020): 233, https://doi.org/10.1515/opphil-2020-0106.

${ }^{10}$ Ibid. 233-234.

${ }^{11}$ Ibid. 234.

${ }^{12}$ Graham Harman. The Quadruple Object. United Kingdom 2011: Zero Books. ISBN 978-184694-700-1. 49.

${ }^{13}$ Graham Harman. On Vicarious Causation. Collapse, 2007, accessed March 31, 2021, https:// pervegalit.files.wordpress.com/2008/06/harman_vicarious_causation.pdf. 192.
} 
you to form connections with and between the (real) artifacts-allowing you to draw your own narratives. The written stories in this project hypothesize how these interactions might take place. The short story frames the memory palace as an object where Madeleine embodies the real and the rooms in the museum embody the sensory. She enables you to access the memory palace intellectually beyond the appearance of its rooms. As she concludes the tour with her visitors, she withdraws into the palace. 


\section{WHAT I HAVE MADE}

The shadow boxes I have crafted are intended to operate on many scales. They can be interpreted as visual manifestations of the workings of my mind and my memory. They are not quite models, not quite drawings. They are collages. While the boxes are intended to contain layers that weave my individual memories with collective memories, the boxes are still my interpretations of place and collective. The boxes are representative of my individual section through a much deeper, taller, and longer collective memory. The boxes - which I have called portals - are simultaneously shelves on a cabinet of curiosities (the tangible shadow boxes I have made), rooms in a museum (as told in the narrative), a memory palace (encompassing the thesis research I have done throughout this project), and imaginations of the present (as engaged by fruitful discussions I have shared and will get to share with others).

The term 'portal' presents the boxes as literal doors or gates to current visions of New York. These portals are not thresholds that teleport us to the future, nor are they time machines that allow us to travel to the past, they engage a reading of place in the present. Time is not represented in a strictly linear or chronological fashion, the notion of the timeline where events exist as mere points on a line with no magnitude on the points that precede or follow becomes mystified. 


\section{WHAT I HAVE WRITTEN}

Six short stories have been composed, inviting readers to imagine the sensorial experience of touring through the portals as if they were rooms that comprised a museum titled The Palace of Manhattan Memories. The stories consist primarily of conversations shared between the visitor who narrates the encounters, and the guide named Madeleine. Their relationship was inspired by the remarkable conversations between author Lawrence Weschler and curator David Wilson at the Museum of Jurassic Technology, as described in Mr. Wilson's Cabinet of Wonder. ${ }^{14}$ My interest in describing Manhattan was not to provide a comprehensive historical lesson about each place, but to relay what I remembered about them from my research and memories. This is why these stories are the only textual depictions of New York in this thesis, as this form of narrative does not promise specificity or accuracy. I am not trying to portray New York as it is in reality, but New York as this thesis project imagines it.

As I wrote each text, I placed the corresponding portal on my desk so that I could reference it. I approached short passages in each story as close readings of the artifacts, divulging its many layers in detail. Writing these sections offered me a chance to reflect on how I crafted each portal. By translating my interpretations of the portals into stories, I was confronted with an additional phase of refining through framing, inevitably omitting detail once again. I am curious about how memory translates across media from reading, to making

${ }^{14}$ Lawrence Weschler, Mr. Wilson's Cabinet of Wonder (New York: Random House Inc, 1995), 44. 
to writing. I am curious about how continuing to alternate between these modes of imagining and thinking might produce work that continues to both distill and displace itself from previous iterations.

Scaling the portals to become rooms in a museum challenged me to determine the experiential essence of each place and imagine an architecture that would support it. Rania Ghosn and El Hadi Jazairy's storytelling in Geostories: Another Architecture for the Environment framed their designs with the typologies: terrarium (Mannahatta and Central Park), aquarium (Hudson River) and planetarium (Grand Central), which became a helpful precedent for me to imagine how my work might be scaled to an expanded spatial condition. ${ }^{15}$ The building as it is described in the stories is absurd and nonsensical. The interstitial spaces between rooms are left a mystery.

By writing the stories with two characters, I felt as I though I was having a conversation with myself. There is the reminding me (Madeleine, a figment of memory) conversing with a remembering me (the visitor). The dynamic between these characters expanded my ability to recognize my own cycles of memory as it oscillates between encoding, storing, and retrieving.

${ }^{15}$ Rania Ghosn and El Hadi Jazairy, Geostories: Another Architecture for the Environment (New York and Barcelona: Actar Publishers, 2019). 
The dialogue between the characters envisioned how imagining the portals welcome collaborative discourse that wander beyond New York to the planetary. These moments that expanded the discussion beyond memories and knowledge of specific places emerged as tangled soliloquies that pull at my unresolved uncertainties about my thesis and how it imagines the planetary.

The ending of the story underscores the value of dynamic and imaginative conversation and proposes a guide to engage with the thesis document collaboratively. It indicates a path forward as I consider how I might revise the format of this thesis document to invite personalization, notes, and the collection of found artifacts, encouraging purposeful interplay with readers. The thesis offers itself as a handbook for exploring New York while also supporting conversation that engages a collective planetary imaginary. 


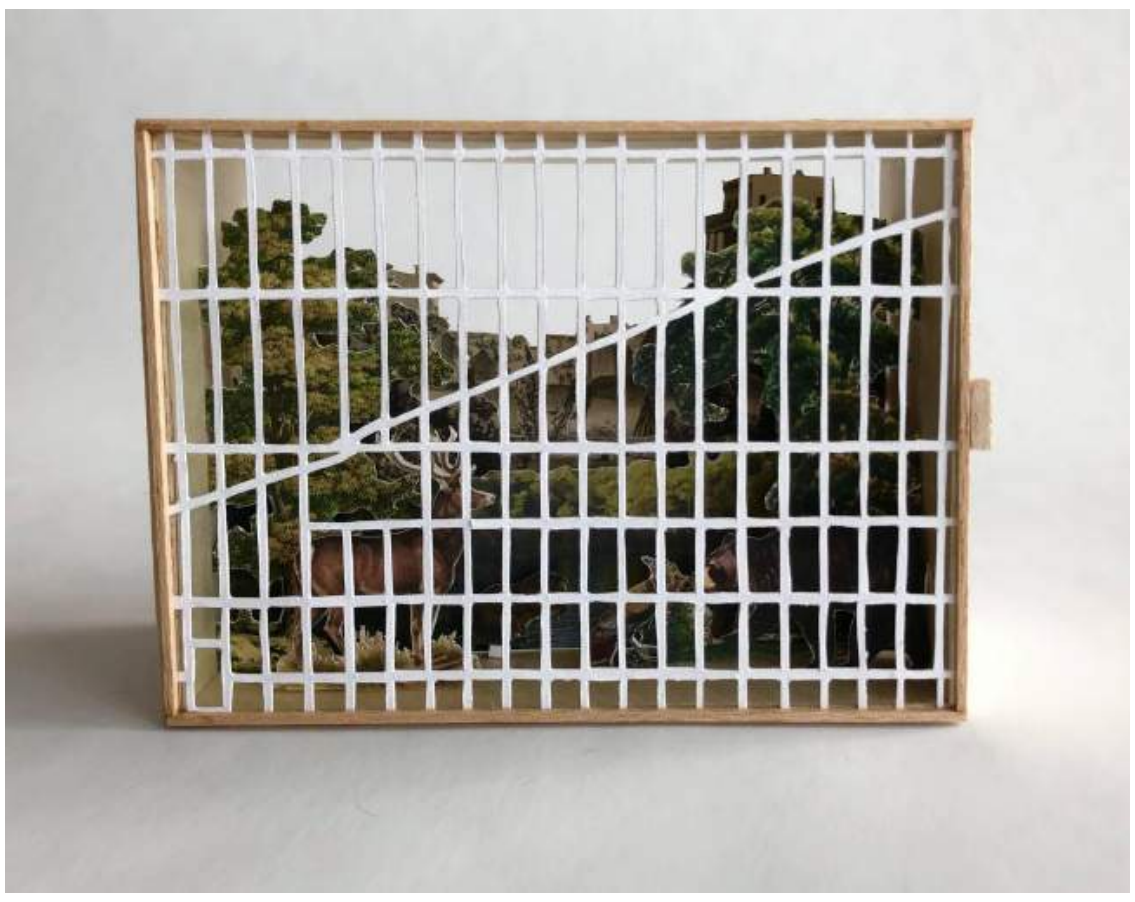

Figure 3. Mannahatta Portal - Front View 


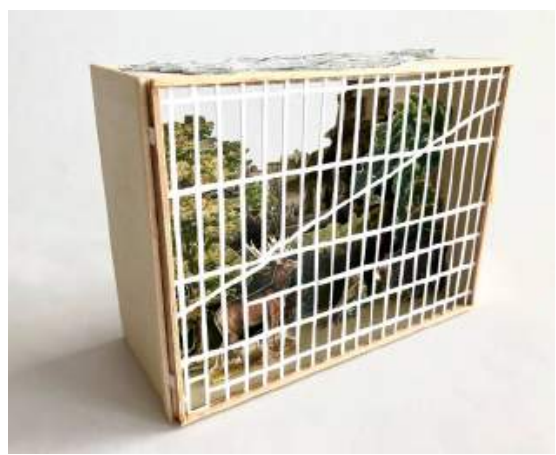

Figure 4. Mannahatta Portal - Closed

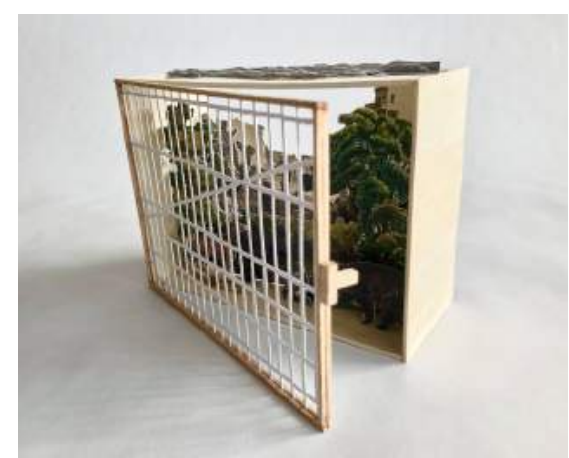

Figure 5. Mannahatta Portal - Open

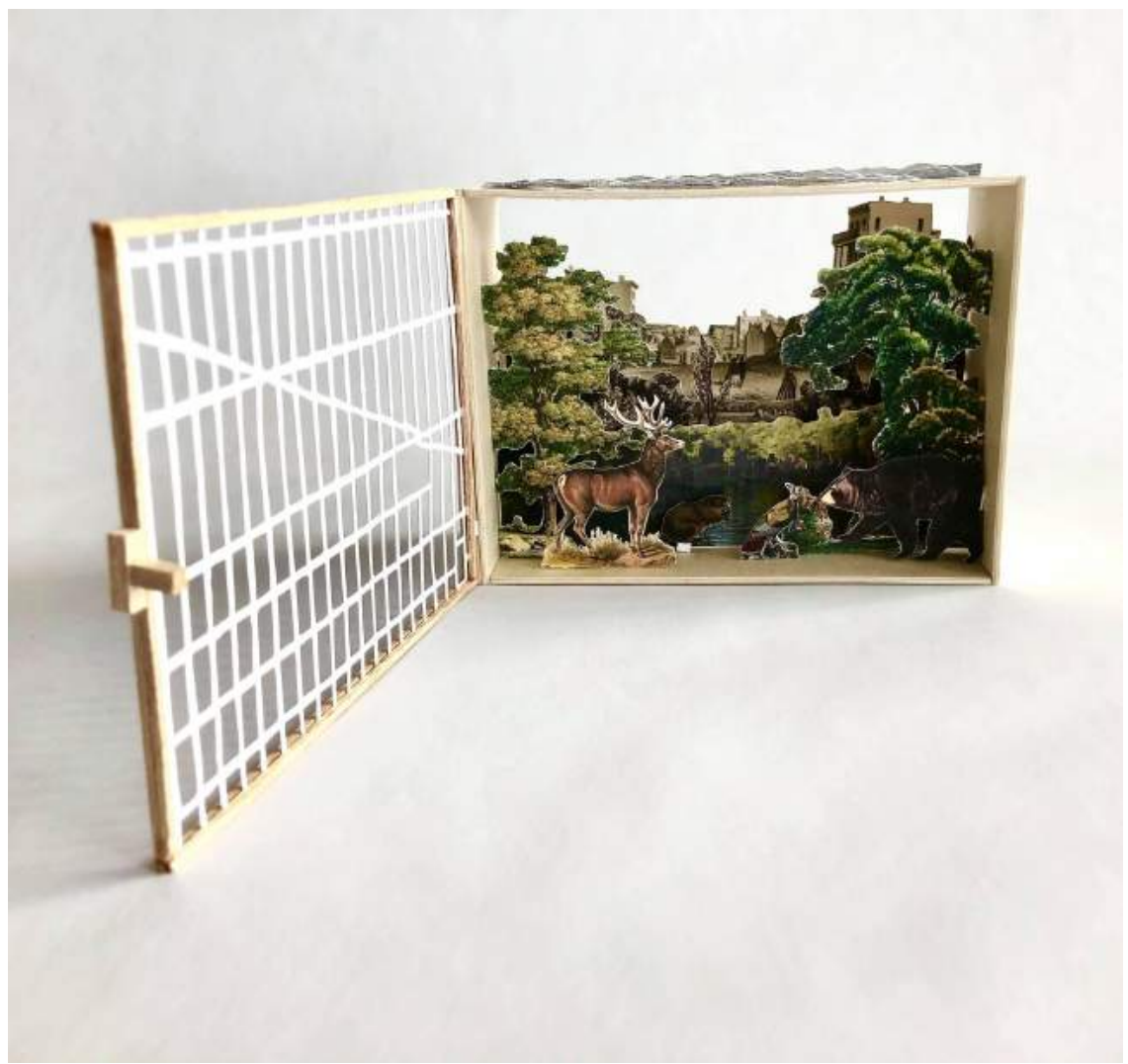

Figure 6. Mannahatta Portal - Reveal 


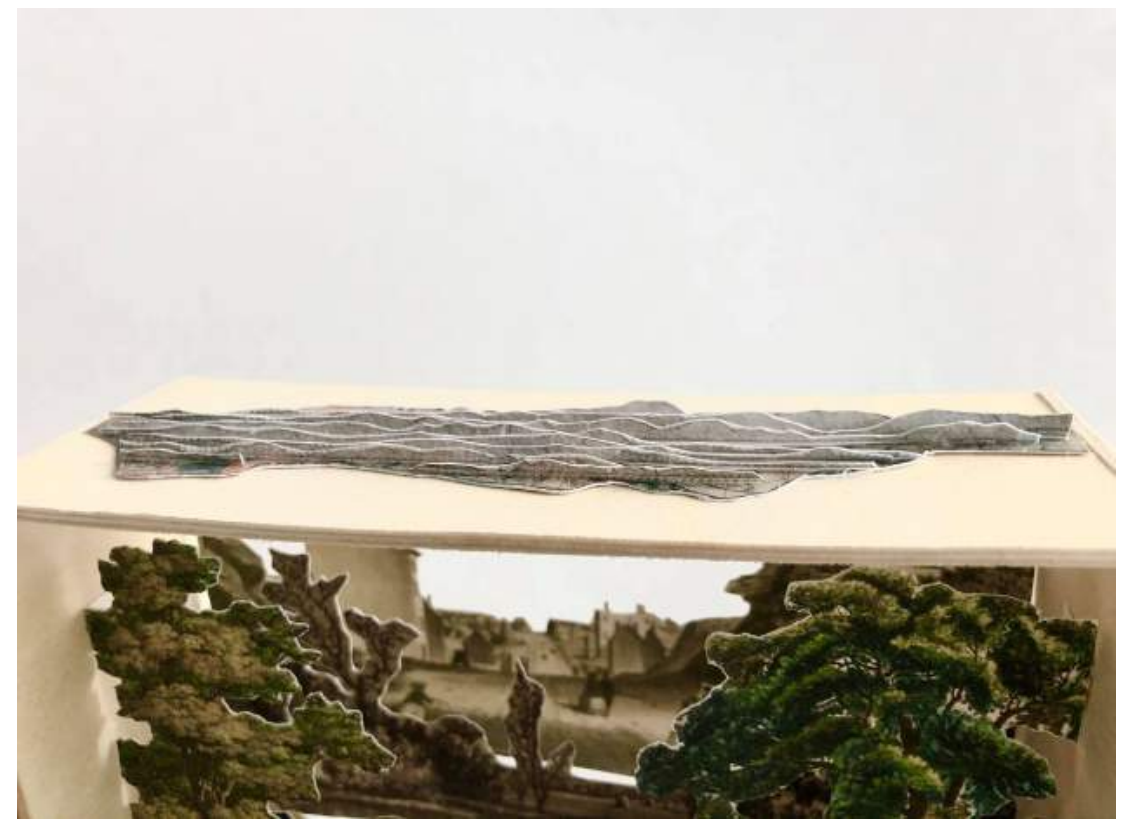

Figure 7. Mannahatta Portal - Topography

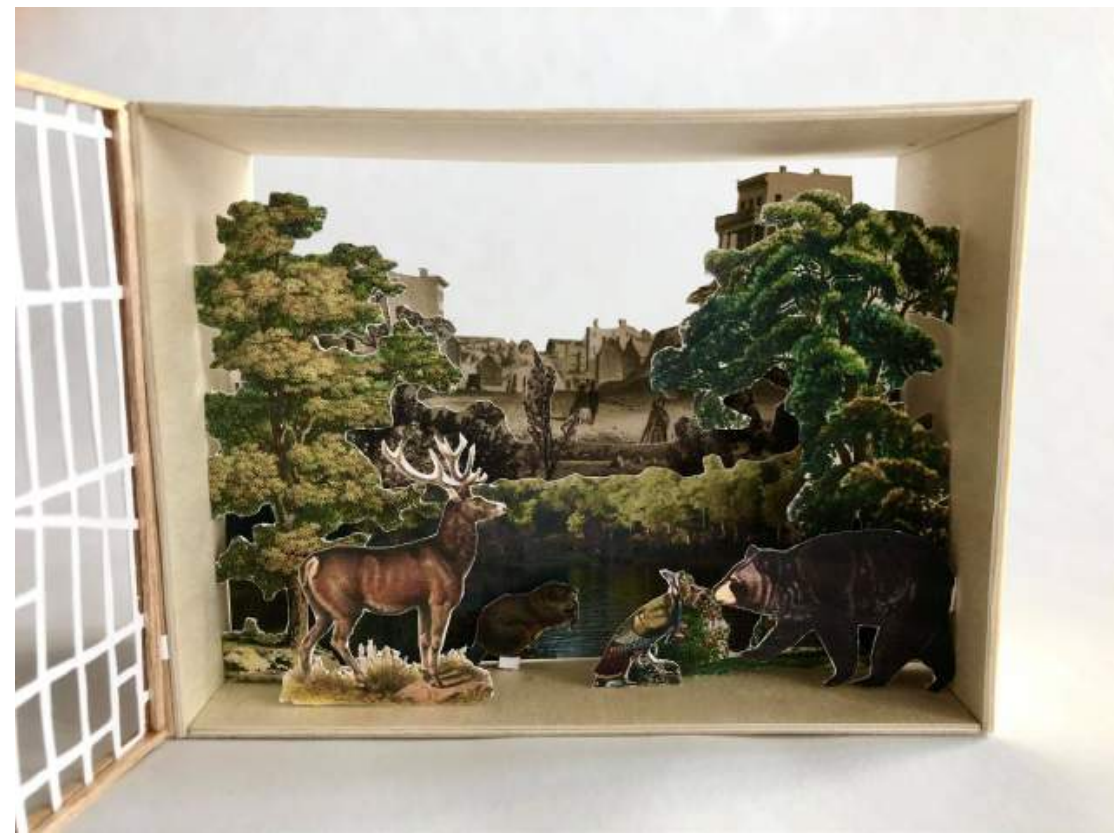

Figure 8. Mannahatta Portal - Inside 


\section{story 3 \\ HUDSON RIVER}

featuring

COLLECTIVE MEMORY

CURATION, MUSEUM,CABINET OF CURIOSITIES

'US', 'WE', 'OUR', 'COLLECTIVE'

THE MEMORY OF THE INTERNET

and

A CONTEMPORARY MEMORY PALACE 


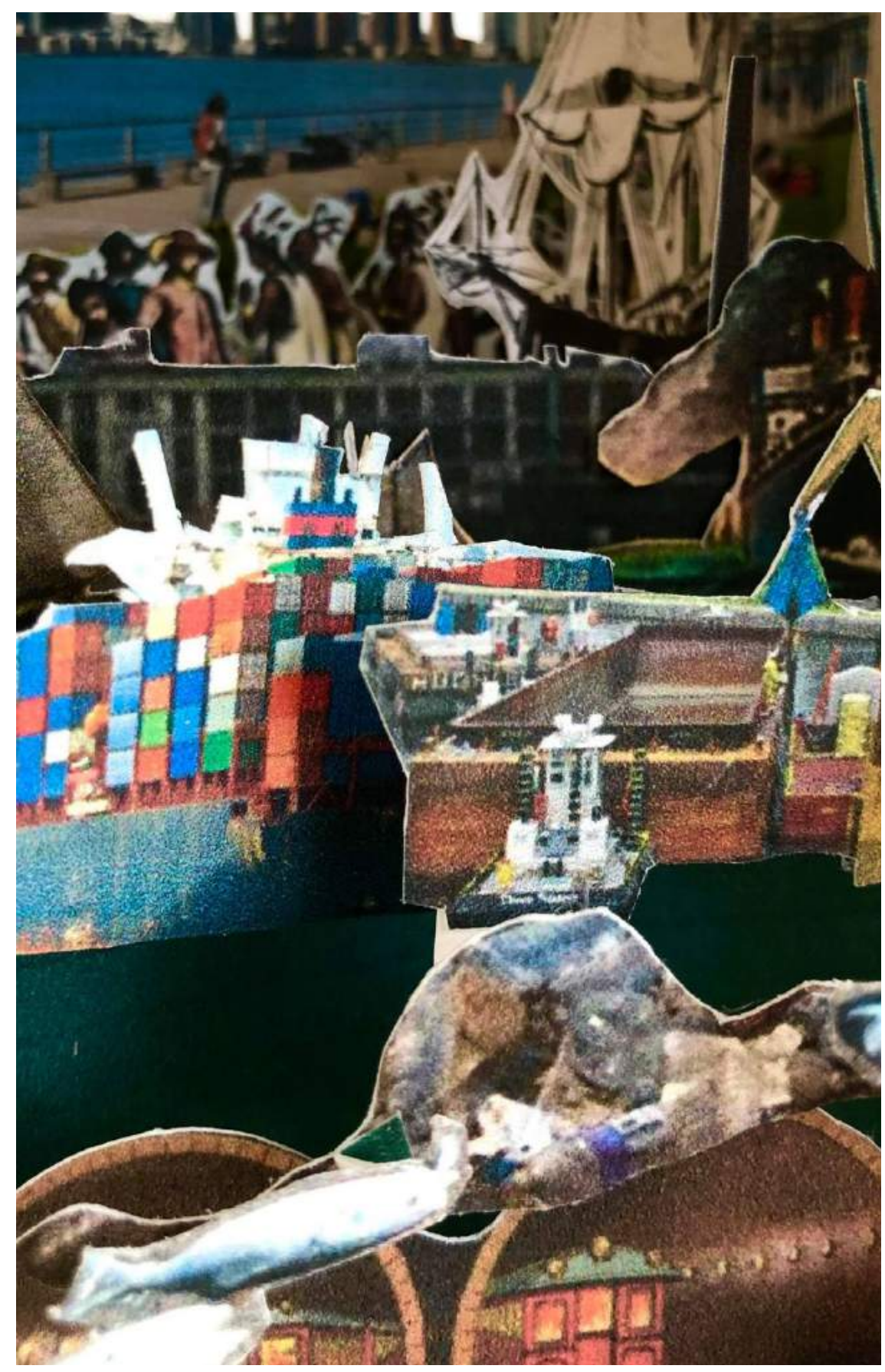

Figure 9. Hudson River Portal - Vignette 
"Let's take a quick peek in here." Madeleine says, opening the door gingerly.

A shimmering blue glow emanates from what's inside. I step into the room, it's tall and narrow. I am greeted by a floor to ceiling wall of glass. I am looking into a giant tank.

"The aquarium we observe submerges us into the depths of the Hudson River, offering us a unique section cut through the water."

Madeleine and I stand in silence as I survey the scene that unfolds. The river floor is embedded with oysters, a diver peeks behind them, happy with the one he has surfaced. Illustrations of enlarged phytoplankton remind us that we are observing their domain. A humpback whale glides under the surface of the water, teasing an appearance. The north river tunnels sit beneath a cacophonous surface. A surface that sways with dead fish and heaps of waste. Sailboats give way to enormous cargo ships coming from who knows where. A factory rests ominously on the scene, decades of industrial contamination pervade this notion tarnished purity. In the distance, European explorers negotiate territory on the water's edge with Indigenous leaders. Skyscrapers shrink in the background.

"There is such a disconnect." Madeleine explains. "Humans in the city observe the water but are disconnected from it. They receive their tap water from watersheds over a hundred miles away. The idea of 'local' expands and contracts... And then, despite our ignorance, there is that wavering plane where the water meets the air. The water's surface is a threshold between two nonhuman worlds." 


\section{COLLECTIVE MEMORY}

Collective memory is defined by the American Psychological Association as a "shared recollection: mental representations of past events that are common to members of a social group. [...] Collective memory is expressed in numerous forms - including oral and written narratives, monuments and other memorials, commemorative rituals, and symbols - and serves a range of functions, such as establishing and maintaining relationships, teaching or entertaining others, and supporting group identity. The memory is common to the group, but it is remembered by individuals, and research suggests that they coordinate their personal memories with those of their groups through a process of attunement: Stimuli assumed to be experienced by one's social group are more prominent in both cognition and behavior because they receive greater attentional focus or more elaborated encoding, which in turn increases their accessibility." 16 This description of collective memory identifies that cultural and social artifacts are reinforced and integrated as ubiquitous narratives and knowledge. The memory palace engages collective memories that are localized to Manhattan while expanding to resonate with collective Western worldviews.

\footnotetext{
16 "Collective Memory - APA Dictionary of Psychology," accessed March 31, 2021, https://dictionary. apa.org/collective-memory.
} 


\section{CURATION, MUSEUM, CABINET OF CURIOSITIES}

The institution that is perhaps closest to embodying a memory palace that houses artifacts for a collective is the museum or more specifically, its precursor: the cabinet of curiosities. A cabinet of curiosities, or wonder cabinet, as they are also called, is a room dedicated to collections of objects of fascination and enchantment from the natural world. ${ }^{17}$ These cabinets emerged in the 16th century, animated by Europe's discovery of the Americas. These cabinets became the containers of elaborate collections of artifacts, decontextualized and displaced from the New World, planting the seeds of sensationalized exoticism. Small collectives were invited to marvel and witness small windows into the peculiar and vast world that was being discovered. As historian Michel de Certeau puts it, "that experience- of the ground opening before one's feet-was at the heart of the sensation of wonder ideally afforded by (or at any rate striven toward in) many of the cabinets of the time." ${ }^{18}$ Bruno Latour calls upon the feeling of the ground opening before one's feet, as the underlying sentiment we all face as we encounter the consequences of the climate crisis: "we are discovering, more or less obscurely, that we are all in migration toward territories yet to be rediscovered and reoccupied." ${ }^{19}$

Museums, cabinets of curiosities and the very notion of collective memory itself are all carefully curated to shape and communicate particular historical

\footnotetext{
${ }^{7}$ Lawrence Weschler, Mr. Wilson's Cabinet of Wonder (New York: Random House Inc, 1995), 80.

${ }^{18}$ Ibid. 79.

${ }^{19}$ Bruno Latour, Down to Earth: Politics in the New Climactic Regime, trans. Catherine Porter (Oxford: Polity Press, 2018), 5.
} 
narratives. These are all processes of selection, containment, enforced order and deliberate framing. In my curation of the portals, I was confronted with my own biased framings of place, the inevitability of omissions, and the selectivity of decisions to include or exclude. The thesis project engages the frictions between artifacts both natural and unnatural and their relation to the containers that display them. How does the artifact affect the form of its container and how does the container transform and objectify the artifact it encloses?

It is also deeply important to consider the practice of collecting through a discerning lens that exchanges romantic wonder for barbarous horror. Philosopher Walter Benjamin reflects on the wonder cabinet, stating that "a historical materialist views [cultural treasures] with cautious detachment. For without exception the cultural treasures he surveys have an origin which he cannot contemplate without horror... There is no document of civilization which is not at the same time a document of barbarism. And just as such a document is not free of barbarism, barbarism taints also the manner in which it is transmitted from one owner to another." ${ }^{20}$ Artifacts contain layered narratives that recount a pluriverse of meaning and can include deep seated traditions of entitled pillaging, exploitation, extraction, and displacement.

\footnotetext{
${ }^{20}$ Walter Benjamin, "On the Concept of History", in: Selected Writings 4, eds. Howard Eiland \& Michael W. Jennings [Cambridge, MA: Belknap Press of Harvard University Press, 2003], 391.
} 


\section{'US', 'WE', 'OUR', 'COLLECTIVE'}

I would like to clarify that when I refer to 'us', 'we', 'our' and 'collective' I am referring to humans that comprise the Western world. As this project turns its focus to our established relationships with nature and climate change, the memory palace becomes critical about our pernicious objectifications of nature. $^{21}$

Professor of architectural history, Adrian Forty notes in The Art of Forgetting that "the Western tradition of memory since the Renaissance has been founded upon an assumption that material objects, whether natural or artificial, can act as the analogues of human memory. It has been generally taken for granted that memories, formed in the mind, can be transferred to solid material objects, which can come to stand for memories and, by virtue of their durability, either prolong or preserve them indefinitely beyond their purely mental existence. Much Western artifact making (and this would include products as diverse as funerary sculpture on the one hand and information technology on the other) has been dedicated to the creation of material substitutes for the fragile world of human memory." ${ }^{22}$ Forty identifies that the act of assigning, ascribing, and collecting memory in objects is an inherently Western practice. He describes that it is perhaps presumptuous of

\footnotetext{
21 The monumentalization and objectification of nature was explored through David Gissen's, A More Monumental, Non-Naturalistic Environment. These abstractions and objectifications of nature were explored further through the production of miniature vitrines that house found objects. These additional experiments were complete for the Miniaturizing the Gigantic Graduate Seminar.

${ }^{22}$ Adrian Forty, "Introduction" to The Art of Forgetting. Adrian Forty and Susanne Kuchler, eds. (Oxford: Berg, 1999), 2.
} 
us to assume we can memorialize something as delicate as a human memory in a material artifact and that it is in fact enabling us to forget. ${ }^{23}$

I recognize the truth and challenge in this, as the memories I recall by interacting with personal artifacts I have collected would not summon the same memories for someone else. Furthermore, an artifact that is interpreted by a collective elicits a multiplicity of memories. However, this thesis argues that the loss of the individual who initially experienced the memory, does not force the artifact to forget. This project frames its memory palace as a venue to host this multiverse of memory and does not wish to privilege my individual memory above the multiplicity of the collective. It understands that the written stories in this thesis represent my own interpretations and memories attributed to the artifacts in the portals and that it is one among countless additional stories that could be written. The thesis views artifacts not as tools to deposit and forget memories, but as opportunities to analyse, and share memories.

The world of the thesis is situated in a memory palace and cabinet of curiosities — which are Western constructs-located in Manhattan-a place that is the embodiment of Western values and attitudes — and I am the author of this work - a person who has lived, grown, and learned in the West. I am biased and am in no position to de-westernize the work. I am not trying to 
de-westernize, but to clarify and be critical about the patterns of Western thought and behaviour that are revealed in this project. The process of this thesis work has sharpened my awareness of how these perspectives affect me as a human being, a student of the universe, a thinker, and a maker. I have become reflective and concerned about our problematic attitudes toward nature and our disregard for the nonhumans with whom we coexist in human made contexts. It can be argued that the oversized contributions of the West to climate change are a result of a cultural inability to engage productively with a planetary imaginary due short-sighted epistemologies and ontologies. Thus, tackling the notion of agency is critical. This project confronts and challenges this self-awareness to find agency in collectivity, curation, and imagination. 


\section{THE MEMORY OF THE INTERNET}

The memory palace asks us to collectively refine our ability to imagine places within the planetary, oscillating between scales of time, space, complexity, and depth, uncovering layered narratives that surpass superficial understanding. The internet has played a heightened role in my education this year and it has been my portal to the world. It has provided me with the means to embark on this thesis during a global pandemic and for that I am deeply grateful. I have connected with my thesis advisors and the school community by virtual means. I have ordered resources and materials that were delivered to my home. I have spent countless hours conducting research on hundreds of websites and databases, reading books and articles, watching videos, and listening to interviews. The internet has allowed me to reach out to complete strangers to ask about their fascinating bodies of work-their incredible generosity fills me with hope and admiration. ${ }^{24}$

While the internet has made this project possible for me, I must be critical of its hegemony over imagination and memory. The omnipresence of easy to access information poses as its own memory palace of collective knowledge that exists outside of any human mind - one may even wonder why a memory palace is relevant if the internet remembers things for you. This is the issue at

\footnotetext{
${ }^{24}$ I am indebted to architect Tiago Torres-Campos, historian Myles Zhang, cartographer Nat Slaughter and his colleagues at the Squirrel Census. These fantastic individuals kindly shared their work with me and offered me incredible help and advice. Thank you for bringing me closer to New York despite my not being able to visit in person.
} 
hand: we rely on the internet to remember things for us and to inspire us. ${ }^{25}$ Despite instantaneously offering thousands if not millions of search results upon every query—an ability the human brain could never summon—the internet is not intelligent. The internet cannot imagine. The internet will not develop solutions to address climate change. Far from it-in fact, the ever-expanding digital footprint is now contributing to climate change. ${ }^{26}$ The internet will not distinguish credible truths from unreliable sources, nor will it help you determine which pieces of information you find are important or entirely insignificant.

What constitutes a contemporary memory palace is the critical curation and framing of information that is not afforded by the chaotic and infinite internet. Memory is not instantaneous. The internet removes much of the time that is preciously needed for critical reflection and remembering. The seductive swarms of information can become all-encompassing, and it is often difficult to break from the cycle of avid information stimulation and consumption to refinement and revision. If the internet is a memory palace, it is one with infinite rooms where you impatiently run from room to room, never reaching a dead end, obsessed to see as much of the building as possible without pausing long enough to properly process the artifacts that are presented to you (unless there is a dead link).

\footnotetext{
${ }^{25}$ Neal Stephenson, "Neal Stephenson: Innovation Starvation," Wired, accessed April 1, 2021, https://www.wired.com/2011/10/stephenson-innovation-starvation/.

26 "What Is a Digital Carbon Footprint?," accessed April 1, 2021, https://www.myclimate.org/ information/faq/faq-detail/what-is-a-digital-carbon-footprint/.
} 
The memory palace in this thesis is a foil to the internet. It disaggregates and selects finite collections of information presented as tangible and tactile artifacts, inviting guests to form meaningful connections and narratives. Its power is not in its expansive representation of all that can be found about a certain place or topic but in its specificity and focus, lending agency and emphasis to conversations that I, as the curator of this work, wish to be integrated into collective understandings and discourse about the planet and our human place within it. 


\section{A CONTEMPORARY MEMORY PALACE}

What the portals and supporting narratives aspire to achieve is to engage their viewers, to ask them to imagine their world differently and to actively participate and contribute to the memory palace via annotations and comments on the pages of this book. In short, I believe a contemporary memory palace of today that is truly collective is a collaborative one.

I believe this is largely how the portals and memory palace address our current misunderstandings and disengagement from topics and conversations surrounding climate change. I believe that enabling open conversations is its own form of activism and that these conversations need to exist in new forms. Engaging the imaginary and capacities of memory offers a new vehicle to discuss climate change that is separate from somber data drowning and doom scrolling. It engages different emotions, different faculties in the mind and is intended to help individuals draw personal connections and concern about the present. While struggling to position the 'usefulness' of my work as a pedagogical tool, I have concluded that people need to actively contribute to conversations about climate change, not be subjected to them.

Rania Ghosn and El Hadi Jazairy describe the true value of storytelling in their introduction to Geostories: "Stories do not rally readers to a cause, nor do they call upon them to make lifestyle adjustments, but rather they entreat 
their readers to envision threats and opportunities together and offer them the means by which to begin to care to respond." ${ }^{27}$ I am not trying to position myself and my work in any moral high ground by curating these discussions, I am not trying to 'teach' people about how the world works. I am not in any position to properly do that! I am trying to help people renew their curiosity about the planet, to find stories that are meaningful to them and to understand individual agency in forming a planetary imaginary.

I have written a story of my own and am deeply grateful that you are here reading it. I hope it invites you to consider what you might add, what memories of yours might share space with mine, how the workings of your mind and memories are linked to mine, and to the collective.

${ }^{27}$ Rania Ghosn and El Hadi Jazairy, Geostories: Another Architecture for the Environment (New York and Barcelona: Actar Publishers, 2019), 20. 


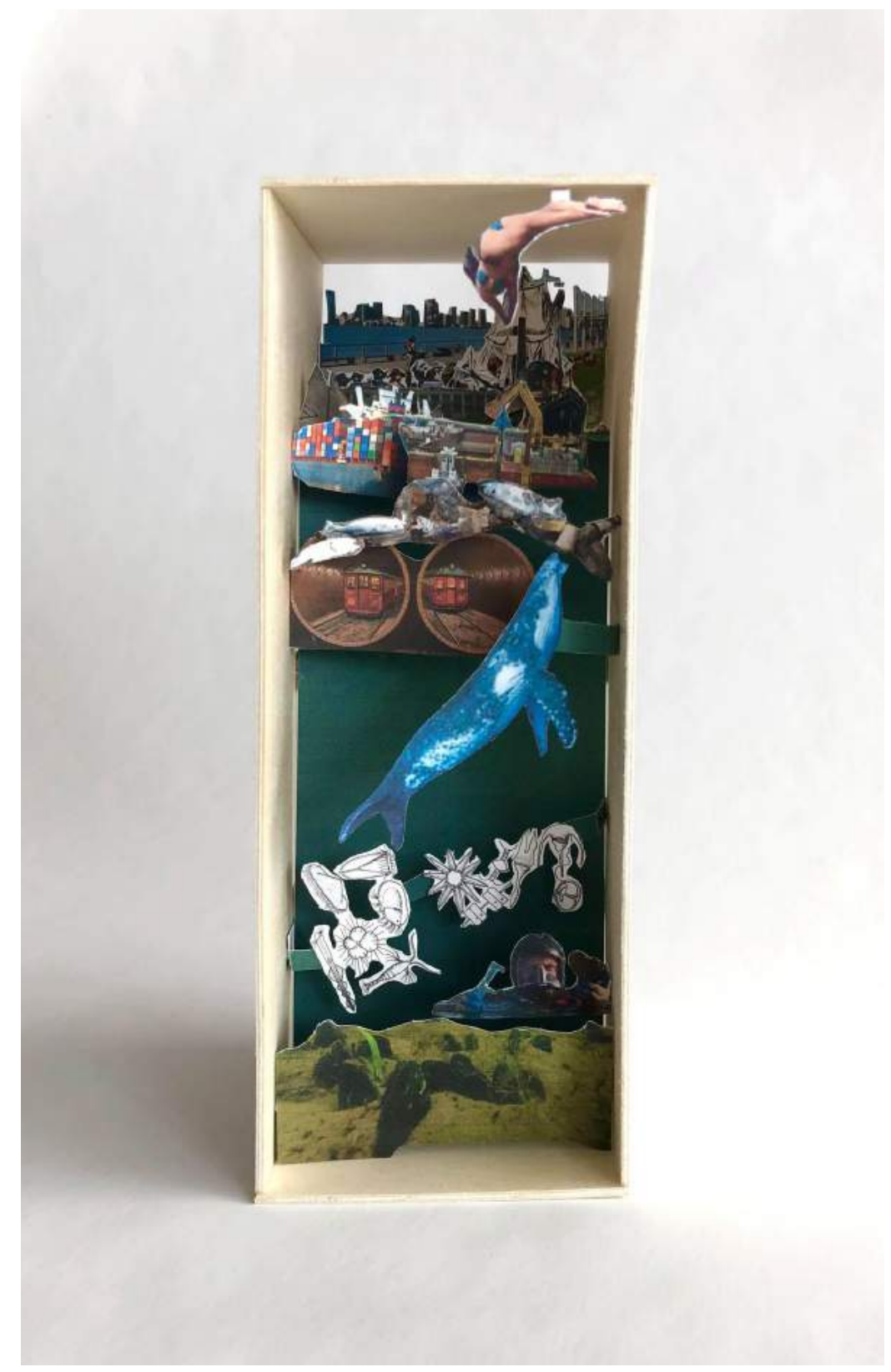

Figure 10. Hudson River Portal - Front View 


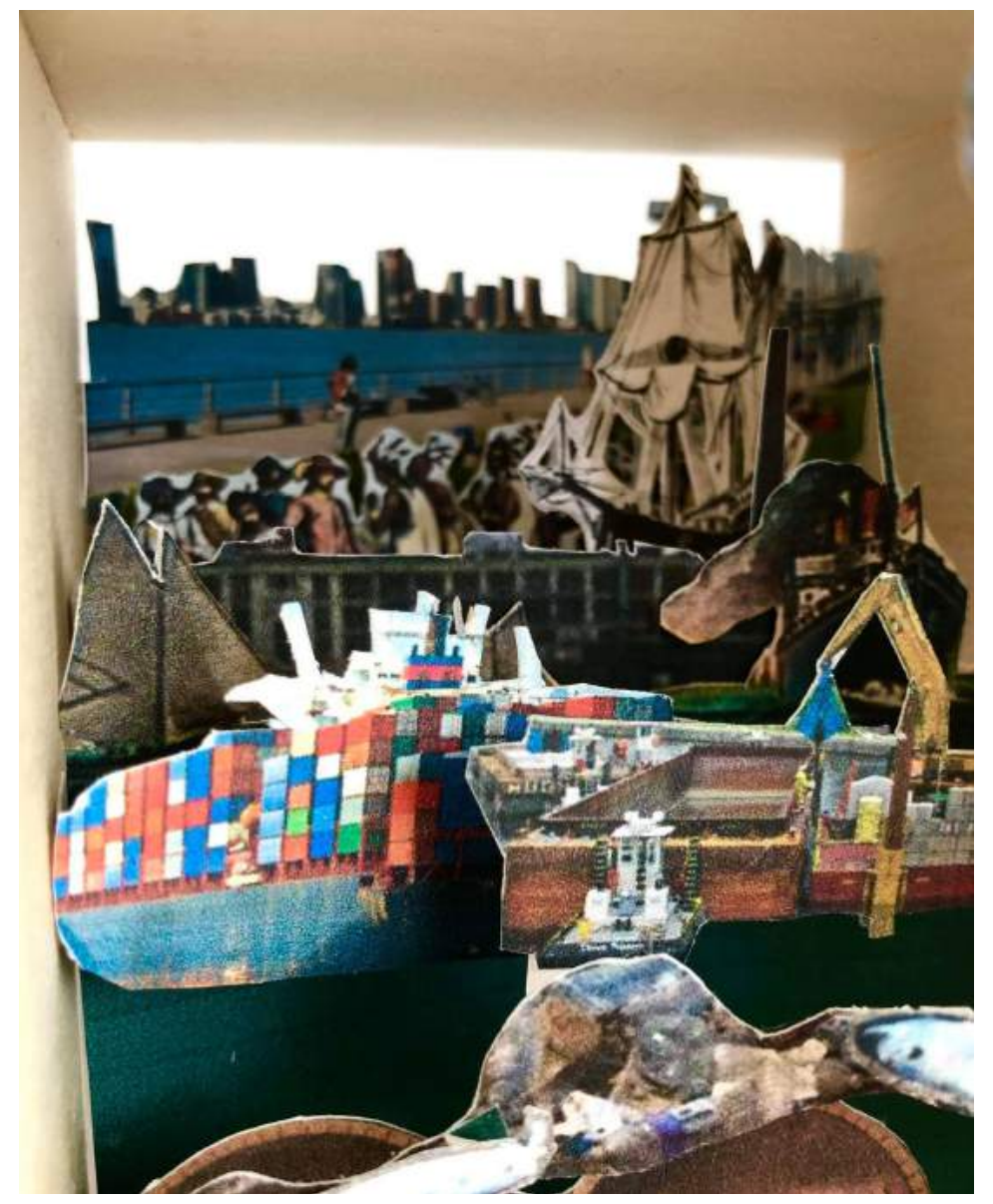

Figure 11. Hudson River Portal - Surface

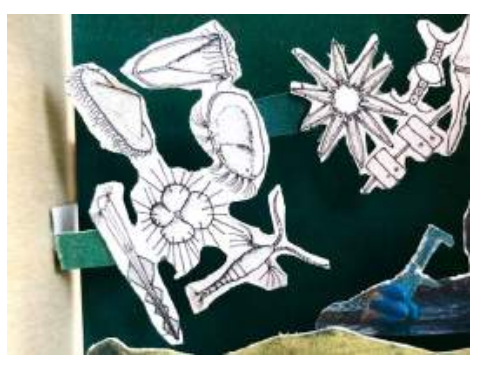

Figure 12. Hudson River Portal Micro

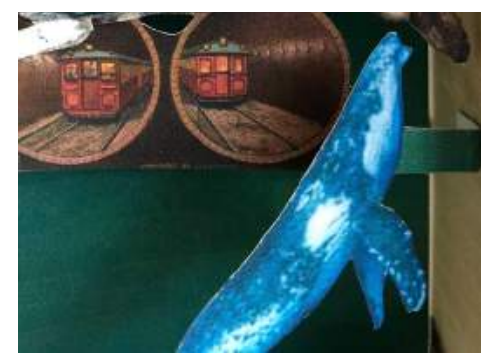

Figure 13. Hudson River Portal Myth 


\title{
story 4 \\ CENTRAL PARK
}

\author{
featuring \\ ENOUGH DATA \\ IT'S HAPPENING \\ WE ARE SMALL
}

and

\section{THE PRODUCTION OF PORTALS (PART 1)}

CUT WOOD AND APPLY GLUE - WHAT IS LARGE? -

COLLECTED IN THE MIND, STORED IN THE INTERNET -

RESIZE AND CROP - PRINT AND CUT 


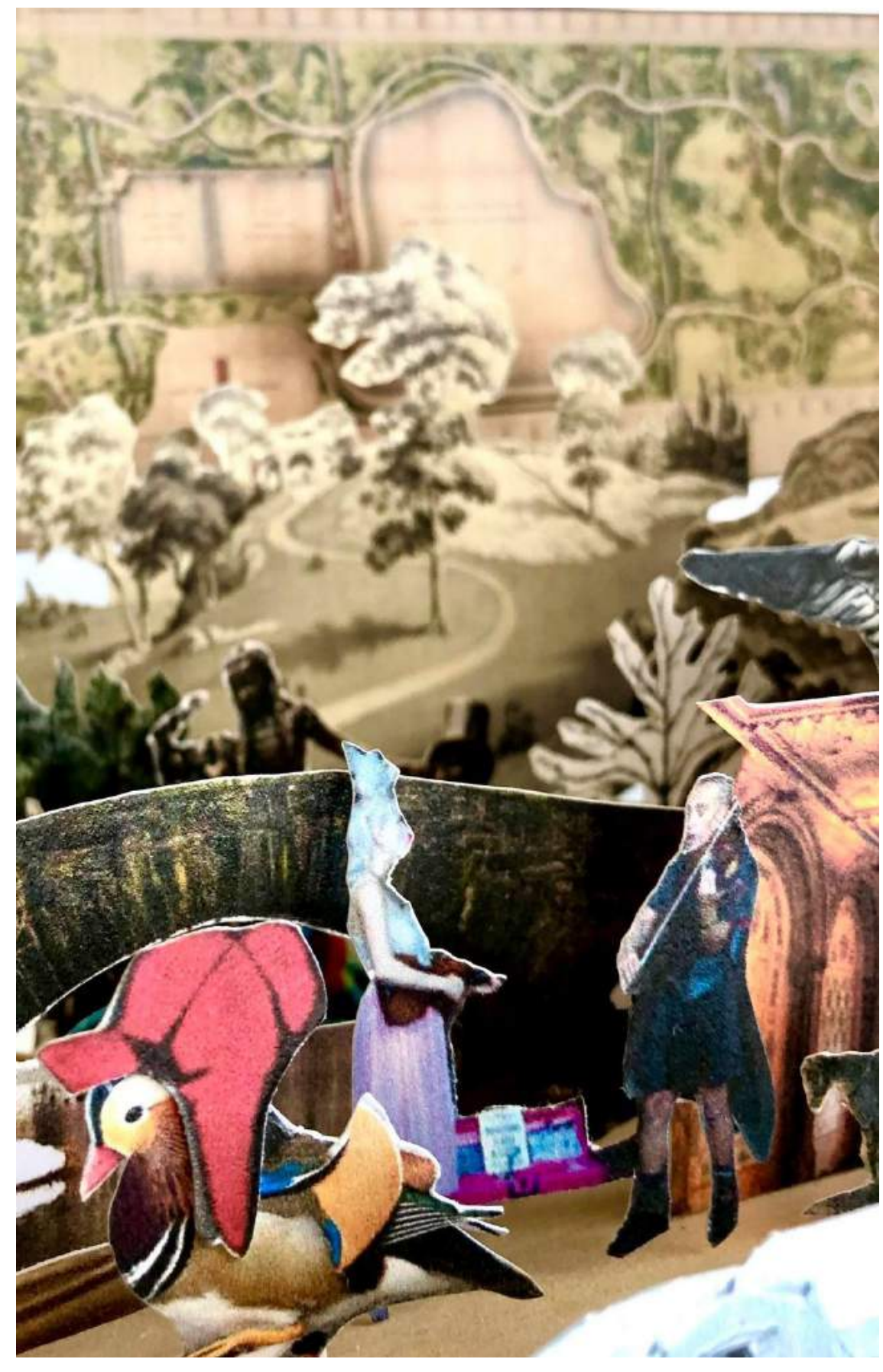

Figure 14. Central Park Portal - Vignette 
Madeleine tries not to give it away, but the excitement emanates from her as we stand in what I gather is her favourite room in the palace. I cannot decide whether I am standing on a grand stage or if I am in the warehouse of set pieces and props behind the curtain. The production is Central Park.

I gaze at all the figures in wonder, taking in the oddities-and there are many. Madeleine is staring too, lost in the scenes that are simultaneously taking place.

"This is my favourite place in the city," she tells me, "even though it's a total cliché."

We walk to the back of the room and Madeleine methodically describes where we are as we pass through the spaces between the figures. The Olmstead and Vaux plan for Central Park hangs from the ceiling, a celebrated tapestry. There is a drawing of a neighborhood plan peeking behind it. It is accompanied by a framed photo and a reconstructed porcelain teapot. Madeleine explains that we are in Seneca Village, an African American neighbourhood that was demolished to build the park. As I walk across the tapestry, the rugged landscape softens into rolling manicured planes. The social elite parade on the paths, modeling their behaviour to the lower classes. A cloud of smoke engulfs the scene. Such delicate and pristine landscaping was accomplished by brute force: manpower and gunpowder. And then everything that makes Central Park Central Park was imported. All of the topsoil was carted in from New Jersey. 
Thousands of trees were planted, none of them native to this land. They form their own museum exhibit of international curiosities.

"The park is what it sets out to be," Madeleine reflects, "it's romantic, it's picturesque..."

I continue where she trails off, thinking aloud. "And yet this iconic park is a production. It's a performance of nature. There's nothing natural about it, it's totally fake."

"A park of contrived follies you might say!"

"Nature..." I laugh, bewildered. My cheeks grow hot. We are now pacing through the recognizable landmarks in the park. "We have such an abusive relationship with nature. It's a manipulative one. We objectify nature for our own exploitation and consumption. We have commodified it. And we are always oscillating between these portrayals of nature. We flip back and forth when it is convenient for us to do so. On the one hand, we say nature is a woman. She's Mother Nature. Yet this personification does not strike the emotional chords within us humans. Why would they? We objectify, abuse, belittle, control, and take ownership of human women. And then there is this counterpoint. We say that nature is chaotic and that it does what it will. It is unfeeling. It is indifferent to us. And this total failure of empathy becomes an excuse for us humans to continue our merry way. If nature does not feel then there is no harm in what we are doing. And this enabling frame of mind is horrifying." 
I realize we are standing at the front of the room again. I stopped paying attention to each figure as I was rambling on.

"Do you think nature really exists in cities?" I ask her.

"Well, I think that it would be easy to answer that with a no." Madeleine begins. "If nature is something that is untouched by humans, it's an unwavering no. I think this binary relationship weve established between nature and urban contexts, imply that they are completely separate."

"But!" Madeleine continues. "I think a productive way of thinking about cities and really any place we are in, is to think about how our human world is entwined with the multitudinous worlds that are nonhuman. Whether you believe nature exists in cities or not is relatively inconsequential. You cannot deny that we are always interacting with nonhumans. Plants, animals, the air, the ground, water, et cetera, et cetera. All of it. We are constantly negotiating space and agency with these other worlds. These intersections between worlds are paths we negotiate as individuals every day. We just fail to notice. So yes! The trees in Central Park are from all over the place. And nature is no more. But the trees are alive. They are still trees. And I love going to Central Park to walk among them." 


\section{ENOUGH DATA}

"The problem with the climate crisis is a failure of language.

The right word would be as long as the lives of my grandchildren and the lives of their grandchildren." 28

Madeleine Jubilee Saito

The climate is changing, humans are responsible, and we do not know how to talk about it with each other. Our words fail us, trapping us in a loop: words give shape to our thoughts and our thoughts give shape to our words. Our Western culture and framework of language has conditioned our fraught relationship with nature and with climate. When we think of these two, seemingly simple, words—climate change-we are paralyzed by our guilt, helplessness, and apathy.

Climate scientist Katharine Hayhoe writes, "Is what we know about climate change the truth? Yes, it absolutely is. We've known since the 1850's that digging up and burning coal—and, later, oil and gas — produces heat-trapping gases that are wrapping an extra blanket around the planet. Since then, thousands of studies and millions of data points have confirmed it's true." 29

\footnotetext{
${ }^{28}$ Madeleine Jubliee Saito. Reframe, All We Can Save (New York: Penguin Random House LLC, 2020), 103.

${ }^{29}$ Katharine Hayhoe. How to Talk About Climate Change, All We Can Save (New York: Penguin Random House LLC, 2020), 110.
} 
As ecological philosopher Timothy Morton describes, public conversations foregrounding climate change have trapped our minds in a constant cycle of confusing and disturbing data drowning followed by a healthy serving of moral guilt tripping. ${ }^{30}$ This endless consumption and obsession with data has ultimately failed to reach our empathy. A critical reframing of climate change is needed to facilitate our understandings of it.

${ }^{30}$ Timothy Morton. Being Ecological. (Cambridge, MA: The MIT Press, 2018), 7. 


\section{IT'S HAPPENING}

Novelist Amitav Ghosh declares that "the climate crisis is also a crisis of culture, and thus of the imagination." ${ }^{31}$ Fictions are imaginations recorded for collectives. The presence of climate change in fiction consists mainly of cautionary tales about unruly forces of nature imprinting mythologized pasts or as speculative futures that test humanity's survival in the wake of apocalyptic natural events. ${ }^{32}$ Yet there is the uncomfortable present, where the condition of our changing climate looms over us and we have difficulty summoning a sense of urgency. Climate change is magnifying natural risks we already face such as storms, floods, drought and fires. ${ }^{33}$ These risks are not fictitious myths and we have convinced ourselves that such terrifying cataclysms that threaten to strike will not affect us in our lifetime. However, climate change is real, it is ongoing, and it is occurring now. The climatic story of 'now' is a story we do not know how to tell.

\footnotetext{
${ }^{31}$ Amitav Ghosh, The Great Dernagement (Chicago and London: The University of Chicago Press, 2016), 9

${ }^{32}$ Jacob Boswell. 'Notes from the Wasteland: Competing Climatic Imaginaries in the Post-Apocalypic Landscape' in Graham, J. ed. Climates: Architecture and the Planetary Imaginary (New York: Lars Muller Publisher, 2016), 41.

${ }^{33}$ Katharine Hayhoe. How to Talk About Climate Change, All We Can Save (New York: Penguin Random House LLC, 2020), 106.
} 


\section{WE ARE SMALL}

Katharine Hayhoe states, “This isn't about saving the planet. The planet itself will survive. The question is, what will happen to the rest of us who call it home?" ${ }^{34}$ Our arrogance enables us to think we are so powerful that we could bring about the end of the planet when in reality, we are bringing about the end of ourselves and our short three hundred thousand years of existence in the relatively long four and a half billion-year story of the Earth. Astronomer Carl Sagan's Pale Blue Dot continues to put humanity into humbling perspective as he reflects on the image of the Earth taken in 1990 by the Voyager 1 space probe from a distance of six billion kilometres:

"Look again at that dot. That's here. That's home. That's us. On it everyone you love, everyone you know, everyone you ever heard of, every human being who ever was, lived out their lives. The aggregate of our joy and suffering, thousands of confident religions, ideologies, and economic doctrines, every hunter and forager, every hero and coward, every creator and destroyer of civilization, every king and peasant, every young couple in love, every mother and father, hopeful child, inventor and explorer, every teacher of morals, every corrupt politician, every "superstar," every "supreme leader," every saint and sinner in the history of our species lived there-on a mote of dust suspended in a sunbeam.

The Earth is a very small stage in a vast cosmic arena. Think of the endless cruelties visited by the inhabitants of one corner of this pixel on the scarcely distinguishable inhabitants of some other corner,

${ }^{34}$ Katharine Hayhoe. How to Talk About Climate Change, All We Can Save (New York: Penguin Random House LLC, 2020), 106. 
how frequent their misunderstandings, how eager they are to kill one another, how fervent their hatreds. Think of the rivers of blood spilled by all those generals and emperors so that, in glory and triumph, they could become the momentary masters of a fraction of a dot.

Our posturings, our imagined self-importance, the delusion that we have some privileged position in the Universe, are challenged by this point of pale light. [...] It has been said that astronomy is a humbling and character-building experience. There is perhaps no better demonstration of the folly of human conceits than this distant image of our tiny world." 35

Sagan's words offer a poignant reminder that the Blue Marble images we produce carry significant power and perspective. The ever-accelerating advancement of contemporary technology has us enamored with our innovations and achievements. Yet these tools have afforded us the cosmic context of the universe and the human made world we have positioned within it. An updated photo of this pale blue dot was taken in 2020 to mark the photograph's thirtieth anniversary, renewing the relevance of Sagan's humbling musings and depicting the beloved and gigantic Earth as a slightly more distinguishable dot.

${ }^{35}$ Carl Sagan, Pale Blue Dot: A Vision of the Human Future in Space (New York : The Random House Publishing Group, 1994), 6-7. 


\section{THE PRODUCTION OF PORTALS (PART 1)}

\section{CUT WOOD AND APPLY GLUE}

The materials used to make the portals were purchased online and delivered to my apartment. I cannot deny the unmatched safety (to me), convenience (to me) and cost effectiveness (to me) offered by the globalized corporate giant. The online marketplace has enabled an accelerated consumerism that is instantly gratifying and numbingly addictive. It is totally unencumbered by the fraught labor practices and poisonous environmental practices that enable the global logistics system.

Basswood sheets were measured and cut with an X-Acto knife and were carefully assembled into various sized boxes with super glue. ${ }^{36}$

\footnotetext{
${ }^{36}$ Memory: This dollar store all-purpose glue may not be the best for the job but it's the glue I had on hand. It also reminds me of the first time I ever tried to make a model in architecture school. I was sitting at my studio desk and the small capsule exploded over my hands and my new cutting mat. Flash forward to the fumes of superglue maddening me after a dozen or so hours as I am hunched over my father's workbench desperately trying to make a labyrinth in the shape of a brain out of bamboo skewers. Flash forward again to a late night, my desk is covered in model making rubble and I've moved to the floor squatting over my final model for studio. I realize the super glue has become a new thick layer of skin on my fingers so much so that I don't realize I have cut my finger until I bleed on the model. I love to hate this glue. It reminds me of all the places I have worked on projects over the past seven years.
} 
The boxes are comprised of a basswood face on four sides, leaving the front and back faces open for the insertion of images. ${ }^{37}$ The depths of the basswood boxes were determined by the estimated number of images that would occupy each box.

\section{WHAT IS LARGE?}

The sites encapsulated within each portal vary in specificity and scale. The first portal houses Grand Central Terminal-a 'large' room. The second box houses Central Park-a 'large' park. The third box houses the Hudson River - a 'large' body of water. The fourth box houses the Manhattan Grid and the ecosystem of Mannahatta-a 'large' island. The increasingly large places allow me to reflect on what it means to be in a place or to have a 'sense of place' while also challenging me to consider how notions of the large and small are scaled to my own memories and understandings. Each site intends to situate our perceptions of the human world within the larger time scales of the nonhuman.

\footnotetext{
${ }^{37}$ Honesty: despite measuring twice and cutting once, the edges did not all join perfectly. The bass wood is thin and bends causing the boxes to deform slightly. Naturally, I tried to select the front and back of each box based upon which edges appeared cleanest. But of course - selecting the most attractive looking side isn't easy. The glue leaves glossy stains in places where I have applied too much. Sanding down the surface of the box changes the texture and colour of the basswood just enough to notice. All of these factors matched with carefully photographing the models on the angles that strategically hide these blemishes are part of my overthinking and agonizing about the details.
} 


\section{COLLECTED IN THE MIND, STORED IN THE INTERNET}

All images used were saved from the internet and embody the accumulation of interests collected throughout the duration of the thesis. I knew that my own memories and research would largely shape the contents of the boxes though I made an effort to operate beyond my thoughts by consulting peers who have been to New York as well as those who hadn't—who perhaps had only "imagined" the city. They offered me poignant images they envisioned when thinking about the sites that would be depicted in the work.

The selected imagery was intended to elaborate on the iconic characteristics of place associated with each site while also offering glimpses of the places in different moments in time. Photographs of individuals from recent news headlines such as birdwatcher Christian Cooper (Central Park portal) and social media influencer Donna Paysepar (Hudson River portal) both appear among photographs and illustrations of each site. When offered millions of images at once, I quickly became aware that I was selecting images and drawings that served the exaggerated, eclectic aesthetic I desired for the boxes. And while my predisposition to a certain collection of images became evident, I wondered why the vintage drawings evoked such romanticism in me (Central Park portal). I wondered why the depictions of creatures and trees in the pristine and beautified botanical styles akin to Alexander von Humboldt ${ }^{38}$ were the most seductive to my eyes (Mannahatta portal). Such

${ }^{8}$ H.W. Lack, Alexander Von Humboldt and the Botanical Exploration of the Americas (Prestel, 2009), https://books.google.ca/books?id=8aRkPgAACAAJ. 
notions of the picturesque and ordering of nature are the ways in which my psychological associations and attitudes toward nature are unconsciously stated. My expressions of thoughts and ideas paint a reflection on the western culture that raised me. Perhaps the representations of nature that I selected for this box contradict my intention - which was to lend nature a greater agency in the narrative of the landscape. The mind contradicts itself; it contains multitudes.

\section{RESIZE AND CROP}

Images collected from the internet were imported in Photoshop. The dimensions of the boxes were noted on the pages allowing the images to be resized according to how they would fit into their box. The subjects in the images were not calibrated to the same scale. There are significant discontinuities in scale from image to image, serving as a reminder that the subjects that appear in the box are removed from their original context. The scaled images play with depth and suggest conceptual hierarchies. After cropping images to minimize the use of excess ink, images were carefully arranged to fit on as few pages as possible for printing.

\section{PRINT AND CUT}

I replaced the usual flimsy printer paper from the tray with A4 heavy white cardstock. ${ }^{39}$

${ }^{39}$ Honesty: I purchased the cheapest possible printer a few months ago and I'm regretting it now. The printed images are streaky, some of the colours are darker than I had intended. 


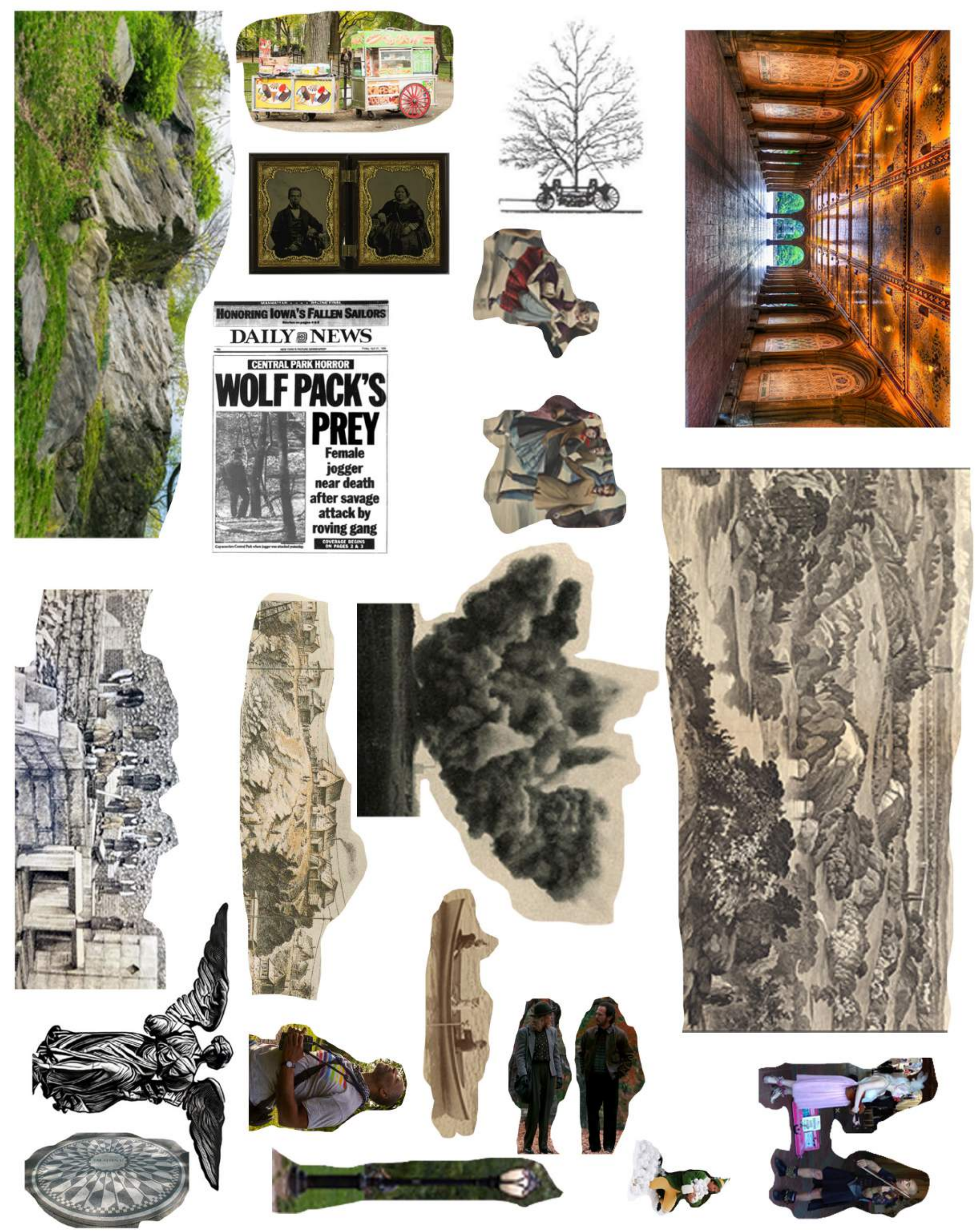



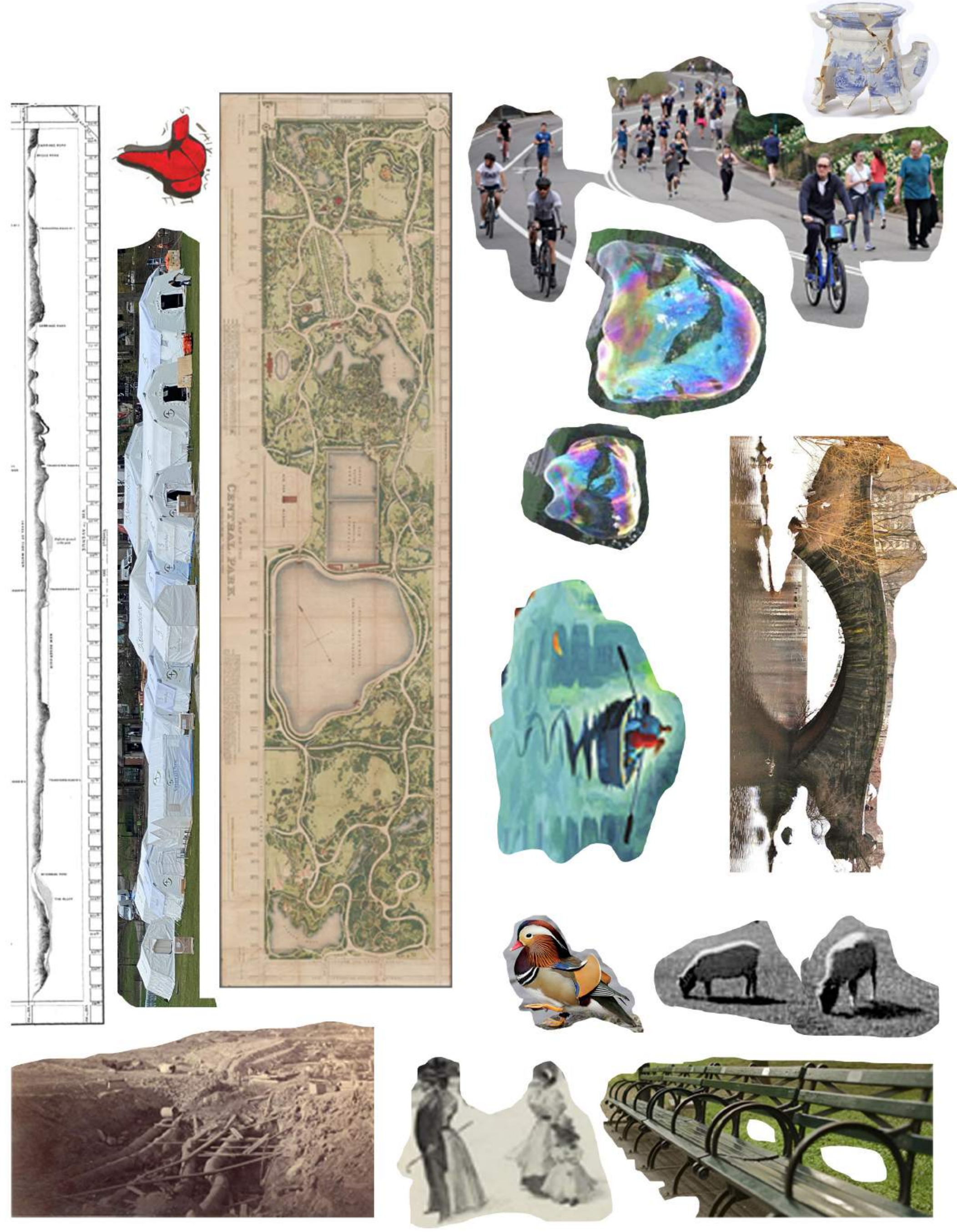


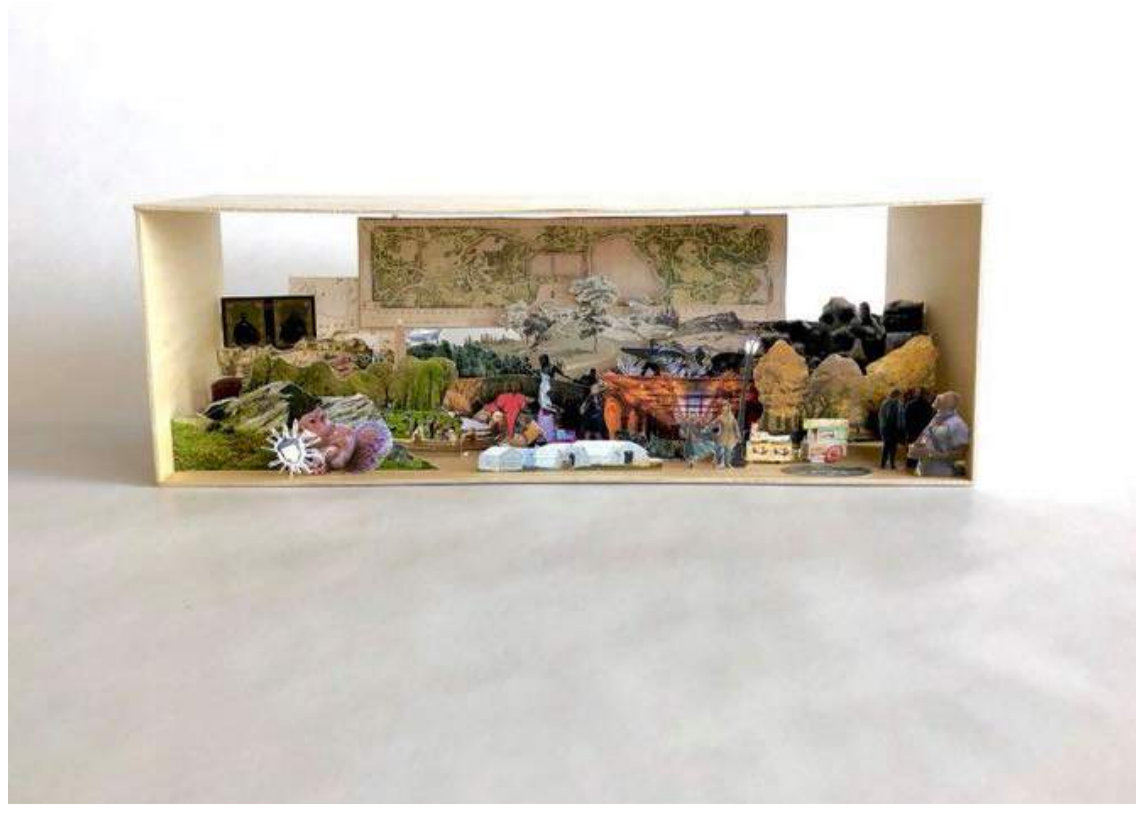

Figure 17. Central Park Portal - Front View 


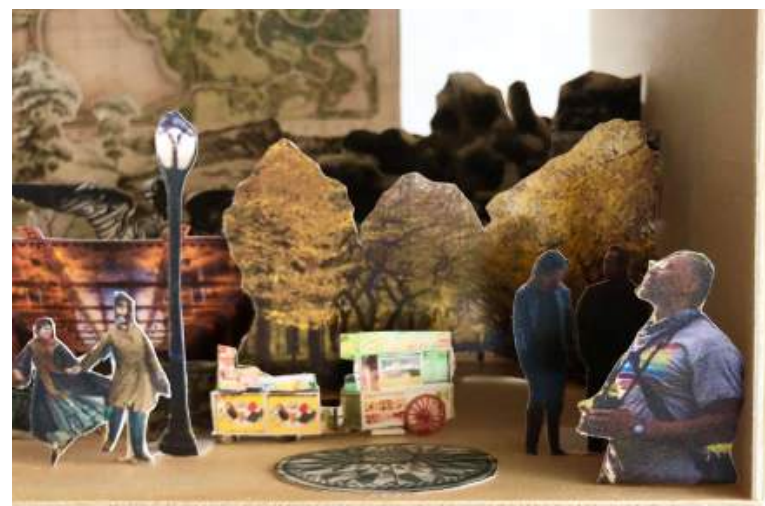

Figure 18. Central Park Portal - Romance

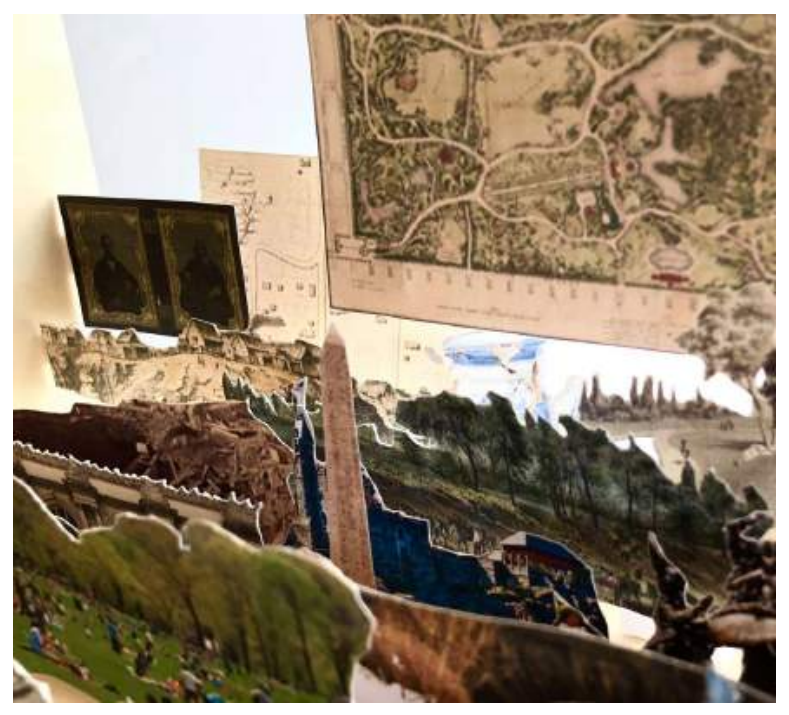

Figure 19. Central Park Portal - Resurface

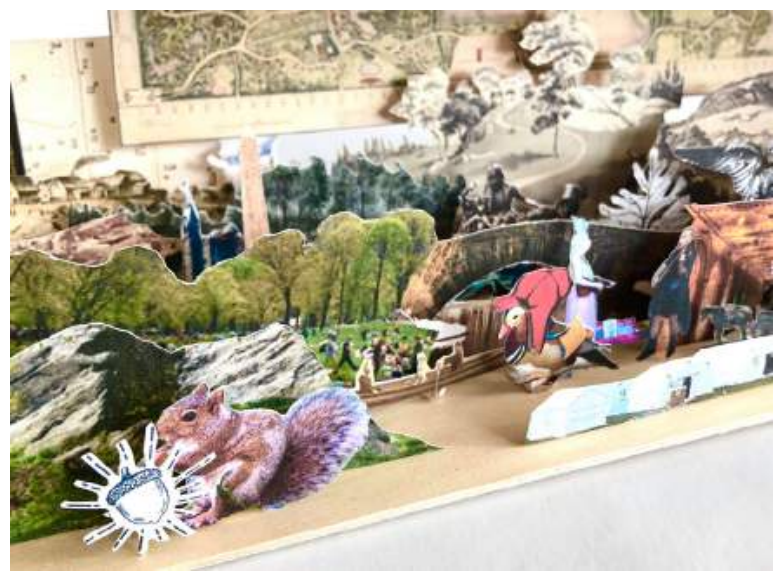

Figure 20. Central Park Portal - Leisure 


\section{story 5 \\ GRAND CENTRAL}

featuring

THE LONG NOW

DEEP TIME

WORLDING

IMAGINING THE PRESENT

and

THE PRODUCTION OF PORTALS (PART 2)

ASSEMBLY - VIDEO - PHOTOGRAPH 


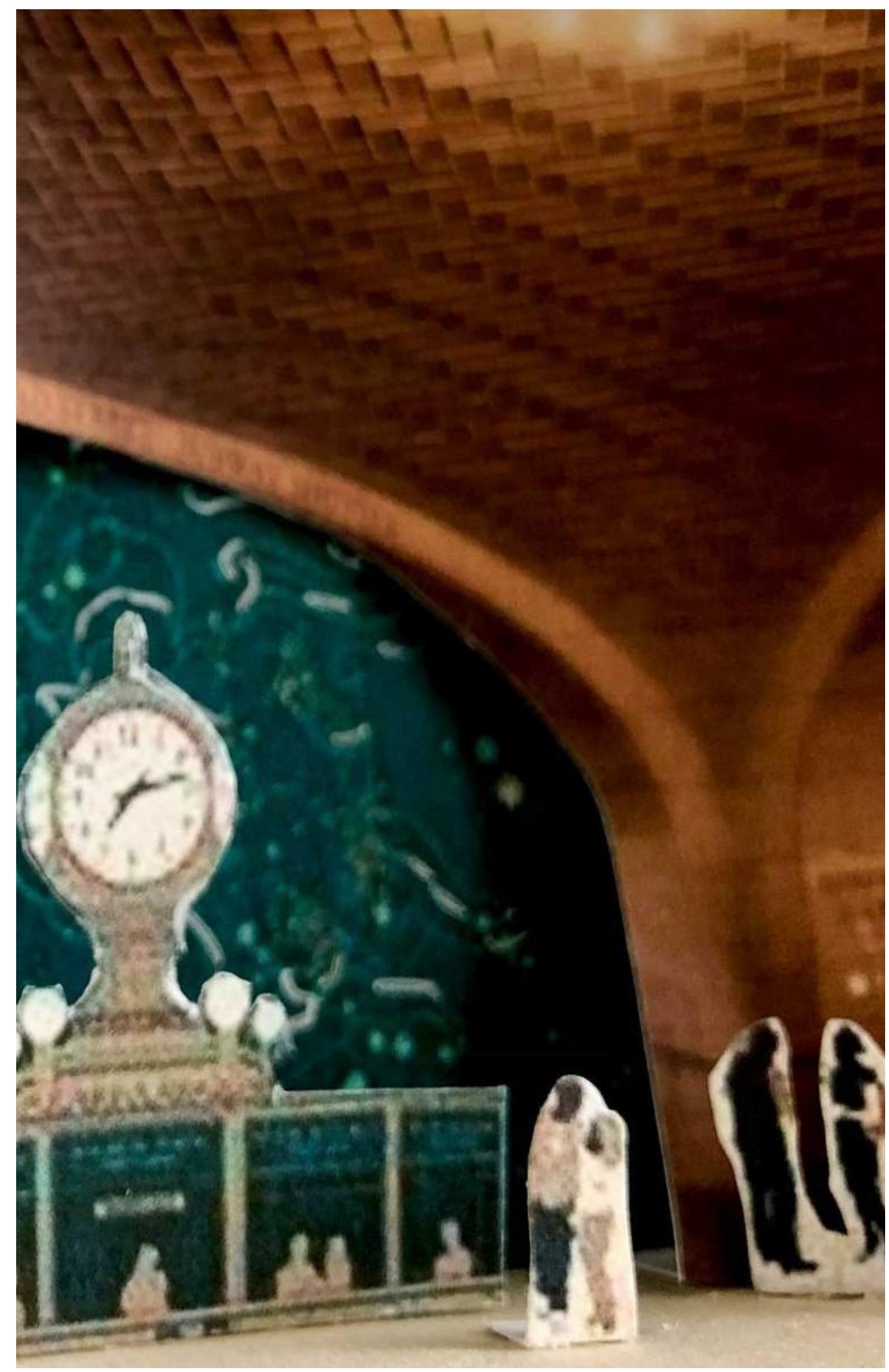

Figure 21. Grand Central Portal - Vignette 
"In this closet," Madeleine says, as she opens the door, "the infinitely large universe reveals itself to you." She has a taste for theatrics. I step inside and she enters behind me, closing the door softly behind her. The room is small and dark. I wait in silence as she reaches along the wall beside the door and flips a switch. The room swells with a warm glow-particles of dust sway in the light. Constellations gleam before me, the celestial pattern on the turquoise wall and the grand clock are immediately familiar even though I have never been there in person.

I look around at the figures that surround me, they are frozen in motion. A man plays his guitar sitting atop a bucket, busking for passersby. A woman pulls her carry-on behind her, focused on the train she needs to catch. Another man is leaning over his telescope, fixated on the zodiac constellations before him. A parent helps their child put on their backpack, while a couple in love are arm-in-arm, marveling at the vaulted ceiling that towers above them.

"You see," she explains with a soft smile and a twinkle in her eye, "when you're in the real place, these vaulted ceilings are pretty magical. They are whispering galleries. I still remember my shock the first time I leaned into the column and could hear my sister talking to me from the column twenty feet away. "Madeleine points at the column in the room and drags her arm in a diagonal across the ceiling, pointing to an imaginary second column. I follow the arc of her finger and notice the ceiling. A poem presents itself to me: 
The city orbits around eight million

centers of the universe

and turns around the golden clock

at the still point of this place.

Lift up your eyes from the moving hive

and you will see time circling

under a vault of stars and know

just when and where you are.

She notices I am reading it. "This room started with this Billy Collins poem. A visitor said he remembered reading it on the subway once and recommended we put it on the ceiling of the palace."

We stand in silence for a moment. Eight million centers of the universe.

"I'm just visiting the city," I start, "though I've been imagining what it's like to live here. I feel like it would be everything I want it to be. To feel the energy. To feel as though I was part of something. 
Something bigger than me. I'd become part of the spirit of this place... But I think it would also be lonely. I'd feel small. I'd become a universe of one and forget there are other universes because I'd become even more fixated on the world of me. I think I'd have moments of pure bliss, moments that the movies promised me. And then I'd have moments where I would feel naïve and alone. Naïve for believing the life movies had sold me. Naïve to think that New York was some collective place unlike any other." I pause. I'm a little startled that I've shared all this with a stranger.

"It can be beautiful you know, feeling small." Madeleine says. "If you choose to visit Grand Central Terminal while you're here, you might feel it. Surrounded by people rushing to where they need to be, absorbed in the totality of their world. Tourists are there too of course, trying to collect the room. And then therell be you. You'll feel small at first, especially if you just stand still. Close your eyes for a moment and hear the echo. Hear the movement. Look up at the ceiling and see the stars. You could be anywhere, but you're here, and in this moment, you are the city, you are eight million universes." 


\section{THE LONG NOW}

The Long Now, ${ }^{40}$ as described by Architect Sean Lally, "questions our preconceptions and established norms that define our evolving planet, reorienting our place and perspectives [where] concepts of environment and body are moments within a much larger arch of time." ${ }^{21}$ It is surmised that this definition finds its origin from the Long Now Foundation, established in 1996. Its founder Brian Eno developed the term after moving to New York City. He noticed that the implications of terms such as 'here' and 'now' referred to 'this room' and 'this five minutes' as opposed to the larger conceptions of here and longer now he was familiar with in England. ${ }^{42}$ The foundation argues that "civilization is revving itself into a pathologically short attention span. The trend might be coming from the acceleration of technology, the short-horizon perspective of market-driven economics, the nextelection perspective of democracies, or the distractions of personal multi-tasking. All are on the increase. Some sort of balancing corrective to the short-sightedness is needed-some mechanism or myth which encourages the long view and the taking of long-term responsibility, where 'long-term' is measured at least in centuries." 43

\footnotetext{
${ }^{40}$ The Long Now is also related to Fernand Braudel's La Longue Durée

${ }^{41}$ Sean Lally, "The Long Now," Sean Lally Architecture Sàrl (blog), March 17, 2019, accessed on March 31, 2021, http://seanlally.net/2019/03/17/exhibit-columbus/.

42 “About - The Long Now," accessed March 24, 2021, https://longnow.org/about/.

${ }^{43}$ Stewart Brand, The Long Now, accessed March 24, 2021, https://longnow.org/about/.
} 
The notion of The Long Now dispels the perception that our present human world is an arrow of steadily advancing progress (as promised by twentieth century modernism $)^{44}$ embedded with overarching globalized and capital systems that are unchanging and permanent. The perspective of The Long Now reminds us that all human made systems can change despite their seemingly insurmountable complexity and domination.

${ }^{44}$ Bruno Latour, We Have Never Been Modern (Cambridge, Mass: Harvard University Press, 1993), 69. 


\section{DEEP TIME}

The thesis expands its understanding of The Long Now as a lens to scale the present through geology and geological time. ${ }^{45}$ Geology denotes the layers of rock that formulate the Earth's crust as pages in the long and complicated history book of the Earth, recording the events of the past and preserving the remains of plants and animals. Layers of the rock contain radioactive isotopes that decay at predictable rates, providing the earth with an atomic clock. These layers of rocks compose the history of the Earth represented by the geologic time scale. ${ }^{46}$ The time scale is often represented as a vertical table which forms a synonymous relationship with the vertical section cut of the Earth's crust, offering a tangible section through time. The time scale is typically represented in a mode that does not scale the vertical dimensions of the table to the number of years being represented. Despite being represented as a vertical and linear table of time, deep time encourages us to consider time as a spiral, acknowledging the infinite cyclical relationships that simultaneously occur in the universe. ${ }^{47}$

Many thought exercises have been developed to enable us to understand the presence of humans in deep time and on the geologic time scale. When we scale the four and a half billion-year history of the Earth to the cycle of a

\footnotetext{
45 "About the Geologic Time Scale," accessed March 28, 2021, https://ucmp.berkeley.edu/exhibit/ histgeoscale.php. 
twenty-four-hour day (beginning at 12:00am), the major ice ages occur at 11:59:11 pm and our human existence arrives within the last millisecond of the day. ${ }^{48}$ The importance of the geologic time scale becomes relevant when we discuss the Anthropocene as a new geological Epoch. ${ }^{49}$

\footnotetext{
48 “Geologic Timescale," accessed March 23, 2021, https://jan.ucc.nau.edu/lrm22/lessons/ timeline/24_hours.html.

49 "Working Group on the 'Anthropocene' | Subcommission on Quaternary Stratigraphy," accessed March 26, 2021, http://quaternary.stratigraphy.org/working-groups/anthropocene/.
} 


\section{WORLDING}

Ecofeminist scholar Donna Haraway's concept of Worlding commits to actively reimagining a non-anthropocentric world whose purpose is not to forecast the future but to emphasize present relations between humans and nonhumans. ${ }^{50}$ Conceptual writer Jessica Foley describes Worlding as "an active, ontological process; it is not simply a result of our existence in or passive encounter with particular environments, circumstances, events or places. Worlding is informed by our turning of attention to a certain experience, place or encounter and our active engagement with the materiality and context in which events and interactions occur. It is above all an embodied and enacted process - a way of being in the world - consisting of an individual's wholeperson act of attending to the world. Wording is worlding, and what we need to do is word the world better." 51 The portals undertake this act of Worlding, inviting the embodied and intellectual engagement from those who interact with them.

\footnotetext{
${ }^{50}$ Donna Haraway. Staying with the Trouble: Making Kin in the Chthulucene, Durham and London: Duke University Press, 2016, 12.

${ }^{51}$ Jessica Foley. 'Word the World Better' postcard, part of Engineering Fictions box set of scores (Dublin: CONNECT, 2017), accessed on March 27, 2021, www.engineeringfictions. wordpress.com.
} 


\section{IMAGINING THE PRESENT}

I invite you to imagine the present with me. Perhaps this is a perplexing request. Why would one need to imagine the present when they are existing in it and experiencing it? What is there to imagine? When we consider exercises in imagining time, we cast backward into the past and forward into the future. The mind dances between nostalgia and longing. These tendencies are their own form of escapism, offering a safe distance from the divisive complexities and daunting uncertainties tethered to the reality of the cacophonous present. Bruno Latour argues that our politics are incapable of engaging with the terrestrial and that nostalgia is a pernicious sentiment that produces Trumps and Brexits. ${ }^{52}$

We are unequipped to fathom complex changes that are occurring at a planetary scale caused by the summative presence of humans and our cumulative behaviours of extraction, destruction, consumption, and waste. As science fiction author Ursula LeGuin poetically states, we live in what is simultaneously "this womb of things to be and tomb of things that were." 53 It is incredibly difficult to imagine and visualize this phenomenon across enormous scales of space and time. It is even more difficult to reconcile these gigantic processes with our daily lives while retaining our individual agency within the totality of human impact.

\footnotetext{
${ }^{52}$ Bruno Latour, Down to Earth: Politics in the New Climactic Regime, trans. Catherine Porter (Oxford: Polity Press, 2018), 101

${ }^{53}$ Ursula K Le Guin, “The Carrier Bag Theory of Fiction,” accessed on March 30, 2021, http:// theorytuesdays.com/wp-content/uploads/2017/02/The-Carrier-Bag-Theory-of-Fiction-Le-Guin. pdf. 154
} 
When thinking of the present, it is simple to assume and define it as a moment in time. When we reflect upon these moments in our minds and describe them to others, we naturally situate ourselves as the protagonist of the moment. I am currently writing on a breezy evening in the office of my apartment amid a global pandemic. This is my reality, my world, and my moment. This is typically the scaled extent to which the mind routinely wanders. We are a hopelessly self-centered species.

Imagining the present means grappling with the profoundly greater processes of nature that minify our human moment. As architect Diana Agrest describes, "nature is the complex weaving of so many timeframes and scales. Everything is moving all the time. The line is never still. An endless choreography of bodies in space-time, a multidimensional opera in a total theater where the stage moves and changes as the drama unfolds, through events that articulate different rhythms, times, and tempos while defining spaces as the traces that overlap and intersect, these presentations of nature are revealed by our expanded perspective. And then as a corollary to this work, there is our human time, our mini-choreographies of reproduction and survival". ${ }^{54}$ It is the critical reframing and reimagining of how these worlds presently collide that enables us to gain a more expansive and gracious understanding of nature, the nonhuman and climate change. The thesis engages the imaginary to interpret the real and the everyday experience of humans, orienting a person walking around New York and their intersection with the planetary.

${ }^{4}$ Diana Agrest, Architecture of Nature : Nature of Architecture (Novato, CA: Applied Research and Design Publishing, 2018), 14. 


\title{
THE PRODUCTION OF PORTALS (PART 2)
}

\begin{abstract}
ASSEMBLY
I love to get lost in this process, I let my intuition take over. ${ }^{55} \mathrm{I}$ cut the pages into pieces separating the images. I do this to all the pages I have printed. I work methodically and try to complete each little step for each image before I move on. I alternate between cosmetic scissors, craft scissors, an X-Acto knife and an ergonomic cutting knife to cut out each image. Each blade creates a different textured edge as I cut the paper. I also alternate between tools to relieve my fingers from the pain of using only one tool for the duration of the cutting. The cutting takes hours. I savour the repetition of the motions, the attentive focus I spend on cutting voids and delicate lines.
\end{abstract}

As I begin to collect these cut out images I am forming a much larger collection of scraps. They are scattered across my desk and I carefully brush them into a plastic bag. I continue to collect these scraps. I am tempted to assign a poetic meaning to this bag, indulge me for a moment. I envision a picture of the scraps poured into a disorderly mountain on my desk and caption the vision: 'the cost of now'. This is something that has lingered in my mind. The waste is small relative to the amount of waste I produce to live every day. The waste is small relative to the amount of waste I have produced throughout all my studio projects. But the waste is large relative to the scale of the images I have

\footnotetext{
5 Honesty: I have had many moments throughout this year where I was paralyzed by my cycles of overthinking. This process of assembling the portals gave me a genuine rest from my mind and put me into a state of what is as close to what I will get to meditation.
} 
cut out and the boxes I have made. The waste is costly, and this pile asks me to think about how I so easily dismiss the scales of consequence as it suits my needs. This is what comes to mind when making miniature models- $\mathrm{I}$ contemplate humanity and what we make and waste on greater scales.

I take scrap pieces of paper and cut them into strips. I select an image and move it around the empty box, I decide on its placement. I fold the scraps into small L shaped tabs and use a glue stick to attach them to the back of the image. I glue the image into the box and the first artifact is born. I repeat this process, constantly relating new images to the ones already glued into the box. I begin to reason with myself, developing a logic to organize the images in front or behind one another, to the left or right of the other. I let the artifacts speak to each other, they tell me where they find good company. Some of them want to live outside the box (the topographical map of Manhattan) and some want to steal the show and enclose the box (the Manhattan grid). Sometimes my logic is consistent and sometimes it falls apart. The images become difficult to tether to the box as the tabs compete for real estate. I begin to fold tabs into $Z$ shapes and use them to secure images to each other. The backside of the portal reveals the intricate web of tabs that tether the images to it.

I eventually accept that I can't fit all of the images I have cut out into the box. I wonder whether the portals appear visually full as I rotate them between 
my hands. A day later, I decide to add an image here and there. I build a shelf to hold a poem on the ceiling of the portal (Grand Central) and build a doorframe and latch to enclose another (Mannahatta).

\section{VIDEO}

My cell phone was placed in a makeshift frame perched atop small boxes and books to record overhead video of my desk space as I cut and assembled the boxes. My awareness of the camera faded throughout the hours, but I was initially self-conscious of it. It was partially due to the fact that the frame my phone was perched on was fixed right where my head would lean while hunched over my desk, causing me to softly bump my head on the frame from time to time. I knew that nobody would likely ever watch these hours and hours of footage, yet I felt as though this relatively mundane activity had suddenly become a performance for some future viewer. By deeming the process of physical making, worthy of documenting, it becomes honoured in the mind. I typically lose myself in this kind of work, so this documentation has offered me some insight and a heightened understanding of my own habits of making. The other steps that precede the assembly of the boxes were not documented-the patterns with which I move myself through digital spaces is perhaps less interesting because perhaps we are all moving through these digital spaces all the time. 

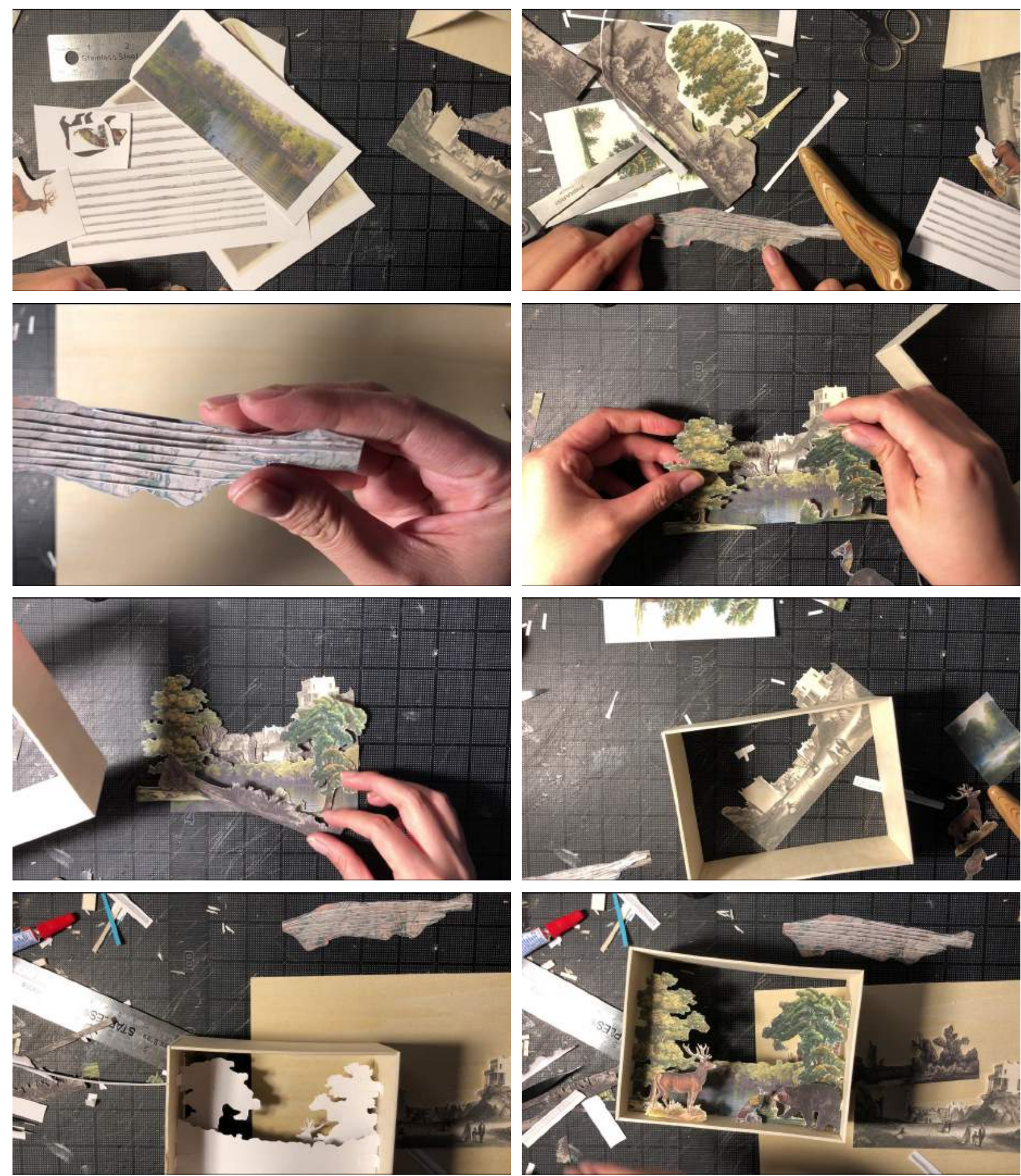

Figure 22. Mannahatta Portal - Video Documentation 

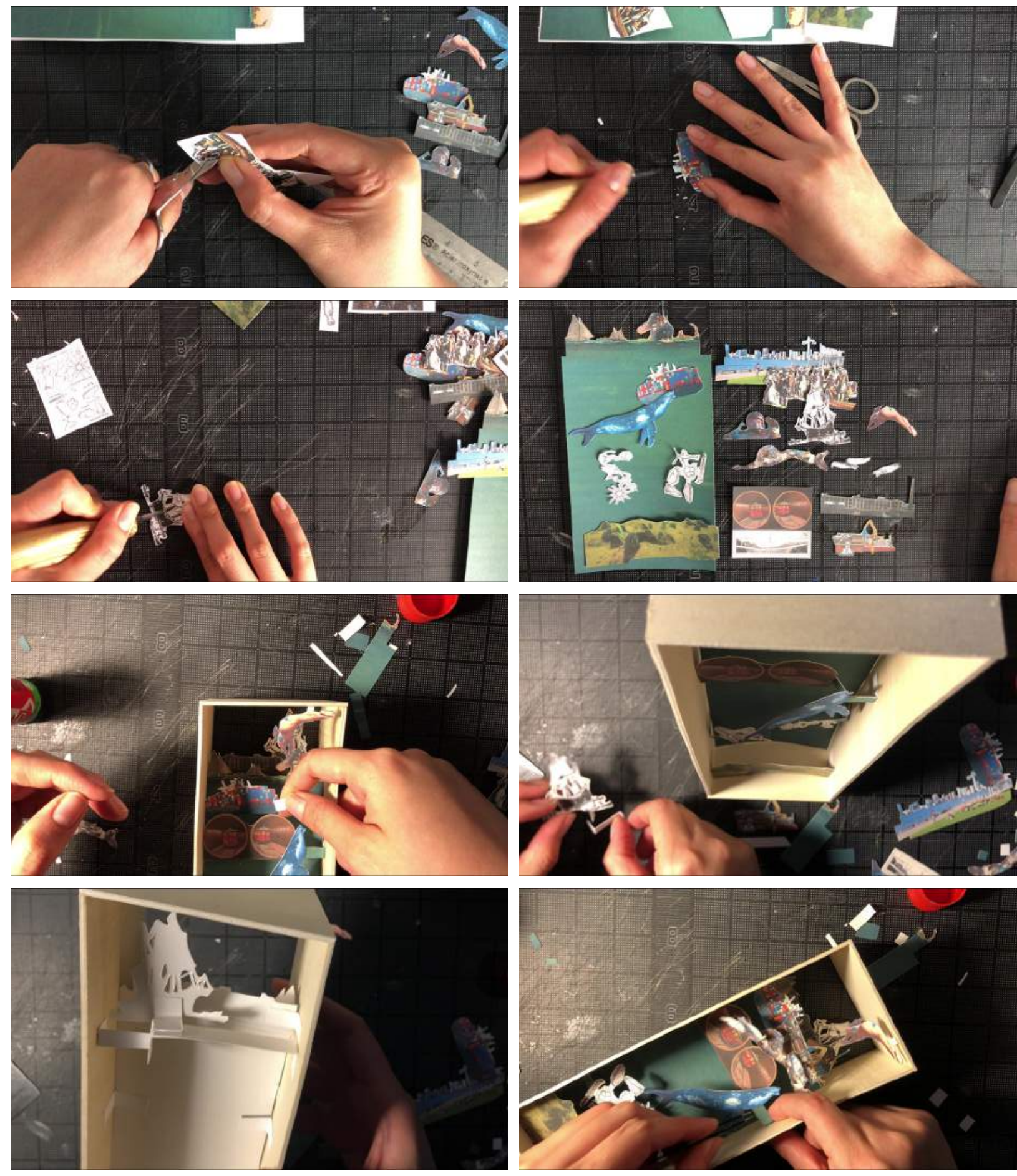

Figure 23. Hudson River Portal - Video Documentation 

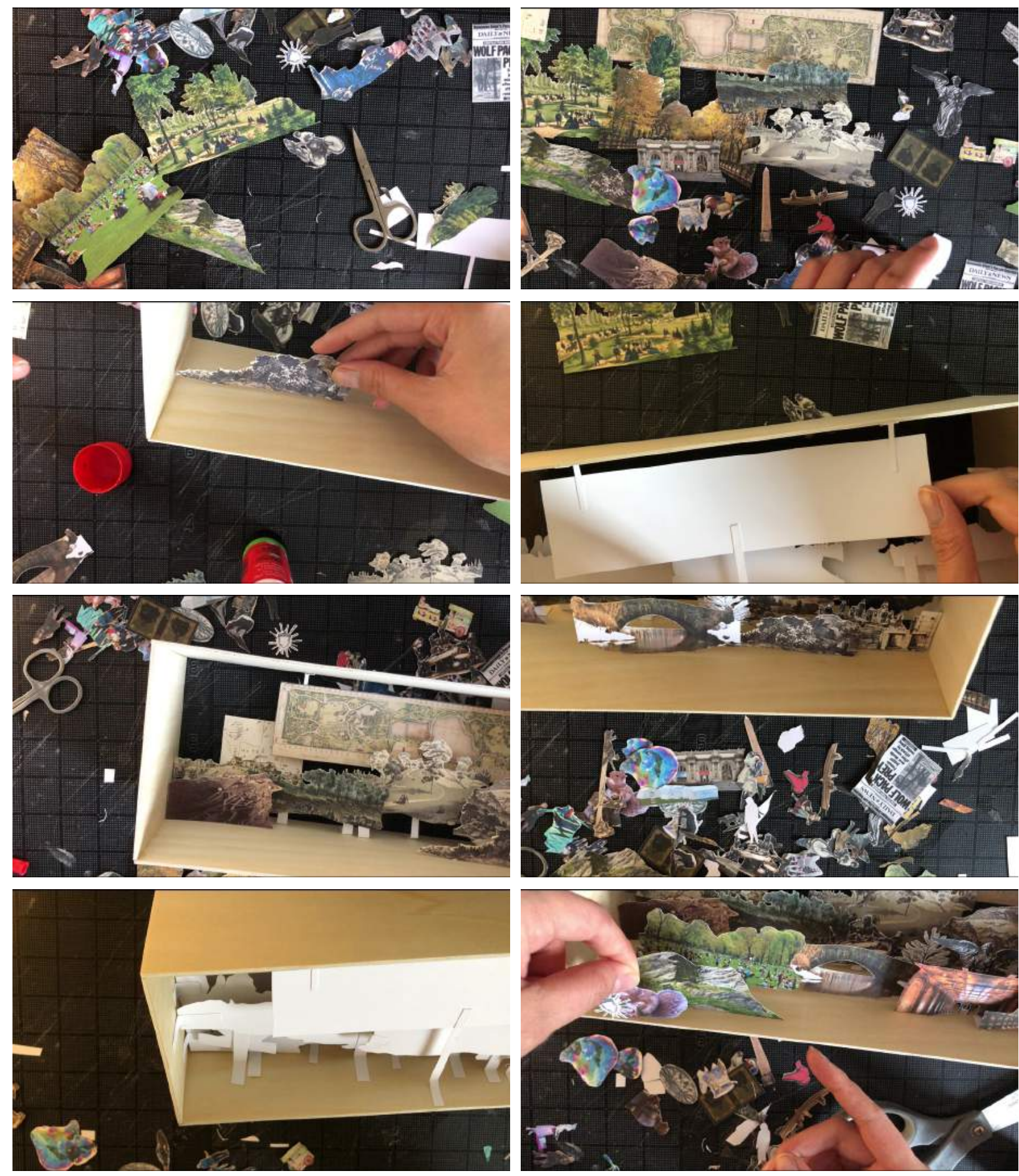

Figure 24. Central Park Portal - Video Documentation 

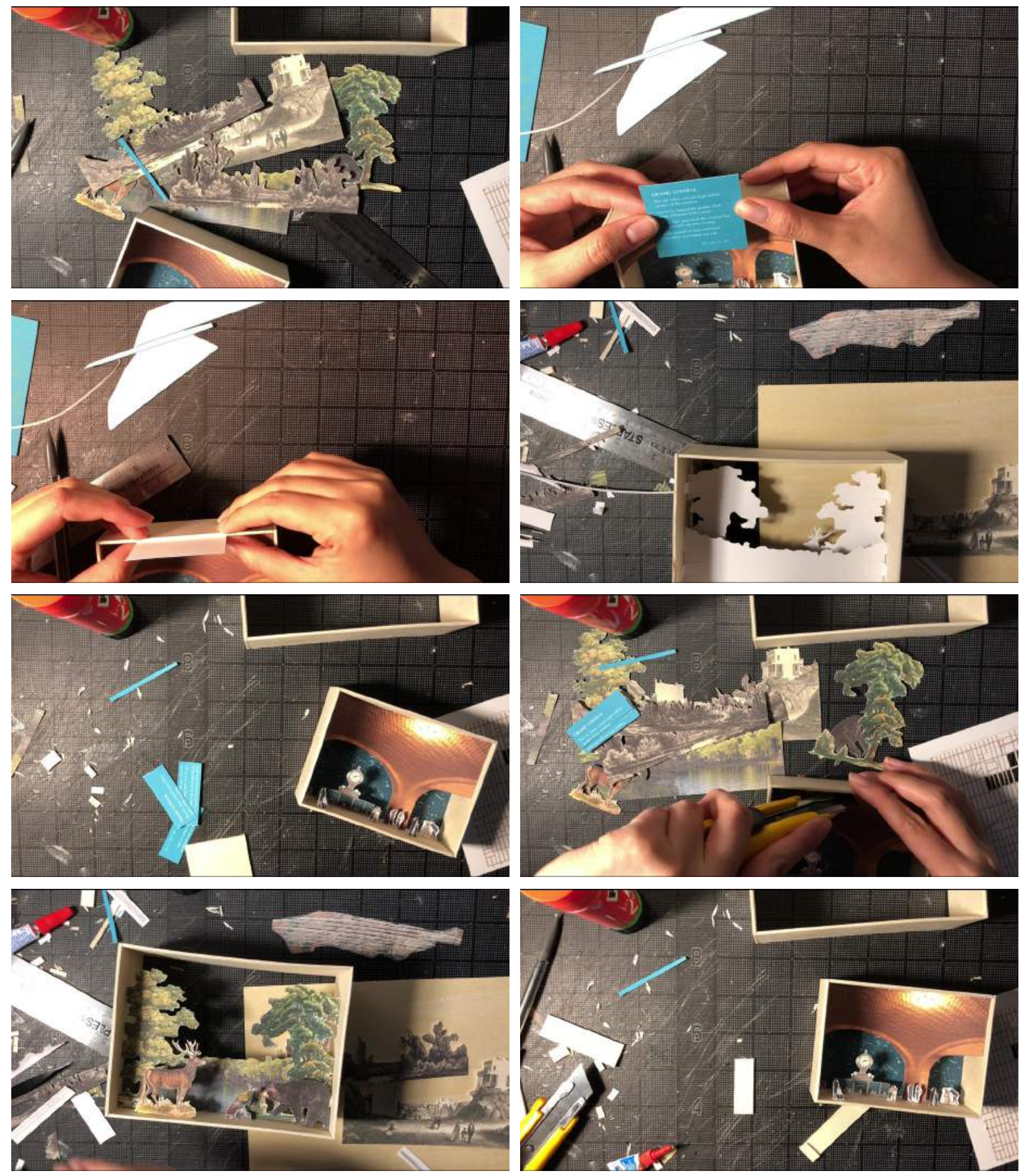

Figure 25. Grand Central Portal - Video Documentation 


\section{PHOTOGRAPH}

I photographed the portals during lunchtime when the daylight shone bright in my living room. I used a large roll of white paper to stage the backdrop and surface for my photo shoot, taping it carefully to my bookshelves to minimize wrinkling. I photograph the portals together and separately. I add additional empty frames, suggesting that additional portals will join my collection. I contemplate their placement next to each other and the narratives that can be drawn with each configuration.

I take a photo of the 'front view' of each portal but know that a perfect front view is never how they would be experienced in person. I photograph them on angles and zoom-in to clusters of artifacts. This is the closest I can get you to holding them-despite it being far. ${ }^{56}$

\footnotetext{
${ }^{56}$ Honesty: I wish you could hold these fragile boxes in your hands and discover them in your own way. I wish you could study them for yourself and wonder about the artifacts and how they relate to each other. I wish you could open the grid door, find the poem in the ceiling shelf, rotate the box to view the Manhattan topography and hold the constellations up to a light.
} 


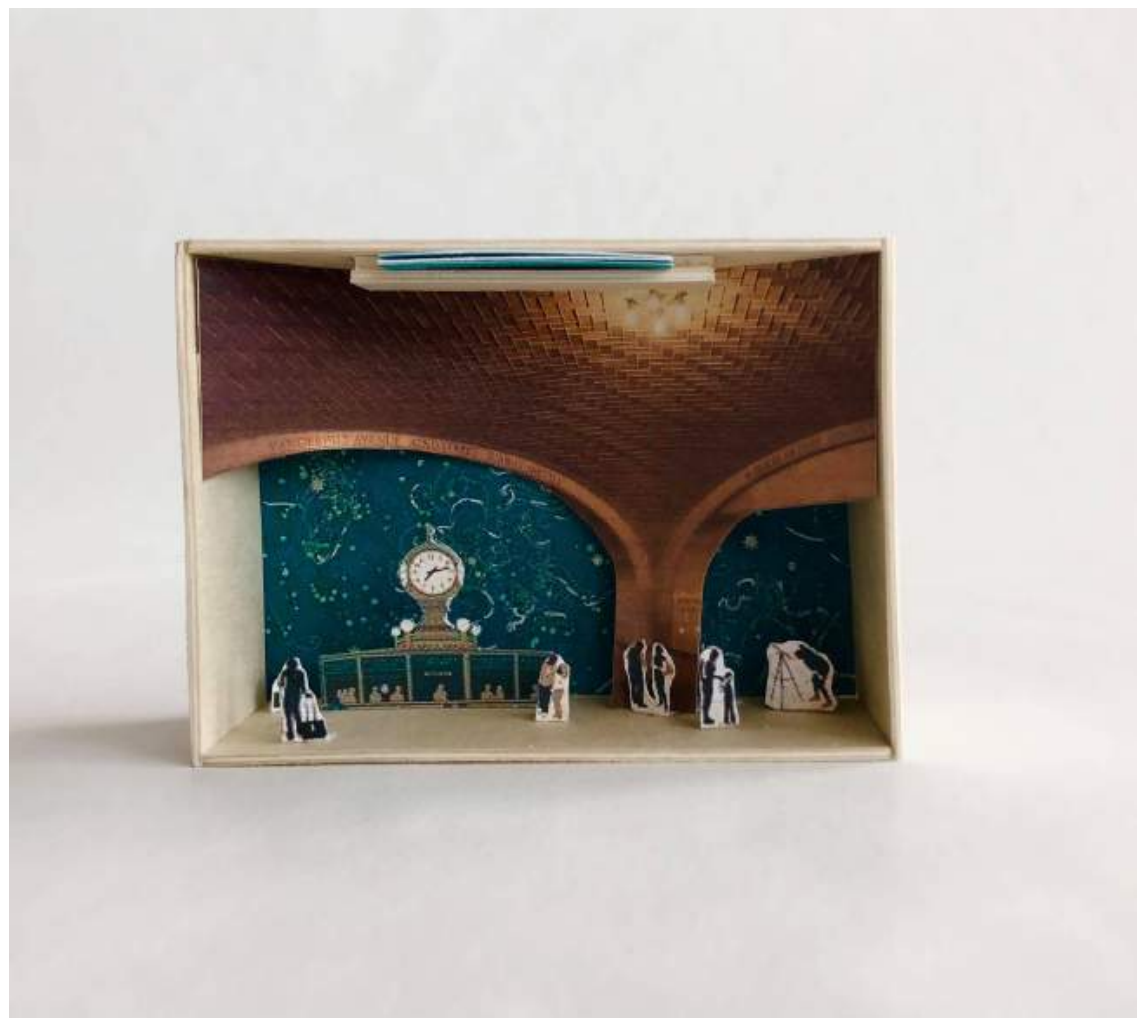

Figure 26. Grand Central Portal - Front View 


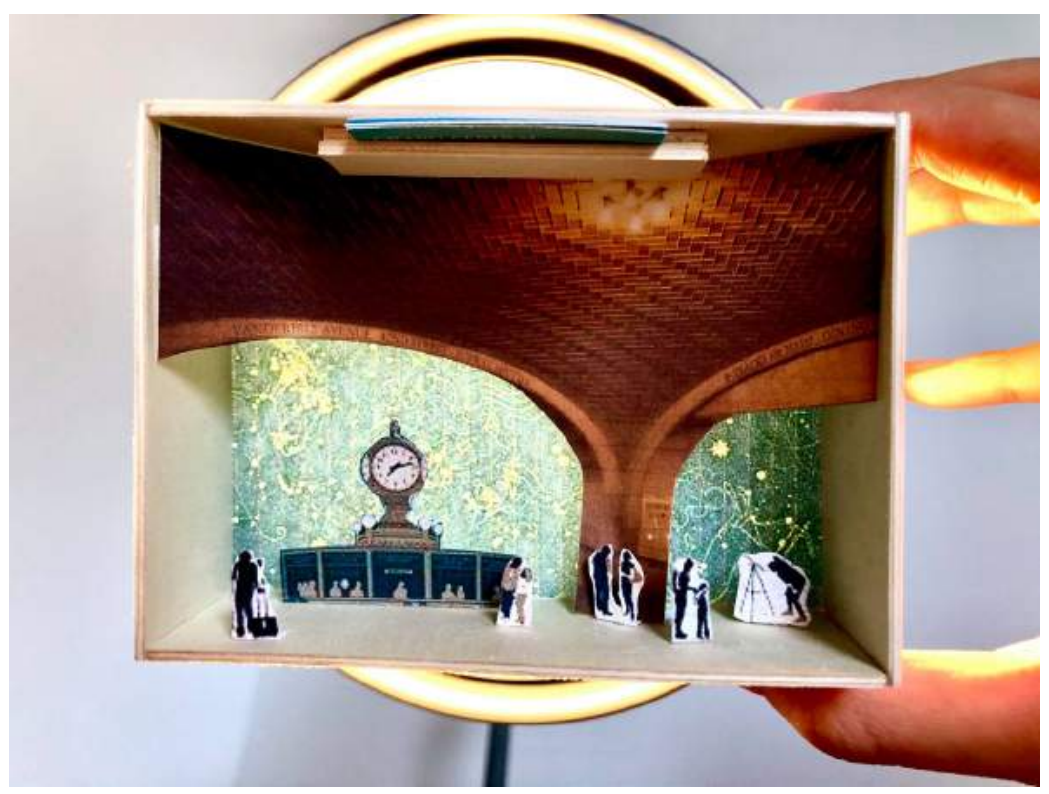

Figure 27. Grand Central Portal - Illuminated
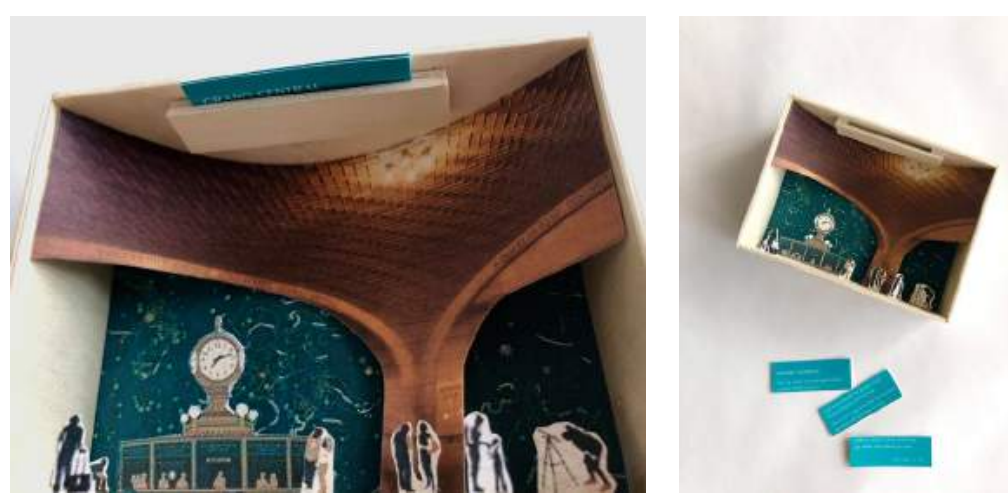

Figure 28. Grand Central Portal - Shelf

Figure 29. Grand Central Portal - Poem 


\section{story 6 \\ GIFT SHOP}

featuring

WE ARE LARGE, WE ARE FRACTURED

A CALL FOR COLLECTIVE

BEING HUMAN

COURAGE

and

LOST AND FOUND 
"Thank you for sharing, imagining, and remembering so generously with me today. I have deeply enjoyed our time together." Madeleine says. "I know you don't have much time left to spend here, so I will take you to one last stop, the gift shop."

"Gift shop?" I laugh.

She opens a door that reveals a tiny courtyard, the afternoon sun casts a soft glow over the garden. There is a small round table with an armchair.

"Please take a seat, I will be right back." She instructs me, gesturing to the armchair as I step outside. She slips away from sight as I take my seat. I take a slow breath of fresh air. I can hear traffic moving in the distance, the honking of horns, a siren wailing. I begin to daydream.

Madeleine returns carrying a small tray in her hands. She walks over and gently rests it on the table. I am greeted by a small book, a steaming cup of tea and delicate scalloped cakes dusted with sugar.

"I will leave you alone again shortly to sit, relax, and take your time with these little gifts from us. What I ask of you in return, is to write down a memory about a place in New York that you would like to live here in the palace. This is an invaluable gift to us and we will work to do it justice as we continue to build new rooms. You see, the palace is always changing. Write your memory on the last page of this book, remove the page and leave it on the tray with the dishes 
when you leave. My second request is that you keep this little book and use it to collect your memories of the city. It's a way of bringing the palace with you wherever you go. There are little sleeves mixed among the texts where you can put whatever you find. Write what you like in the margins, it's your book and I want you to make it your own. The very last thing I ask is that you share this book and your collection within it. Lend it to someone and ask them to read it. Talk to them about your collection, exchange stories and fall in love with the beautiful moment you are sharing together."

I extend her an earnest thank you. She nods politely and disappears into the palace. I gingerly take a sip of the tea and nibble on the cake. I reach into my pocket and pull out a pen. I begin to write. 


\section{WE ARE LARGE, WE ARE FRACTURED}

While it is important to humble our human existence, we cannot minimize the gravity of our impacts. It is paramount that we hold ourselves accountable for the devastation we have imposed on the planet throughout our short occupation, permanently killing and damaging nonhuman worlds in our wake. While it may be seen as an act of othering to suggest the separation of humans from nature and nonhumans in this discourse, it is absolutely critical that we identify ourselves as the sole owners responsible for this crisis.

In academic contexts, conversations relating to climate change often include discussion regarding the Anthropocene; the proposal to identify this current age as one separate from the Holocene on the geologic time scale due to the radical impact of humans. ${ }^{57}$ The value of the Anthropocene is recognized for its ability to identify and assume responsibility for the tangible and measurable affects humans have had on the planet as well as the social and political systems that have enabled these affects at a heightened scale in recent generations. As philosopher Bruno Latour identifies, the issues of climate change are inseparable from systemic issues that are social, cultural, economical, and political. ${ }^{58}$ However, the project is apprehensive about the Anthropocene's ability to address these systemic issues and call for collective action.

\footnotetext{
7 Simon L. Lewis and Mark A. Maslin, "Defining the Anthropocene," Nature 519, no. 7542 (March 2015): 171-80, https://doi.org/10.1038/nature14258.

${ }^{58}$ Bruno Latour, Down to Earth: Politics in the New Climactic Regime, trans. Catherine Porter (Oxford: Polity Press, 2018), 18.
} 


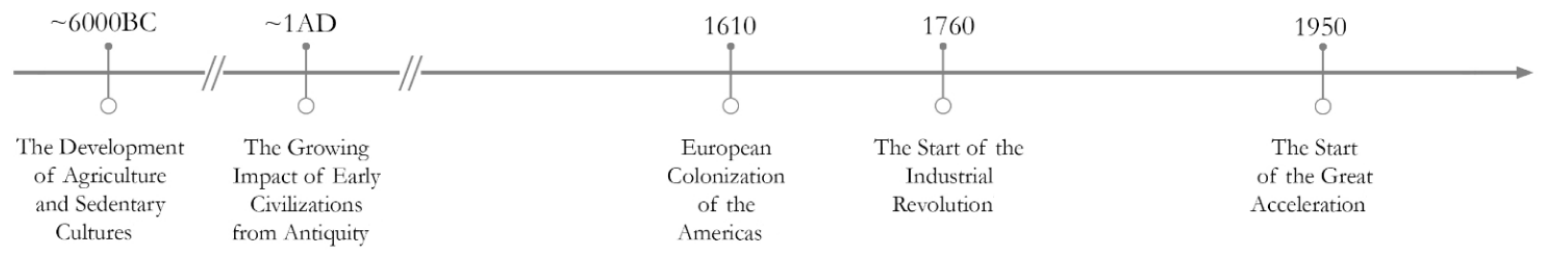

Figure 30. The Contested GSSP for the Anthropocene Age

The first underlying concern involves the controversial placement of the Global Boundary Stratotype Section and Point (GSSP), also known as the Golden Spike. ${ }^{59}$ The placement of the GSSP denotes when the Anthropocene age would have begun. Many diverging arguments have been made to determine the placement the of the GSSP (Figure 30). The official consensus of the Anthropocene Working Group was disappointingly short sighted, identifying that the Anthropocene began in the mid twentieth century, a period that designates itself the start of the Great Acceleration. ${ }^{60}$ This decision underpins the second concern about the construct of the Anthropocene: that it is a colonial and capitalist perspective of humanity that is operated by and for the benefit of established patriarchal systems. ${ }^{61}$ While the condition of climate change is planetary, the Anthropocene is an affliction that is uniquely Western. Author Naomi Klein explains that "as scientists in the 1980s started to document signs of the impending climate crisis, politics took a turn away from the collective (and against regulation), while culture deepened into consumerism." ${ }^{62}$ Latour continues this strand of thought describing that "the ruling classes stopped purporting to lead and began instead to shelter themselves from the world. We are experiencing all the consequences of this flight, of which Donald Trump is merely a symbol, one among others.

\footnotetext{
${ }^{59}$ The search for the Golden Spike is a disciplinary endeavor to geologically map the material relation of space and time according to stratigraphic principles and scientific precedents. It is a physical marker placed in a canyon wall to mark geological eras.

60 "Working Group on the 'Anthropocene' | Subcommission on Quaternary Stratigraphy," accessed March 26, 2021, http://quaternary.stratigraphy.org/working-groups/anthropocene/.

${ }^{61}$ Heather Davis and Zoe Todd, On the Importance of a Date, or Decolonizing the Anthropocene. ACME: An International Journal for Critical Geographies, 2017, 16(4): accessed on March 23, 2021, https://www.acme-journal.org/index.php/acme/article/view/1539, 770.

${ }^{62}$ Naomi Klein, "Climate Change Is the Fight of Our Lives - Yet We Can Hardly Bear to Look at It," Guardian, April 23, 2014, accessed on March 23, 2021, https://www.theguardian.com/ commentisfree/2014/apr/23/climate-change-fight-of-our-lives-naomi-klein.
} 
The absence of a common world we can share is driving us crazy." ${ }^{3}$ The implications of the Anthropocene threaten to perpetuate these retreats from the collective and intensify the geopolitical inequalities that are already being felt. ${ }^{64}$

Katharine Hayoe remarks: "Is climate change fair? Absolutely not. The poorest and most vulnerable among us, those who have done the least to contribute to the problem, are most affected. These include the women and children; farmers struggling to raise their crops in East Africa; Bangladeshis losing their land to sea level rise and erosion; and Arctic peoples whose traditions are threatened and whose homes are being displaced by rising seas and thawing permafrost. The carbon footprint of these groups is miniscule. They've contributed so little to the problem, yet they bear the brunt of the impacts." ${ }^{65}$ While several counter Anthropocenes have been proposed to acknowledge its proprietors, such as Donna Haraway's "Capitalocene, Plantationocene and Chthulucene: Making Kin"66 a third concern is brought to light. The discourse that surrounds these Anthropocenes can be viewed as exclusionary and is largely inaccessible to the public and therefore alienates the majority of humans from this so-called collective human claim.

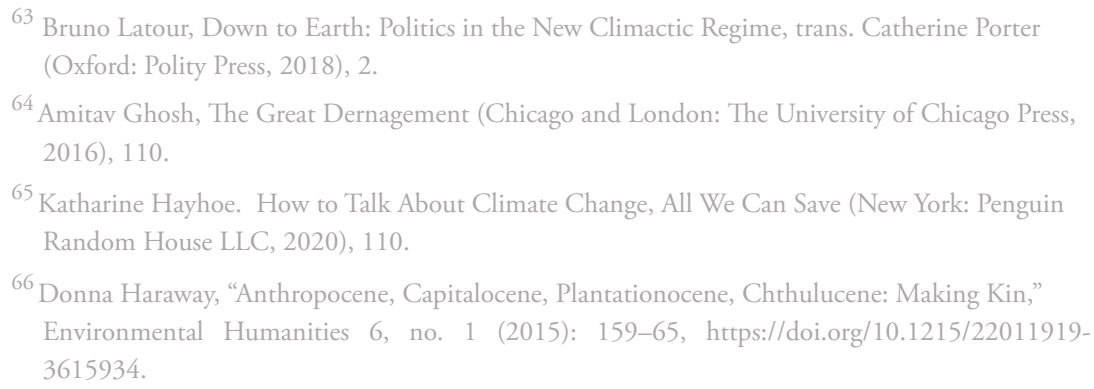




\section{A CALL FOR COLLECTIVE}

This thesis recognizes that reframing how we think, understand, and remember climate change calls for a greater and more inclusive sense of collectivity. This involves a call for interdisciplinarity in discourse and the exchange of knowledge from contributors encompassing a multiplicity of life experiences and perspectives. ${ }^{67}$

I think that the role of architects in this discourse is that of an interdisciplinary mediator. We as architecture students, academics, and practitioners learn and operate within the role of master coordinator and organizer. We think reflexively and shift between scrutinizing detail and big picture thinking while oscillating between scales of understanding the world. We are taught to critically empathise with what we observe and are positioned to moderate, interpret and vision opportunity by interlacing a diverse range of disciplinary perspectives. Above all, we have the representational and narrative capabilities to convey these visions to the world. Architects Rania Ghosn and El Hadi Jaziary's Geostories, intends to move beyond a toolkit of solutions-based approaches by presenting fictions that offer matters of concern rather than matters of fact. ${ }^{68}$ They desire "to release accounts of the Earth from the facticity of exchange value and eco-centric hubris of problem solving." ${ }^{69}$ This thesis project does not generate a problem that demands capital 'A' architecture as a

\footnotetext{
${ }^{67}$ Jainey K. Bavishi, A Tale of Three Cities, All We Can Save (New York: Penguin Random House LLC, 2020), 164.

${ }^{68}$ Rania Ghosn and El Hadi Jazairy, Geostories: Another Architecture for the Environment (New York and Barcelona: Actar Publishers, 2019), 19.

${ }^{69}$ Ibid. 23.
} 
solution. Instead, it focuses on architecture's capacity to assemble a collective, offering a place that learns to ask and wonder rather than assume and solve. ${ }^{70}$

Scholar Kate Knuth is convinced that "our only hope for successfully grappling with this crisis will come from deep investment in the day-to-day work of democracy and, more specifically, citizenship. [...] Citizenship, at its core, is a sacred trust between the individual and collective." ${ }^{71}$ She states, "As we face the climate crisis, this trust-and how we understand and act on it-is more critical than ever. [...] We need institutional and cultural tools and spaces that enable everyone to contribute. In other words, the work of our time is to reweave the fabric of our democracy even as the broken systems seem overwhelming, even as the work we each can do feels so small. It's time for an intentional practice of climate citizenship. ${ }^{72}$

New York is a city that celebrates and is known for its atomistic mindset, its eight million centers of the universe. However, it faces a future that will require a resolute sense of community and resilience in the face of mass displacement

\footnotetext{
${ }^{70}$ Rob Holmes, "The Problem with Solutions," Places Journal, July 2020. Accessed 01 Apr 2021. https://doi.org/10.22269/200714

${ }^{71}$ Kate Knuth, Becoming a Climate Citizen, All We Can Save (New York: Penguin Random House LLC, 2020), 132

${ }^{72}$ Ibid. 131.
} 
due to devastating and vastly transformative sea level rise. ${ }^{73}$ Emergent strategy practitioner Christine E. Nieves Rodriguez survived Hurricane Maria which devastated her home country Puerto Rico. She advocates that community is our best chance: "When everything collapses, the life-saving infrastructure is our knowledge of one another's skills, our trust of one another, our capacity to forgive our neighbor, work with our neighbor, and mobilize. When everything collapses-no ATMs, no water, no food, no diesel, no communication-you have to tap into a pre-existing system of trust and dignity and reciprocity." ${ }^{74}$

\footnotetext{
${ }^{73}$ Mike Orcutt. "New York City Has Big Plans—and \$20 Billion-to Save Itself from Climate Change,"MIT Technology Review, accessed March 12, 2021, https://www.technologyreview. com/2019/09/19/132942/new-york-city-has-big-plansand-20-billionto-save-itself-from-climatechange/.

${ }^{74}$ Christine E. Nieves Rodriguez, Community is our Best Chance, All We Can Save (New York: Penguin Random House LLC, 2020), 366.
} 


\section{BEING HUMAN}

As we navigate our lives, we connect with each other, we empathize with each other, we love each other, and we hate each other. We think things, we make things, we break things. Humans are concerned about humans. Our hubris has no bounds. We seldom consider perspectives of the world from one that is nonhuman because the very notions of perspective, value and meaning are fundamentally human constructs. And because I am human-meaning is everything to me. It is the joy and privilege of embarking on a thesis project.

I cannot escape my consciousness; we cannot escape our humanity. And perhaps I am only further demonstrating my humanity by positioning this project about climate change with a focus on examining the human mind. Yet, we are the problem, our minds have limitations, and we are daunted by the inconceivable. We are responsible for the climate crisis and we must embrace a deeper understanding and empathy toward the nonhuman entities with whom we are entangled and have affected due to our collective behaviours. This thesis is not about inhabiting or imagining existence as a nonhuman. It is an introspective examination of our human memory and our ability to understand beyond ourselves. The workings of the human mind underpin any planetary imaginary, epistemology, or ontology. This work is an important first step toward new paradigms. 


\section{COURAGE}

I find strength in admitting my vulnerability

Climate change makes me feel overwhelmed, anxious, and lost

There is so much that I do not know

So much I will never know

There have been moments where my cynicism consumes me

Fatalist thoughts numb me with sadness

But I have learned that self doubt is my useless undoing

It is a bitter luxury I cannot afford

So much is lost and yet there is still so much to lose

The world has transformed so much

And it is transforming again

It was never still 
The world we will hand our children will be a different one In its beauty and in its terror

Life will not be easy

But I believe it will be life worth living

I must set aside my fear

I must set aside my pride

I must set aside my assumptions

I will share what I know and be honest about what I do not

Today I choose courage

Today I choose hope 


\section{LOST AND FOUND}

By reflecting on the process of making the portals in scrutinizing detail, I am reminded that I am making hundreds of small decisions every day. These decisions typically do not amount to big things or big changes in my life. But they do amount to something, and when I intend to, hundreds upon hundreds of small decisions amount to something meaningful over time. Individual habits amass planetary impacts and individual memories amass a planetary imaginary. 


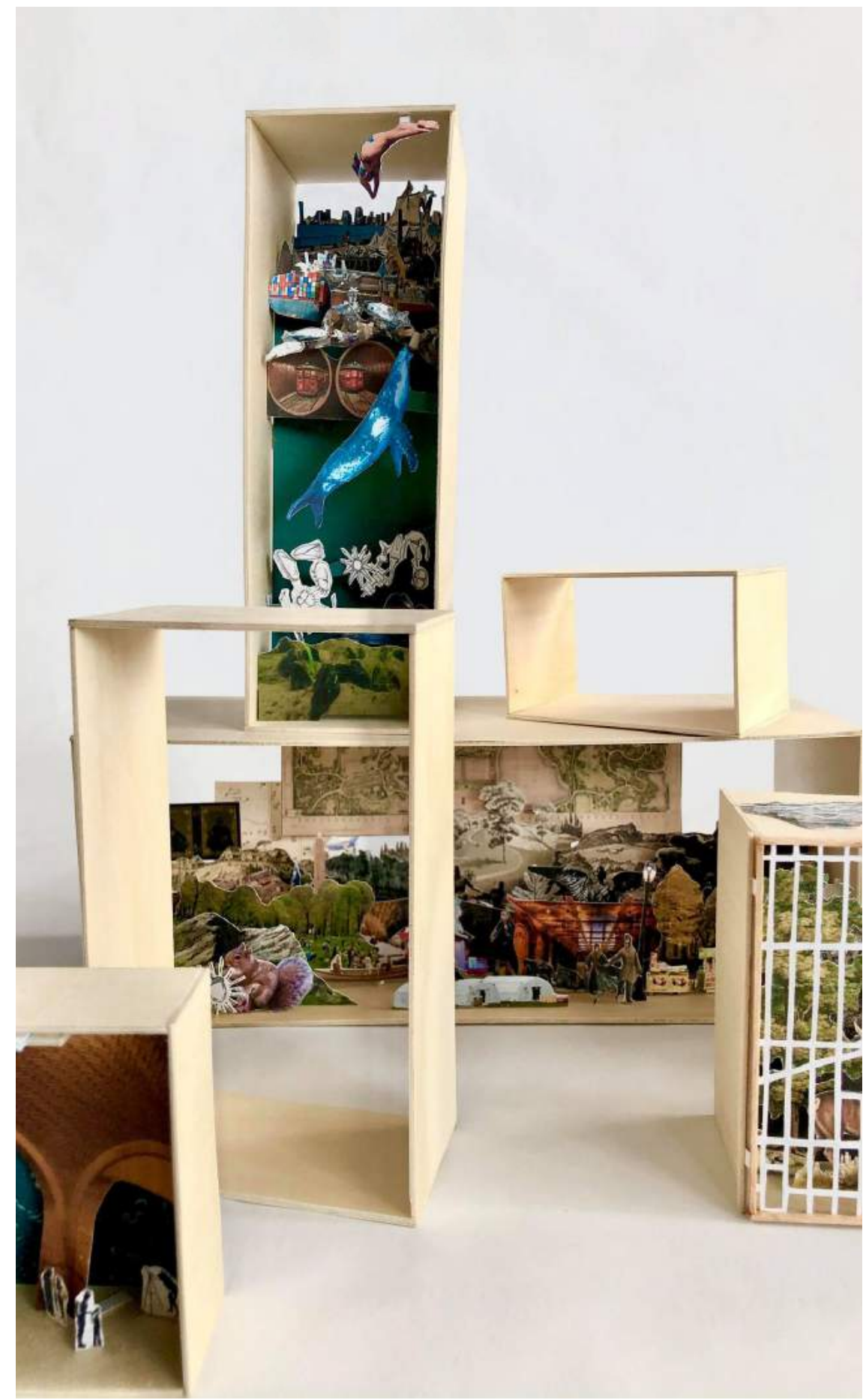

Figure 31. Collection of Portals 


\section{epilogue \\ FRESH KILLS}

featuring

\section{REPRESENTATION AND PROXIMITY \\ LANDFILL \\ RETURN TO PRODUCTION \\ INHABITING LIES}




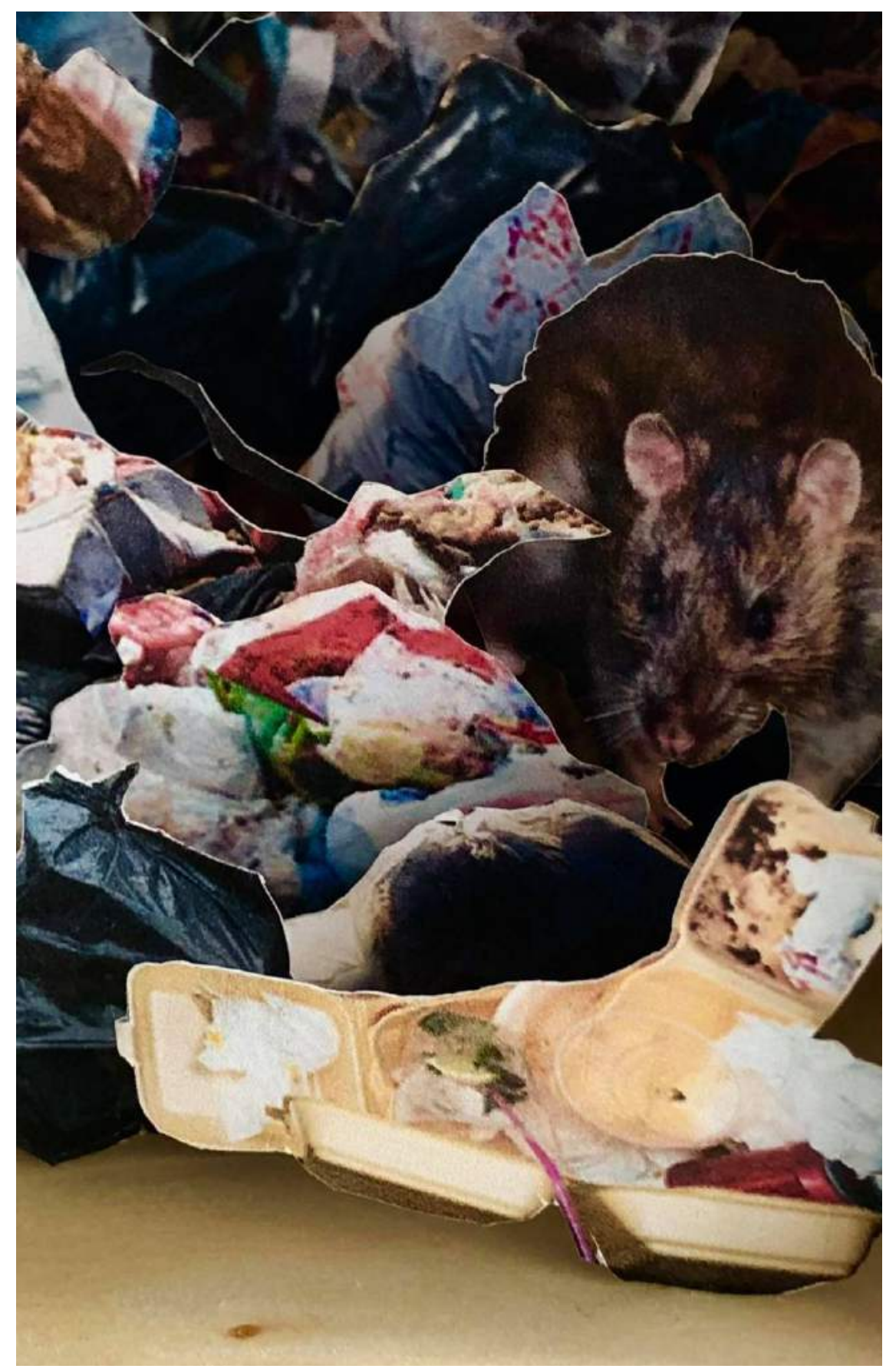

Figure 32. Fresh Kills Portal - Vignette 


\section{REPRESENTATION AND PROXIMITY}

As I reflect on the four portals I have crafted, I recognize the eclectic, whimsical and somewhat romanticized aesthetic they portray. It is true that the portals mourn the loss of the ecology native to the land due to the imposition of the grid. They entertain what Mannahatta might have been for the Lenape before it was colonized. They ponder the decades of poisonous industrial waste that has contaminated the Hudson River. They lament the displacement and erasure of a community of Black people to make way for Central Park not to mention the brute extraction and destruction it took to manufacture a picturesque and imported landscape.

All these ruminations are folded into the artifacts that live in the portals, some of which are more explicitly foregrounded than others. While I am not questioning the breadth of the content I have included in my work-I am concerned about their representation.

At a glance and with no context, the portals may be reduced to a fantastical perspective that is disconnected from the unromantic realities of the present. Despite my intentions to convey a multitudinous long 'now' in the places I have imagined, the ugliness of an uncomfortable now is somewhat lost in my attempt to beautify my work and represent how these places are experienced today. 
As I continue to grapple with what it means to imagine the present, to make memories of the present-I have started to assess my own patterns of thought and my own urges to represent and revise my depictions with a heightened awareness. To beautify and romanticize is a process. To tell a story is a process. To make memories is a process.

To imagine the present, is to acknowledge our uncomfortable proximity to ugliness. I hope my thesis asks its readers to acknowledge what we as humans have done knowingly and to contemplate what we as humans have done unknowingly. I admit, I am twenty-four years old and am certainly naïve. There is so much I have to learn about the workings of the world. But what I mean when I say unknowingly_-is that we as humans massage our memories into romantic imaginations and longing stories. We idealize and sensationalize our own behaviour and presence while we minimize, edit, and erase the magnitude of our barbarous impacts on the planet and the traumas we inflict on communities we have marginalized.

I want to confront how I have pictured the present thus far and establish that the planetary imaginary I wish to collect and share does not gloss over or conceal uncomfortable memories that are difficult to digest. I am consciously aiming to represent ugly ongoings that cannot be beautified. 


\section{LANDFILL}

The final portal I have crafted steps away from Manhattan to Staten Island, which has held a reputation as the 'forgotten borough'. Staten Island residents have given their home this name due to the neglect by the city and government-particularly in relation to the complete mishandling and mismanagement of the Fresh Kills Landfill—which is now under construction to be transformed into Fresh Kills Park. ${ }^{75}$

My thesis calls for the formation of a collective while asking us to recognize our agency and individual impacts, to be aware of the thoughts and choices we negotiate and encounter every day. A daily testament to this collective impact and cumulative behaviours is the waste we discard on a daily basis. It is smelly, it is disgustingly dirty. We dispose of trash and never have to worry about where it is going because we will never have to see it again. We can forget about it. It is out of sight and out of mind. But where is out? How do we designate a space as in and a space as out?

For a long time, New York's 'out' was the ocean. The city dumped its garbage into the ocean until 1934, when it was prohibited by the US Supreme Court. ${ }^{76}$ Robert Moses, hailed as the 'master builder' of mid twentieth century New

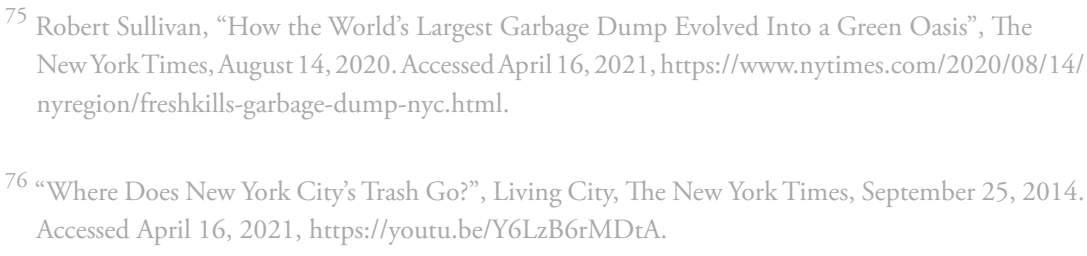


York, eventually proposed a filling of the Staten Island marshlands with the city's waste, stating that "you have an immense acreage of meadow land in this locality which is presently valueless." 77 And what began as a temporary solution quickly and clearly became increasingly permanent and expansive.

The Fresh Kills landfill would become the primary repository of New York's daily garbage for fifty-four years and was once the world's largest dump. Barges would make daily trips to the landfill, disposing of twelve thousand tons of garbage each day. ${ }^{78}$ These garbage mountains tower over the statue of liberty, it has been said that if the landfill had remained in operation longer, it would have become the tallest elevation on the east coast. But, in March 2001, Fresh Kills received its last barge of trash. ${ }^{79}$ It was closed. And then, six month's later, it reopened. Tragedy struck, the landfill became a sorting ground and burial site for personal affects and human micro remains from Ground Zero. ${ }^{80}$ The site that was eventually capped and named the West Mound now

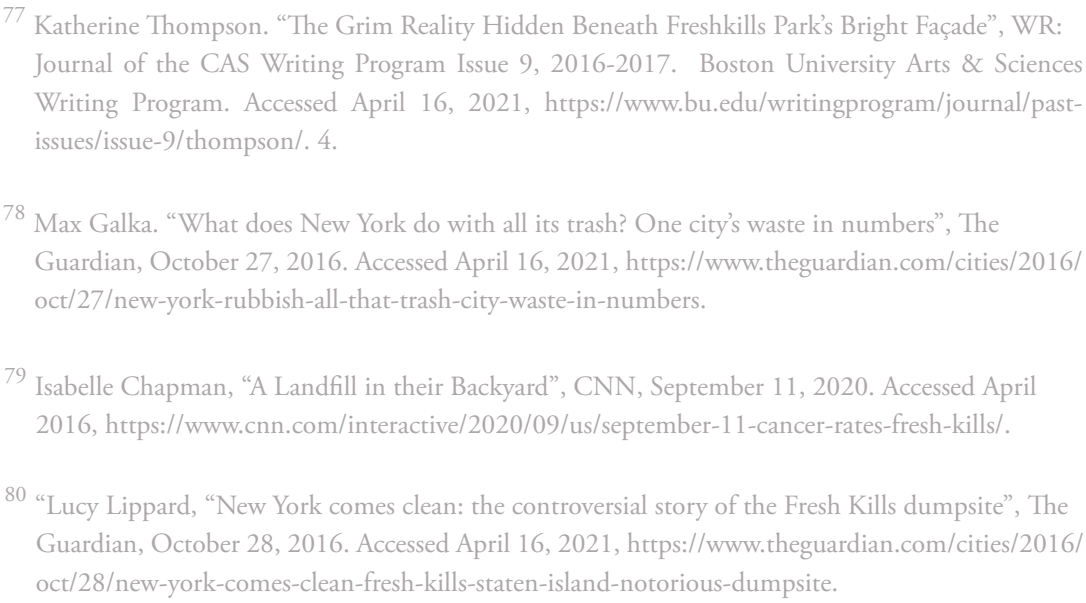


encases the million and a quarter tons of human and architectural remains. Fresh Kills Landfill ultimately capped its four mounds in layers of plastic and earth, compacting a choking one hundred and fifty million tons of waste. It Is a proof of cumulative impacts beyond fathoming. My human mind cannot wrap itself around such a monstrously large number.

Fresh Kills has not received daily garbage in over twenty years and New York City has found multiple spaces to throw out its waste. Everyday, the tons of garbage-whose volumes have amplified to record highs in this pandemic year-are transported by massive vehicles to landfills in New Jersey, Pennsylvania, Ohio, and Virginia. ${ }^{81}$ The effects of New York reach far beyond the lines of its geography. Its scalar implications continue to inflate what the portals contemplate as large places.

For some time now, Fresh Kills has been undergoing an extensive transformation. In roughly twenty years, Freshkills Park will be complete and open to the public. This Park project is the City's largest since the construction of Central Park and boasts that it will be three times its size, roughly 2,200 acres of playgrounds, sports fields, and delightfully scenic hiking trails. ${ }^{82}$ This

\footnotetext{
81 “The Impact of NYC's Trash on Other Communities", Landfill Operations, Waste 360, February 6, 2021. Accessed April 16, 2021, https://www.waste360.com/landfill-operations/impact-nycstrash-other-communities.

82 James Corner, "Lifescape - Fresh Kills Parkland". Accessed April 16, 2021, https://www.nextroom. at/data/media/med_binary/original/1121022434.pdf.
} 
massive project has been promoted with a saccharin positivity. This is being positioned as a story of redemption and metamorphosis from wasteland to environmental oasis. ${ }^{83}$ And of course, when considered on an immediately surface level, this project sponsors an incredible improvement to Staten island residents.

Landscape architect James Corner and his firm Field Operations are responsible for the design of the park. In an interview, Corner has noted that "the Fresh Kills landfill is the best thing that has happened to Staten Island. What you have here is four square miles of land preservation." ${ }^{84}$ What concerns me about this statement about preservation, reclamation and remediation is that it carries a dangerous implication. It declares that we humans can reverse the horrifying devastation we cause by covering it up and effectively erasing our ugly behaviour with a beautified, wholly manufactured conception of nature. This self-aggrandizing power we have allowed ourselves, to selectively assign importance to land as it suits our capital ends perpetuates our extremely harmful and manipulative attitude toward nature. ${ }^{85}$

\footnotetext{
${ }^{83}$ Robert Sullivan, "How the World's Largest Garbage Dump Evolved Into a Green Oasis", The New YorkTimes, August 14, 2020. Accessed April 16, 2021, https://www.nytimes.com/2020/08/14/ nyregion/freshkills-garbage-dump-nyc.html.

${ }^{84}$ Katherine Thompson. "The Grim Reality Hidden Beneath Freshkills Park's Bright Façade", WR: Journal of the CAS Writing Program Issue 9, 2016-2017. Boston University Arts \& Sciences Writing Program. Accessed April 16, 2021, https://www.bu.edu/writingprogram/journal/pastissues/issue-9/thompson/. 7 .

${ }^{85}$ Ibid. 10.
} 
This is a landscape that has been long neglected and abused by humans that deemed it valueless and identified it as a space that was out. It was filled with decades of garbage and now our ugly behaviours are being concealed with a new layer that we deem attractive while garbage mountains are being exported out of the city to other states. In a lot of ways, this is an act that extends our disconnect and responsibility from the costly consequences of our habits of exploitation, consumption, and waste. ${ }^{86}$ And this detrimental mentality reverberates beyond Fresh Kills and beyond New York City. These short- sighted politics and worldviews are the reasons why humans in the Western world are cumulatively responsible for the climate crisis and are cumulatively responsible for how we chose to react.

\footnotetext{
86 “Where Does New York City's Trash Go?”, Living City, The New York Times, September 25, 2014 Accessed April 16, 2021, https://youtu.be/Y6LzB6rMDtA.
} 


\section{RETURN TO PRODUCTION}

I glue together the tallest and deepest box I have made thus far. I print out dozens of images that encompass the Fresh Kills stories I wish to convey. I perch my cell phone above my desk and begin to record as I cut out images.

As this ritual shifts timescales, I return to the familiarity and relief of being completely engrossed in my work. I am suddenly present in a way that only focused, repetitive activities ask me to be. I have created an indefinite job for myself. It turns out that cutting out little pieces of garbage from images of landfills could go on for an eternity and then some.

I cut out recognizable pieces: takeout containers, garbage bags, old car tires, cardboard boxes filled with indistinguishable things. I wonder where all the garbage I have produced in my life has gone, what far away landfills contain my waste. I cut out many small individual pieces of garbage that never make it into the final piece. I am trying to fathom the uncountable tons of garbage that flat images of technicolour heaps cannot effectively impart.

I become fixated on cutting out garbage I cannot quite identify. They are different coloured blobs, blurred perhaps, by the resolution of the original 
image I have used or by the quality of my printer. I could be cutting out anything. I continue until it feels futile and pointless. Until the very notion of cutting out images of objects becomes so skewed and abstract that I do not feel in control of what and how I am objectifying these 'artifacts'. Can I even call these garbage blobs 'artifacts'? I assemble the portal with supporting distinguishable artifacts that imbue the garbage with greater significance.

I shoot video walkthroughs of all five portals. It is the closest I can get you to holding the portals in your hands, to experiencing them for yourself. I splice together all the footage I have taken throughout the production of the Fresh Kills Portal and produce a time lapse video. You can watch both videos by clicking on the buttons below.

I have produced five portals. I have also produced a mountain of scraps.

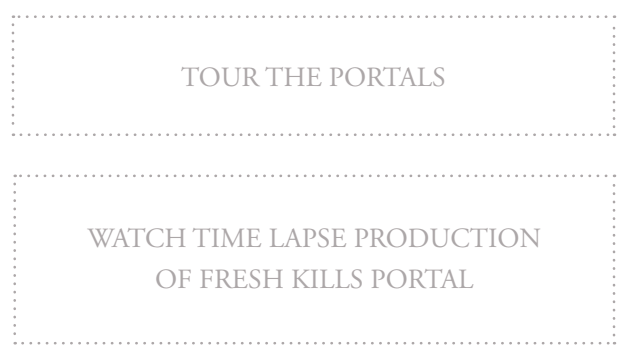




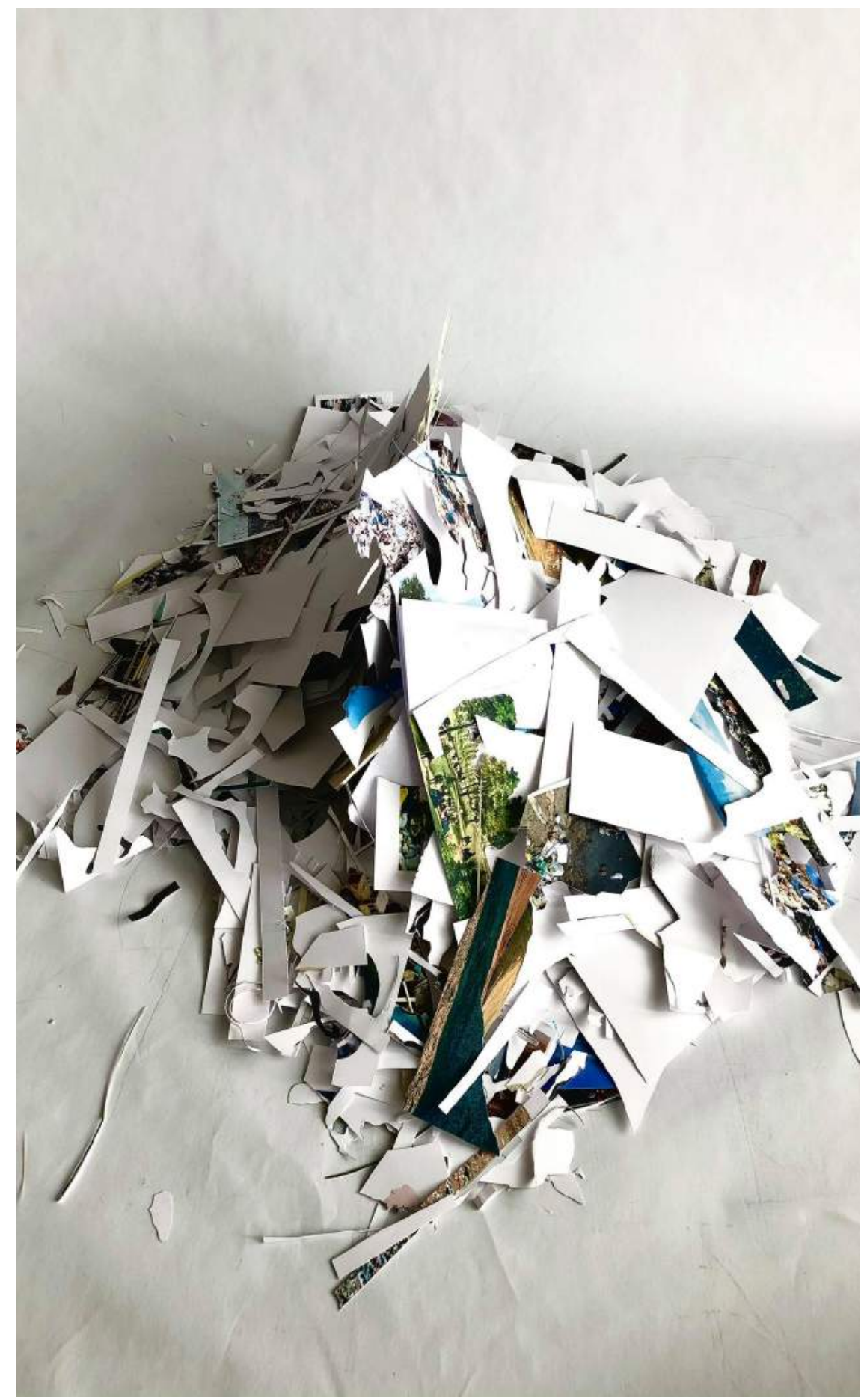

Figure 33. A Mountain of Scraps Collected 


\section{INHABITING LIES}

Perhaps I could have found a more hopeful note with which to conclude my thesis. It finds its pit stop at a garbage dump, which is melancholic and slightly anticlimactic. However, this moment does not represent the end to any stories and there are so many stories I did not find and tell throughout this past year.

Immersing myself in this thesis project has reinforced a voracious curiosity and desire within me to continue learning and more importantly to engage in productive and critical conversations.

I am grateful to Tom Caruthers (external critic), Natalia Escobar Castrillón (internal critic) and Piper Bernbaum (chair) for attending my thesis defense, for engaging my work with empathy, thoughtfulness, and care and for offering fruitful insights and discussion. Fragments of our conversation have lingered with me in the weeks that have passed. 
I have thought at length about a question Tom asked me: "Can we inhabit a lie and critique from within it?" I think about the lies I inhabit, the lies I perpetuate, the lies I participate in fabricating. We inhabit lies and the lengths we go to uphold them are immeasurable and remorseless.

This lie we are referring to is the world we live in. The world the West has made for itself. This world was-and continues to be-built on multiscalar inequality. We define spaces as in or out. We then permit or deny access to those spaces. We decide whether people are in or out. We lie to ourselves, justifying our cruelties and disconnected empathy.

I have come to learn that the pursuit of climate justice is inextricably tethered to the pursuit of social justice. I have written that I believe enabling conversation is its own form of activism and that is what fills me with gratitude, courage, and hope. 


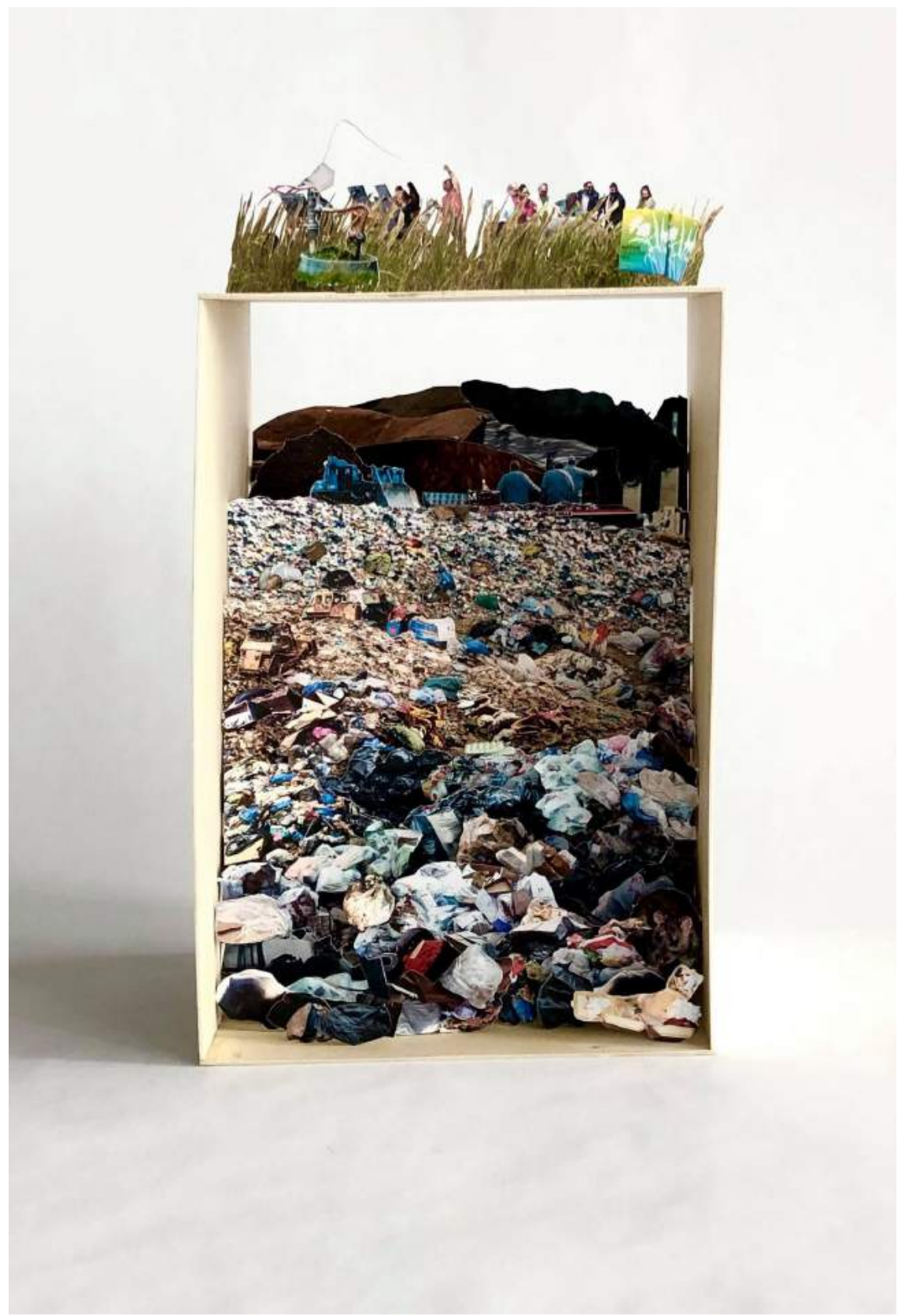

Figure 34. Fresh Kills Portal - Front View 


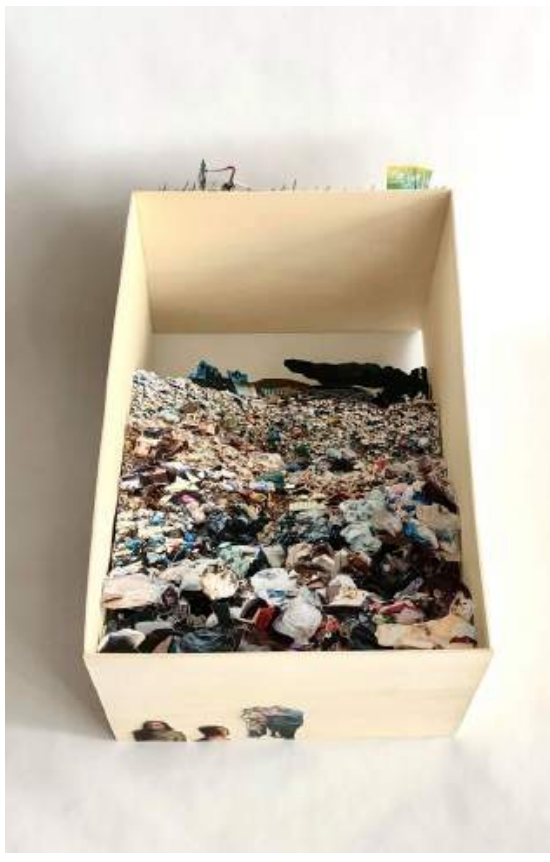

Figure 35. Fresh Kills Portal - Buried

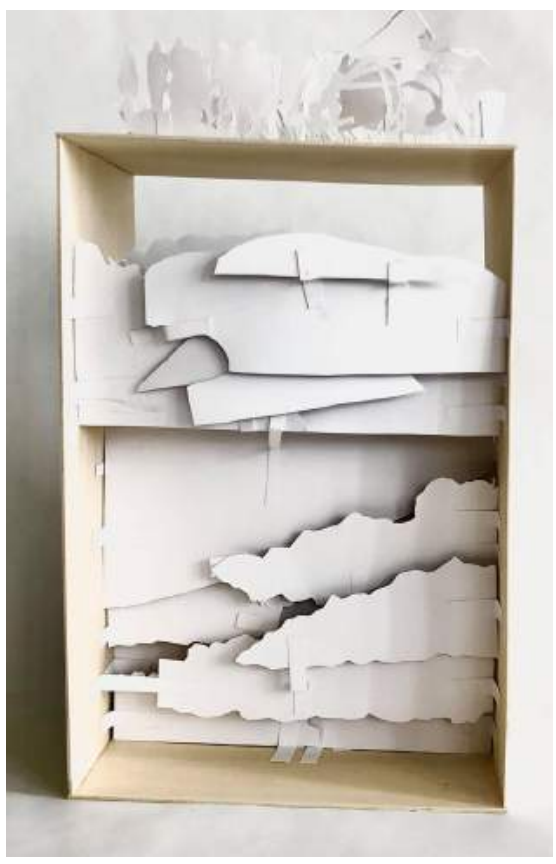

Figure 36. Fresh Kills Portal - Behind

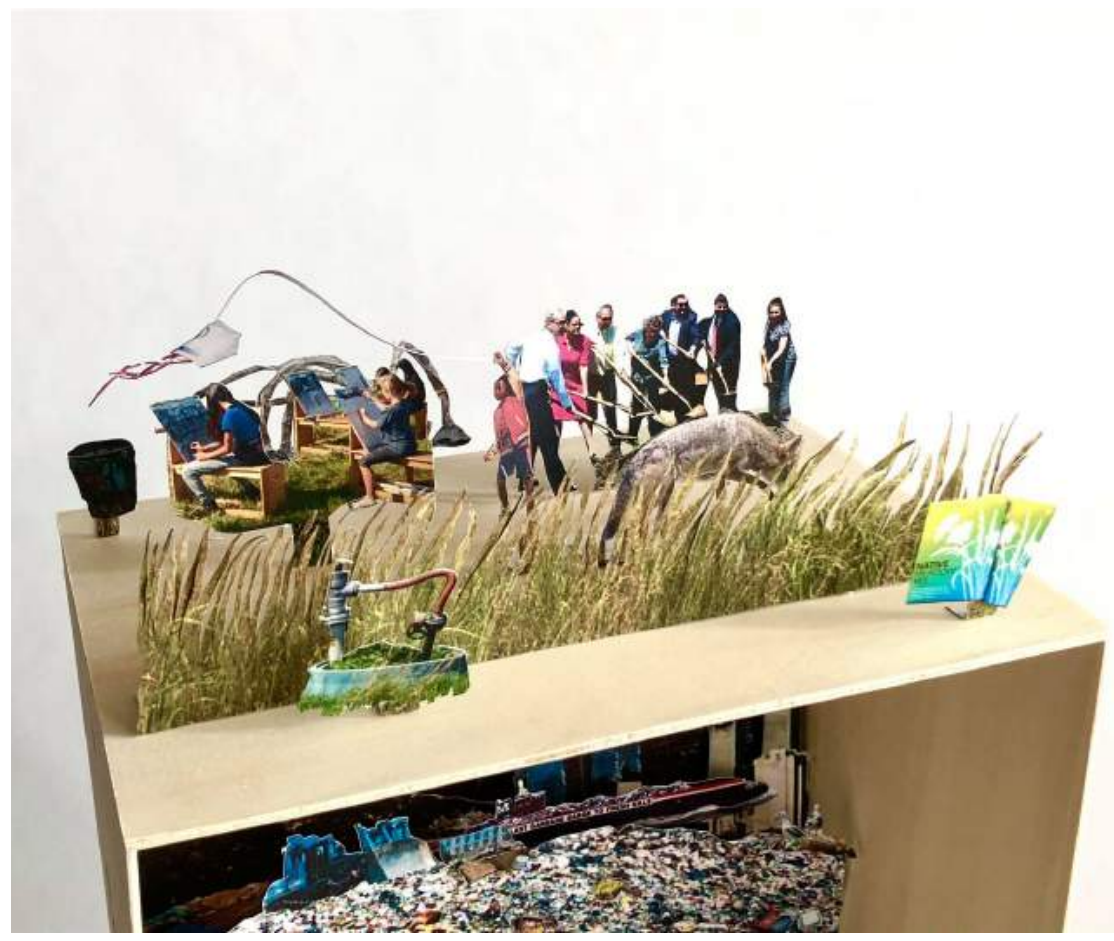

Figure 37. Fresh Kills Portal - Oasis 


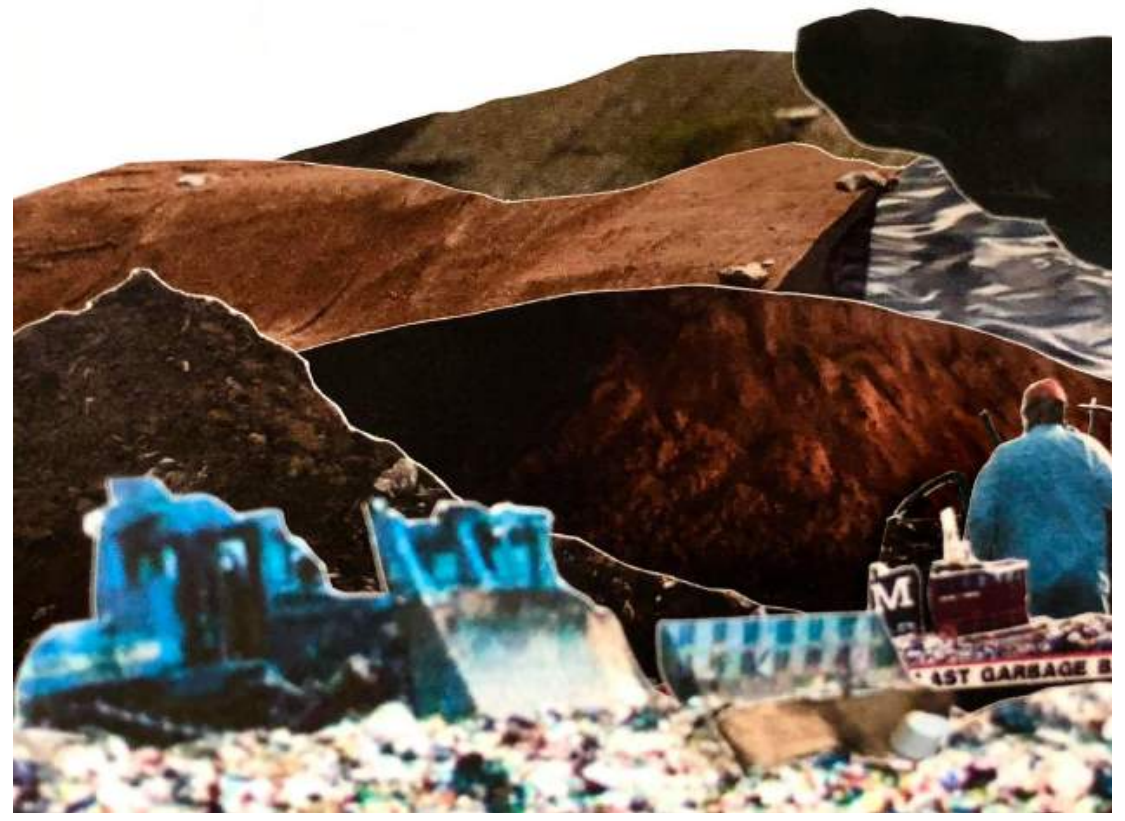

Figure 38. Fresh Kills Portal - Conceal

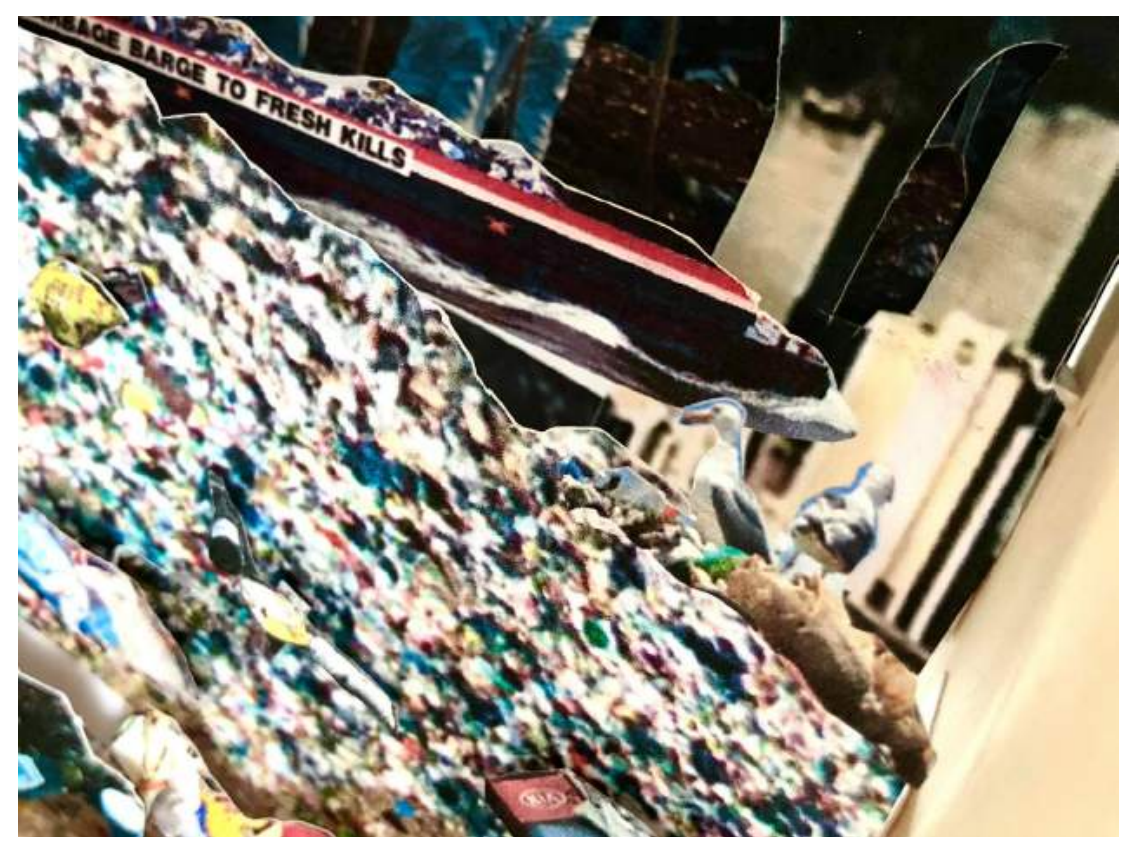

Figure 39. Fresh Kills Portal - (Un)close 


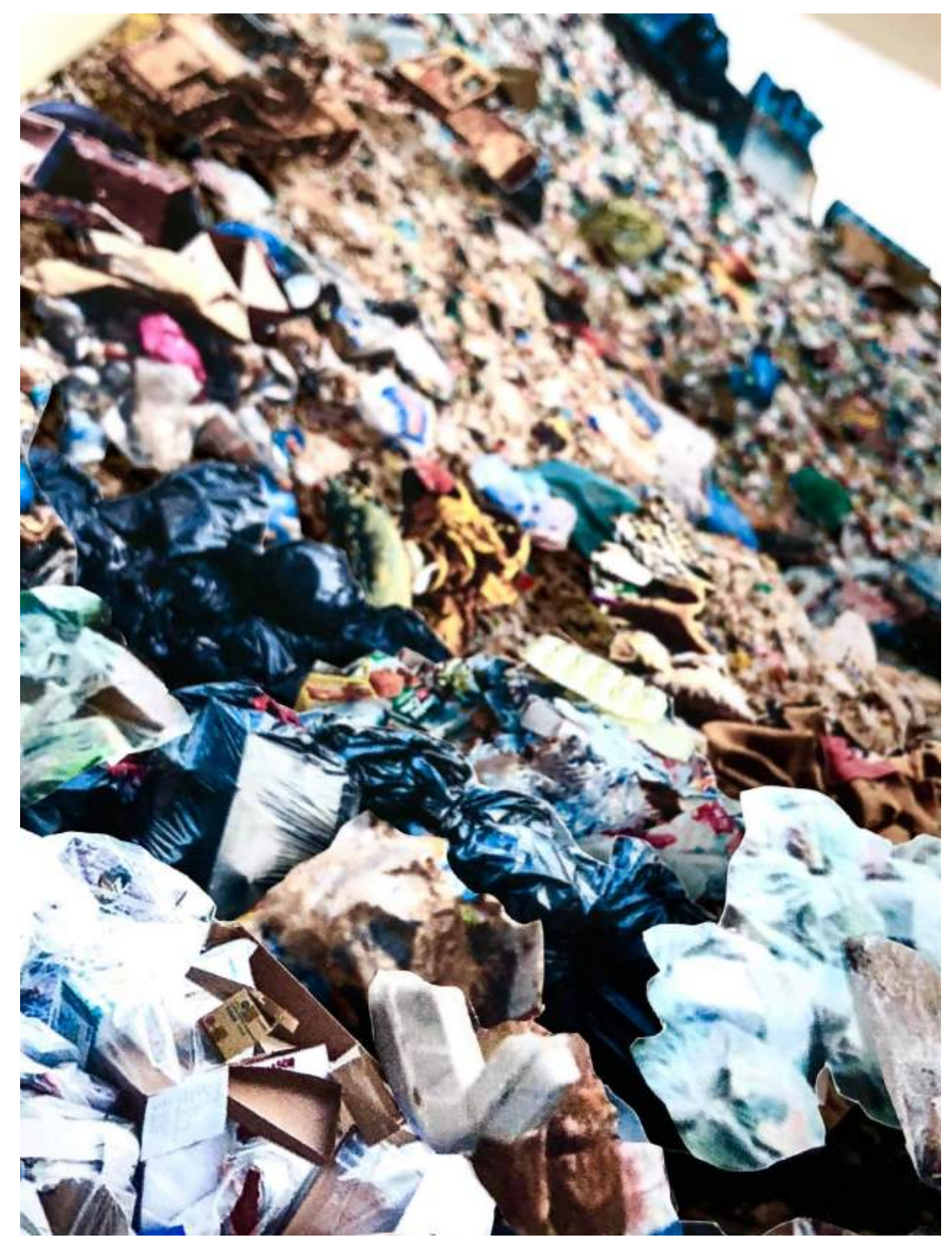

Figure 40. Fresh Kills Portal - Fill 


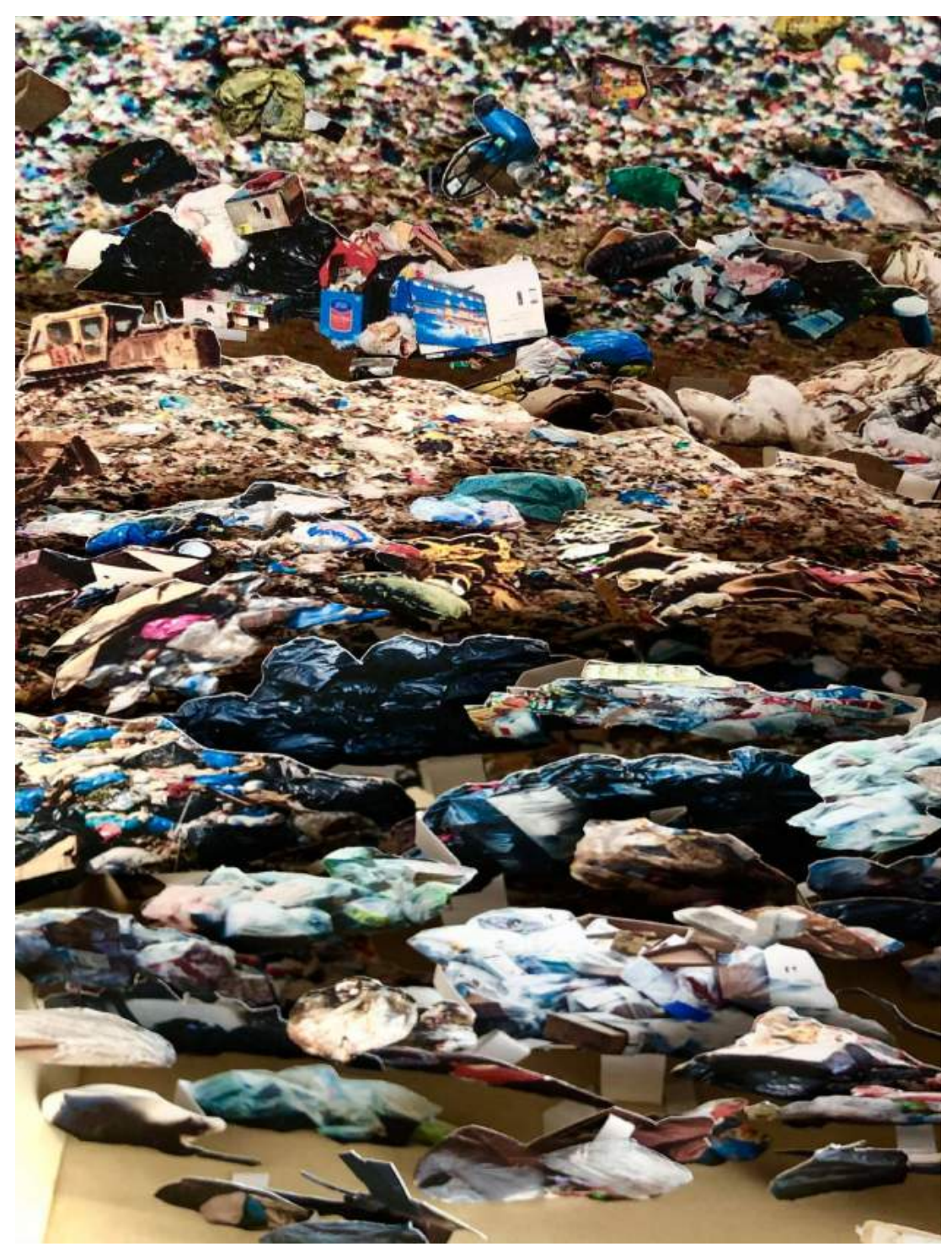

Figure 41. Fresh Kills Portal - Expand 


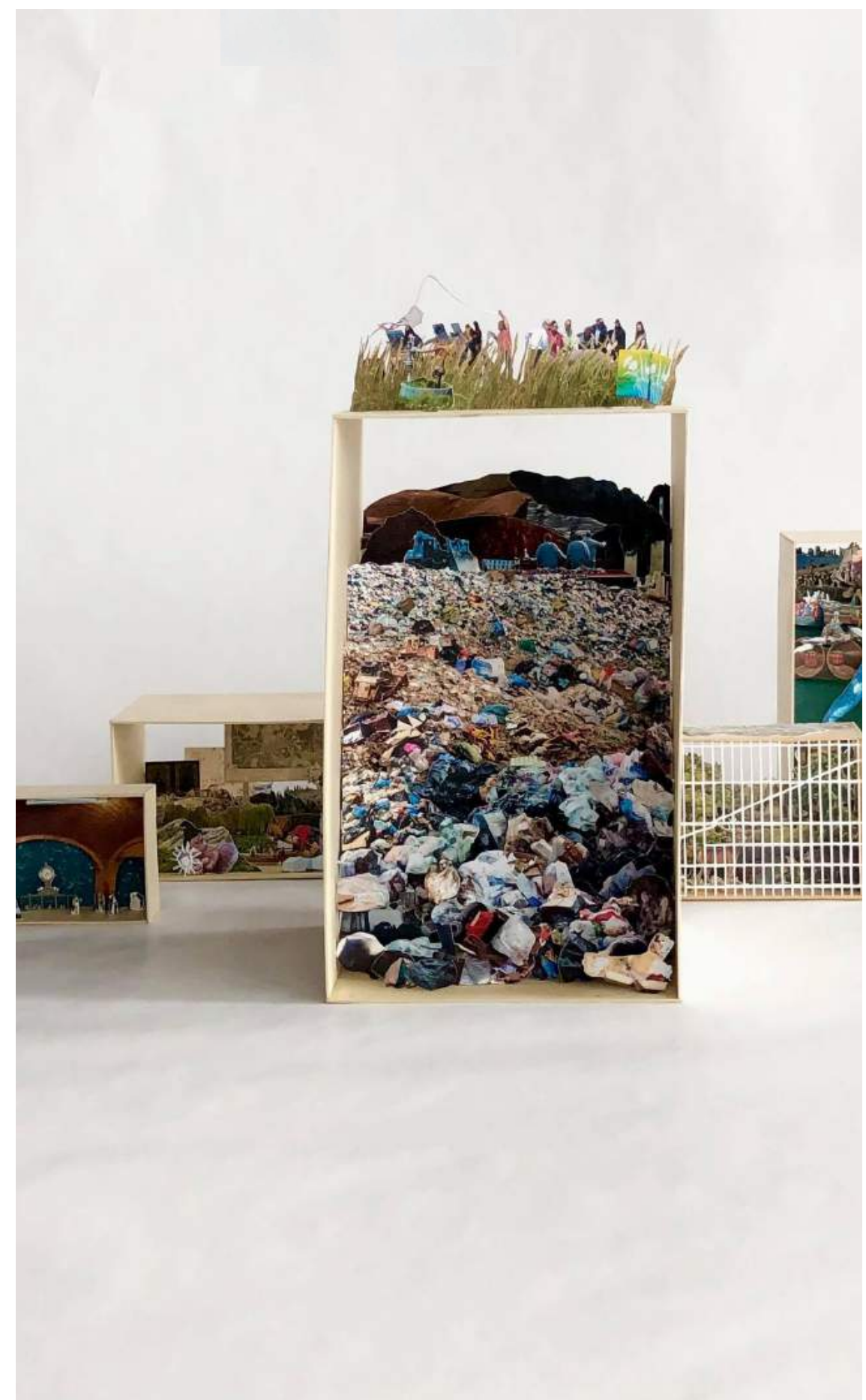

Figure 42. Continued Collection of Portals 


\section{APPENDIX A: TRANSECT STUDIES}

The thesis project initially identified Central Park as the primary site for the memory palace. The research expanded beyond the park, organizing research curiosities and analysis in Manhattan along a horizontal and vertical transect.

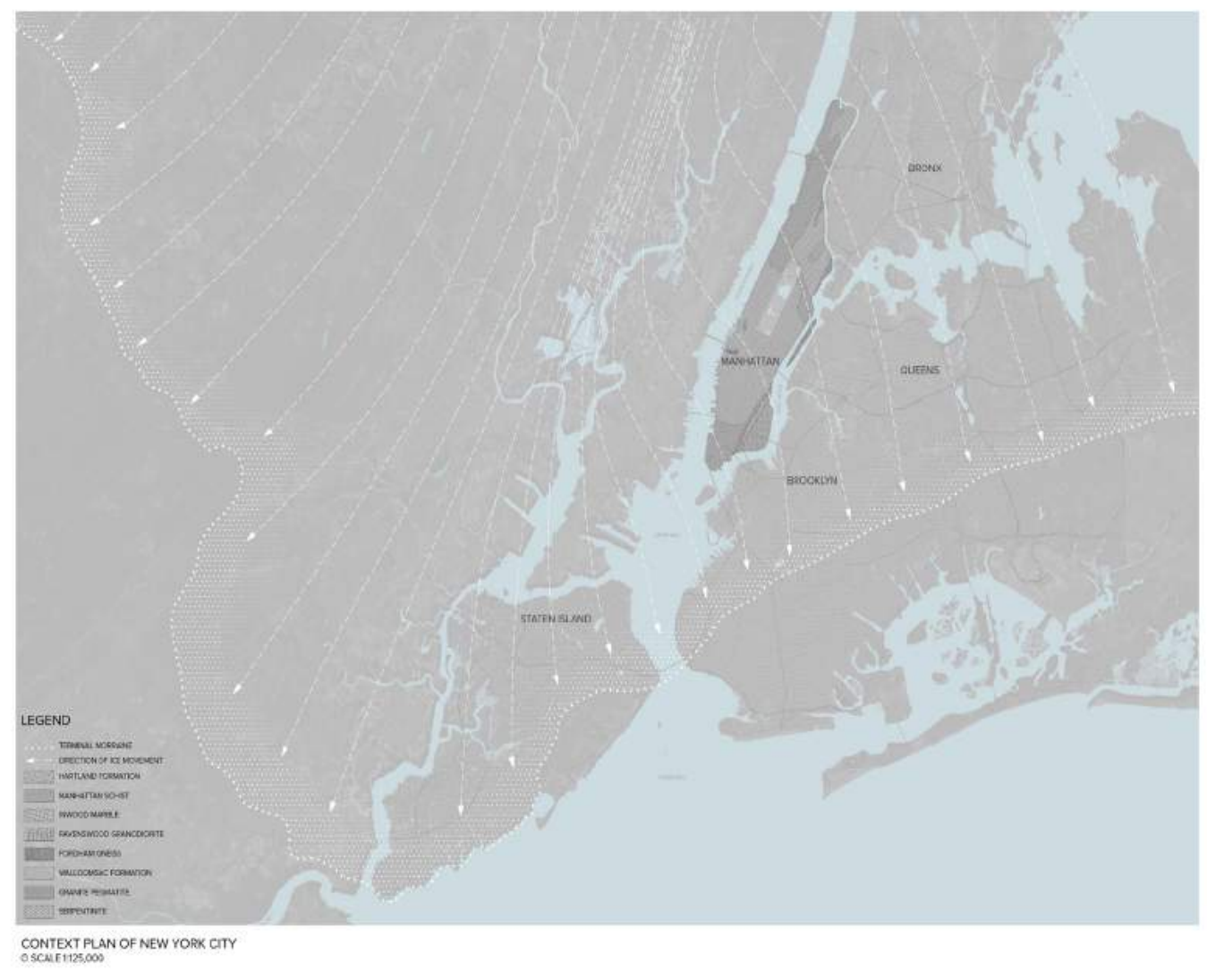

Site plan of New York City layering the geological compositon of Manhattan and the Laurentide ice sheet 


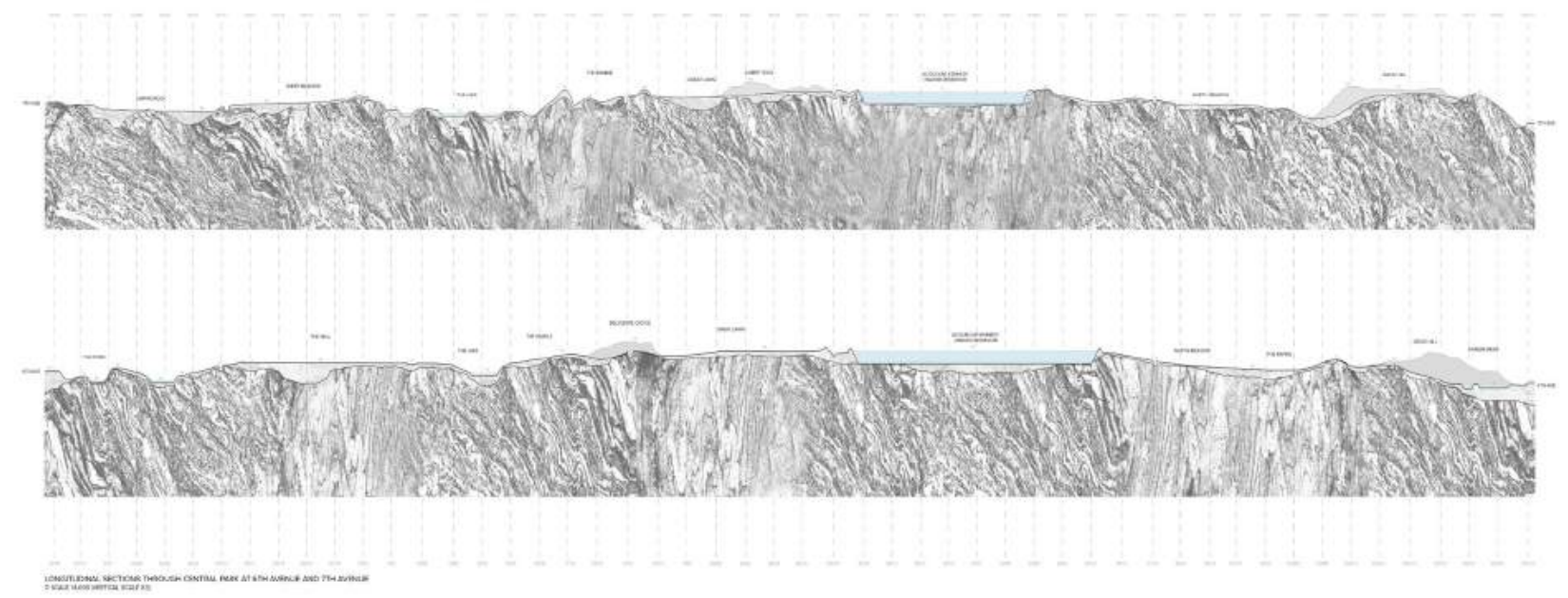

Longitudinal sections through Central Park at 6th and 7th Ave.

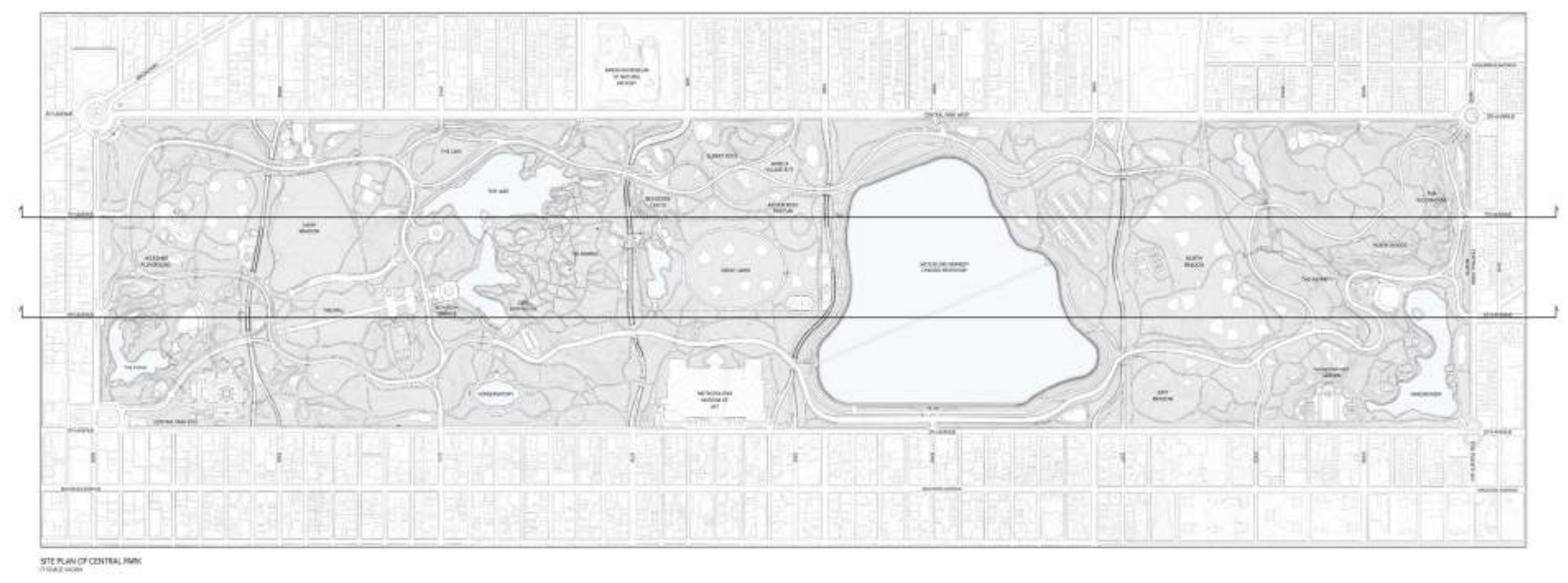

Plan of Central Park 


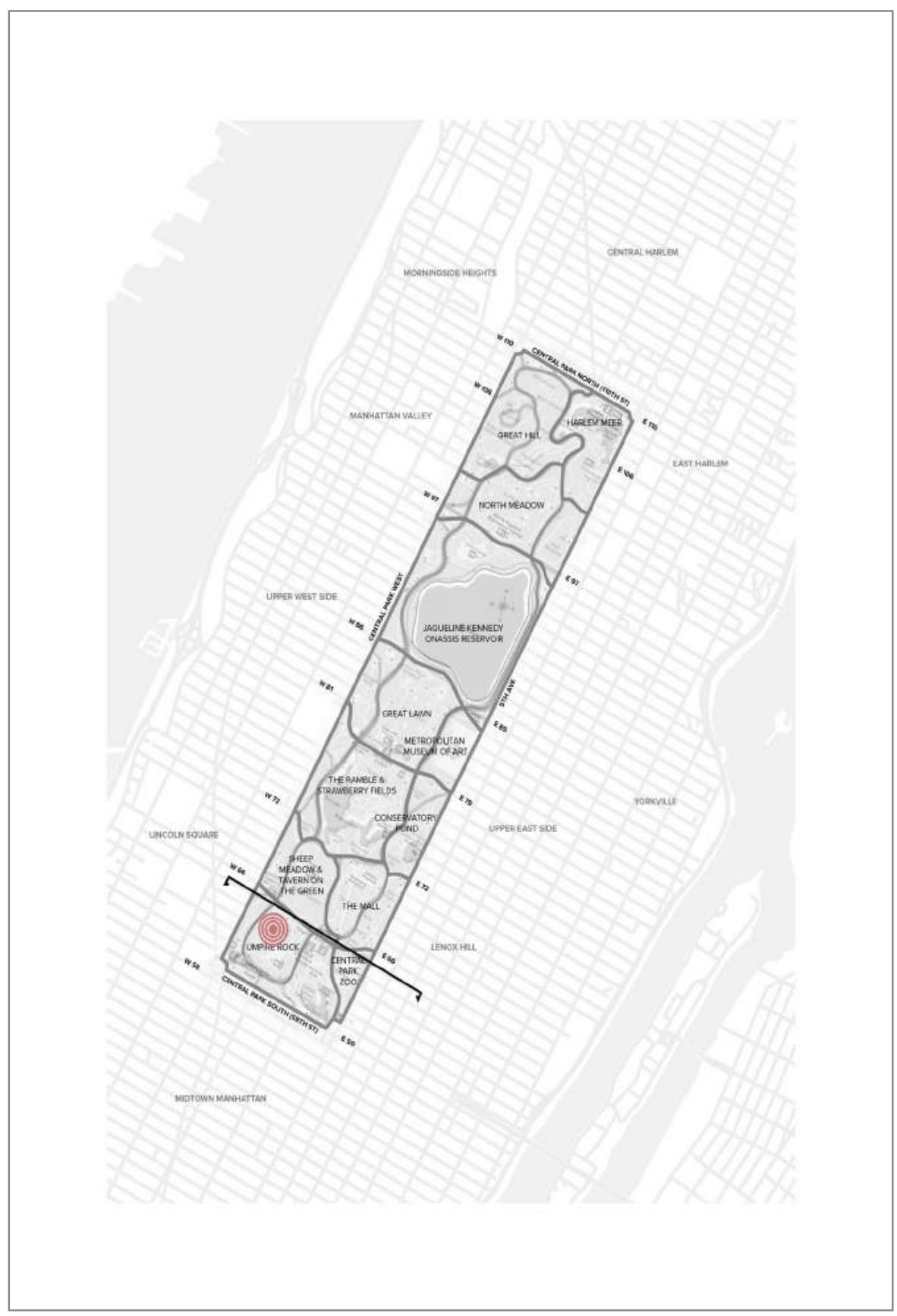

Vertical transect at UmpireRock in Central Park 


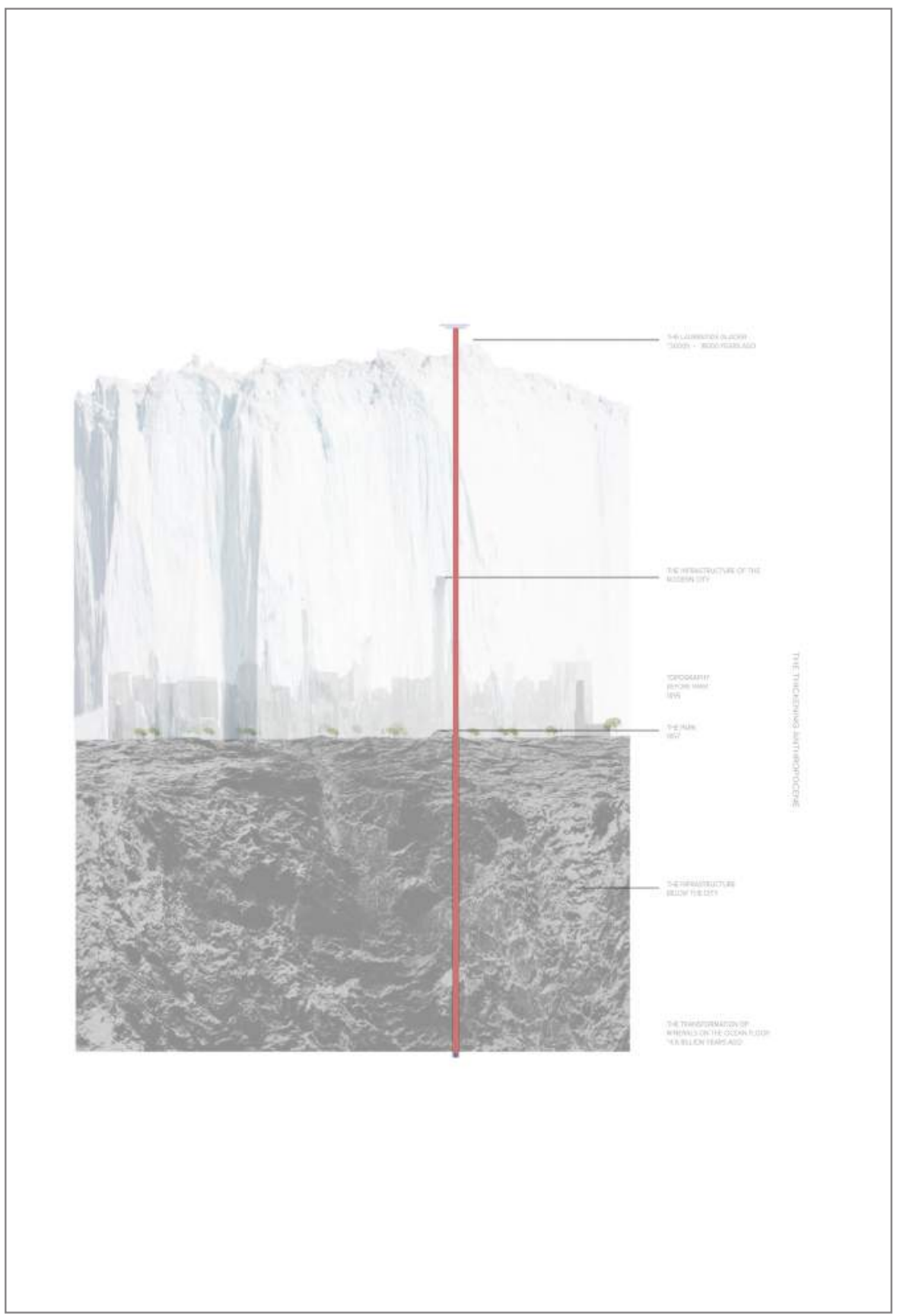

Section through Central Park denoting conceptula strata and time scales 


\begin{tabular}{|c|c|c|c|c|}
\hline & Vertical Transect & & & \\
\hline \multirow[t]{2}{*}{ No } & Title & Year & Altitude & Notes \\
\hline & $4.5 \mathrm{~b}$ years in the making & & & \\
\hline & 4. & & & \\
\hline 1 & Exosphere & & $>400 \mathrm{~km}$ & \\
\hline 2 & Thermosphere & & $400 \mathrm{~km}$ & \\
\hline 3 & Karman Line & & $100 \mathrm{~km}$ & Imaginary boundary \\
\hline 4 & Mesosphere & & $50 \mathrm{~km}$ & \\
\hline 5 & Stratosphere & & $30 \mathrm{~km}$ & \\
\hline 6 & Ozone layer & & $15-35 \mathrm{~km}$ & \\
\hline 7 & Troposphere & & $10 \mathrm{~km}$ & \\
\hline & & & & \\
\hline 8 & Laurentide glacier & 18000 years ago & $609.6 \mathrm{~m}$ & \\
\hline & & & & \\
\hline 9 & One World Tade Center & 2014 & $541 \mathrm{~m}$ & Tallest Building in the City \\
\hline 10 & Empire State Building & 1931 & $381 \mathrm{~m}$ & $\begin{array}{l}\text { First building in the world to reach } \\
\text { over } 100 \text { floors }\end{array}$ \\
\hline 11 & Chrysler Building & 1930 & $319 m$ & First building to reach above $1000 \mathrm{ft}$ \\
\hline 12 & Historic max at Umpire rock & & $25 \mathrm{~m}$ & \\
\hline & & & & \\
\hline 13 & $\begin{array}{l}\text { Glass buildings this tall and above must } \\
\text { have a pattern to help prevent birds from } \\
\text { flying into them }\end{array}$ & & $22 \mathrm{~m}$ & \\
\hline 14 & Historic Average at Umpire rock & & $20 \mathrm{~m}$ & \\
\hline 15 & $\begin{array}{l}\text { Datum - max six storey height before water } \\
\text { tank is needed }\end{array}$ & & $19 \mathrm{~m}$ & \\
\hline 16 & Historic min at Umpire rock & & $13 \mathrm{~m}$ & \\
\hline 17 & Average change in elevation & & $150 \mathrm{~cm}$ & Levelling of the ground \\
\hline 18 & The 'ground' today & 2021 & $\theta$ & $10 \mathrm{~m}$ above sea level \\
\hline 19 & Asphalt & & $-7.6 \mathrm{~cm}$ & \\
\hline & Coarse concrete & & $-25.4 \mathrm{~cm}$ & \\
\hline & Thin layer of absorbant soil & & $-30.5 \mathrm{~cm}$ & \\
\hline 20 & $\begin{array}{l}\text { Wires: telephone, electric, cable, encased } \\
\text { and buried under street curbs }\end{array}$ & & $-38.1 \mathrm{~cm}$ & \\
\hline 21 & gas lines funnel fuel across the city & & $-61 \mathrm{~cm}$ & \\
\hline 22 & $\begin{array}{l}\text { watermains bring water from catskill and } \\
\text { delaware watersheds and croton reservoir }\end{array}$ & & $-1.2 \mathrm{~m}$ & \\
\hline 23 & pneumonic mail tubes & 1897 & $-1.2 \mathrm{~m}$ & \\
\hline 24 & $\begin{array}{l}\text { steam pipes covered in aesbestos - to heat } \\
\text { and cool buildings }\end{array}$ & & $-1.8 \mathrm{~m}$ & \\
\hline 25 & $\begin{array}{l}\text { mysteriously mirrored room @ bowery and } \\
\text { canal }\end{array}$ & & $-1.8 \mathrm{~m}$ & \\
\hline 26 & $\begin{array}{l}\text { sewage pipes - installed around the vaults } \\
\text { of subway tunnels }\end{array}$ & & $-2.1 \mathrm{~m}$ & \\
\hline 27 & subways vary in depth between & & $-3 m--54.9 m$ & \\
\hline 28 & shipwrecked boat in the mud under broad st & $1600 \mathrm{~s}$ & $-4.6 \mathrm{~m}$ & \\
\hline 29 & tunnels under chinatown & $1800 \mathrm{~s}$ & $-6.1 \mathrm{~m}$ & \\
\hline & & & & \\
\hline 30 & Sea level & & $-10 \mathrm{~m}$ & \\
\hline 31 & $\begin{array}{l}\text { Lower east side, six lane highways, start } \\
\text { of Lomex (abandoned lower east side } \\
\text { express project) }\end{array}$ & 1960s & $-15.2 \mathrm{~m}$ & \\
\hline & & & & \\
\hline 32 & depth of east river & & $-51 m$ & \\
\hline 33 & depth of hudson river & & $-62 m$ & \\
\hline 34 & & 1935 & $-182.9 \mathrm{~m}$ to $-243.8 \mathrm{~m}$ & \\
\hline $\begin{array}{l}34 \\
35\end{array}$ & $\begin{array}{l}\text { first two water tunnels } \\
\text { third water tunnel }\end{array}$ & $\begin{array}{l}1935 \\
\text { pending }\end{array}$ & $\begin{array}{l}-182.9 m \text { to }-243.8 m \\
-243.8 m\end{array}$ & \\
\hline & & & & \\
\hline 36 & Earth's Crust & & $-100 \mathrm{~km}$ & \\
\hline 37 & Upper Mantle & & $-700 \mathrm{~km}$ & \\
\hline 38 & Lower Mantle & & $-2885 \mathrm{~km}$ & \\
\hline 39 & Outer Core & & $-5155 \mathrm{~km}$ & \\
\hline 40 & Inner Core & & $-6371 \mathrm{~km}$ & \\
\hline & & & & \\
\hline & $4.5 \mathrm{~b}$ years in the making & & & \\
\hline
\end{tabular}

List of human and non human vertical layers in the city (and the Earth) 

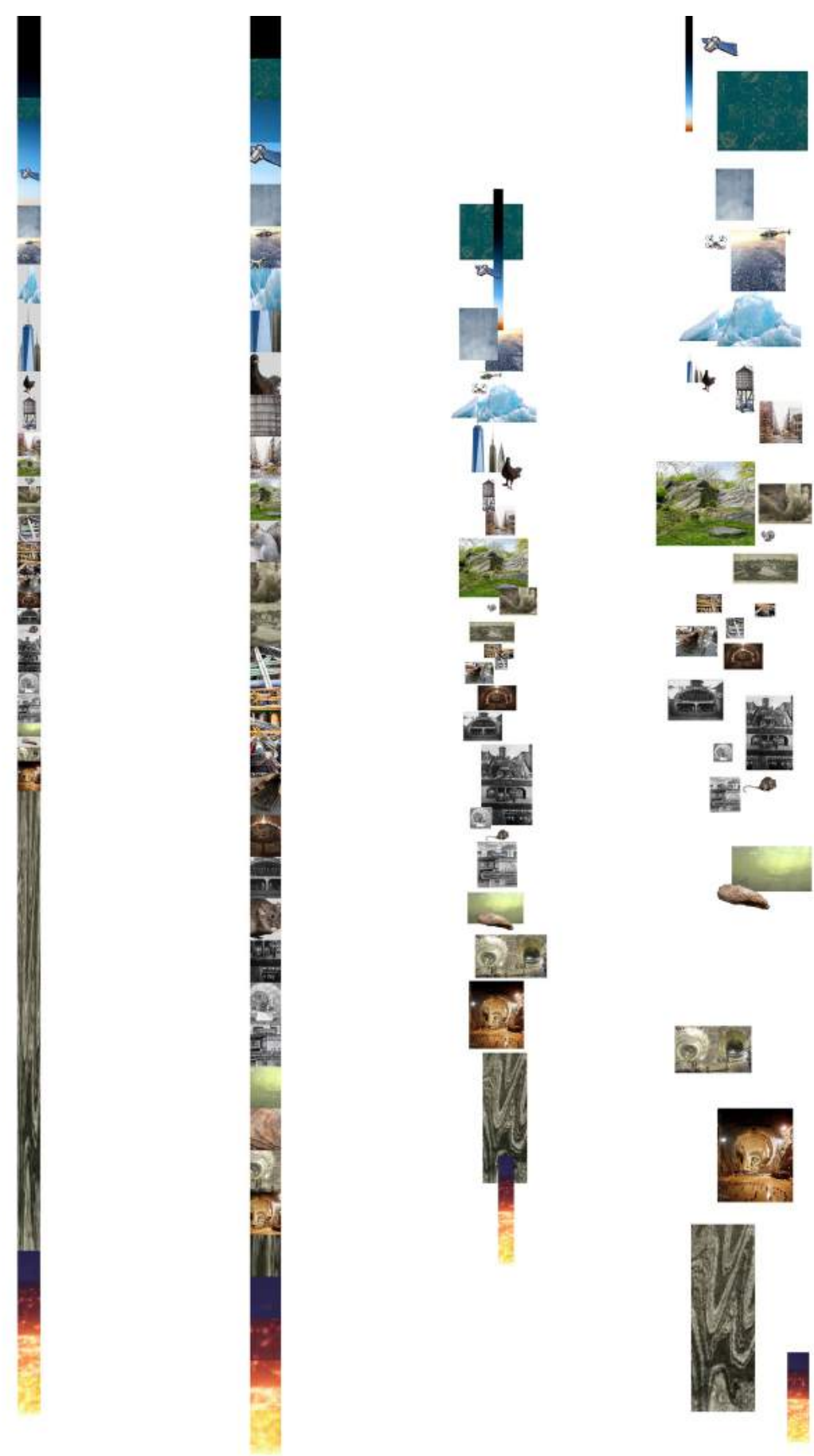

3.
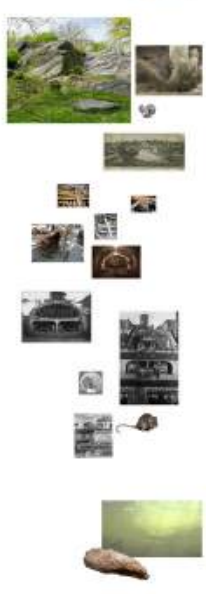

$-$
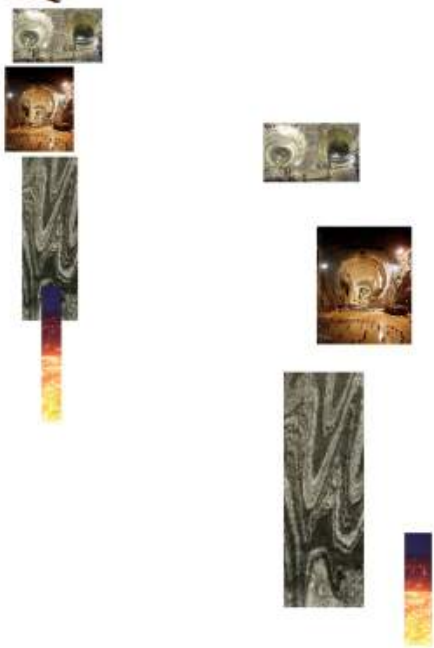

List translated into a series of collages that deconstruct the parameters of a transect and how they may be disrupted 


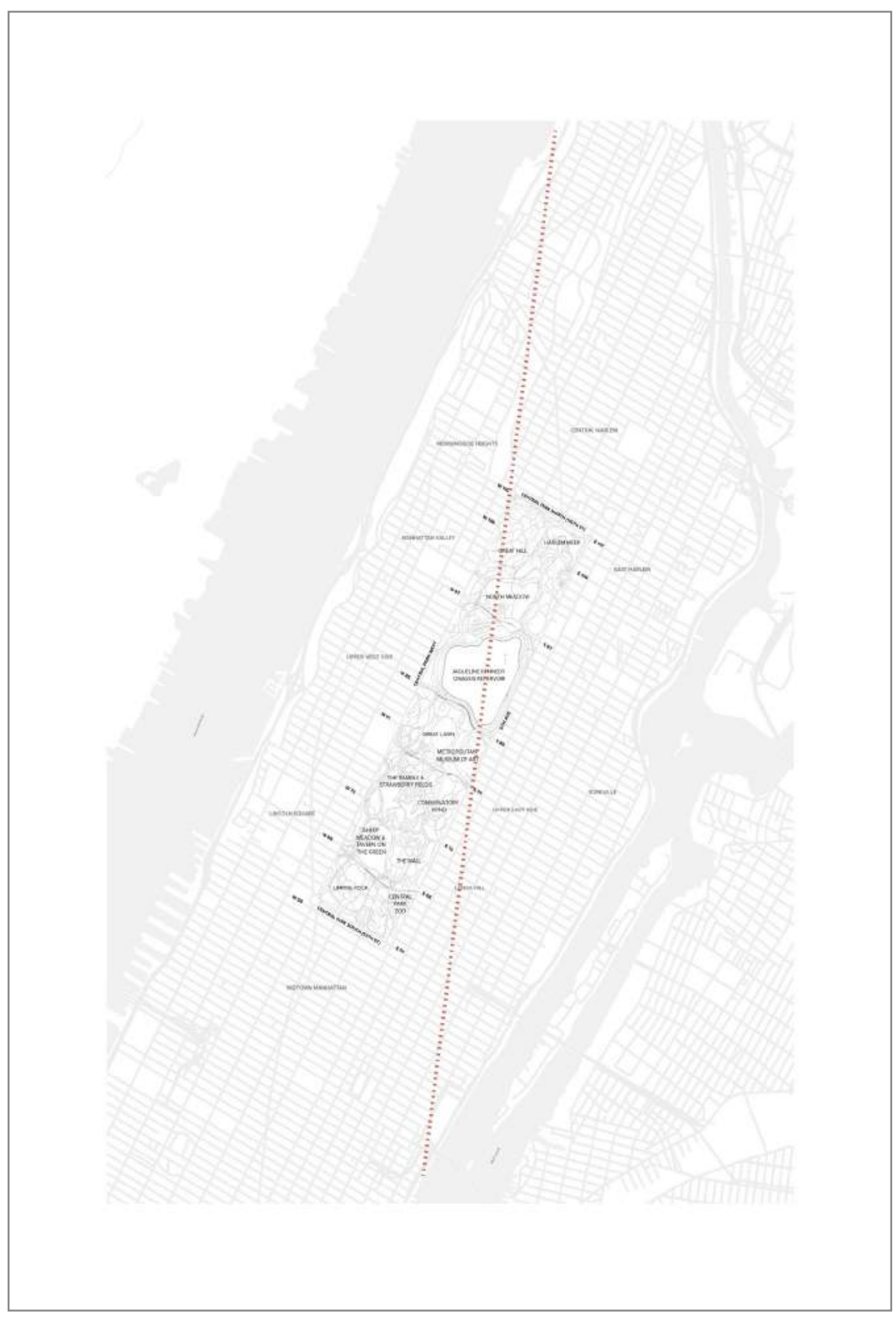

Plan of horizontal transect connecting the Hudson River and the East River 


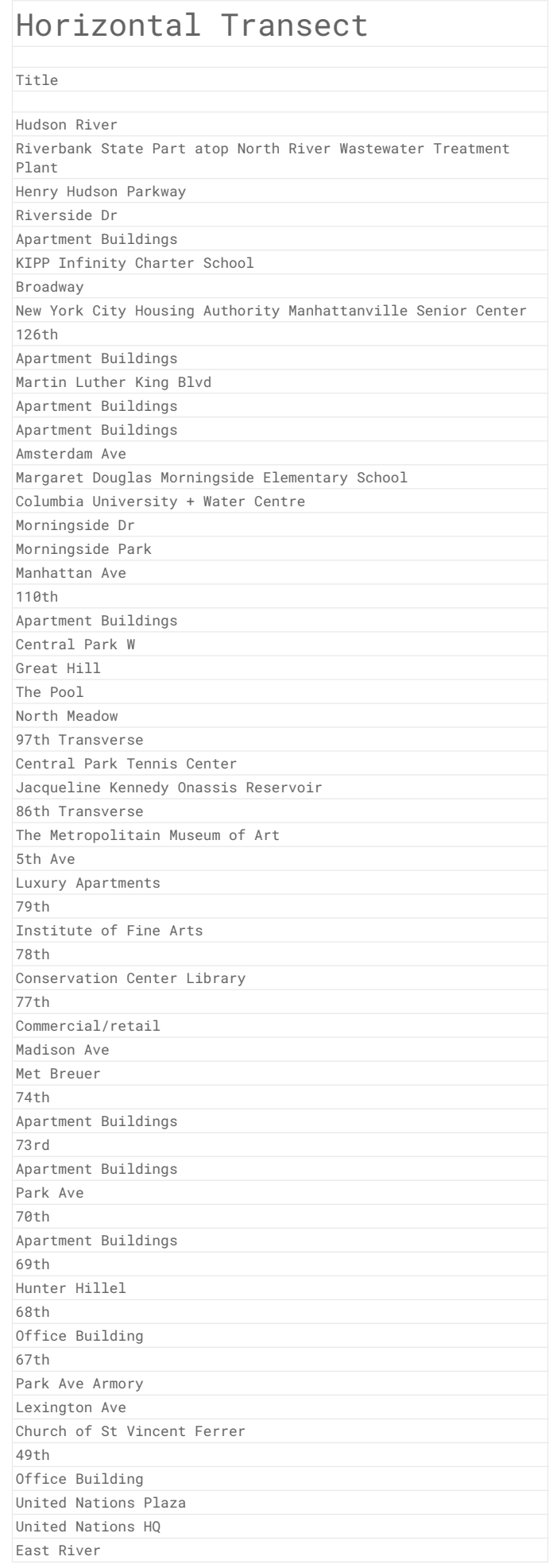

List of buildings and infrastructure located along the horizontal transect 


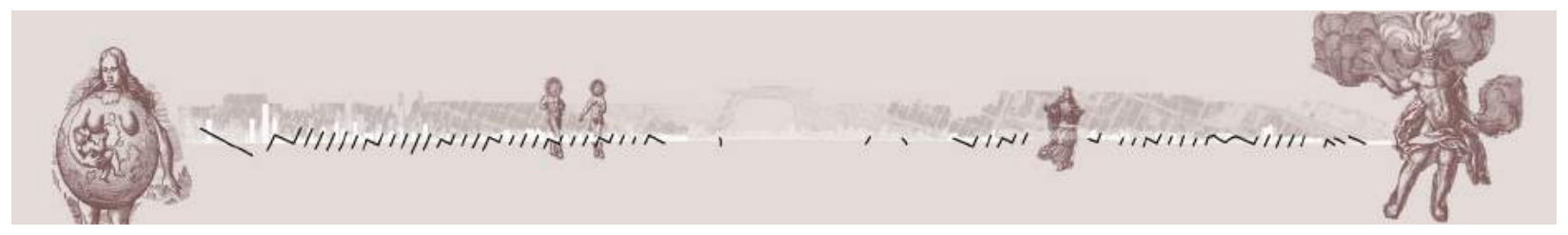

Section collage analyzing the rhythmic register of the grid as it intersects the horizontal transect

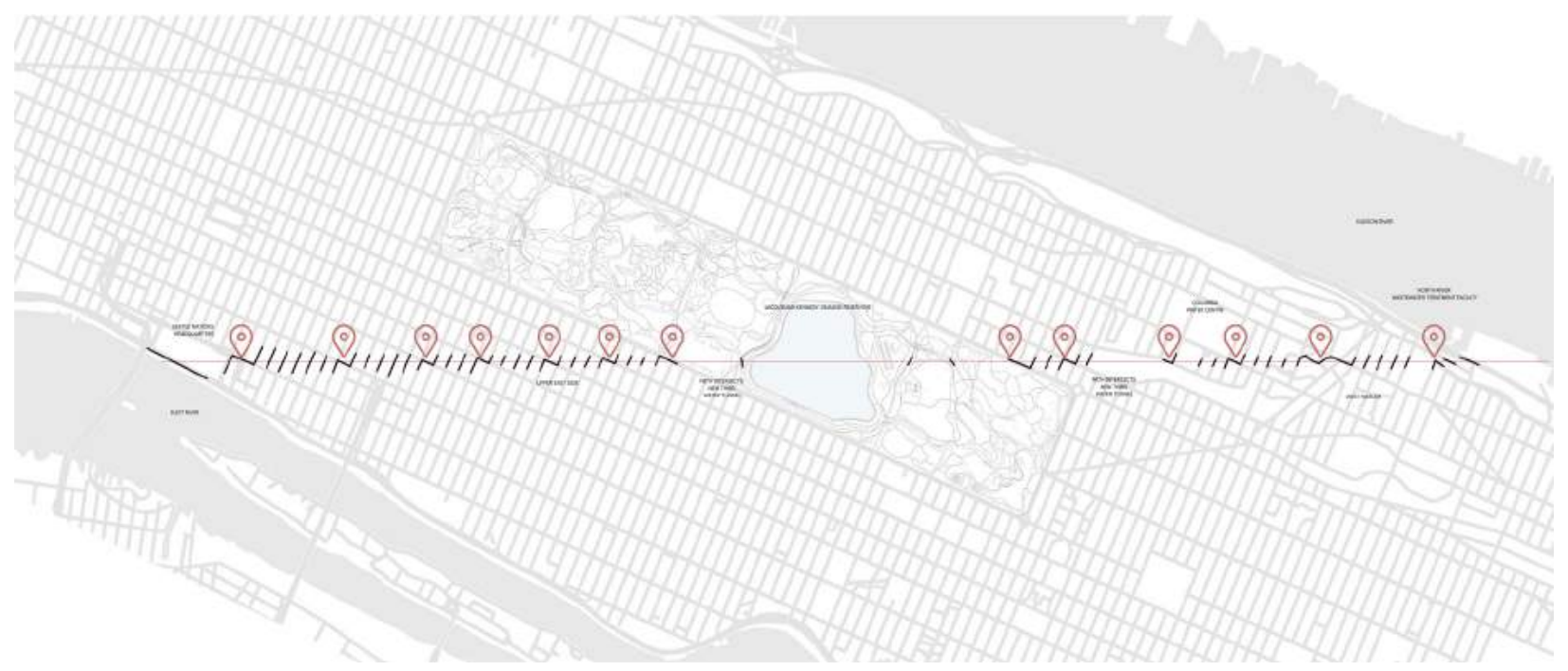

Plan analyzing the rhymic register of the grid as it intersects the horizontal transect 


\section{APPENDIX B: IDEOGRAMS}

The ideograms produced were inspired by the work of Douglas Darden and served as micro-memory palaces within the research project.

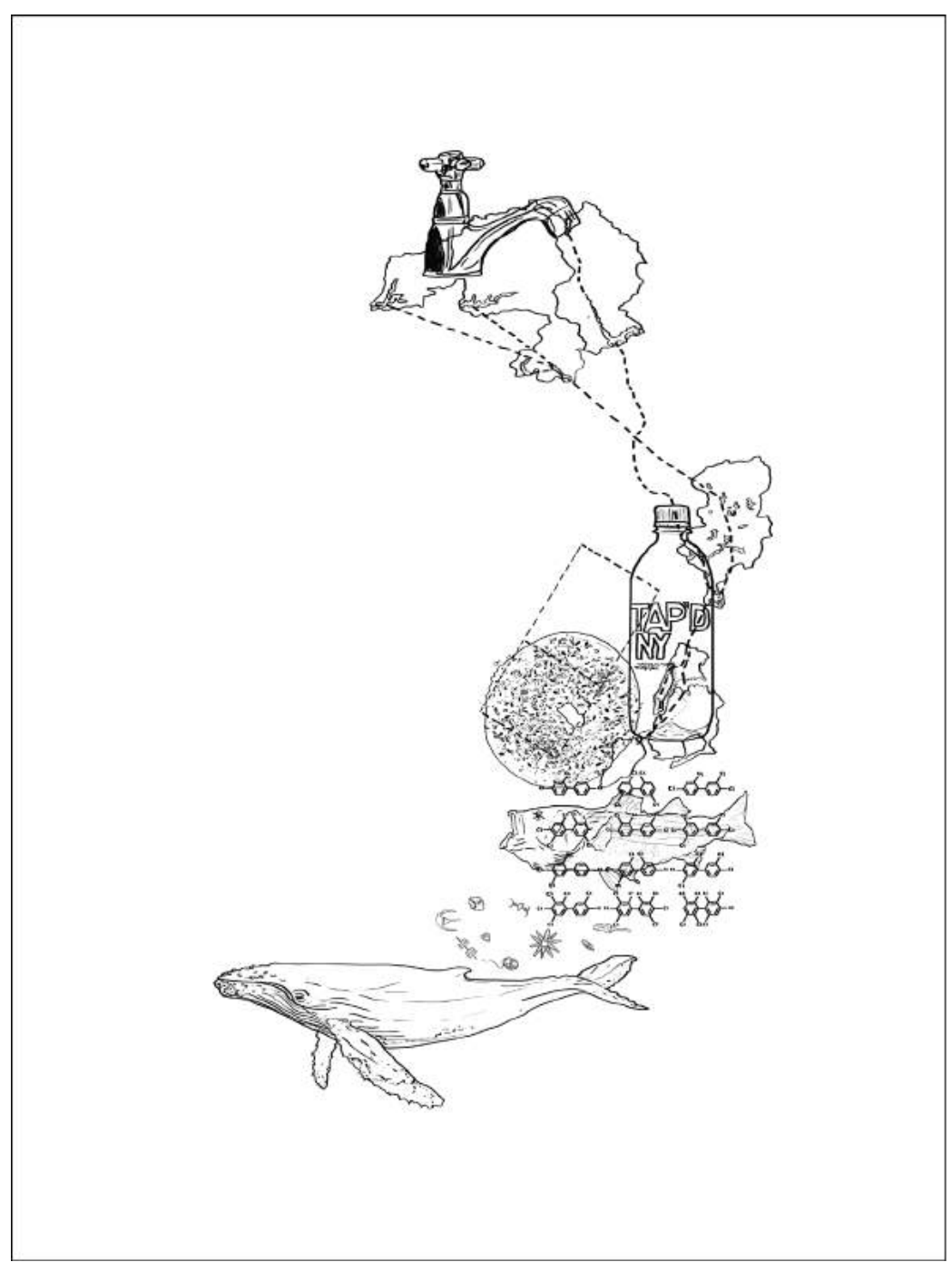

Ideogram 1: New York and Water 

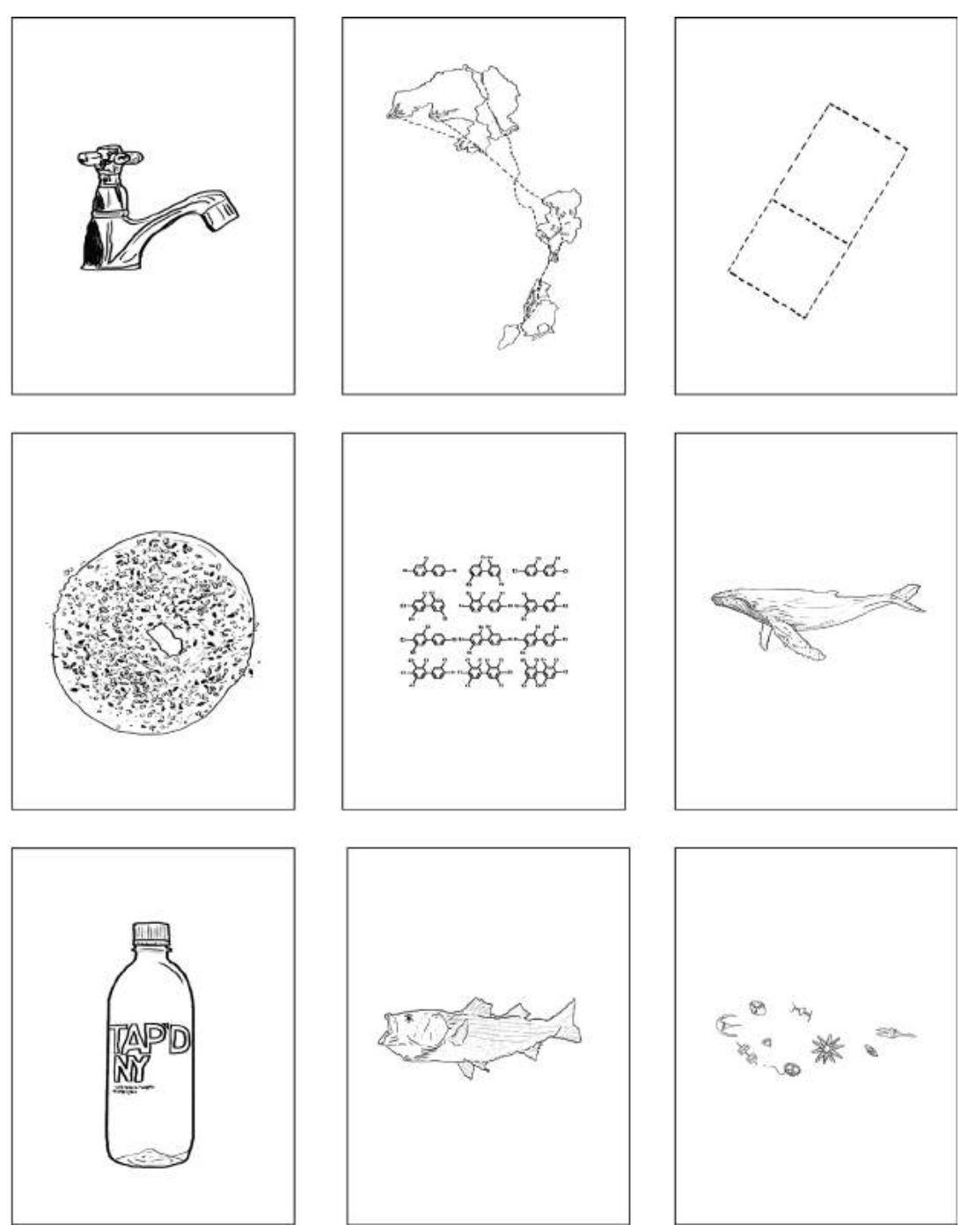

Ideogram 1: New York and Water research fragments 


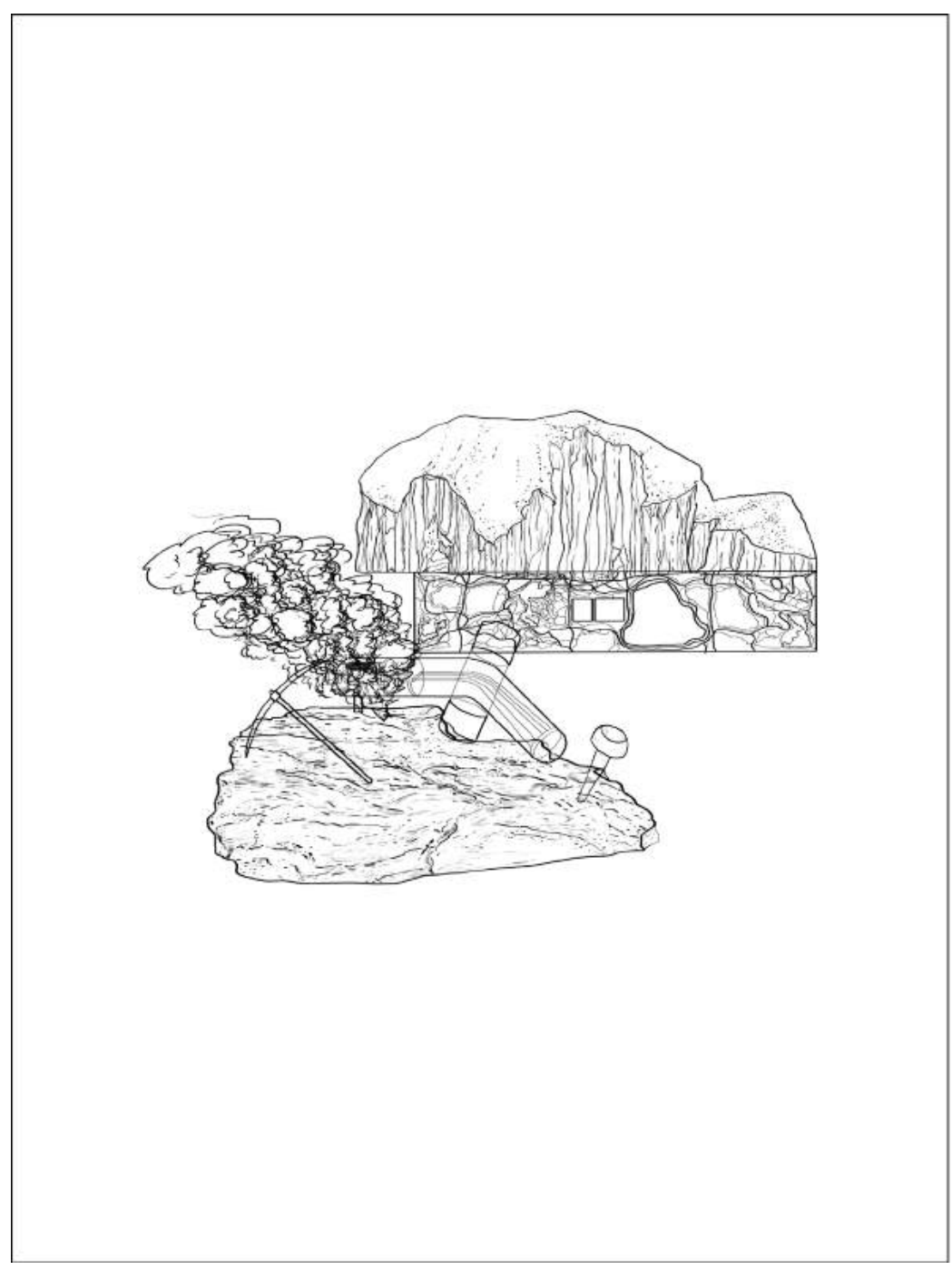

Ideogram 2: New York and the Ground 

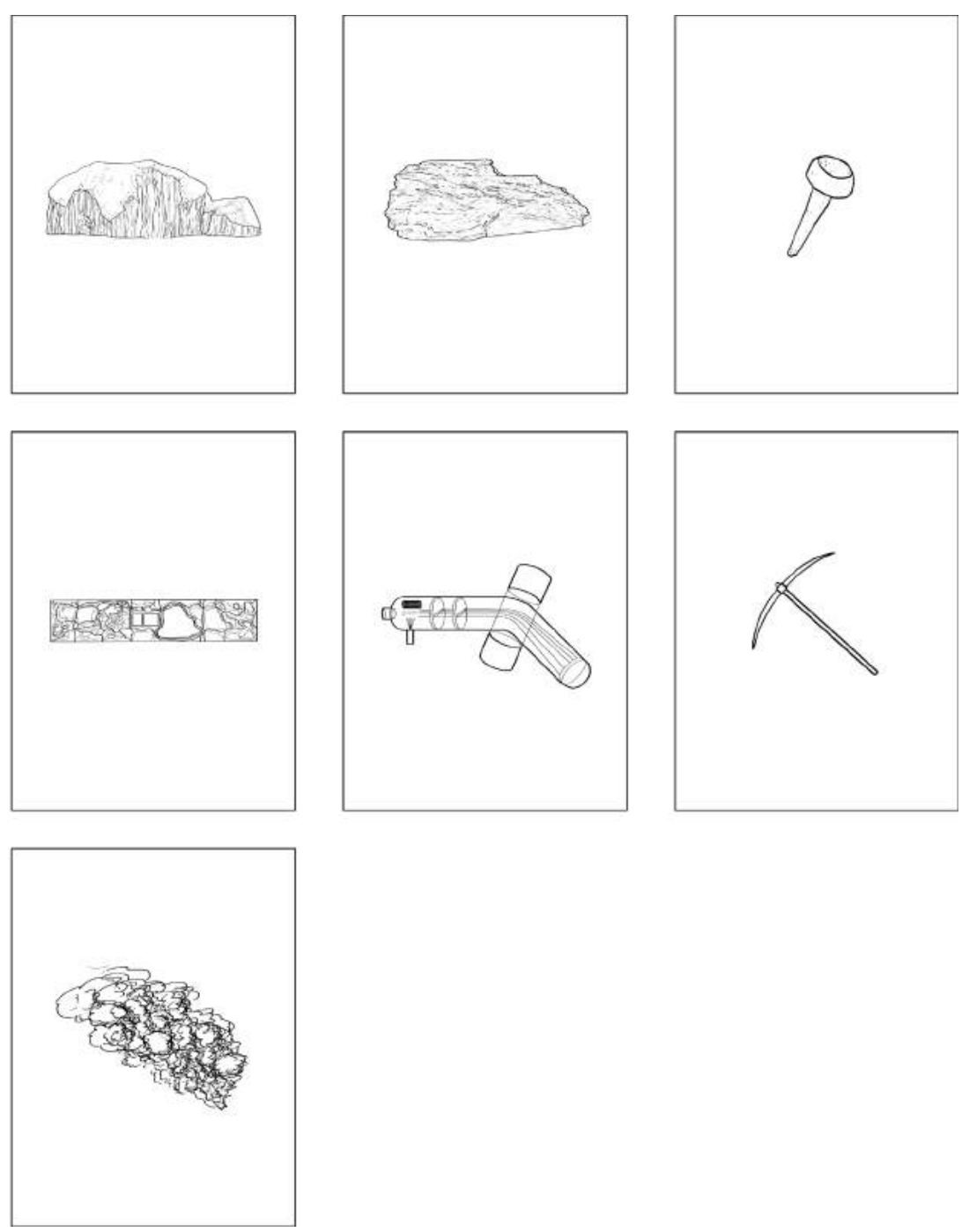

Ideogram 2: New York and the Ground research fragments 


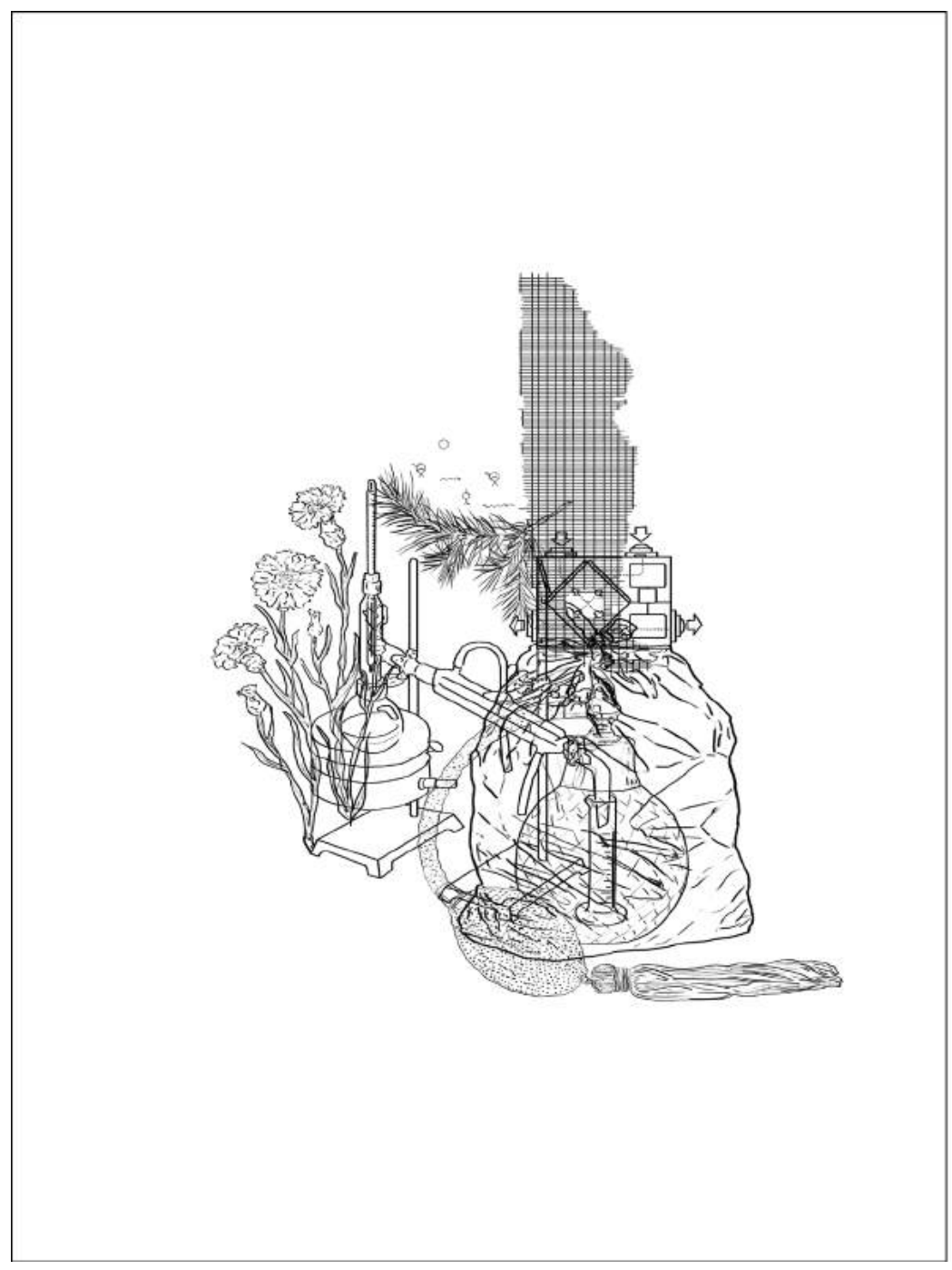

Ideogram 3: New York and the Air 

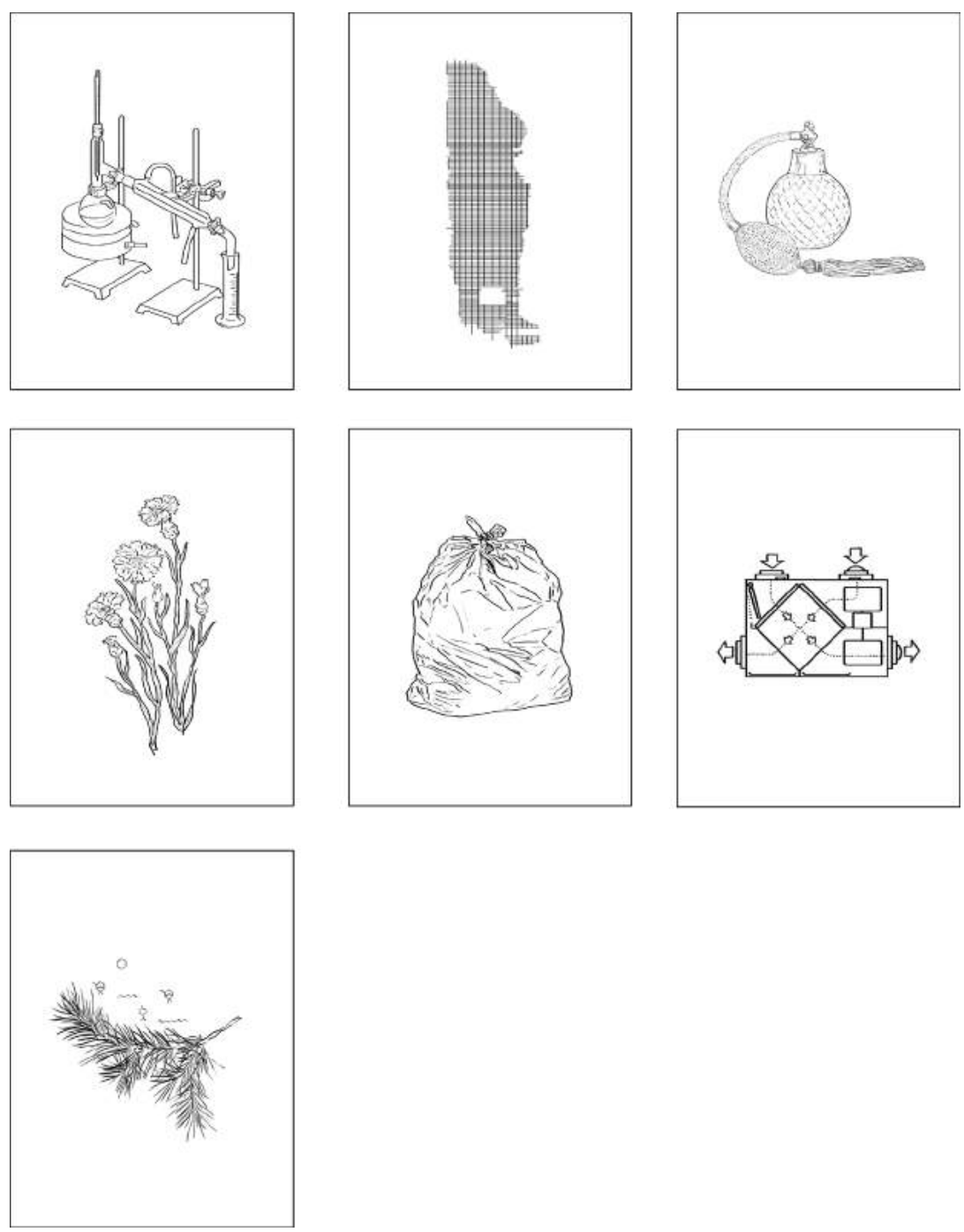

Ideogram 3: New York and the Air research fragments 


\section{APPENDIX C: TANK WORLD MODELS COLLECTING (SUB)NATURE}

This supplementary project was completed for the Graduate Seminar Course, Miniaturizing the Gigantic, instructed by Professor Lisa Moffitt.

This project frames the device of the tank as a vitrine to explore the agency, selectivity and control of human collectors as well as to study the attributes and practices of memorializing artifacts that evoke memories. The vitrines are contemplated as devices of objectification, exploring their relationship with the found objects that are placed within them. David Gissen's, A More Monumental, Non-Naturalistic Environment, contemplates acts of memorializing nature through abstract representation. Enter the vitrines.

The vitrines engage various scales, acknowledging that they contain miniature worlds while also making evident the worlds that lie beyond their control. The selected artifacts provoke our human agency in the process of collecting. They ask us to confront our inconsistent behaviours and attitudes about objects of nature as we oscillate between controlled delight and untamed disgust. The photographic representations of the work contrast the ordered and pristine world of the vitrines (romantic naturalism) with the messy reality of the world that overtakes them (subnaturalism). The characteristics of the vitrines themselves are challenged as their imperfections are revealed. 
Gissen's work, Subnature: Architecture's Other Environments, elaborates on how the nonhuman worlds that surround our everyday are selectively celebrated as beautiful and delightful, while other worlds, forms, and objects are deemed ugly and displeasing and are therefore erased from our consideration and design thinking. These outcasts are what Gissen identifies as 'subnatures' and they constitute the artifacts that the vitrines in this projects ultimately embrace, subverting what we typically observe as subjects of wonderment and joy.

Gissen, David. "A More Monumental, Non-Naturalistic Environment (Pratt Journal).” Pratt School of Architecture Journal, no. Spring (2012), https://www.academia.edu/8168289/A_More_Monumental_Non_Naturalistic_ Environment_Pratt_Journal_. Accessed on March 11, 2021.

Gissen, David. 2009. Subnature: architecture's other environments : atmospheres, matter, life. New York: Princeton Architectural Press. 
part 1
NATURE 


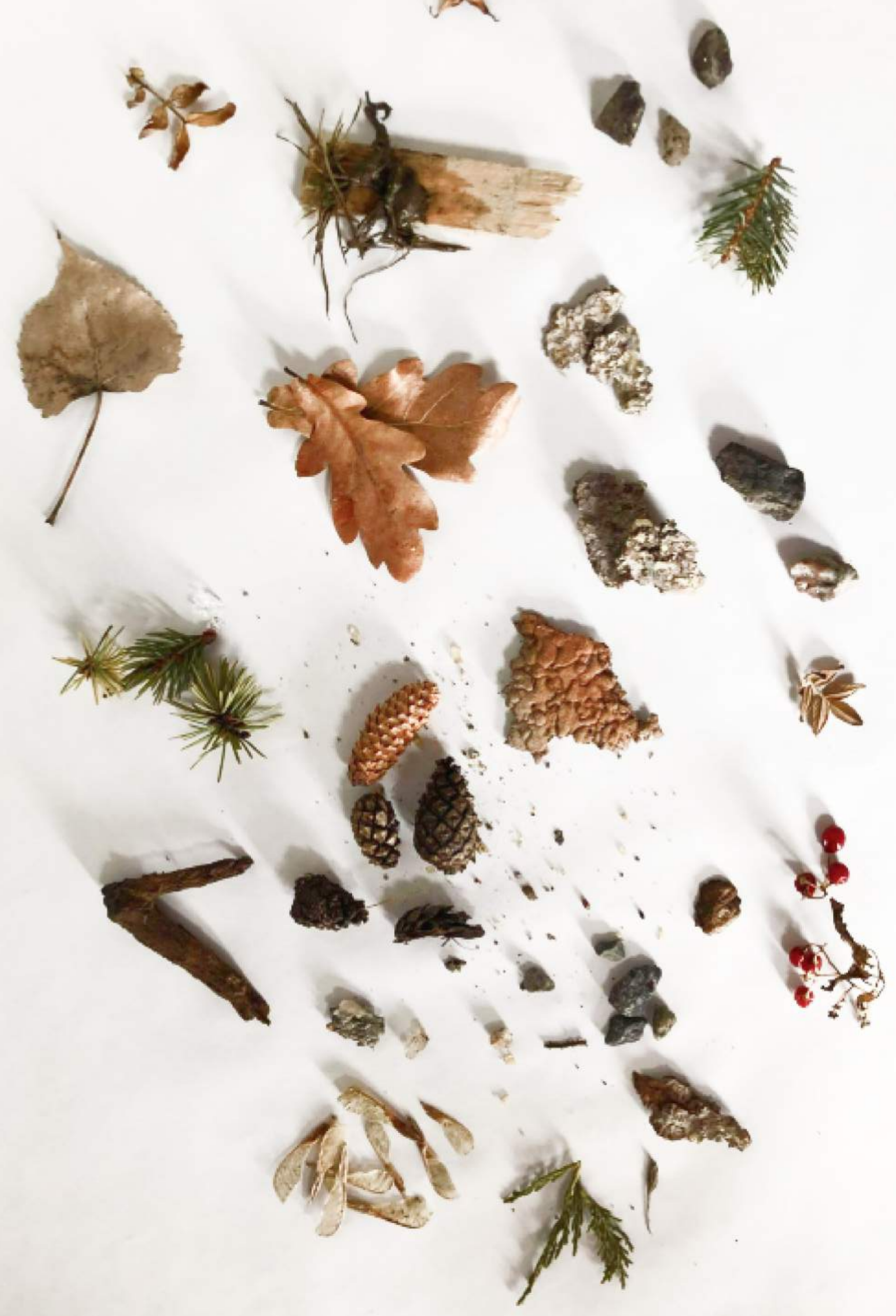

Found artifacts of nature gathered on a walk are carefully placed on the table.

These collected artifacts evoke a sense of romance and delight, perhaps stirring memories of a pleasant hike.

Their beauty is magnified by the saturated image. 

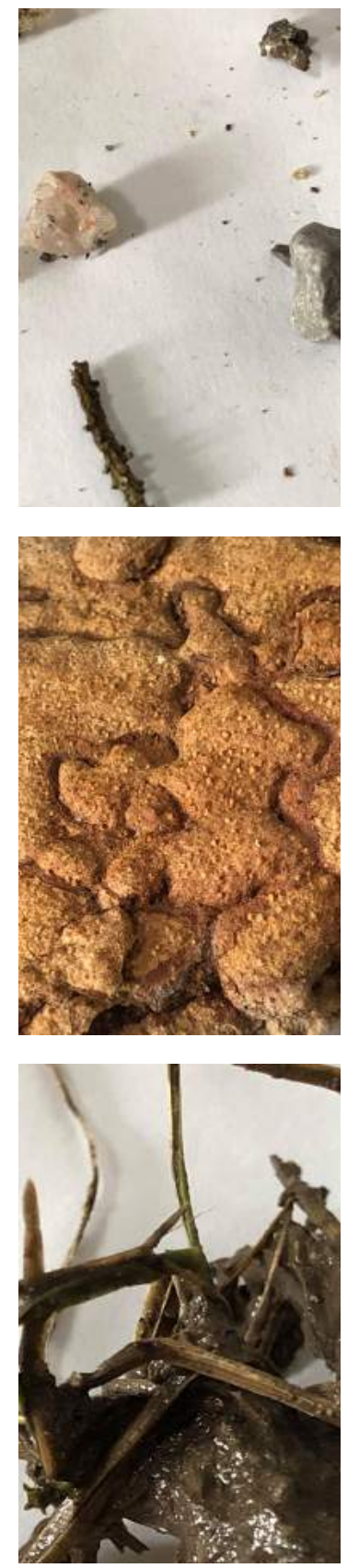

The artifacts are carefully photographed.

They are selectively cropped, descaled and decontextualized.
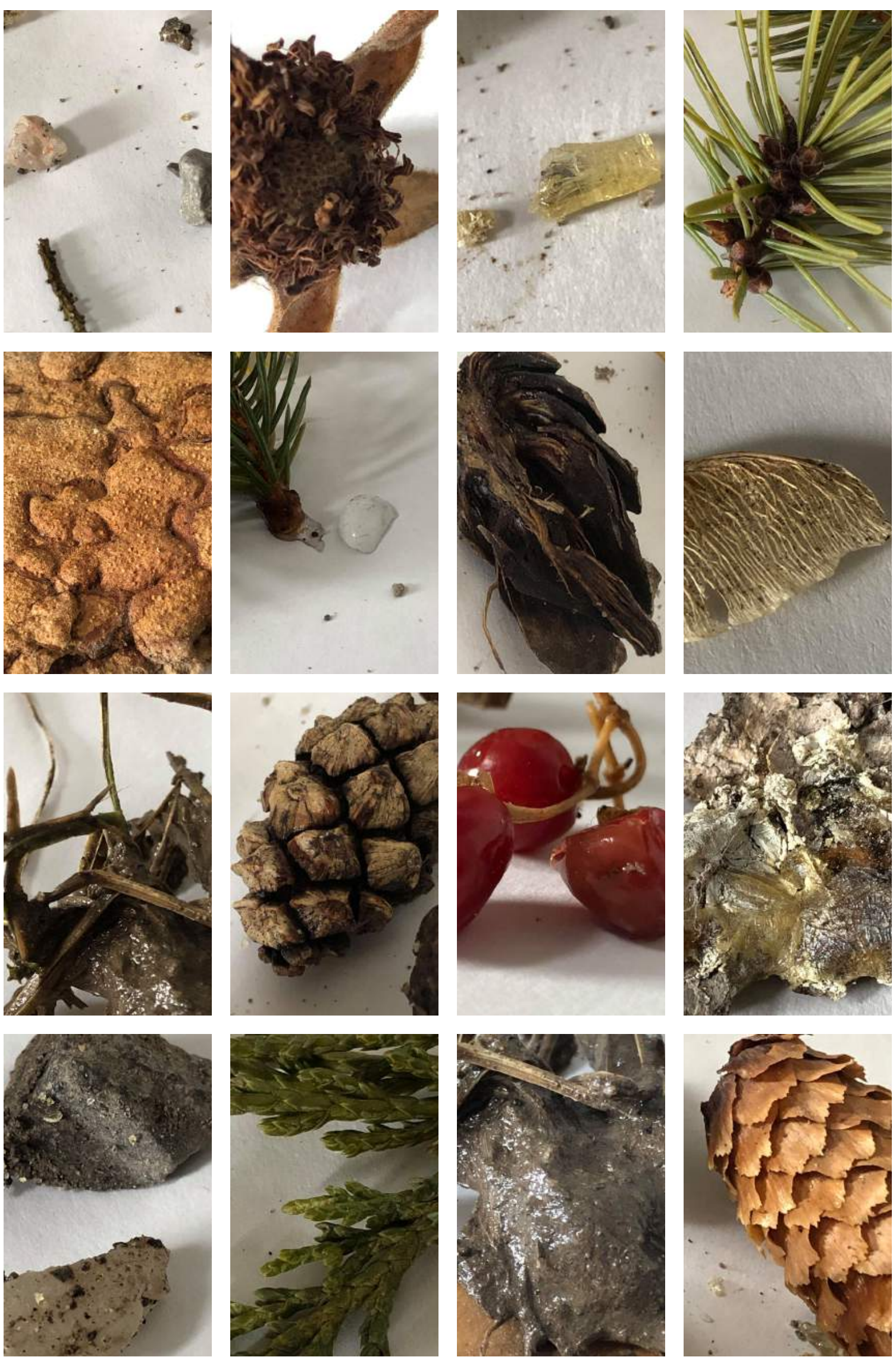

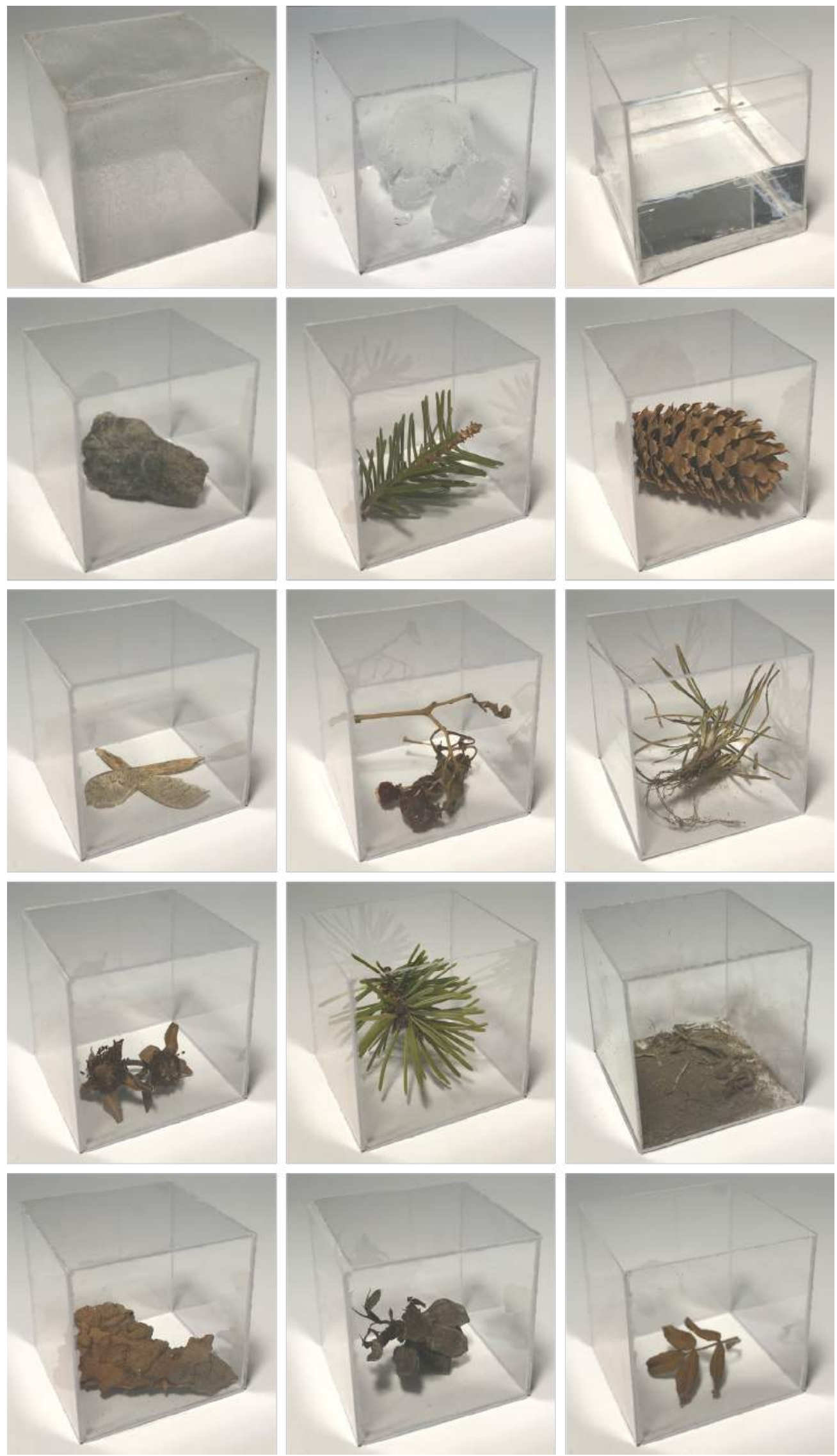

The artifacts are placed in a plexiglass vitrine (miniature tank). Nature is objectified.

Some artifacts are not selected to be displayed, they are omitted.

A pristine photoshoot systematically captures the vitrines satisfying the urge to order and curate. 

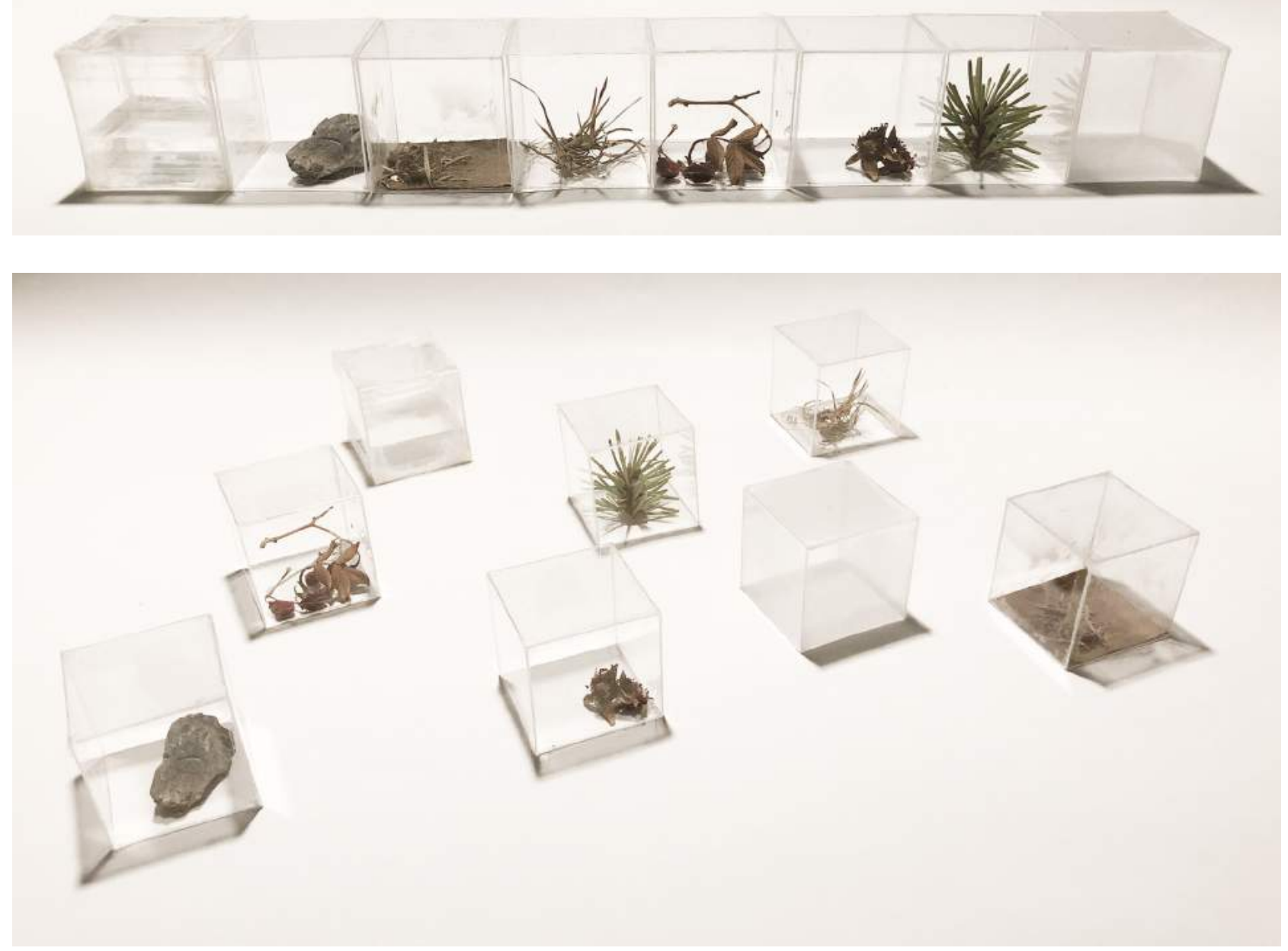

The vitrines are curated into several arrangements, forming a multitude of interpretations and abstract narratives. 

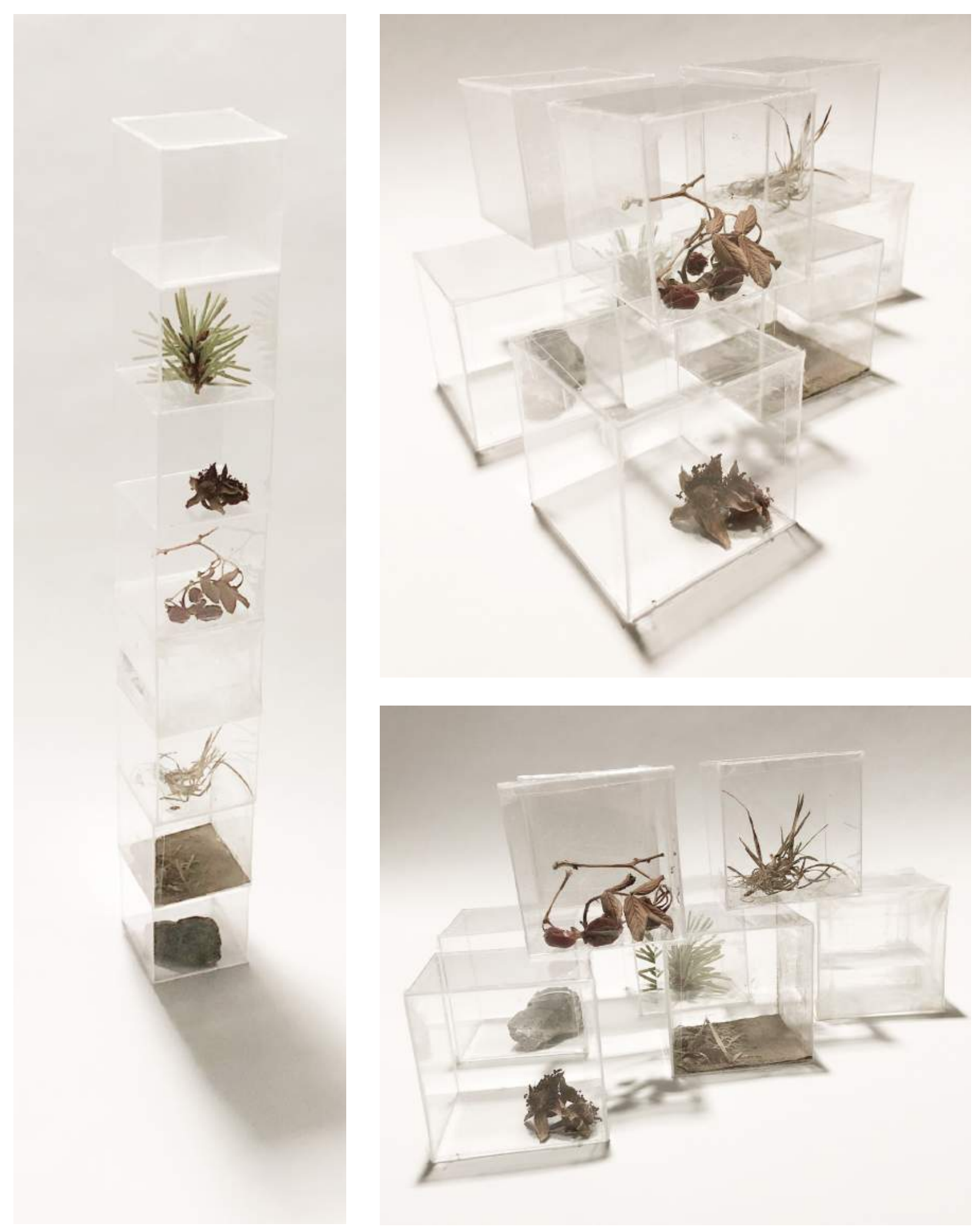

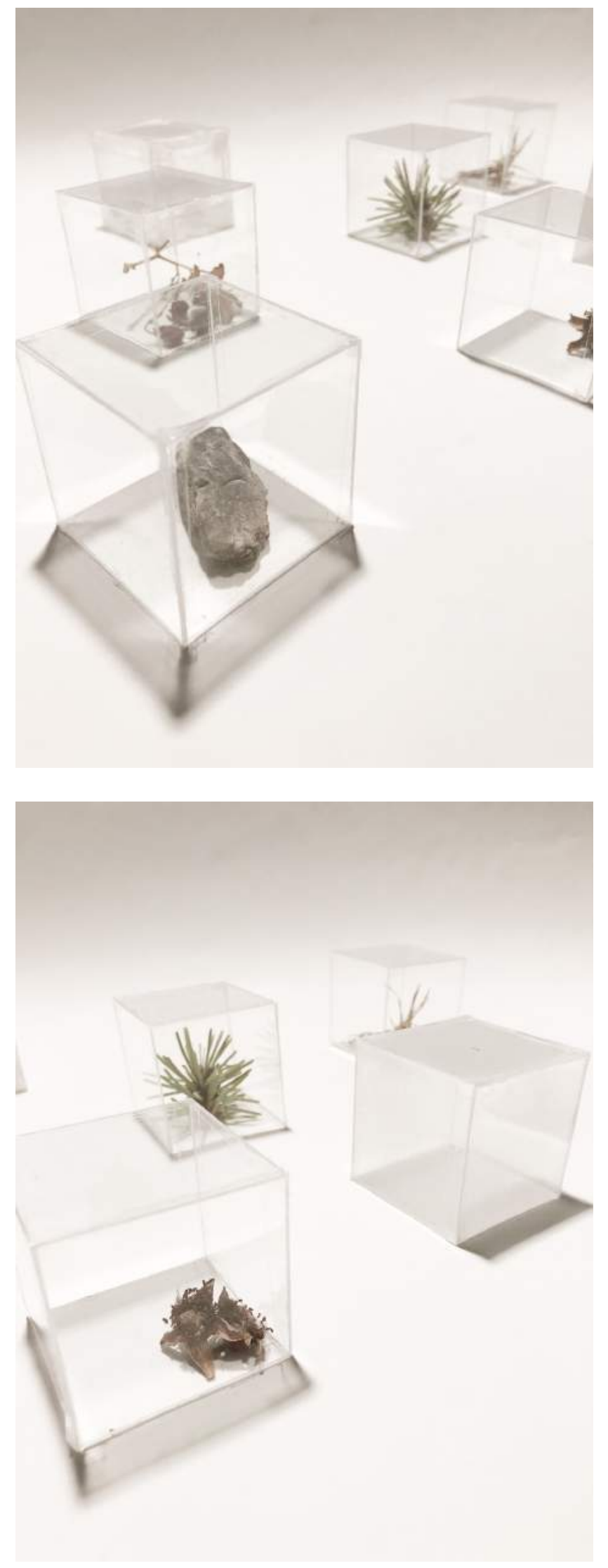

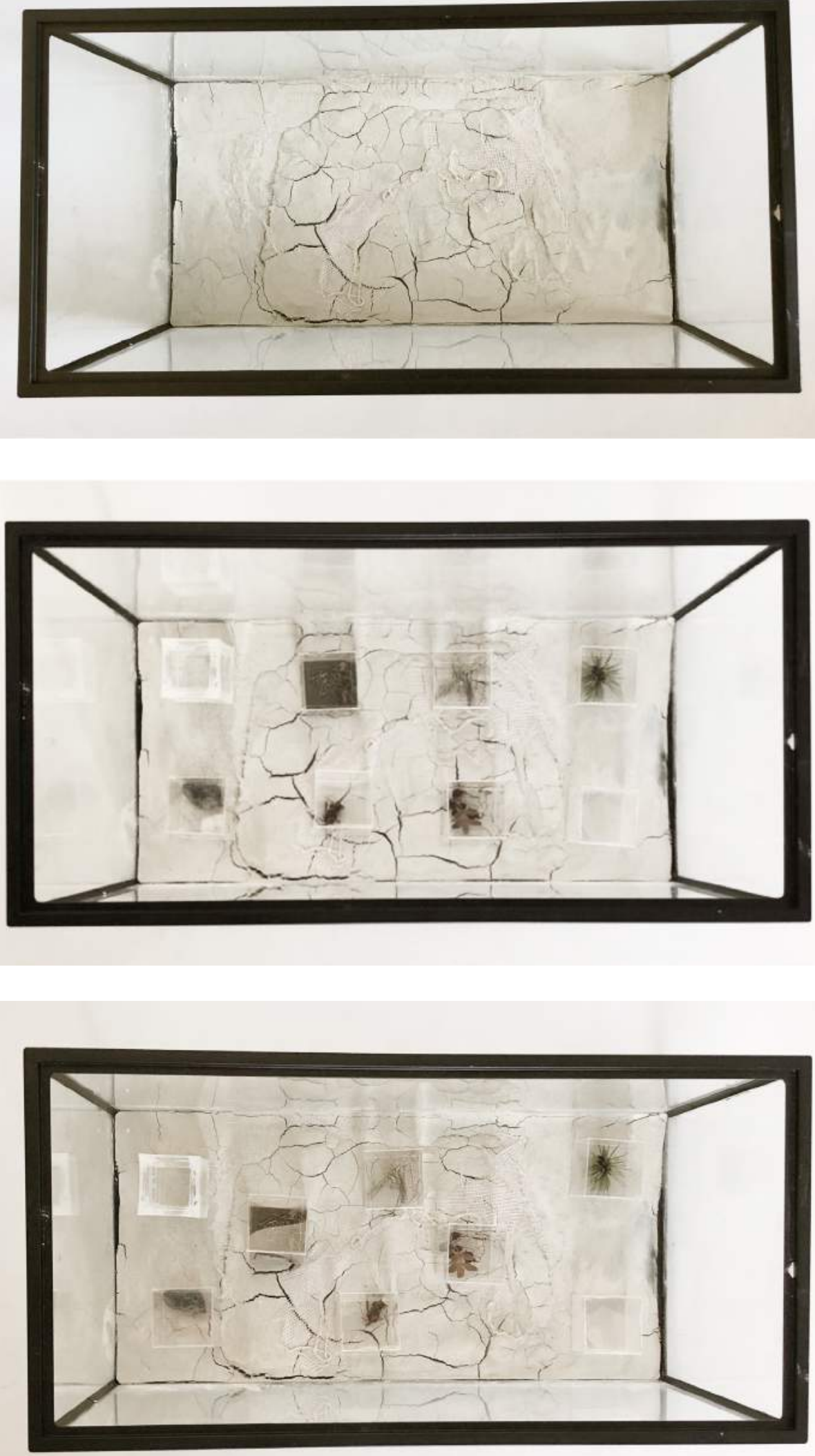

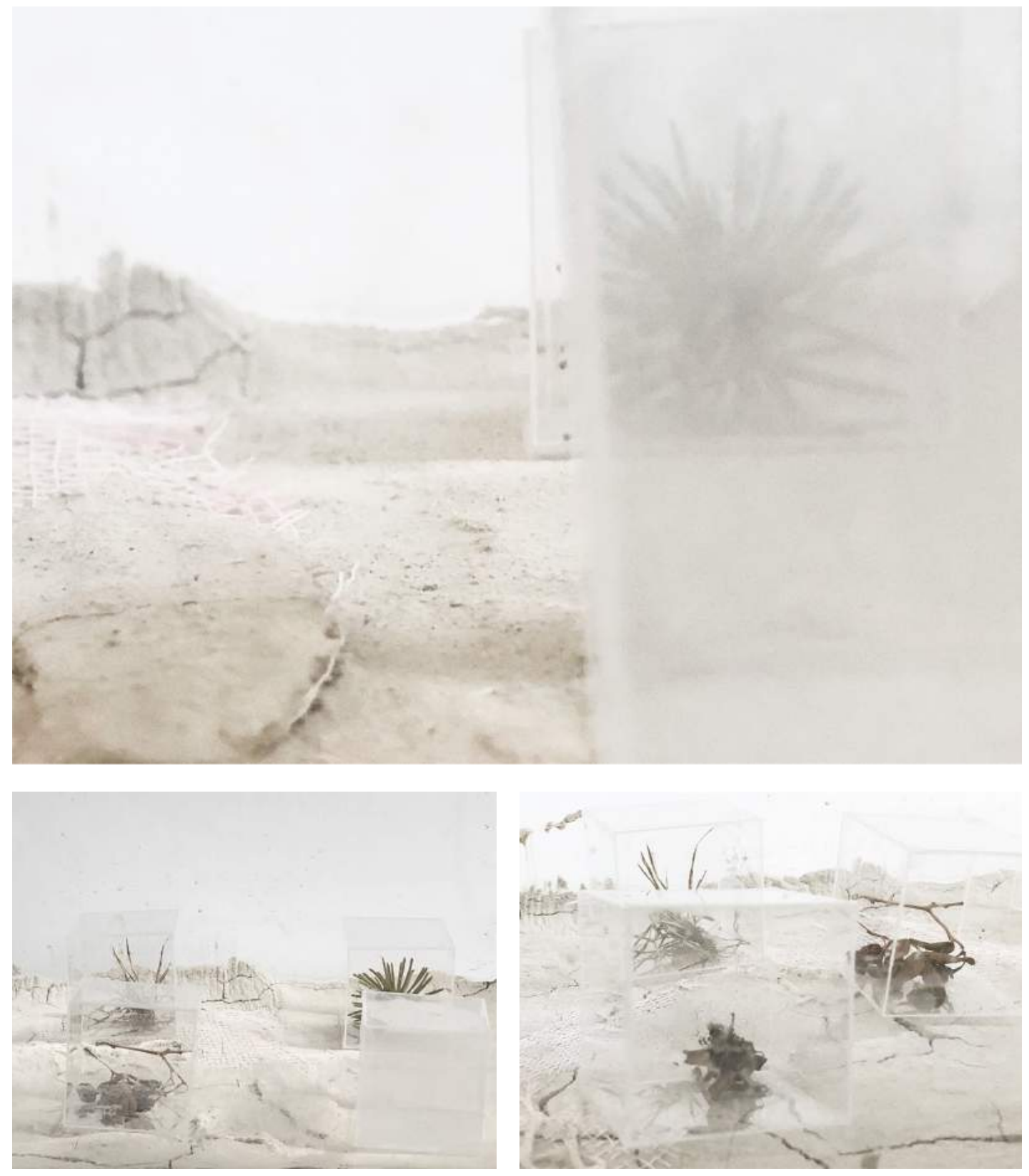

It is easy to imagine these images as alien capsules on a barren, dry apocalyptic landscape, ordered nature preserved from its own chaos. 

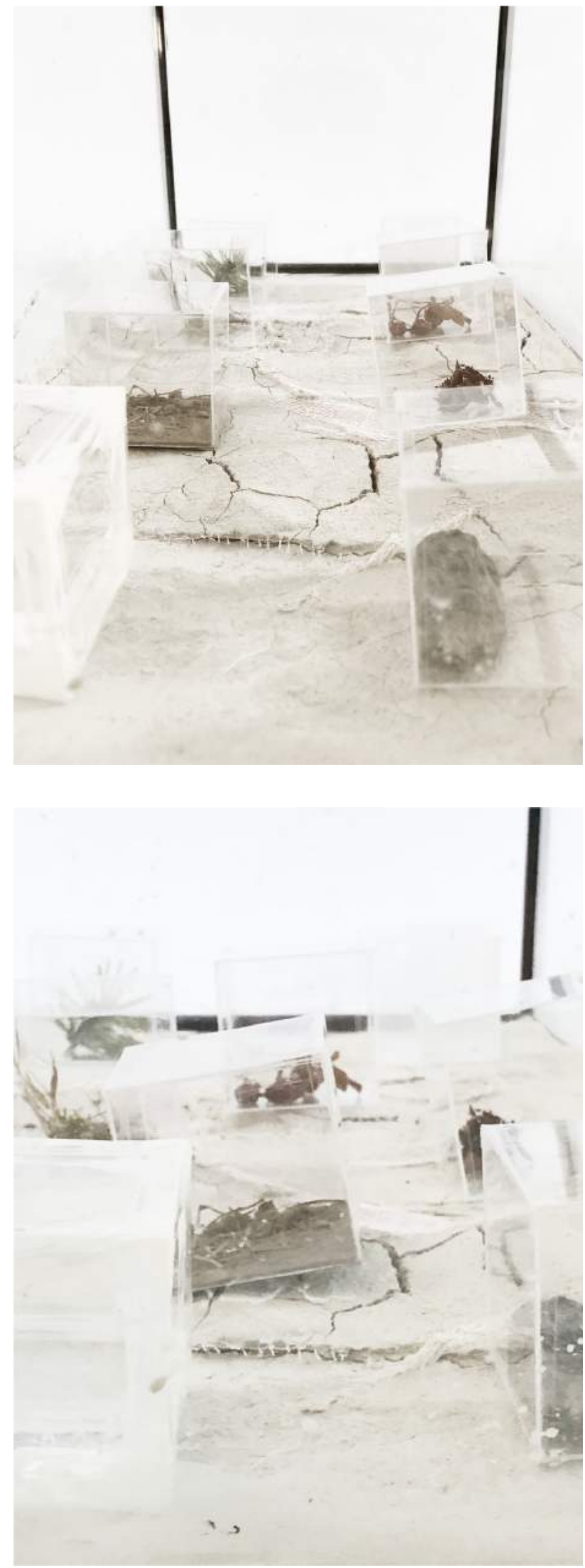

And yet, these vitrines do not freeze time.

In the days that passed since the artifacts were placed in their displays, they transformed.

The tape that presents the illusion of clean edges began to lift.

The condensation evaporated, the fragile little box is not air tight.

The water evaporated, the fragile little box is not air tight.

The colours of the pine and the berries continued to dull and brown, the fragile little box is not air tight. 


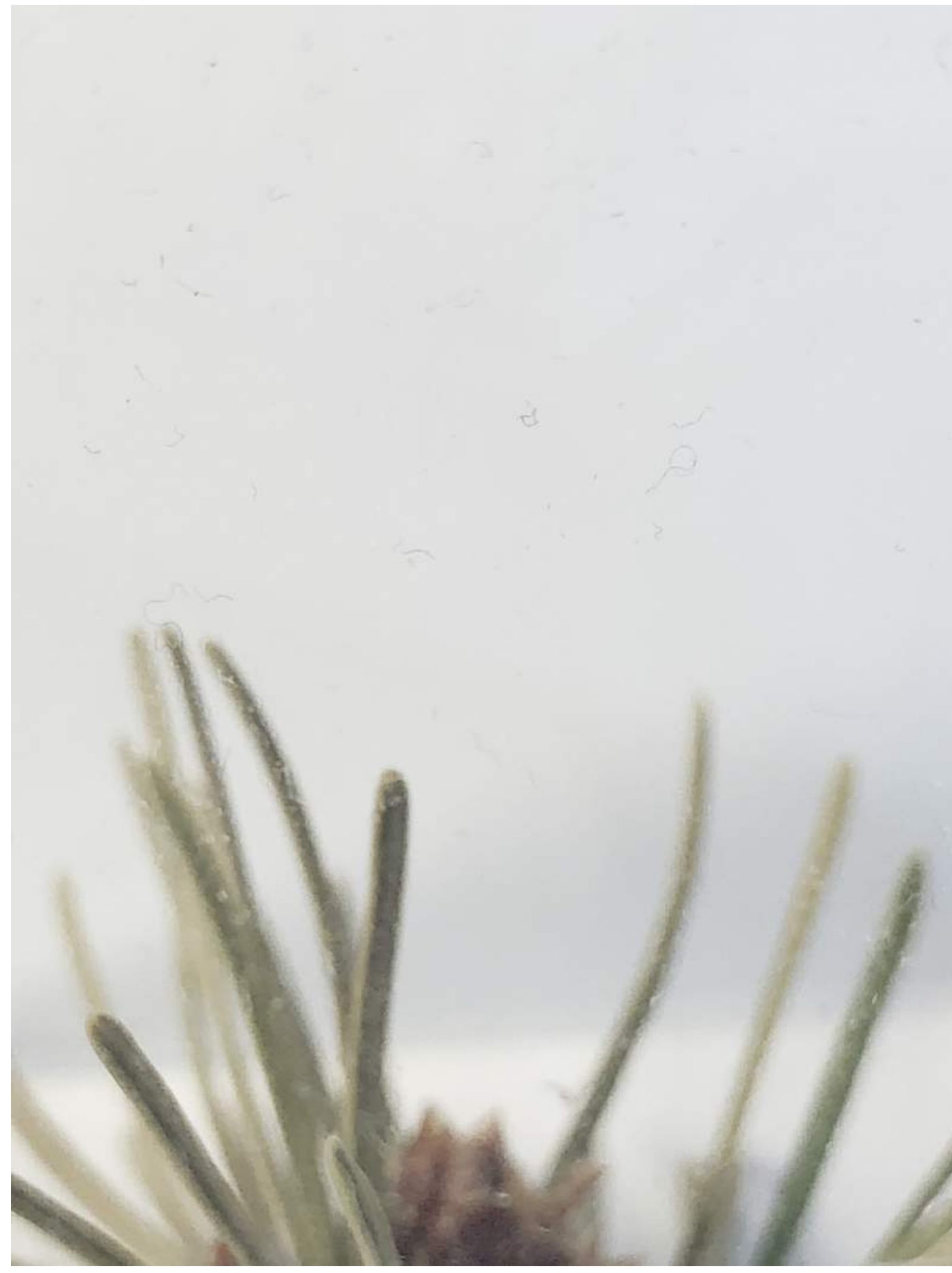

The vitrines themselves become subject to inspection.
Dust has collected on the surface of the plexiglass, the condition of sterility must be preserved. 


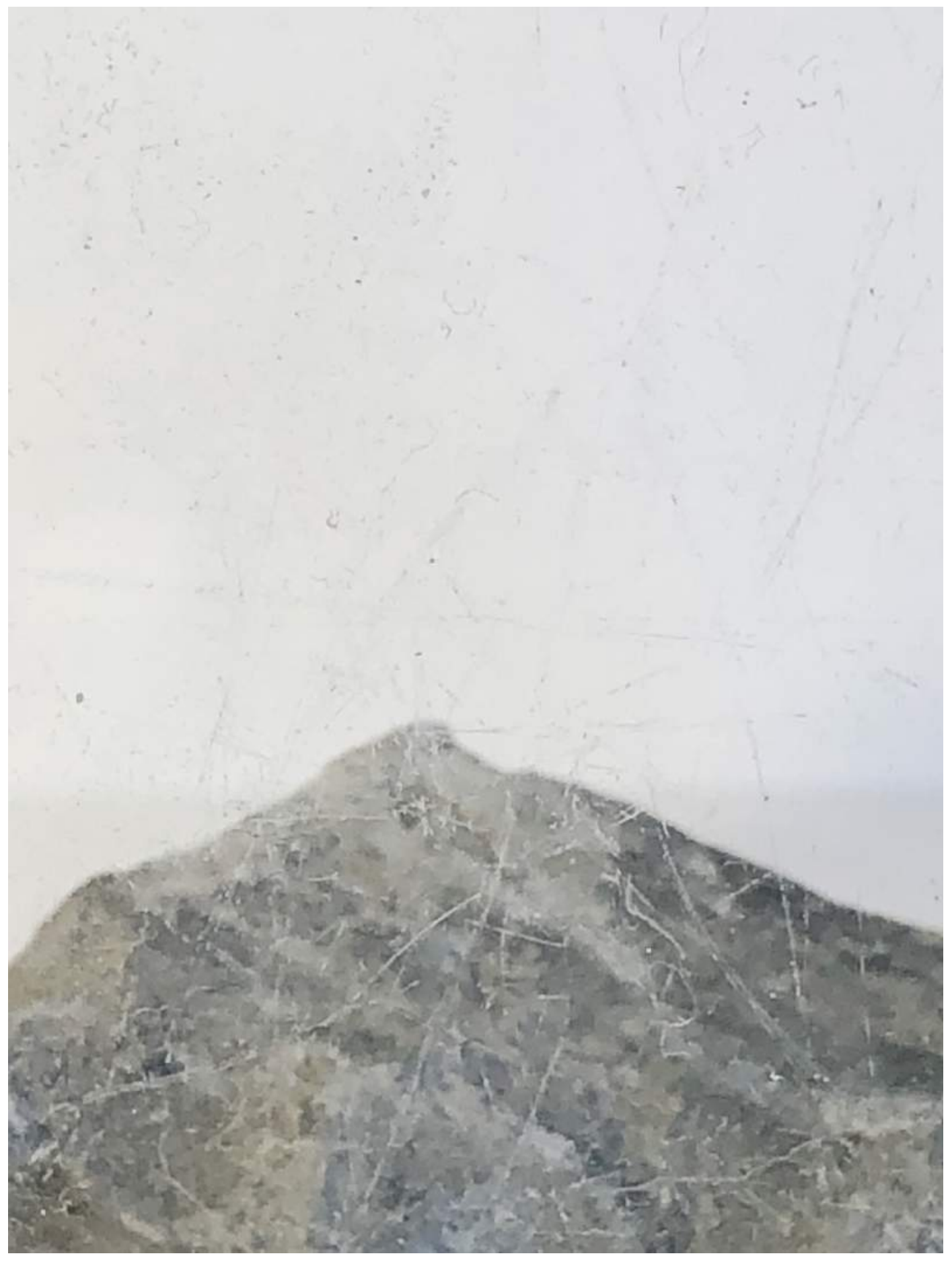

The rock has scratched the fragile interior of the vitrine as it was moved around. 


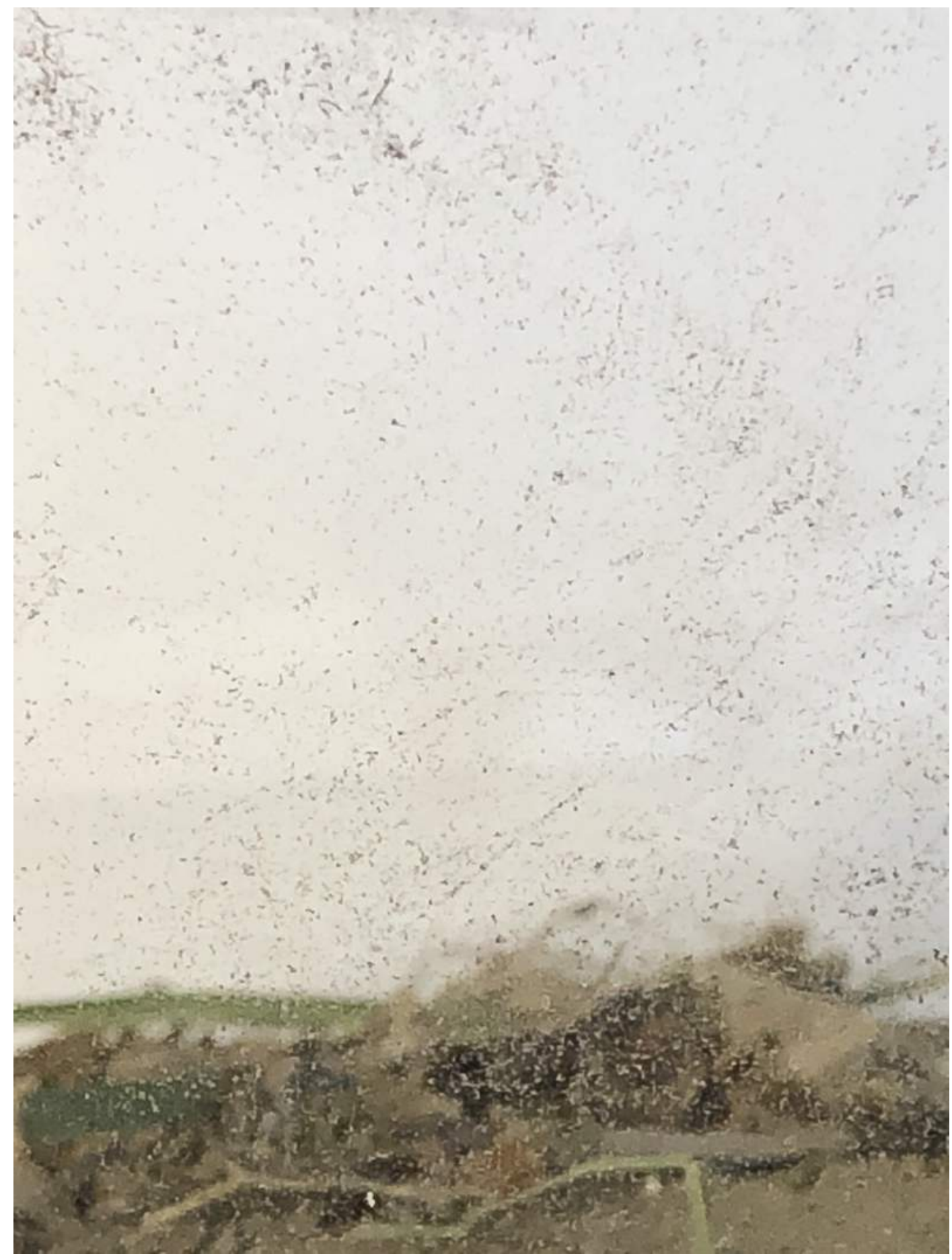

The sandy dirt has speckled the sides of the vitrine, also due to it being moved and rotated. 


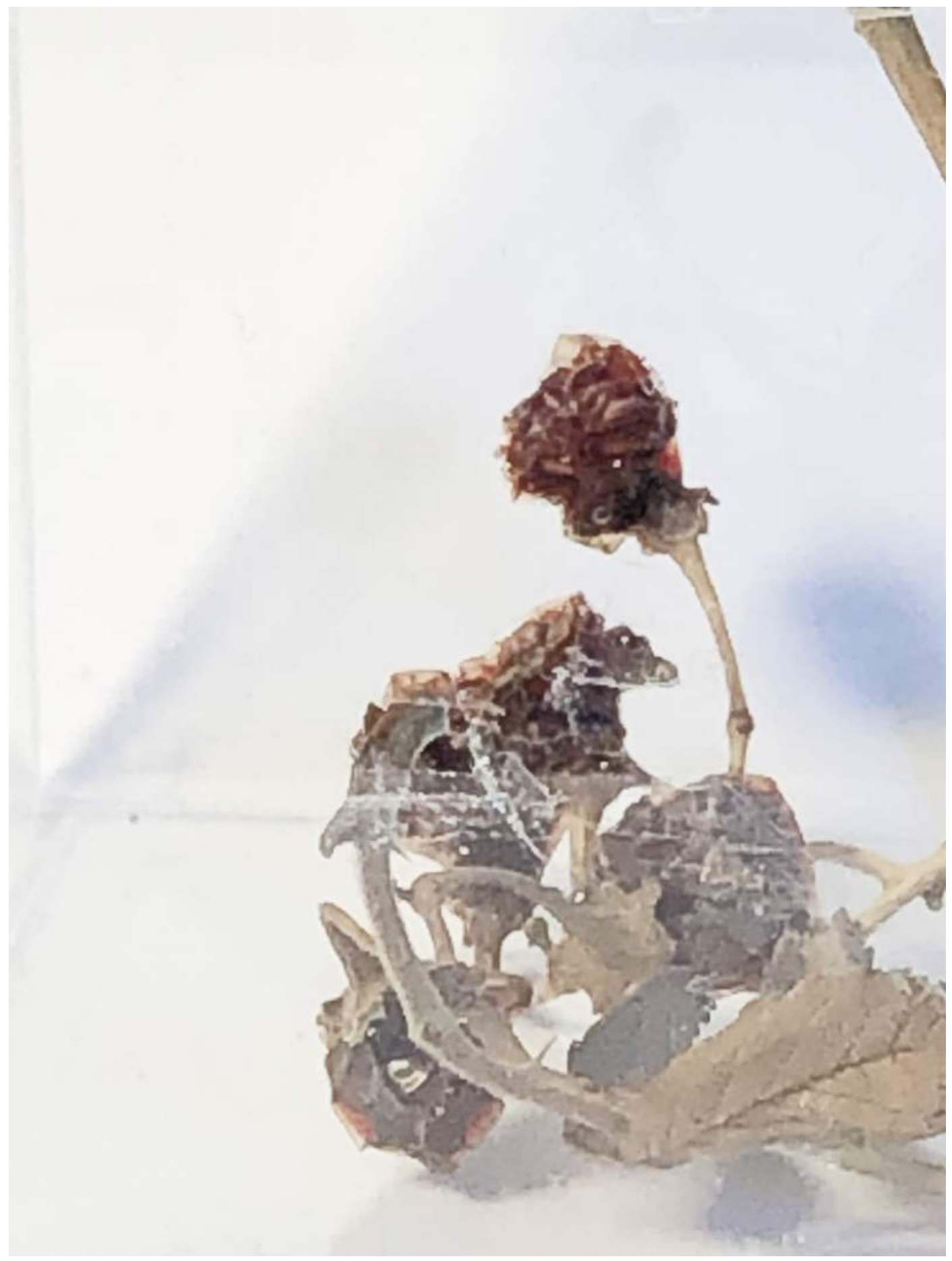

The clay surface of the tank has Reality introduces messiness. created scratches on the exterior of the vitrines as well. 


\section{part 2 SUBNATURE}

"forms of nature become subnatural when they are envisioned as threatening to inhabitants or to the material formations and ideas that constitute architecture. Subnatures are those forms of nature deemed primitive (mud and dankness), filthy (smoke, dust, and exhaust), fearsome (gas or debris), or uncontrollable (weeds, insects, and pigeons). We can contrast these subnatures to those seemingly central and desirable forms of nature-e.g., the sun, clouds, trees, and wind. These latter forces are generally worked into the forms, practices, and ideas that constitute the primary realization of nature within architecture."

Gissen, David. 2009. Subnature: architecture's other environments : atmospheres, matter, life. New York: Princeton Architectural Press. 21-22. 


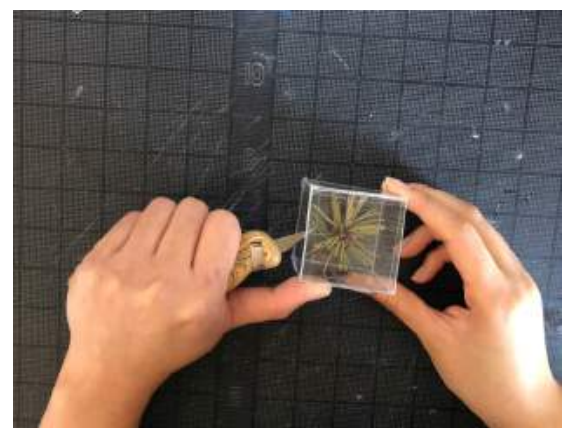

Three edges of the vitrine were cut.

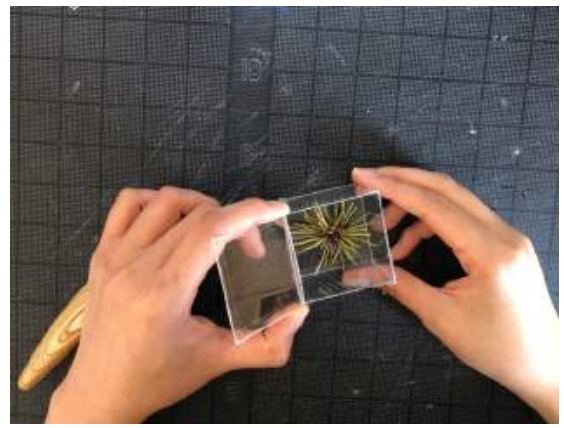

The new 'lid' of the plexiglass container is opened.
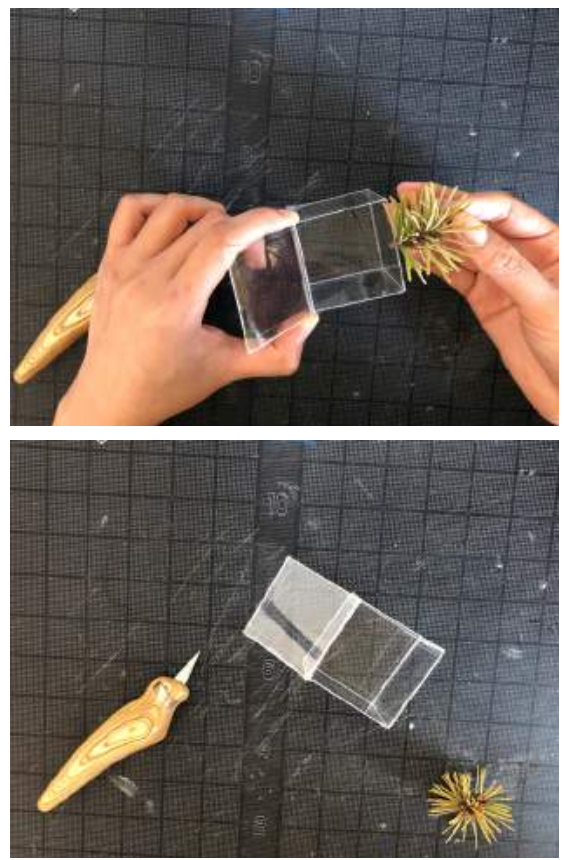

The artifact is set aside.

The artifact is removed.

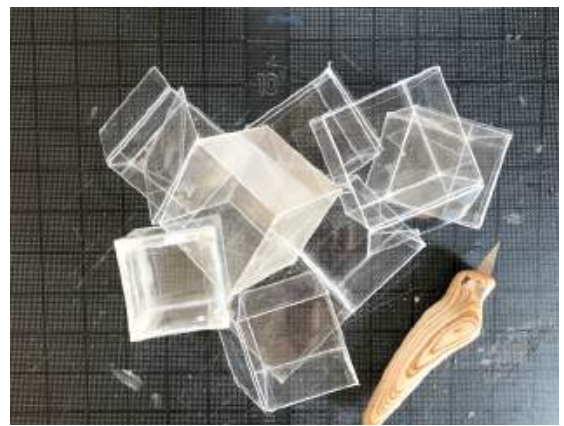

The same steps were repeated until all of the containers were empty. 


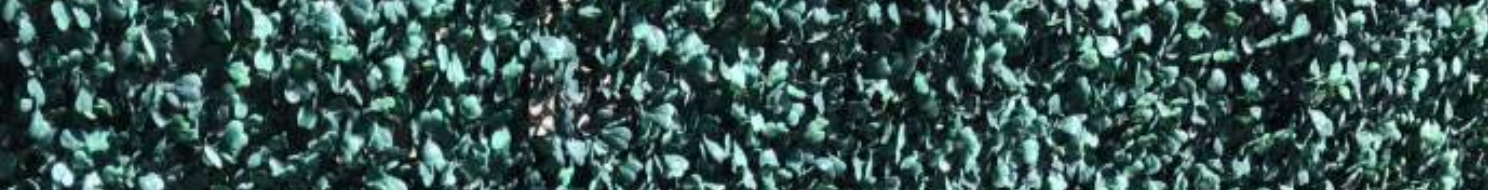
5. 5 .

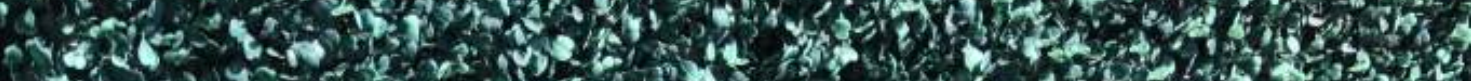

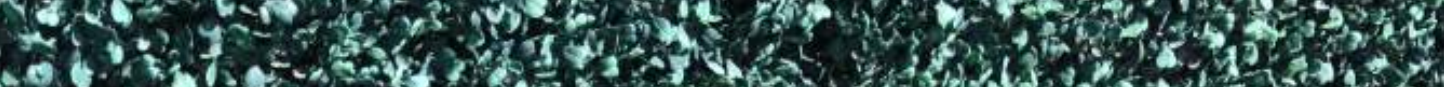

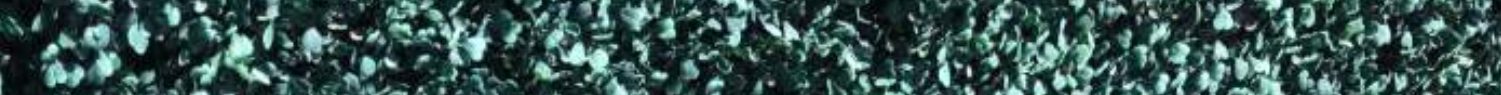

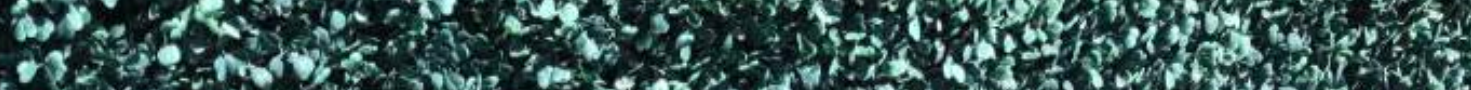

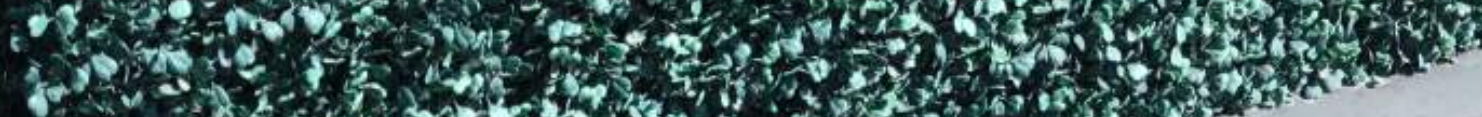

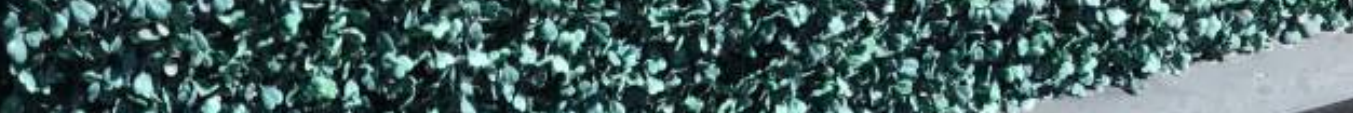

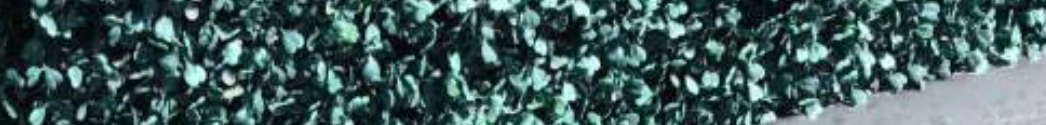

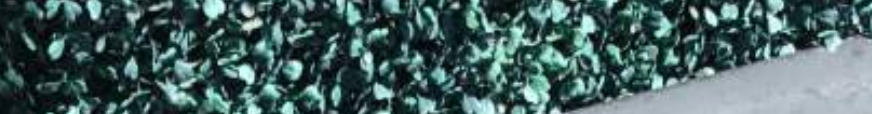
x.

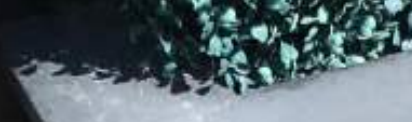

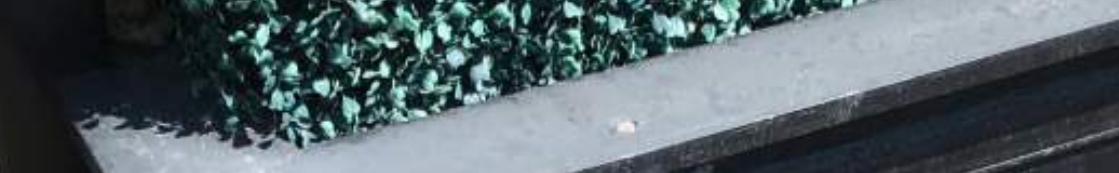

1

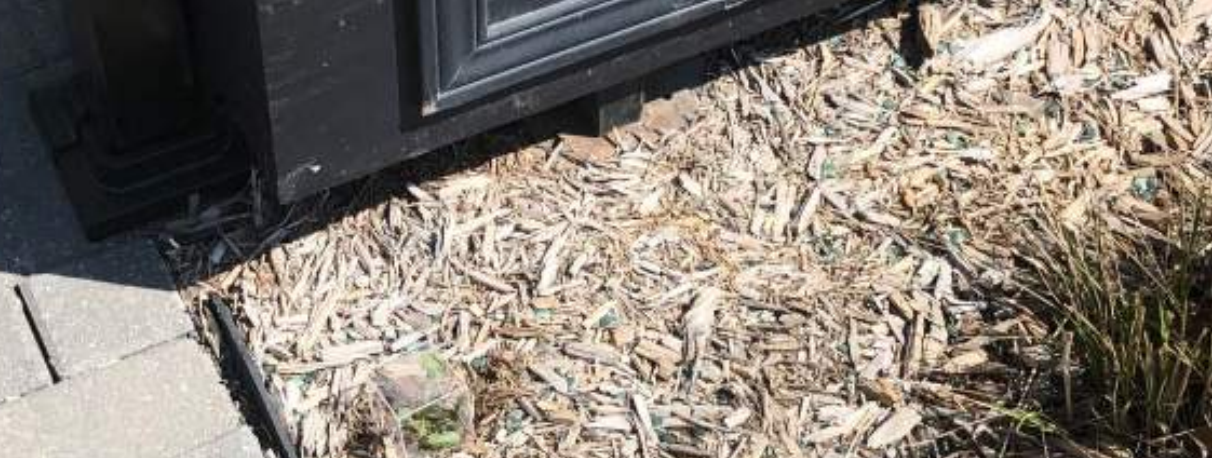

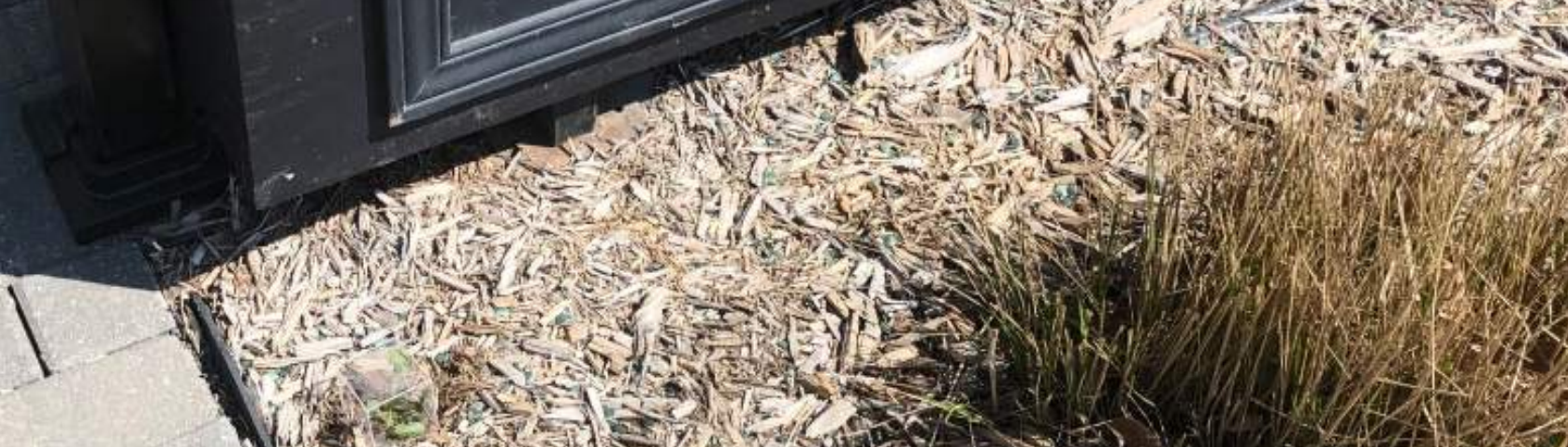

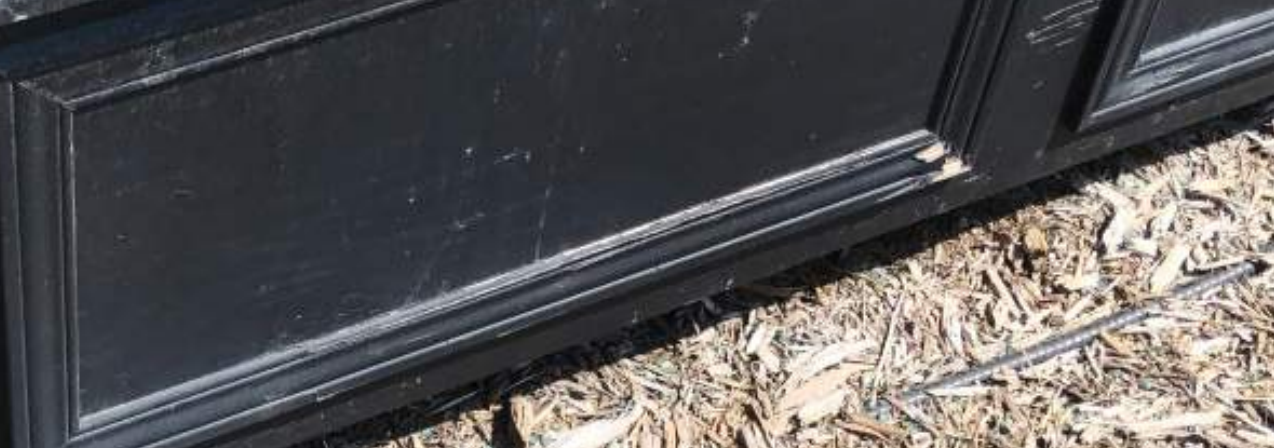

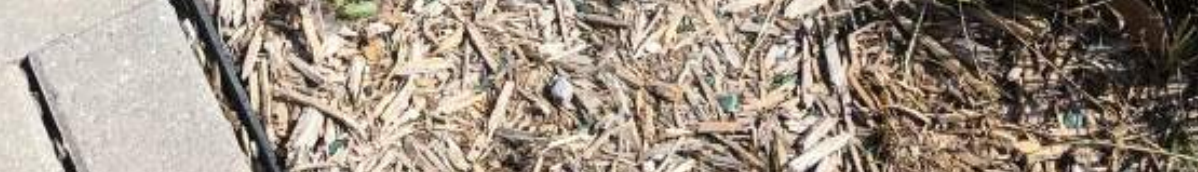

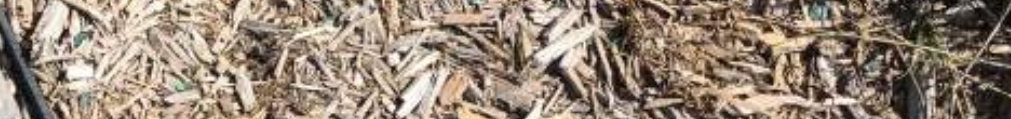

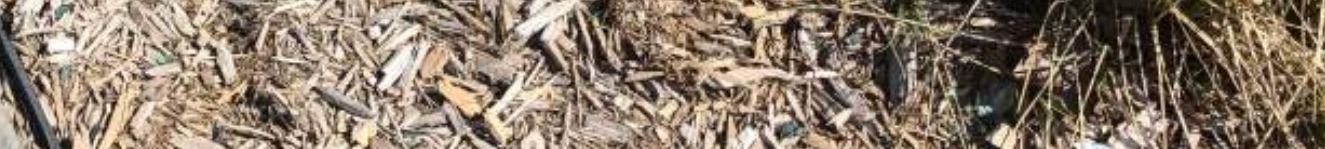
1.

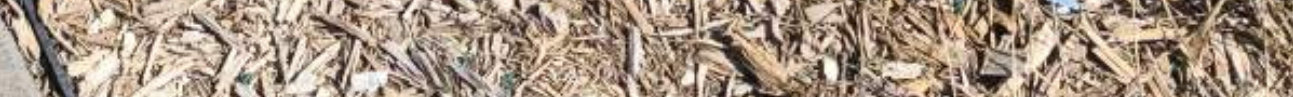

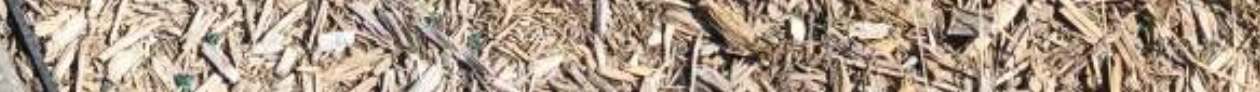

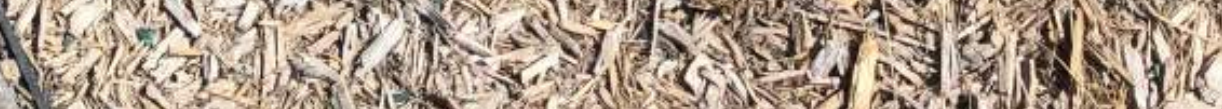
If

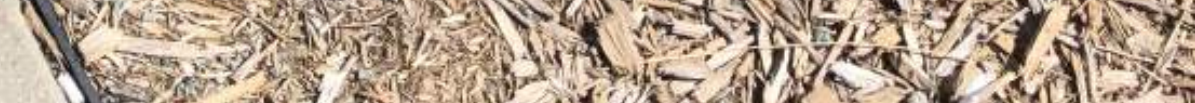

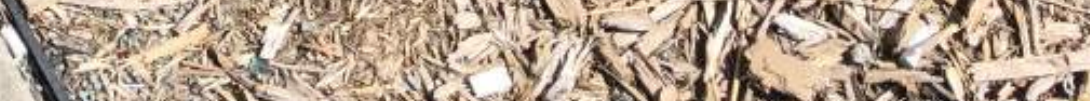

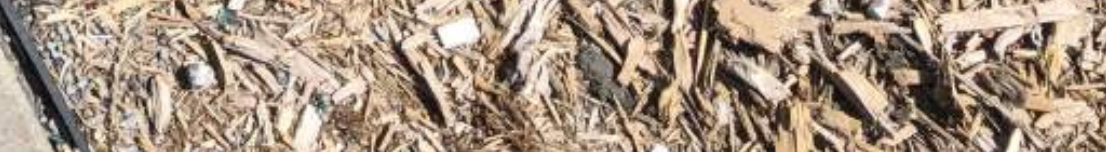

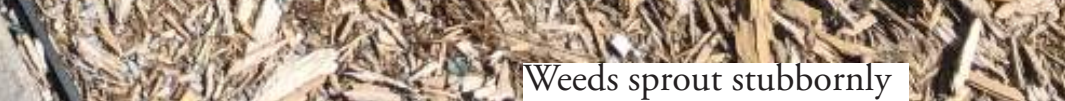

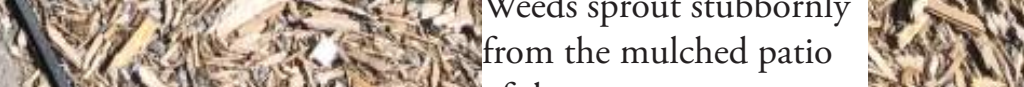

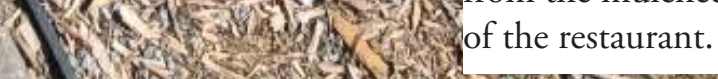
$1972, \ldots=2$

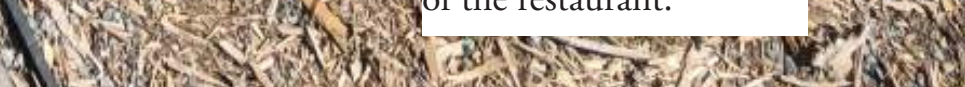

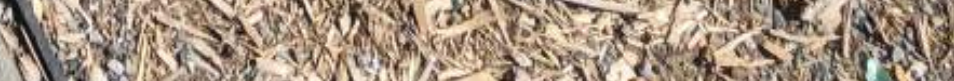
Ales 


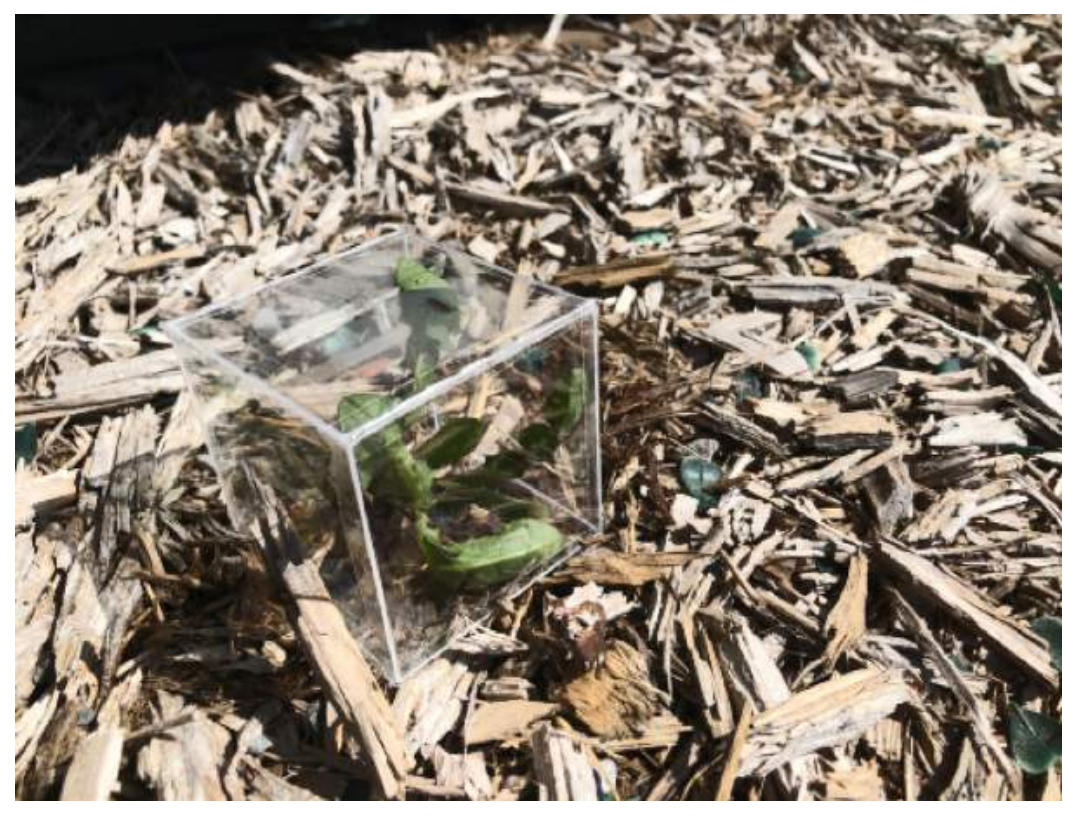

The weed sits among the plastic petals of the fake plants that adorn the patio.

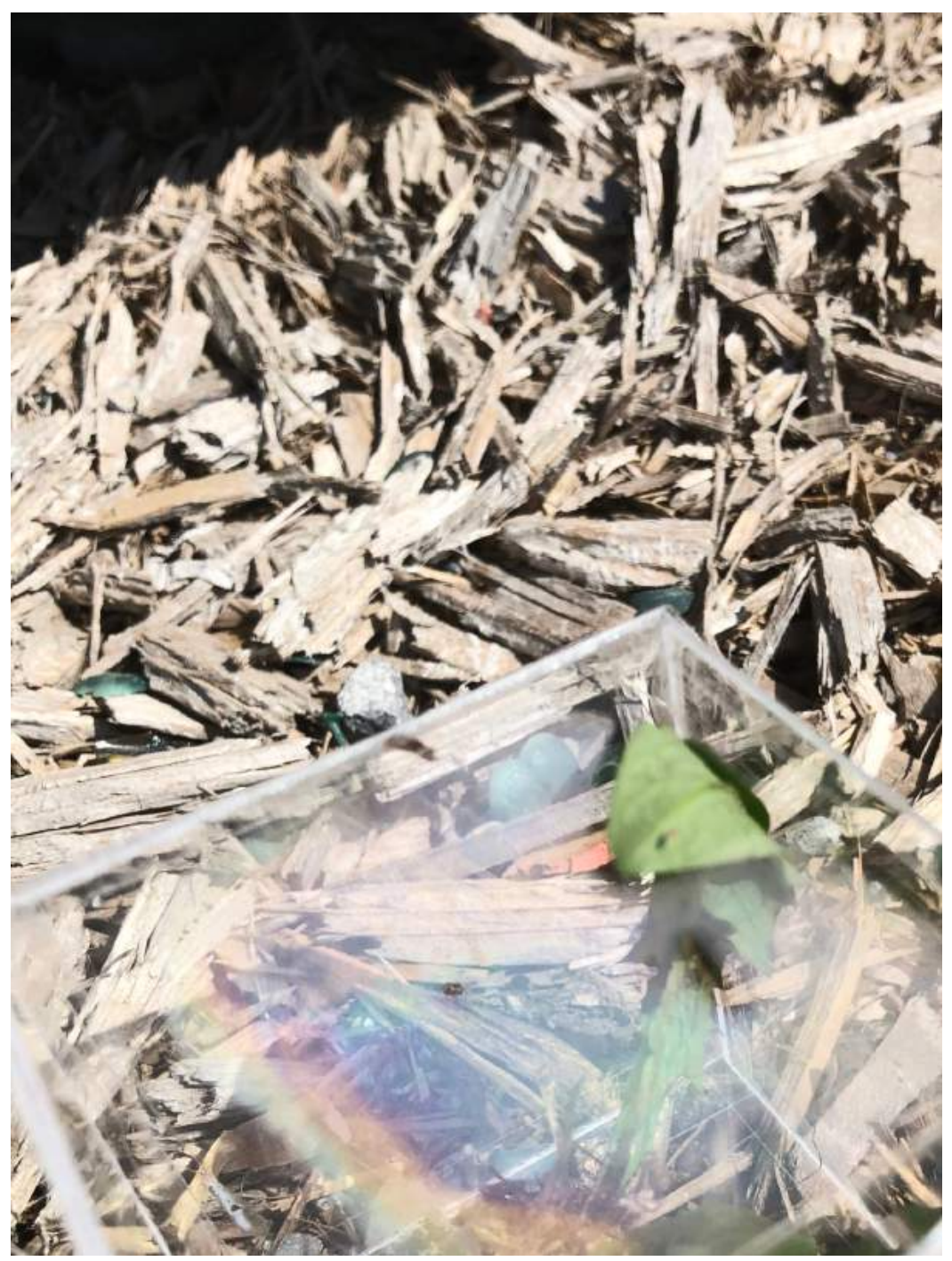

The day is hot, seam begins to collect inside the vitrine as the sun beams down on it. 


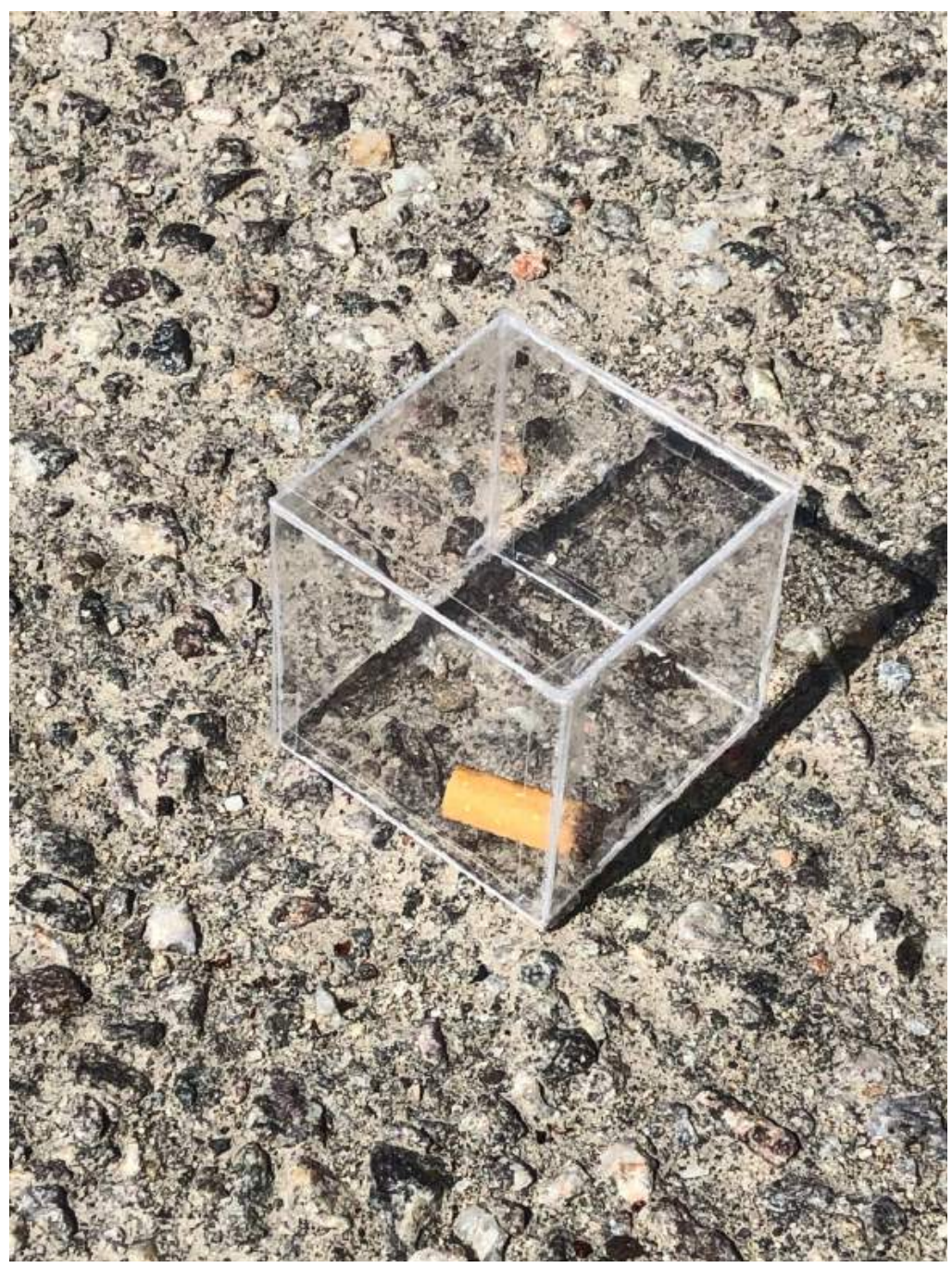

The cigarette butt spreads ashes on the surface of the vitrine. It smells of tobacco.

The vitrine is a tiny world, dwarfed within a much larger planetary 'tank'. 


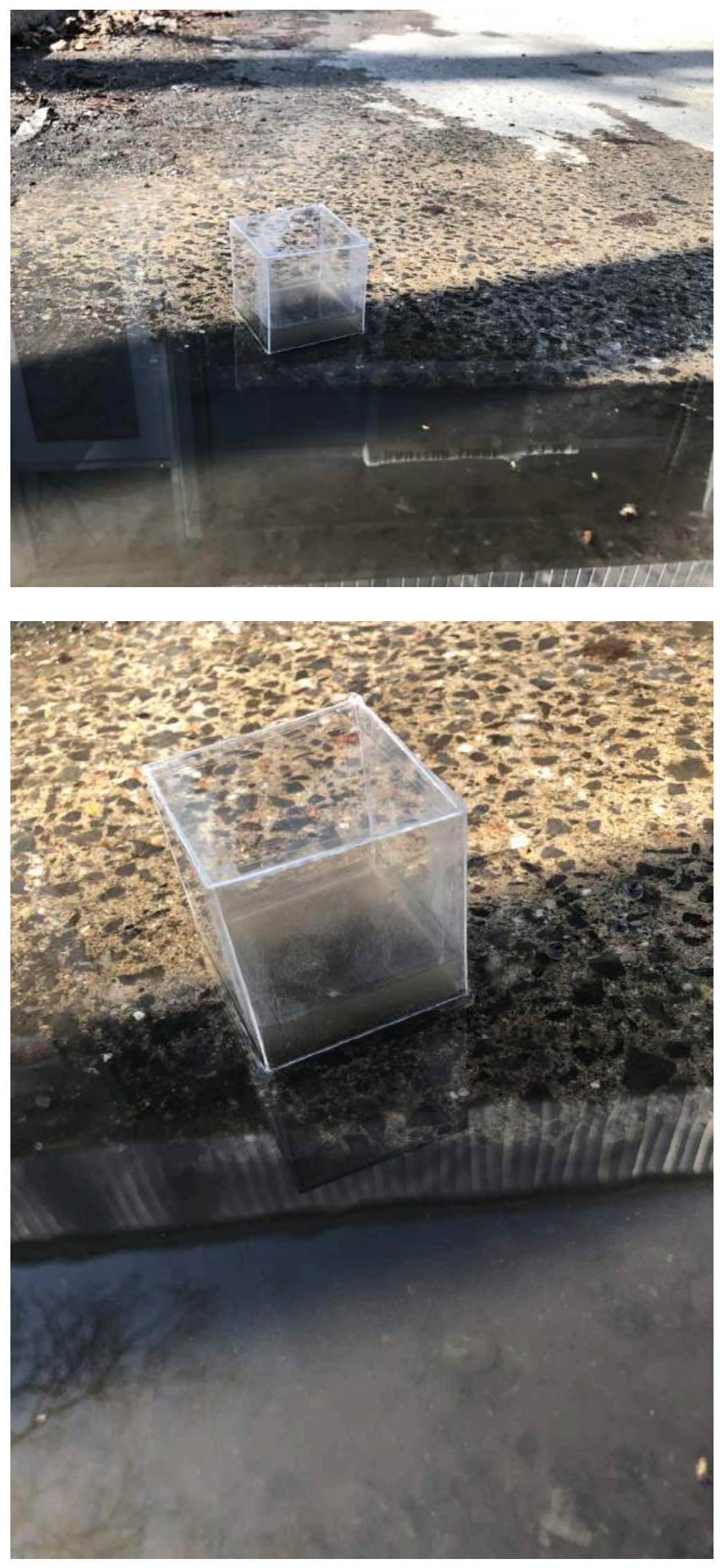

The water settles into the vitrine as sediments slowly sink to the bottom.

The water leaves dusty streaks on the wall of the vitrine. 



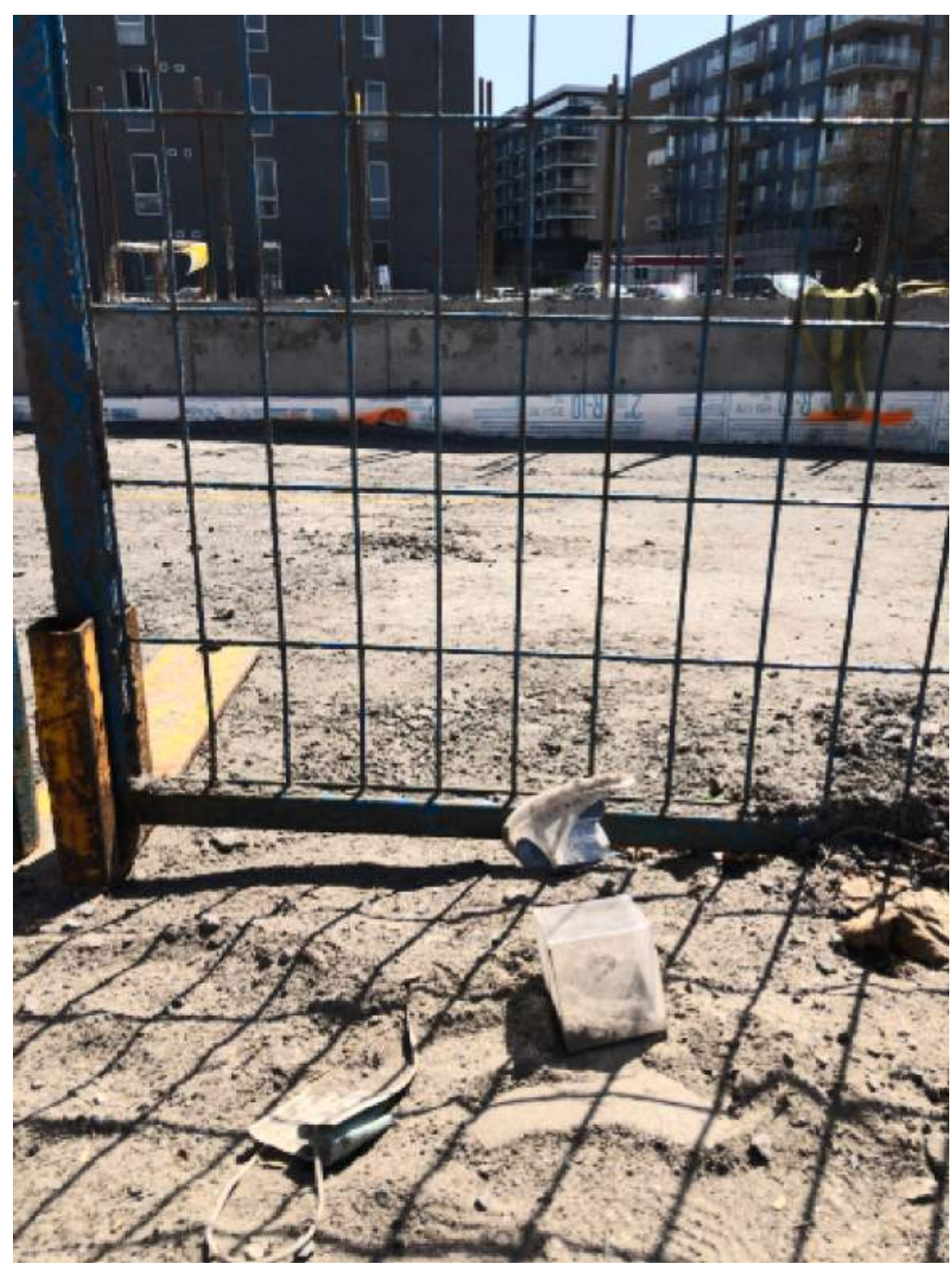

Plastic and a face mask litter the site. The fence casts a gridded shadow onto the vitrine.

The vitrine is cloudy with dust, sitting in the lopsided mound. 

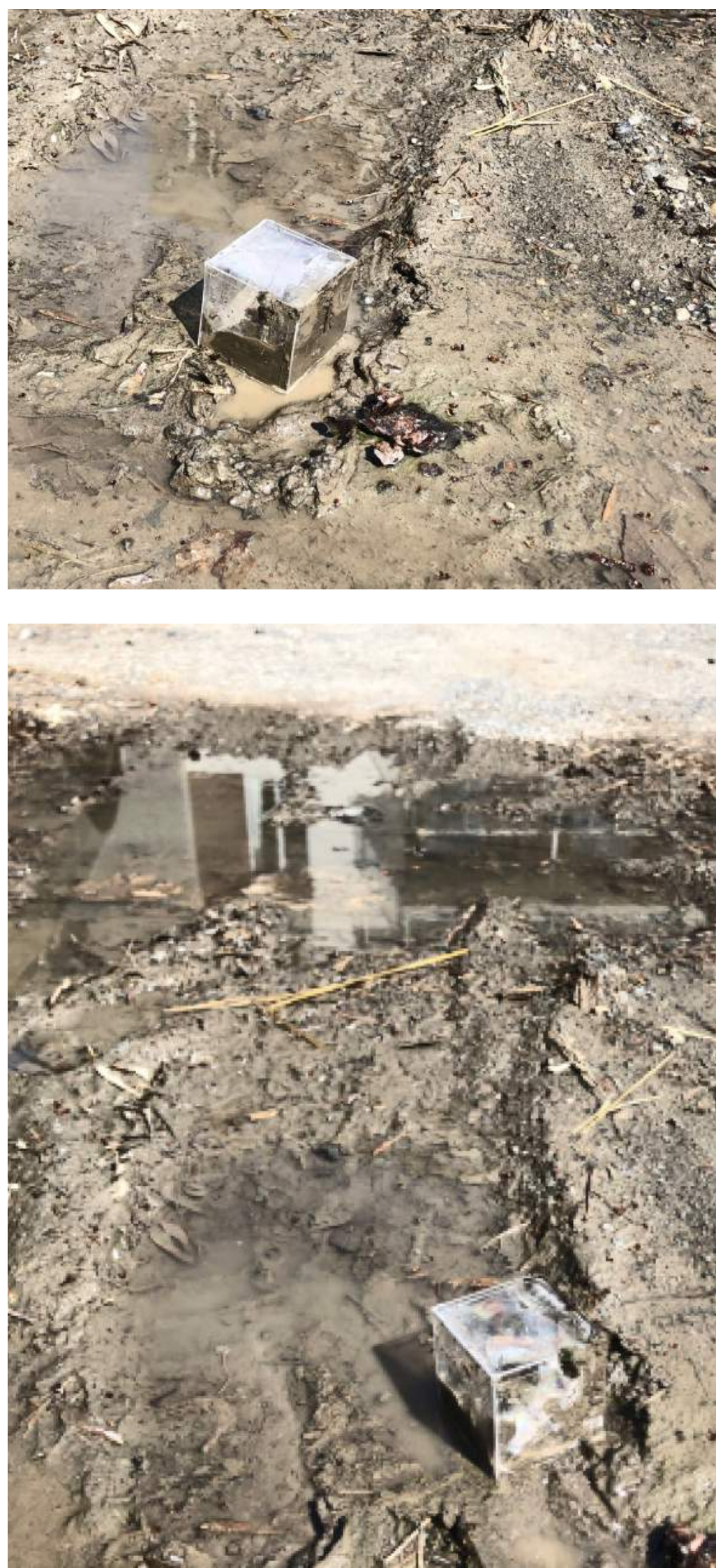

Mud oozes out of the vitrine, smearing onto its sides.

Steam collects in the vitrine as it sits in the sun. 

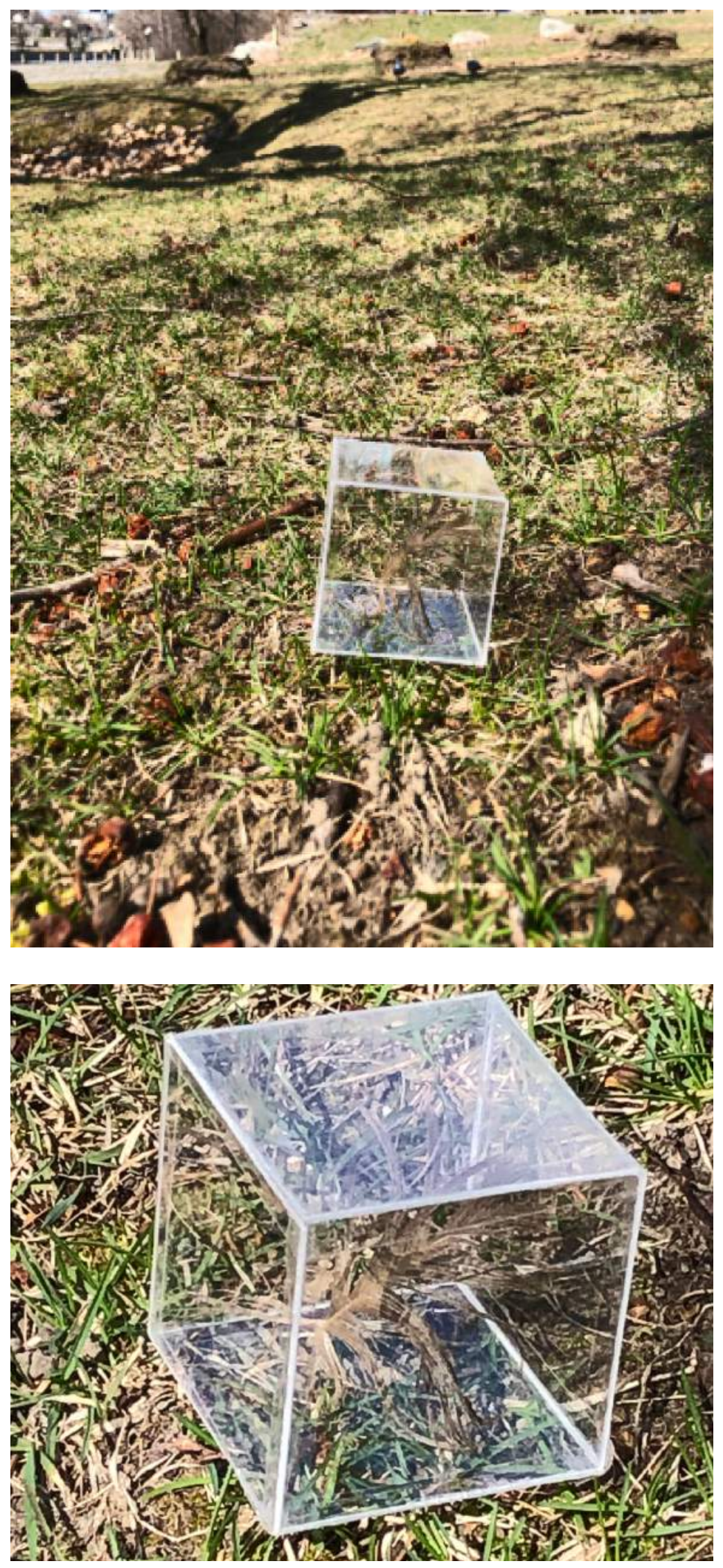

Pigeons peck at the ground in the distance, though the feather that folds into the vitrine is likely one that belonged to a seagull.

The feather is difficult to distinguish from the grass the vitrine rests upon. 


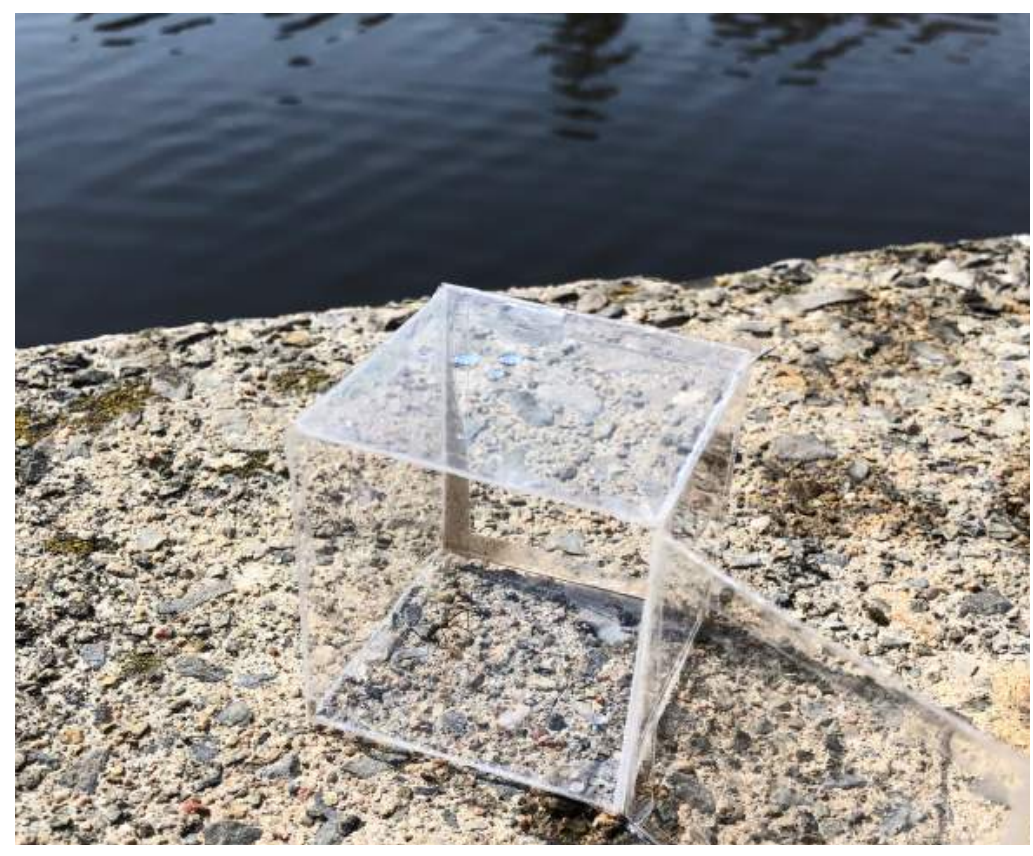

The spider paces about, examining its temporary captor.

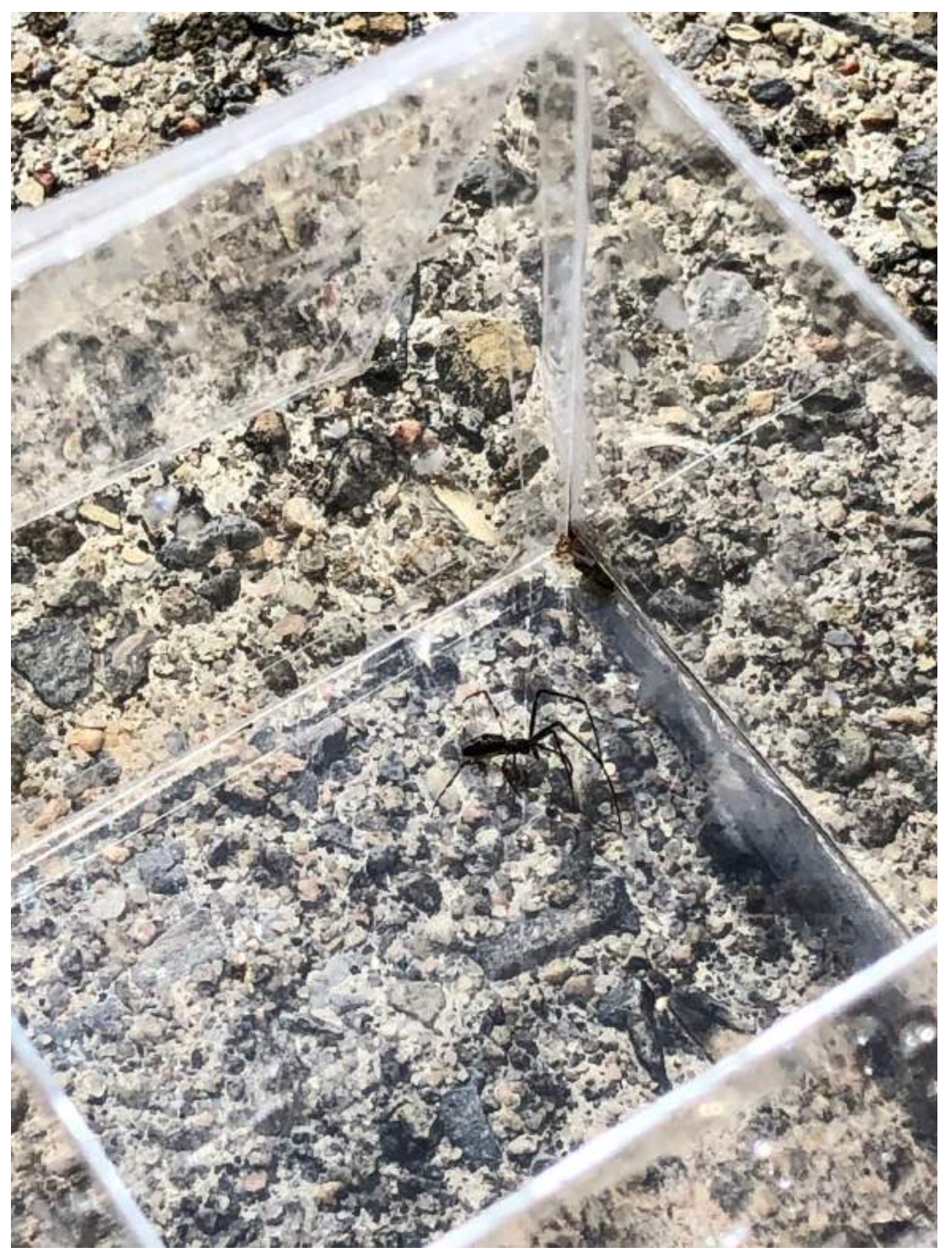




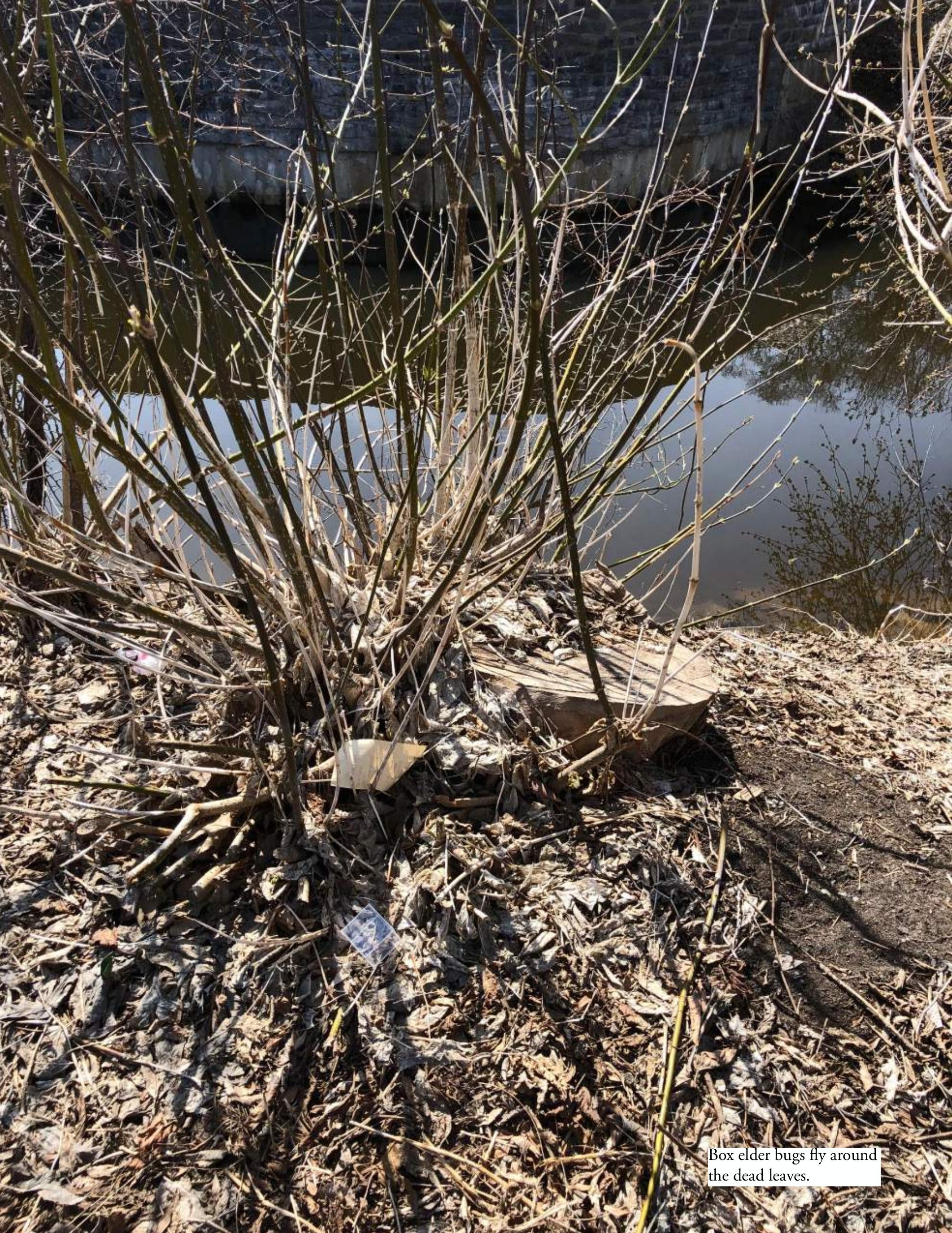




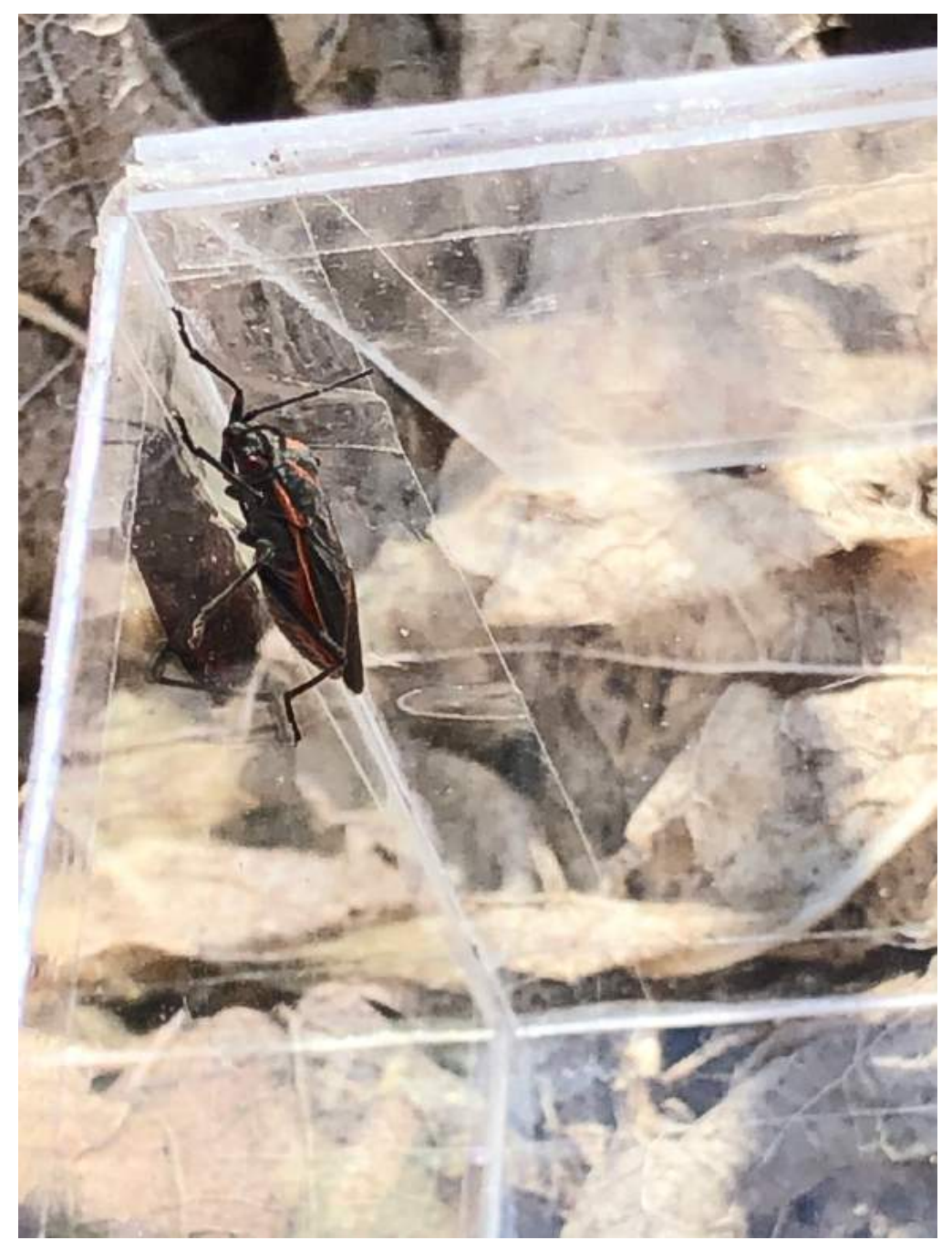

The box elder bug climbs the edge of the vitrine.

The bug defecated in the

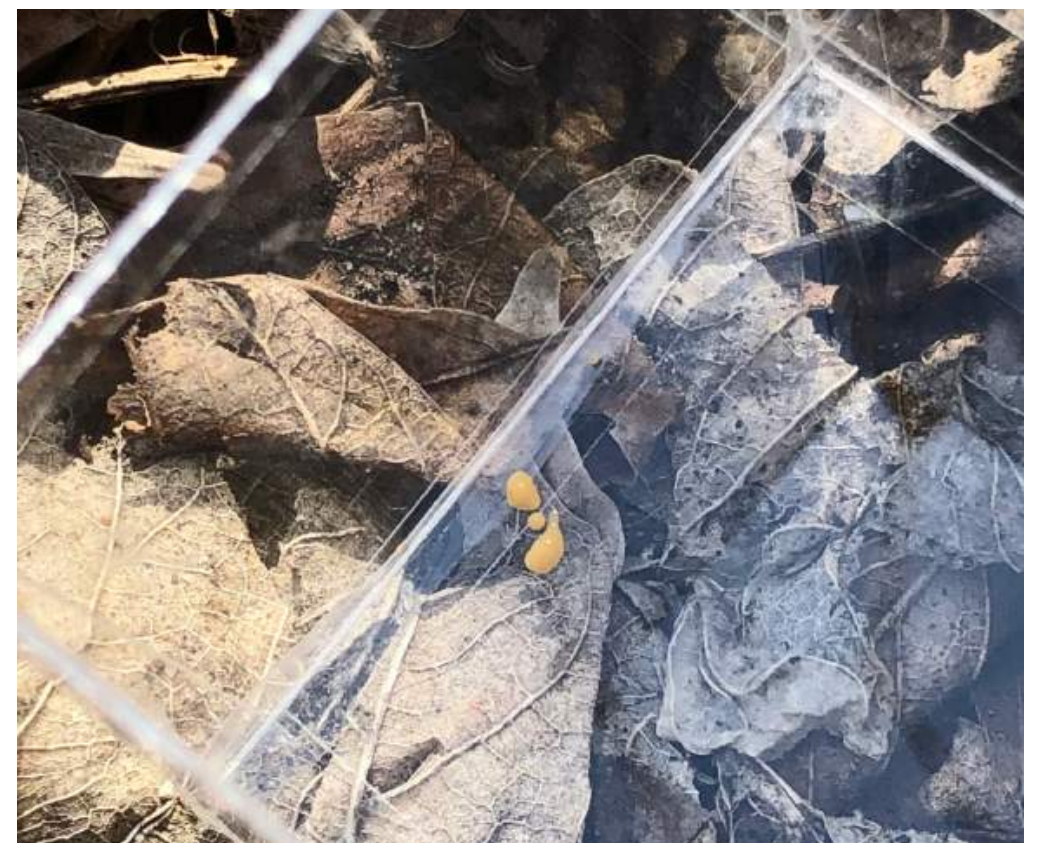

vitrine before flying away. 


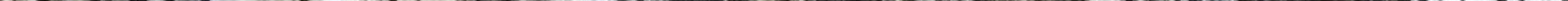




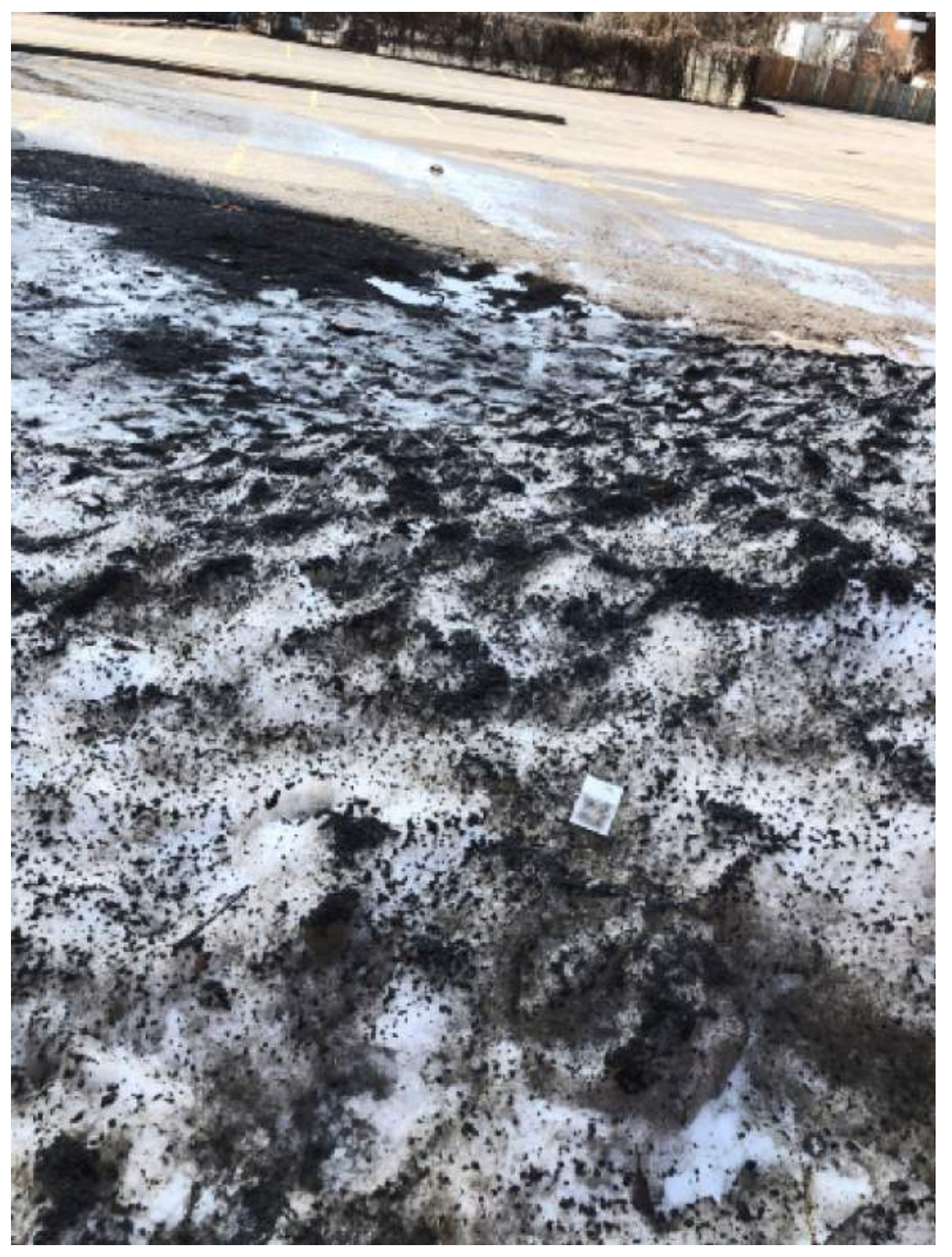

The vitrine balances

vicariously on the slippery

and craggy surface.

The black salt drips onto

the faces of the vitrine.

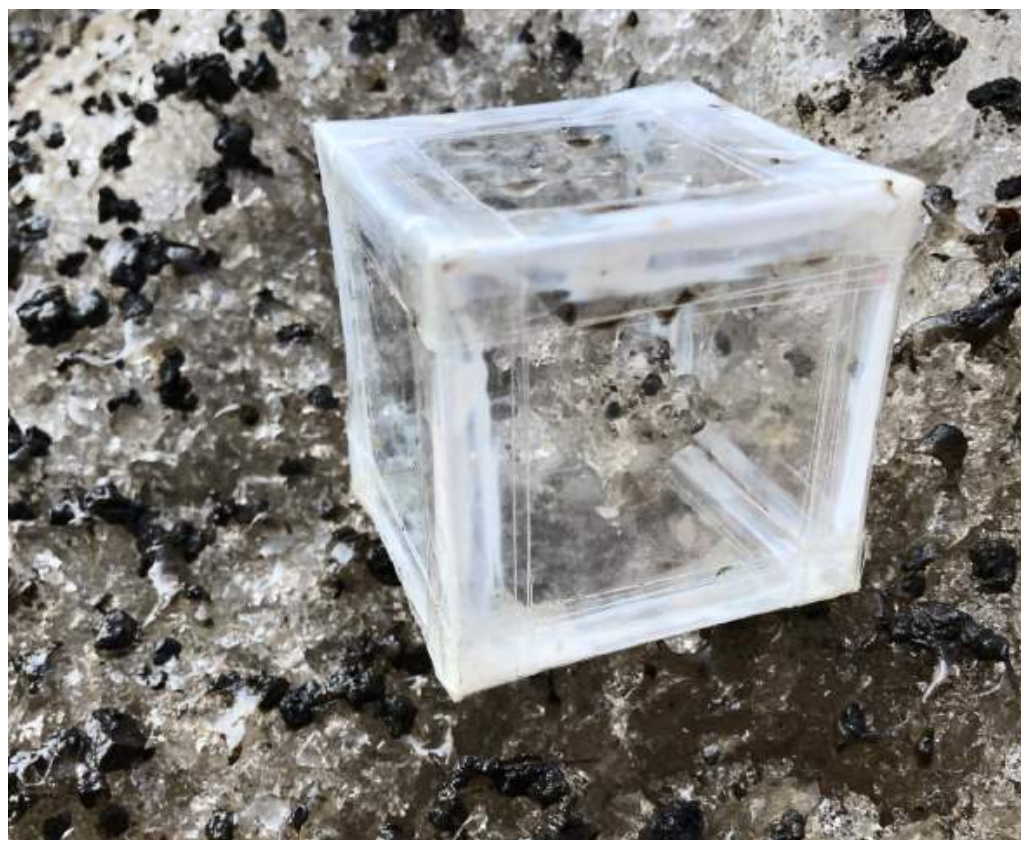



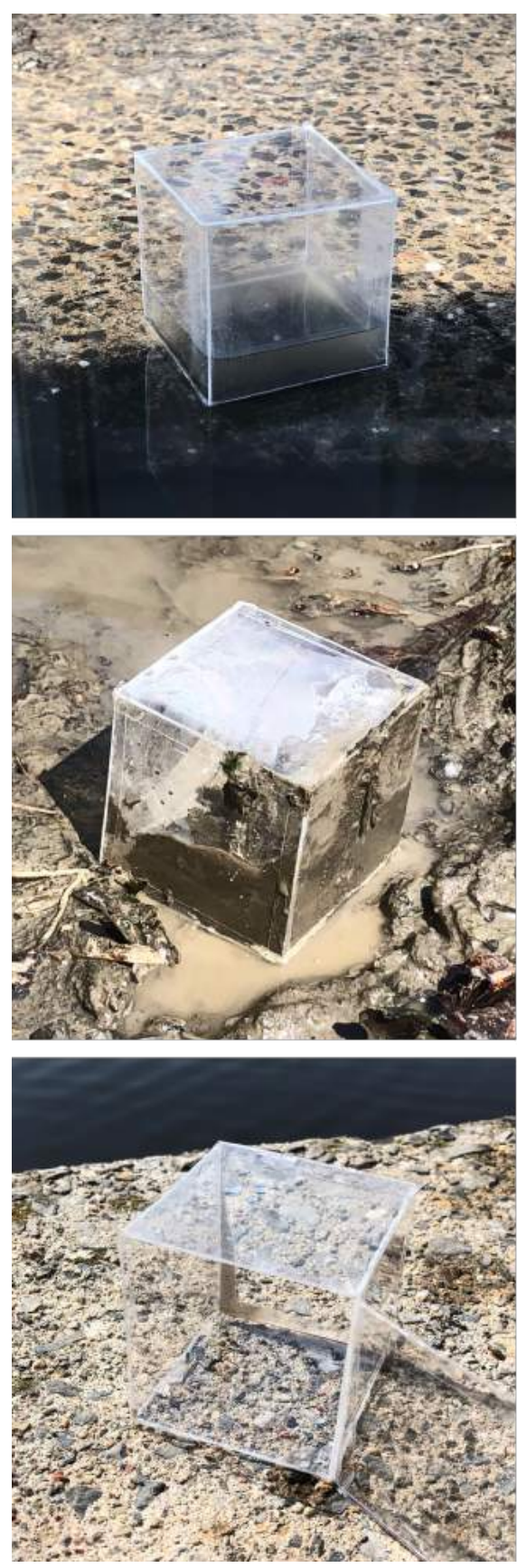

The vitrines contain the subnatures we deny, the subnatues we erase from our memory.
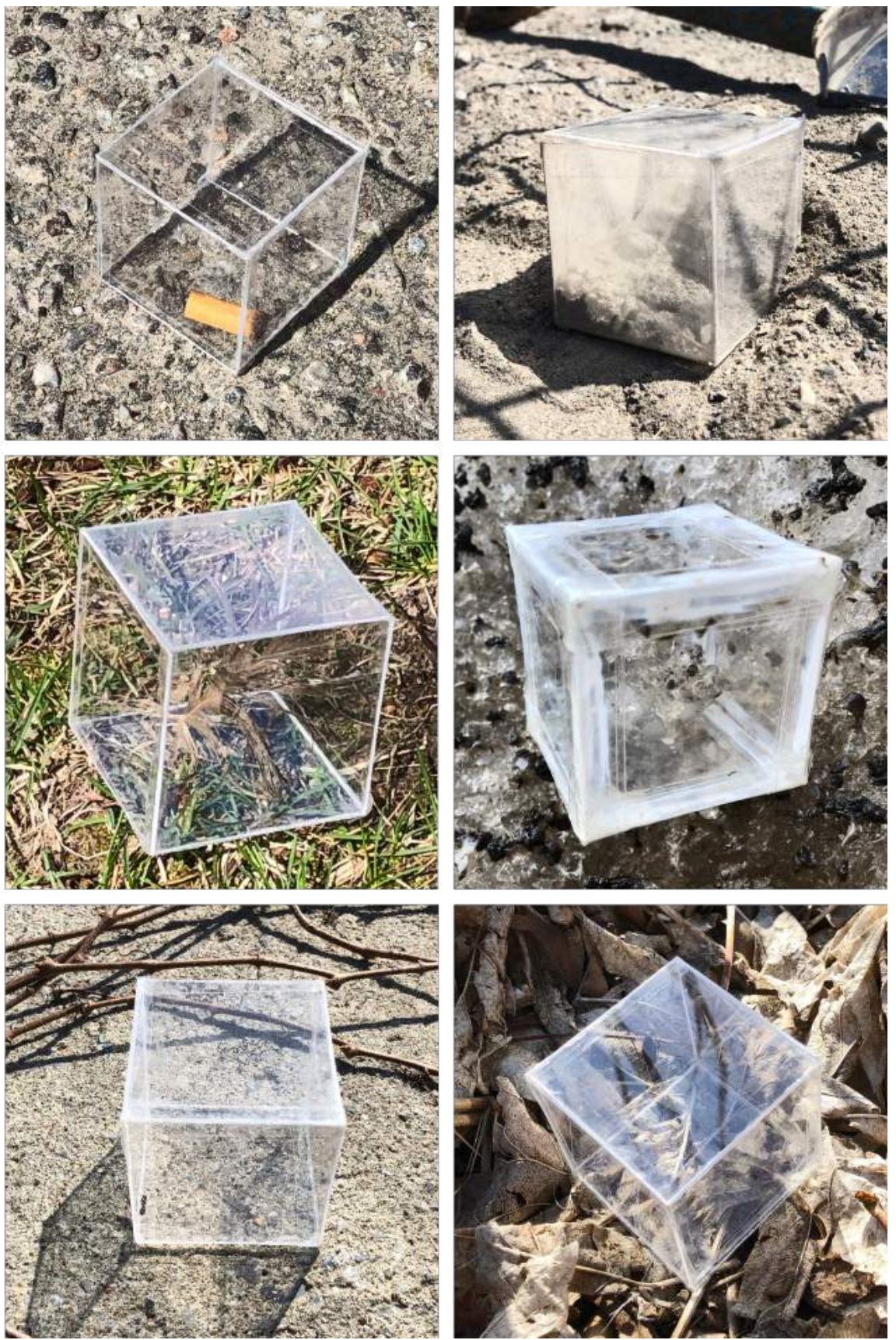

The vitrines are not clean

little plexiglass containers, they are painted with the messiness of the artifacts they encounter.

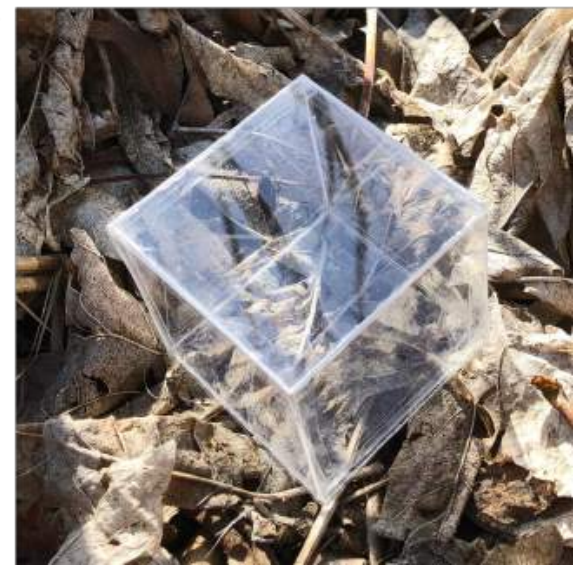

The vitrines are not staged in a sterile or controlled photoshoot. They rest uncomfortably within the context they are depicting. 

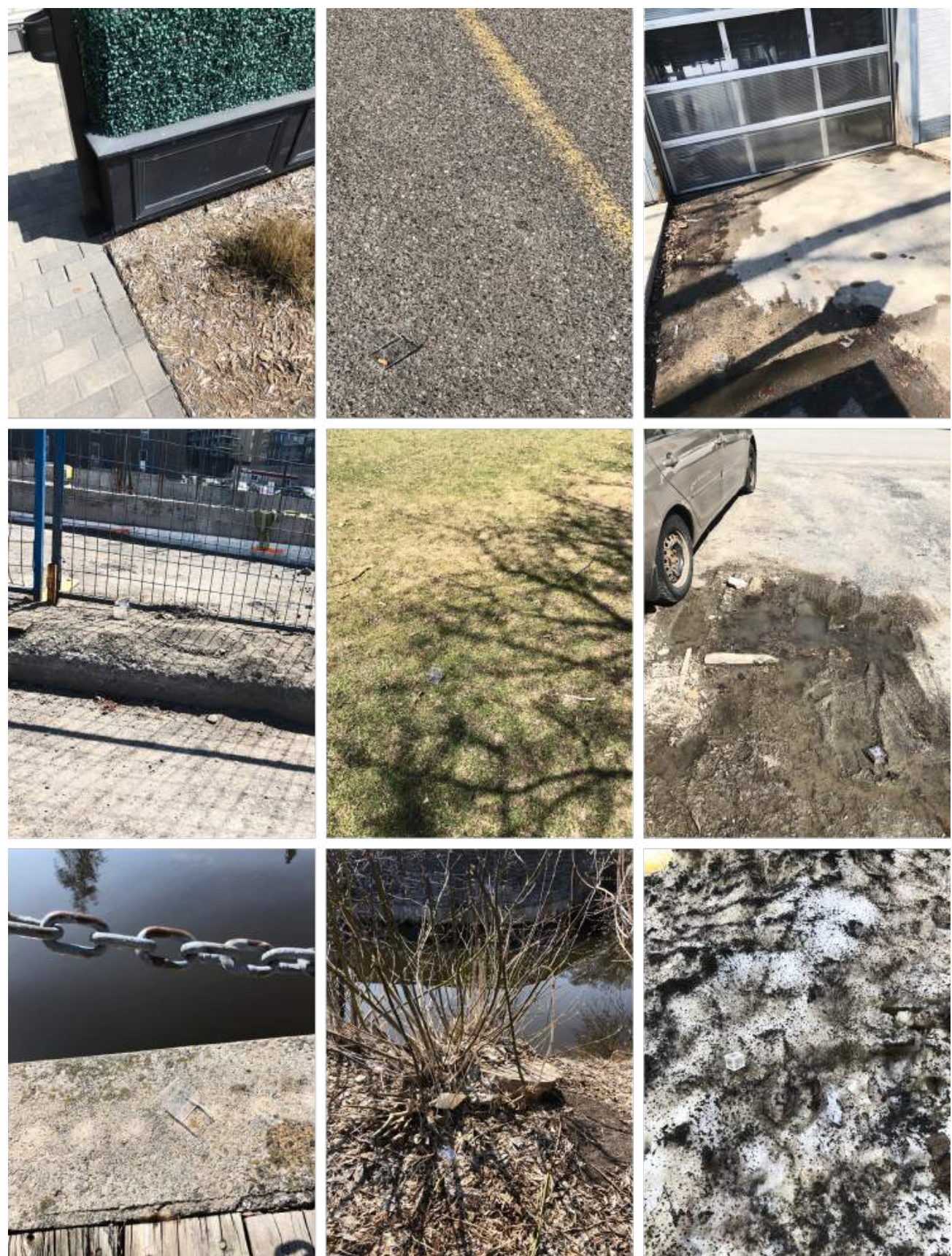

In these images, the vitrines are almost unidentifiable, they disappear.
The images do not depict nature. If nature is untouched by humans, there is no nature.
The world is messy and the images reveal it. They do not evoke delight, they invite your grimace. 


\title{
APPENDIX D: ANTHROPOCENE STUDY
}

\author{
DECIPHERING THE \\ ANTHROPOCENE
}

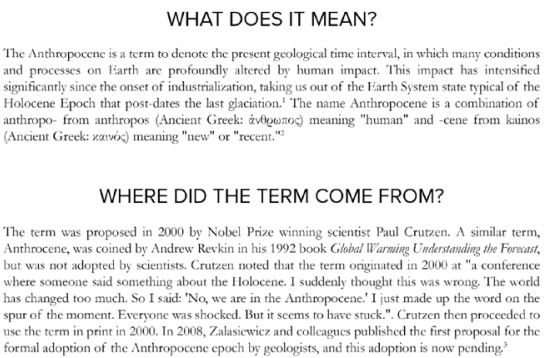

WHO DEFINES THE ANTHROPOCENE AND ITS PARAMETERS?
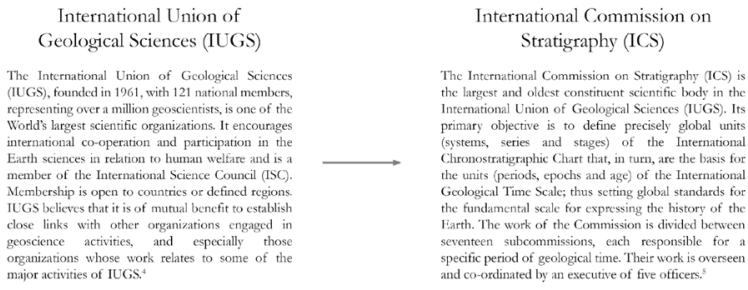

ther

organizations whose work relates to some of the
maior

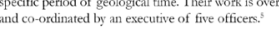

Anthropocene Working Group (AWG)

Subcommission on Quaternary Stratigraphy (SQS)

The 'Anthropocene' has developed a range
meanings among vastly different scholat communities, Here we examine the Anthropocene

a geological time (chronostratigraplic), unit an
potential addition to the Geological Time Sal consistent with Crutzen and Stoermer's original proposal.

The Anthropocene Working Group (ANG) charged with this task as a component body of the Subcommission on Quatermary Siratigraphy (SQS
which is itsclf a constituent body of the Internationa

The Subcommission on Quaternary Straigraphy (SQS) is t construent body of the International Commission on Stratigraphy (ICS), the largest scientific organisation
within the International Union of Geological Sciences

It is also the only body concerned with stratigraphy on a

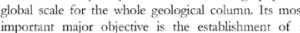
scandard, globally-applicalle strationaphical scalk, which seeks to achieve through the co-ordinated contributions
of a netrork of Subcommissions and Working Groups Commission on Stratigraphy (ICS) of a network of Subcommissices
with a specific limited mandate

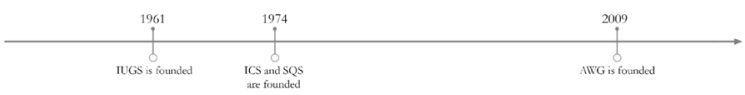


DEFINITIONS

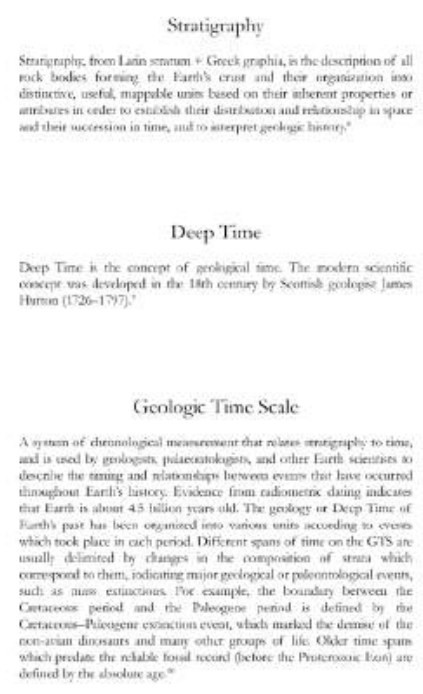

Global Boundary Stratotype Section and Points (GSSP)

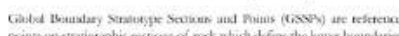

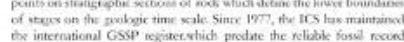

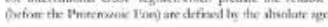
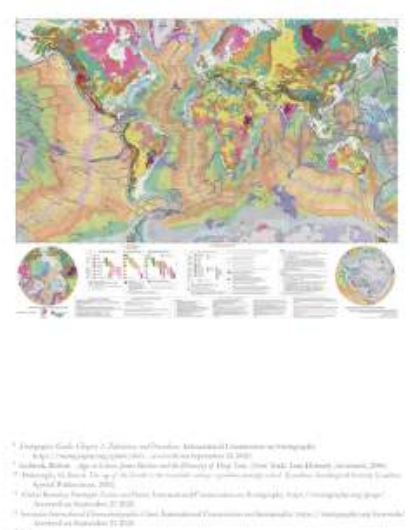

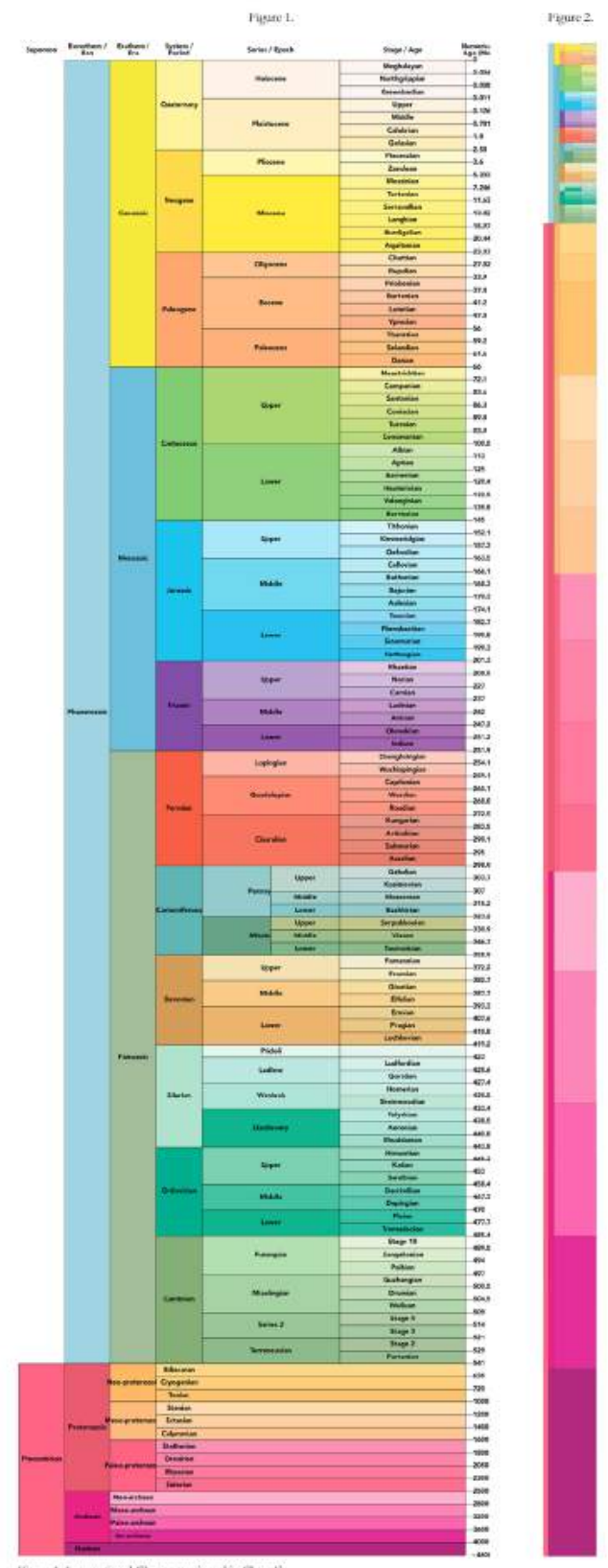

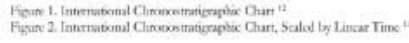




\section{WHERE SHOULD A GSSP BE PLACED FOR THE ANTHROPOCENE?}

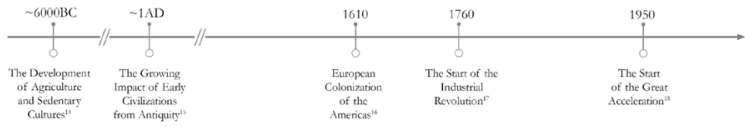

WHAT IS THE AWG'S CURRENT STANCE ON THE PLACEMENT OF A GSSP?

International Geological Congress (IGC)

Durng the mid 19th century, the necessity of holding an international congress was strongly felt among the communuity of geologisss in Europe and
North America On occasion of the meeting of the American Association fo the Advancement of Science held in Buffalo, New York, USA, in 1875, . of the time, was hater called the Founding Committee of Philadelphia by the

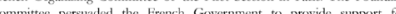
convening an international pathering, and succeded to host the Fist

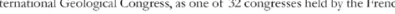
Sinistry of Agriculfure and Commerce in the Trocadero Palace during th

The International Genlogical Congress is a nonprofir scientific and education organization whose metings are held in collaboraton thith, and under

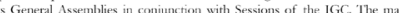
arpose of the Congress is to encourage the advancement of fundamental and pplied research in the Earth scier

Since the first session which was held in Paris in 1878, thirr-five conoreseses ries throughour the world three to five year intervals. The thirty fifth IGC was held in 2016 in Capc Tow

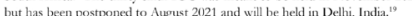

Results of binding vote by AWG
Released on the 21st of May, 2019

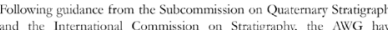
completed a binding vote to affirm some of the key questions that we IGC Cape Tor meeting in 3016 The detols

No. of potential voting members: 34
No. rcquired to be quoratc $\left(60^{\circ}\right): 21$

No of voutes rececived $33(97 \%$ of voring membership)

Q1. Should the Anthropoccenc be treated as a formal chrono-stratigraphic
unit defined by a GSSP?

29 voted in fivour ( $88 \%$ of votes cast):
4 voted against; no alsstentions

Q2. Should the primary guide for the base of the Anthropocene be one of the stratigraphic signals around the mid-twenticth century of the Common 29 voted in finour ( $88 \%$ of votes cast):

Both votes esceed the $60 \%$ supermaionity of cast votes recuired to be

DOES ANY OF THIS MATTER?

TIE ANTHROPOCENE IS A JOKE

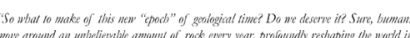

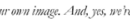

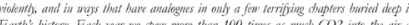

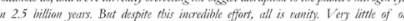

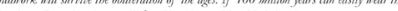

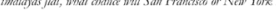

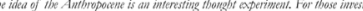

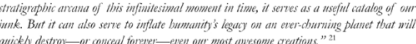

IF THE ANTHROPOCENE IS A JOKE, TTS A USEFUL ONE

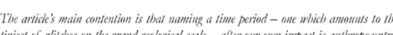

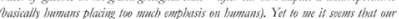

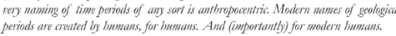

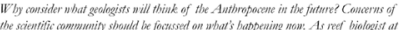

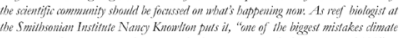
(1)

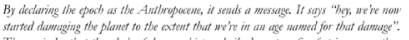

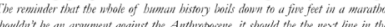

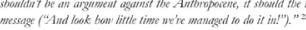

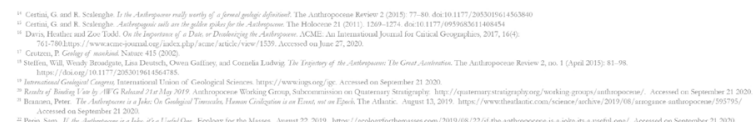




\section{APPENDIX E: LITERATURE MAP}

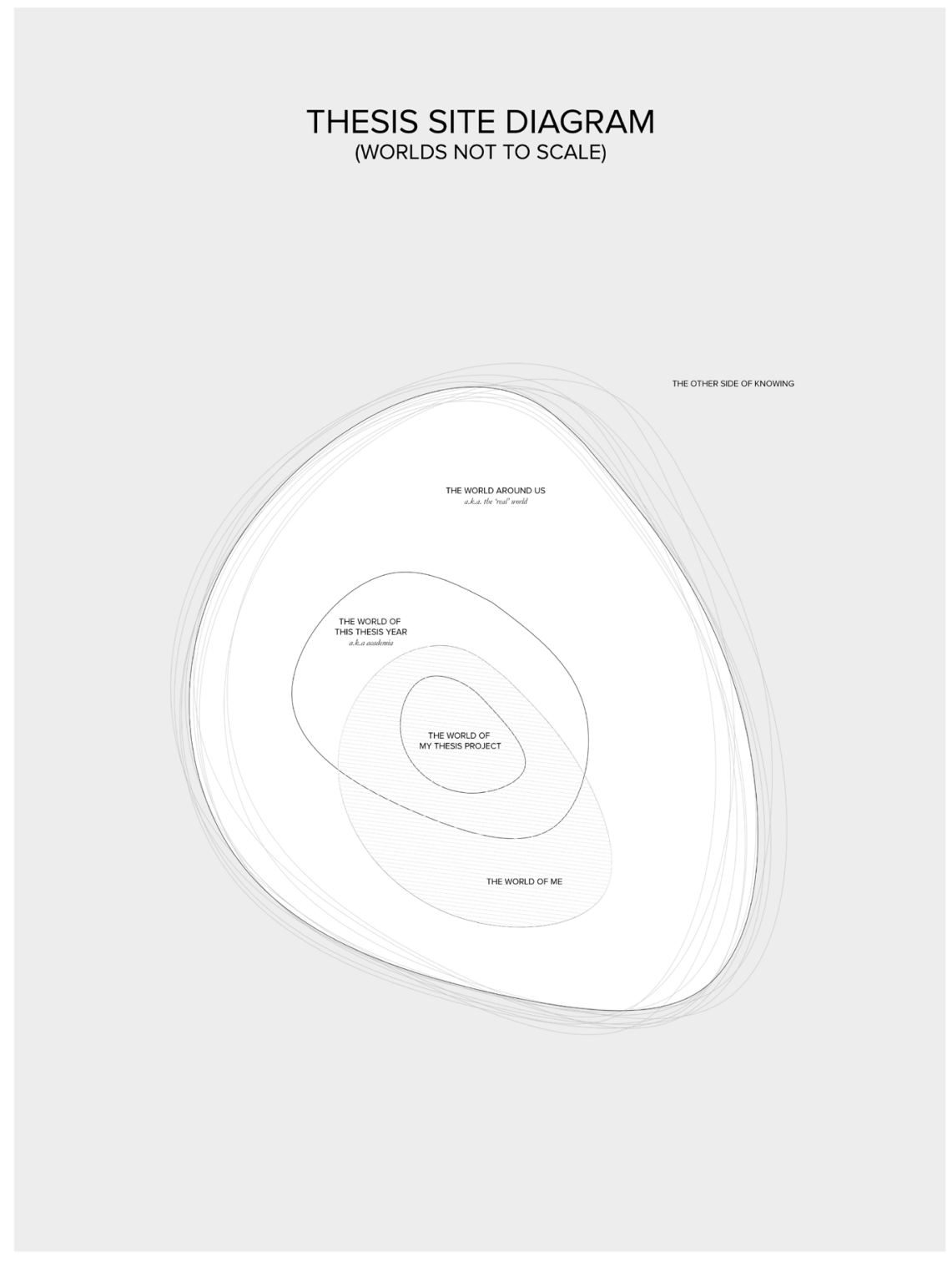

Diagram to site the thesis project in my mind and in the world(s) 


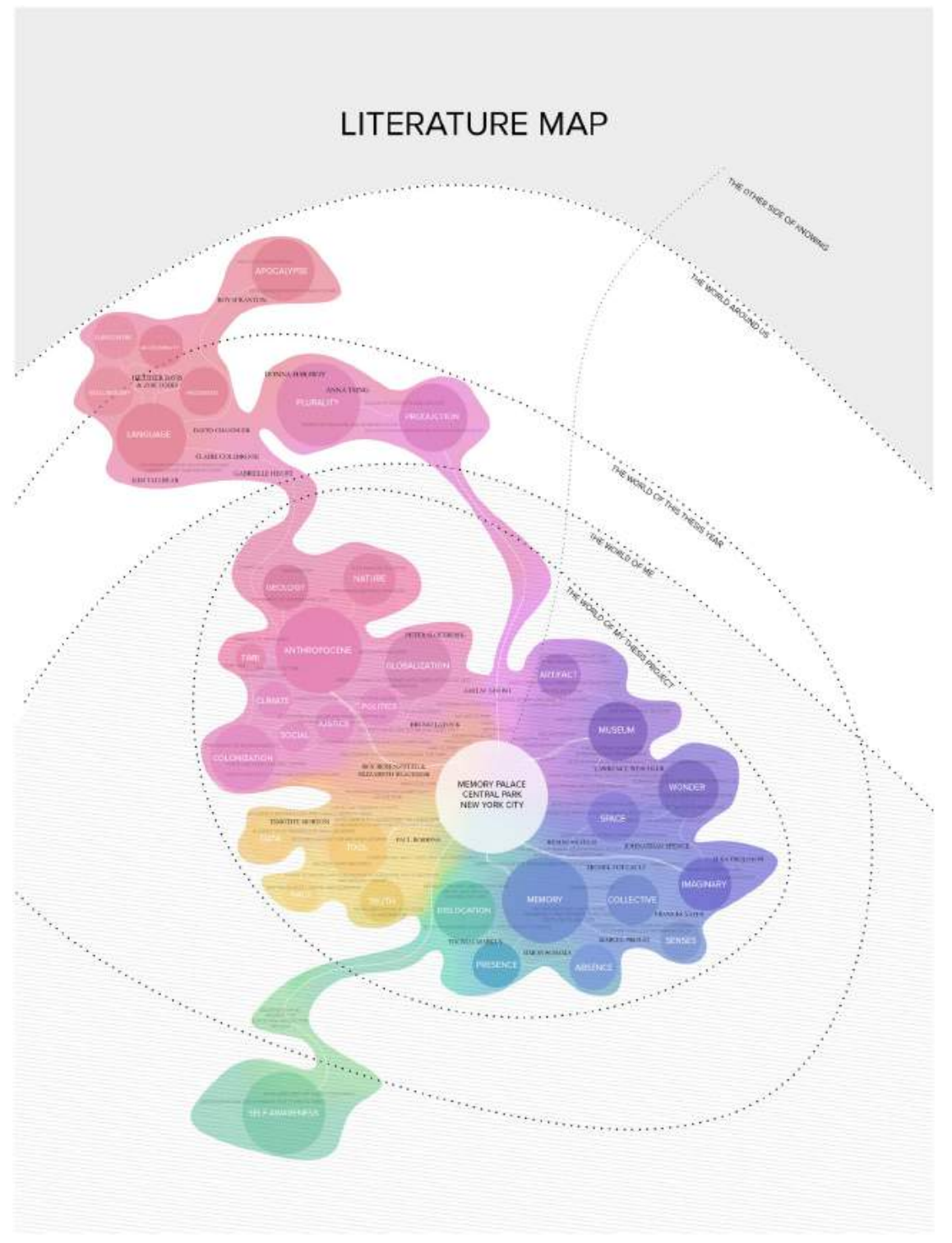

Literature map produced at the beginning of the thesis project 


\section{BIBLIOGRAPHY}

\section{PRINT}

Agrest, Diana et al. Architecture of Nature : Nature of Architecture . Novato, CA: Applied Research and Design Publishing, 2018.

Ascher, Kate. Anatomy of a City. New York: The Penguin Press, 2005.

Ballard, J. G., and Richard M. Powers. Billenium.1962.

Bavishi, Jainey K. A Tale of Three Cities, in All We Can Save. New York: Penguin Random House LLC, 2020.

Benjamin, Walter. On the Concept of History, in: Selected Writings 4, eds. Howard Eiland \& Michael W. Jennings. Cambridge, MA: Belknap Press of Harvard University Press, 2003.

Boswell, J. 'Notes from the Wasteland: Competing Climatic Imaginaries in the Post-Apocalypic Landscape' in Graham, J. ed. Climates: Architecture and the Planetary Imaginary. New York: Lars Muller Publisher, 2016.

Cicero, Marcus Tullius, E. W. Sutton, and H. Rackham. 1942. Cicero. De oratore. In two volumes. Cambridge, Mass: Harvard University Press.

Darden, Douglas. Condemned Building: an Architect's Pre-Text. New York: Princeton Architectural Press, 1993.

Forty, Adrian. Introduction to The Art of Forgetting. Adrian Forty and Susanne Kuchler, eds. Oxford: Berg, 1999.

Ghosh, Amitav. The Great Derangement. Chicago and London: The University of Chicago Press, 2016. 
Ghosn, Rania and El Hadi Jazairy. Geostories: Another Architecture for the Environment. New York and Barcelona: Actar Publishers, 2019.

Gissen, David. 2009. Subnature: architecture's other environments: atmospheres, matter, life. New York: Princeton Architectural Press.

Haraway, Donna. Staying With the Trouble: Making Kin in the Chthulucene. Durham: Duke University Press, 2016.

Hayhoe, Katharine. How to Talk About Climate Change, All We Can Save. New York: Penguin Random House LLC, 2020.

Jubliee Saito, Madeleine. Reframe, in All We Can Save. New York: Penguin Random House LLC, 2020.

Knuth, Kate. Becoming a Climate Citizen, in All We Can Save. New York: Penguin Random House LLC, 2020.

Koolhaas, Rem. Delirious New York : a Retroactive Manifesto for Manhattan. New York :Monacelli Press, 1994.

Latour, Bruno. Down to Earth: Politics in the New Climactic Regime. Translated by Catherine Porter. Oxford: Polity Press, 2018.

Latour, Bruno. We Have Never Been Modern. Cambridge, Mass: Harvard University Press, 1993.

Morton, Timothy. Being Ecological. Cambridge, MA: The MIT Press, 2018.

Nieves Rodriguez, Christine E. Community is our Best Chance, in All We Can Save. New York: Penguin Random House LLC, 2020. 
Proust, Marcel. Swann's Way: In Search of Lost Time Volume 1. Translated by C.K. Scott Moncrief and Terrence Kilmartin. New York :Chatto and Windus and Random House, 1992.

Robbins, Paul, ed. Encyclopedia of Environment and Society. 5 vols. Thousand Oaks, CA: SAGE Publications, Inc., 2007. doi: 10.4135/9781412953924.

Rosenzweig, Roy and Elizabeth Blackmar. The Park and the People: A History of Central Park. Ithaca and London: Cornell University Press, 1992.

Sagan, Carl. Pale Blue Dot: A Vision of the Human Future in Space. New York: The Random House Publishing Group, 1994.

Tehrani, Nader. Section Cut: an Allegorical Construct of the World, Geostories: Another Architecture for the Environment. New York and Barcelona: Actar Publishers, 2019.

Weschler, Lawrence. Mr. Wilson's Cabinet of Wonder. New York: Random House Inc., 1995. 


\section{WEB}

Baranovas, Ruslanas. Virtuality and the Problem of Agency in ObjectOriented Ontology. Open Philosophy 3, no. 1. De Gruyter, May 27, 2020. https://doi.org/10.1515/opphil-2020-0106. Accessed on March $31,2021$.

Brand, Stewart. The Long Now, https://longnow.org/about/. Accessed on March 15, 2021.

Broad, William. How the Ice Age Shaped New York. The New York Times, 2018: https://www.nytimes.com/2018/06/05/science/how-the-ice-ageshaped-new-york.html. Accessed on January 11, 2021.

Carnall, Mark. "What Is Geologic Time, and How Does It Work?," the Guardian, May 2, 2018, http://www.theguardian.com/science/2018/ may/02/geologic-time-scale. Accessed on March 20, 2021.

Chapman, Isabelle. A Landfill in their Backyard, CNN, September 11, 2020. Accessed April 16, 2021, https://www.cnn.com/interactive/2020/09/us/ september-11-cancer-rates-fresh-kills/.

Charles, Jacoba. Longtime Emblems of City Roofs, Still Going Strong. The New York Times. https:/www.nytimes.com/2007/06/03/nyregion/ thecity/03wate.html. Accessed on January 11, 2021.

Cheever, John. The Swimmer. The New Yorker. July 181964 ISSUE. https:// www.newyorker.com/magazine/1964/07/18/the-swimmer. Accessed on February 20, 2021.

Collins, Billy. Grand Central. Poetry in Motion Atlas. https://poetrysociety. org/poetry-in-motion/grand-central. Accessed on March 10, 2021. 
Collins, Glenn. The Very Cold Case of the Glacier. The New York Times. 2005. https://www.nytimes.com/2005/09/14/nyregion/the-very-coldcase-of-the-glacier.html. Accessed on January 11, 2021.

"Collective Memory - APA Dictionary of Psychology," accessed March 31, 2021, https://dictionary.apa.org/collective-memory.

Corner,James.Lifescape-Fresh KillsParkland. Accessed April 16,2021, https:// www.nextroom.at/data/media/med_binary/original/1121022434.pdf.

Davis, Heather and Zoe Todd. On the Importance of a Date, or Decolonizing the Anthropocene. ACME: An International Journal for Critical Geographies, 2017, 16(4): 761-780.https://www.acme journal.org/ index.php/acme/article/view/1539. Accessed on June 27, 2020.

Dessanay, Margherita. Leaves of Grass by Geoffrey Farmer, FRAME, 2012, https://www.frameweb.com/article/leaves-of-grass-by-geoffrey-farmer. Accessed on March 31, 2021.

Dworkin, Mona. ARTIST'S STATEMENT + CV| Mona Dworkin," https:// www.monadworkin.com/pages/about. Accessed on March 21, 2021.

Foley, Jessica. 'Word the World Better' postcard, part of Engineering Fictions box set of scores. Dublin: CONNECT, 2017, www.engineeringfictions. wordpress.com. Accessed on March 21, 2021.

Galka, Max. What does New York do with all its trash? One city's waste in numbers, The Guardian, October 27, 2016. Accessed April 16, 2021, https://www.theguardian.com/cities/2016/oct/27/new-york-rubbish-allthat-trash-city-waste-in-numbers. 
Gissen, David. "A More Monumental, Non-Naturalistic Environment (Pratt Journal)." Pratt School of Architecture Journal, no. Spring (2012), https://www.academia.edu/8168289/A_More_Monumental_Non_ Naturalistic_Environment_Pratt_Journal_. Accessed on March 11, 2021.

Handwerk, Brian. Neuroscientists Unlock the Secrets of Memory Champions. Smithsonian Magazine, 2017: https:/www.smithsonianmag.com/ science-nature/why-you-can-train-your-brain-memory-champion-stillforget-your-car-keys-180962496/. Accessed on January 11, 2021.

Harman, Graham. The Quadruple Object. United Kingdom, Zero Books 2011, ISBN 978-1-84694-700-1. 49. Accessed on March 31, 2021.

Harman, Graham. On Vicarious Causation. Collapse, 2007, https:// pervegalit.files.wordpress.com/2008/06/harman_vicarious_causation. pdf. 192. Accessed on March 31, 2021.

Holmes, Rob. "The Problem with Solutions," Places Journal, July 2020. https://doi.org/10.22269/200714. Accessed 01 Apr 2021.

"How is the Hudson Doing". New York State. https://www.dec.ny.gov/ lands/77105.html. Accessed on January 11, 2021.

Kilgannon, Corey. Talking Trash in New York, and Taking Photos of It, The New York Times, August 13, 2019. Accessed April 16, 2021, https:// www.nytimes.com/2019/08/13/nyregion/newyorktoday/nyc-newstrash.html. 
Klein, Naomi. "Climate Change Is the Fight of Our Lives-Yet We Can Hardly Bear to Look at It," Guardian, April 23, 2014, https://www. theguardian.com/commentisfree/2014/apr/23/climate-change-fight-ofour-lives-naomi-klein. Accessed on March26, 2021.

Lack, H.W. Alexander Von Humboldt and the Botanical Exploration of the Americas. Prestel, 2009, https://books.google.ca/ books?id=8aRkPgAACAAJ. Accessed on March 31, 2021.

Lally, Sean. "The Long Now," Sean Lally Architecture Sàrl (blog), March 17, 2019, http://seanlally.net/2019/03/17/exhibit-columbus/. Accessed on March 31, 2021.

Le Guin, Ursula K. “The Carrier Bag Theory of Fiction," http://theorytuesdays. com/wp-content/uploads/2017/02/The-Carrier-Bag-Theory-of-FictionLe-Guin.pdf. 154. Accessed on March 29, 2021.

Lewis, Simon L. and Mark A. Maslin, "Defining the Anthropocene," Nature 519, no. 7542, March 2015, https://doi.org/10.1038/nature14258. Accessed on March 21, 2021.

Lippard, Lucy. New York comes clean: the controversial story of the Fresh Kills dumpsite, The Guardian, October 28, 2016. Accessed April 16, 2021, https://www.theguardian.com/cities/2016/oct/28/new-yorkcomes-clean-fresh-kills-staten-island-notorious-dumpsite.

Lipton, Eric. Five States Challenge New York's Trash Plan, The Washington Post, February 7, 1999. Accessed April 16, 2021, https://www. washingtonpost.com/archive/local/1999/02/07/five-states-challengenew-yorks-trash-plan/6abd4987-b4f6-4cdf-bd24-bf66e4765975/. 
"Locus | Origin and Meaning of Locus by Online Etymology Dictionary,", https://www.etymonline.com/word/locus. Accessed on March 31, 2021.

Orcutt, Mike. "New York City Has Big Plans—and \$20 Billion-to Save Itself from Climate Change,"MIT Technology Review. https://www. technologyreview.com/2019/09/19/132942/new-york-city-has-bigplansand-20-billionto-save-itself-from-climate-change/. Accessed on March 23, 2021.

Riley, Joe and Audrey Snyder. "Wastestreaming", Urban Omnibus, October 2, 2019. Accessed April 16, 2021, https://urbanomnibus.net/2019/10/ wastestream/.

Rueb, Emily. How New York Gets its Water. The New York TImes. https:// nyti.ms/2jRSmqf. Accessed on January 11, 2021.

Scranton, Roy. Beginning with the End. Emergence Magazine. 2020. https:// emergencemagazine.org/story/beginning-with-the-end/. Accessed on June 27, 2020.

Solomon, Deborah. Joseph Cornell: Pioneer of Assemblage Art | Blog | Royal Academy of Arts, https://www.royalacademy.org.uk/article/josephcornell-shadow-boxes-assemblage-art. Accessed on March 25, 2021.

Stephenson, Neal. "Neal Stephenson: Innovation Starvation,” Wired, 2011. https://www.wired.com/2011/10/stephenson-innovation-starvation/. Accessed March 28, 2021.

Stewart, Susan. On Longing: Narratives of the Miniature, the Gigantic, the Souvenir, the Collection. Durham; London: Duke University Press, 1993. doi:10.2307/j.ctv1220n8g. Accessed January 28, 2021. 
Sullivan, Robert. How the World's Largest Garbage Dump Evolved Into a Green Oasis, The New York Times, August 14, 2020. Accessed April 16, 2021, https://www.nytimes.com/2020/08/14/nyregion/freshkillsgarbage-dump-nyc.html.

Swanson, Lori J. "A Feminist Ethic That Binds Us to Mother Earth." Ethics and the Environment 20, no. 2 (2015): 83-103. doi:10.2979/ ethicsenviro.20.2.83. Accessed January 28, 2021.

"Treasure Trove: Constructing the Central Park Reservoir". New York Historical Society, 2018. http://blog.nyhistory.org/treasure-troveconstruction-of-the-central-park-reservoir/. Accessed on January 11, 2021.

"The Impact of NYC's Trash on Other Communities", Landfill Operations, Waste 360, February 6, 2021. Accessed April 16, 2021, https:// www.waste360.com/landfill-operations/impact-nycs-trash-othercommunities.

"The Transect". Center for Applied Transect Studies: https://transect.org/ transect.html. Accessed on January 11, 2021.

Thompson, Katherine. "The Grim Reality Hidden Beneath Freshkills Park's Bright Façade", WR: Journal of the CAS Writing Program Issue 9, 20162017. Boston University Arts \& Sciences Writing Program. Accessed April 16, 2021, https://www.bu.edu/writingprogram/journal/past-issues/ issue-9/thompson/. 
Tsing, Anna L., Jennifer Deger, Alder Keleman Saxena, and Feifei Zhou. Feral Atlas: The More-Than-Human Anthropocene, Redwood City: Stanford University Press 2020, http://doi.org/10.21627/2020fa. Accessed on March 31, 2021.

"What Is a Digital Carbon Footprint?," https://www.myclimate.org/ information/faq/faq-detail/what-is-a-digital-carbon-footprint/. Accessed on March 28, 2021.

"Where Does New York City's Trash Go?", Living City, The New York Times, September 25, 2014. Accessed April 16, 2021, https://youtu.be/ Y6LzB6rMDtA.

"Working Group on the 'Anthropocene' | Subcommission on Quaternary Stratigraphy,", http:/quaternary.stratigraphy.org/working-groups/ anthropocene/. Accessed on March 25, 2021. 
